GA Technologies

DO NOT MILKOFILM
COVER

\title{
SP-100 THERMIONIC TECHNOLOGY PROGRAM ANNUAL INTEGRATED TECHNICAL PROGRESS REPORT FOR THE PERIOD ENDING SEPTEMBER 30, 1984
}

\author{
by \\ GA TECHNOLOGIES INC. \\ RASOR ASSOCIATES, INC. \\ SPACE POWER, INC.

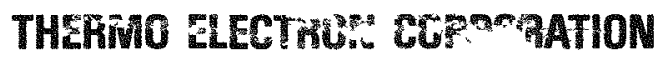

Edited by

J. W. HOLLAND

\begin{abstract}
Prepared under Contracts
DE-AF03-84SF11906 - GA Technologies Inc.

DE-AC03-84SF12192 - Rasor Associates, Inc. DE-AC03-84SF12193 - Thermo Electron Corporation

for the San Francisco Operations Office

Department of Energy
\end{abstract}




\section{DISCLAIMER}

This report was prepared as an account of work sponsored by an agency of the United States Government. Neither the United States Government nor any agency Thereof, nor any of their employees, makes any warranty, express or implied, or assumes any legal liability or responsibility for the accuracy, completeness, or usefulness of any information, apparatus, product, or process disclosed, or represents that its use would not infringe privately owned rights. Reference herein to any specific commercial product, process, or service by trade name, trademark, manufacturer, or otherwise does not necessarily constitute or imply its endorsement, recommendation, or favoring by the United States Government or any agency thereof. The views and opinions of authors expressed herein do not necessarily state or reflect those of the United States Government or any agency thereof. 


\section{DISCLAIMER}

Portions of this document may be illegible in electronic image products. Images are produced from the best available original document. 


\section{DISCLAIMER}

This report was prepared as an account of work sponsored by an agency of the United States Government. Neither the United States Government nor any agency thereof, nor any of their employees, makes any warranty, express or implied, or assumes any legal liability or responsibility for the accuracy, completeness, or usefulness of any information, apparatus, product, or process disclosed, or represents that its use would not infringe privately owned rights. Reference herein to any specific commercial product, process, or service by trade name, trademark, manufacturer, or otherwise, does not necessarily constitute or imply its endorsement, recommendation, or favoring by the United States Government or any agency thereof. The views and opinions of authors expressed herein do not necessarily state or reflect those of the United States Government or any agency thereot.

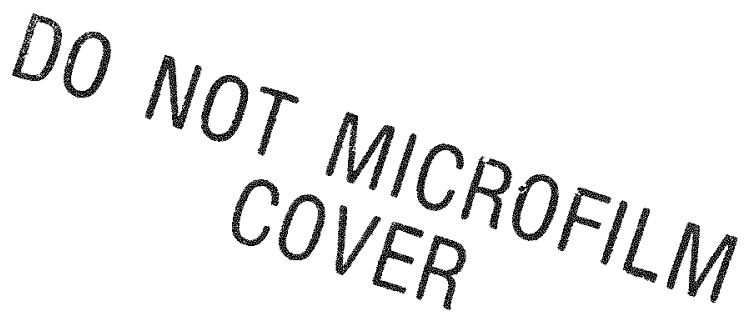




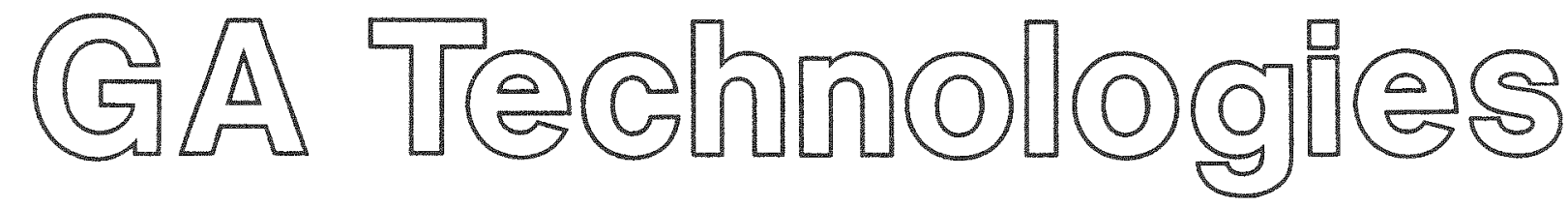

GA-A17773

\title{
SP-100 THERMIONIC TECHNOLOGY PROGRAM ANNUAL INTEGRATED TECHNICAL PROGRESS REPORT FOR THE PERIOD ENDING SEPTEMBER 30, 1984
}

\author{
by \\ $\mathrm{GA}-\mathrm{A}--17773$ \\ GA TECHNOLOGIES INC. \\ RASOR ASSOCIATES, INC. \\ DE85 012311 \\ SPACE POWER, INC. \\ THERMO ELECTRON CORPORATION
}

Edited by

J. W. HOLLAND

Prepared under Contracts

DE-AT03-84SF11906 - GA Technologies Inc.

DE-AC03-84SF12192 - Rasor Associates, Inc.

DE-AC03-84SF12193 - Thermo Electron Corporation

for the San Francisco Operations Office

Department of Energy

GA PROJECT 3423

NOVEMBER 1984 
ABSTRACT

The thermionic technology program addresses the feasibility issues of a seven-year-life thermionic fuel element (TFE) for the SP-100 Thermionic Reactor Space Power System. These issues relate to the extension of TFE lifetime from three to seven years, one of the SP-100 requirements. The technology to support three-year lifetimes was demonstrated in the earlier TFE development program conducted in the late-1960s and 1970s. Primary life-limiting factors were recognized to be (1) thermionic emitter dimensional increases due to swelling of the nuclear fuel and (2) electrical structural damage from fast neutrons. The 1984-85 technology program is investigating the fueled emitter and insulator lifetime issues, both experimentally and analytically. The goal is to analytically project the lifetime of the fueled enitter and insulator and to experimentally verify these projection methods. In 1984, the efforts were largely devoted to the design and building of fueled emitters for irradiation in 1985, validation of fuel-emitter models, development of irradiation-resistant metal-ceramic seal and sheath insulator, modeling of insulator lifetime, and development of wide-spaced, high-performance thermionic converters. 
BLANK 
CONTENTS

ABSTRACT . . . . . . . . . . . . . . . . . . . . iii

1. INTRODUCTION/SUMMARY .. . . . . . . . . . . . . . . 1-1

1.1. Fueled Emitter Deformation ............. . . 1-1

1.1.1. Task Objectives/Approach/Requirements ..... 1-1

1.1.2. Emitter Deformation Analysis ......... 1-2

1.1.3. Capsule Design .............. 1-4

1.1.4. Capsule Fabrication ............ 1-6

1.1.5. Instrumentation ............ 1-7

1.1.6. Test Reactor Preparation .......... . 1-8

1.2. Metal Ceramic Seal ............. . . . 1-9

1.2.1. Task Objectives/Approach/Requirements . . . . 1-9

1.2.2. Fabrication Development ......... 1-10

1.2.3. Testing ............... 1-11

1.3. Metal-Ceramic Sheath Insulator ............ 1-11

1.3.1. Task Objectives ............. 1-11

1.3.2. Fabrication Development ......... 1-12

1.3.3. Testing ................ 1-13

1.3.4. Analysis............... 1-14

1.4. Converter Performance ............ . . 1-15

1.4.1. Task Objectives/Approach/Requirements .... 1-15

1.4.2. Converter Performance of Oxygenated-Collector

1.4.3. Cesium-Cesium Oxide Converter ...... 1-17

2. FUELED EMTTTER DEFORMATION .............. 2-1

2.1. Task Objectives/Approach/Requirements . . . . . . 2-1

2.1.1. Objectives ............ 2-1

2.1.2. Approach .............. 2-1

2.1.3. Requirements ............... 2-9 
2.2. Emitter Deformation Analysis . . . . . . . . . 2-9

2.2.1. Fuel Swelling ............... 2-9

2.2.2. Bladder Effect . . . . . . . . . . . 2-21

2.2.3. Thermal Ratcheting ........... 2-26

2.2.4. Conclusions ............ 2- 2- 28

2.3. Capsule Design ............... . . 2-28

2.3.1. Design Description . . . . . . . . . 2-28

2.3.2. Capsule Design Analysis ........ . . 2-36

2.4. Capsule Fabrication . . . . . . . . . . . 2-65

2.4.1. Component Fabrication ......... 2-65

2.4.2. Assembly ............. 2- . . 272

2.5. Instrumentation ............... 2-84

2.5.1. Emitter Power Supply ............ 2-97

2.5.2. Bus Bar Cooling . . . . . . . . . 2-101

2.5.3. Cesium Reservoir Control .......... 2-101

2.5.4. Gas Exchange System . . . . . . . . 2-103

2.5.5. Data Acquisition System . . . . . . . 2-103

2.5.6. Scram Instrumentation ........ 2-105

2.6. Test Reactor Preparation . . . . . . . . . 2-105

2.7. References....................... 2-111

3. METAL-CERAMIC SEAL .................... . . . . . .

3.1. Task Objectives/Approach/Requirements . . . . . . 3-1

3.1.1. Insulator Seal Functional Requirements .... . 3-1

3.1.2. Seal Operational Requirements ........ . 3-1

3.1.3. Candidate Materials for the Seal ....... 3-1

3.1.4. Objectives for Insulator Seal Tests ... . . 3-4

3.2. Fabrication Development . . . . . . . . . 3-6

3.2.1. Solid-Body Ceramics ........... 3-6

3.2.2. Cermet ............. 3-12

3.3. Metal-Ceranic Seal Testing ........... 3-17

3.4. References . . . . . . . . . . . . . 3-20

4. METAL-CERAMIC SHEATH INSULATOR ............. . . 4-1

4.1. Task Objectives/Approach/Requirements . . . . . . . 4-1

4.1.1. Sheath Insulator Functional Requirements . . . 4-1

4.1.2. Sheath Insulator Operating Requirements ... 4-1 
4.1.3. Candidate Materials for Sheath Insulator . . . 4-3

4.1.4. Objectives and Test Plan for Sheath

Insulators .............. 4-3

4.2. Fabrication Development . . . . . . . 4-6

4.2.1. Cermet Sheath Insulator . . . . . . . 4-6

4.2.2. Graded Sheath Insulator . . ...... 4-10

4.3. Testing of Sheath Insulator Assemblies . . . . . . 4-14

4.3.1. Thermal Conductance ........... 4-14

4.3.2. Electrical Conductivity . . . . . . . 4 4-14

4.3.3. Electrical Properties and Conductivity Data to

Support Analytical Work .......... 4-19

4.3.4. Resistance to Debonding in Preapplication

Period................. 4-19

4.4. Sheath Insulator Analyses . . . . . . . . . 4-21

4.4.1. Electrolytic Degradation in Ceramic

Insulators ............ 4-21

4.4.2. Analytical Modeling ........... 4-24

4.4.3. Degradation Modes ........... . 4-27

5. CONVERTER PERformanCE . . . . . . . . . . . . . . 5-1

5.1. Task Objectives/Approach/Requirements . . . . . . . 5-1

5.1.1. Objectives ............... 5-1

5.1.2. Performance Requirements ......... 5-1

5.1.3. Approach ............. 5- . .

5.2. Converter Performance of an Oxide-Collector

5.3. Cesium-Cesium Oxide Converter . . . . . . . . 5-12

5.3.1. Dual Reservoir Alternative to Oxygenated

Collectors ........... 5-12

5.3.2. Converter Design ......... 5-12

5.3.3. Test Procedures .......... 5-17

5.3.4. Results .............. 5-17

5.4. Fueled Emitter Temperature Correlation . . . . . . 5-21

5.4.1. Test Device Design . . . . . . . . . 5-21

5.4.2. Input Power ............ . 5-22

5.4.3. Emitter Temperature .......... . 5-22

5.5. G-Series Converter ............ . . 5-32 
FIGURES

2-1. Fueled emitter deformation/lifetime experimental and analytical approach ............... 2-2

2-2. Ratcheting experiment definition ........... 2-8

2-3. LIFE4 phenomenological models.............. 2-13

2-4. LIFE4 deformation analysis of GA experiment 6F3..... 2-17

2-5. Onset of knee in the emitter deformation analysis . . . . 2-18

2-6. Enitter distortion due to bladder pressure at $5 \%$ vold fraction ................... 2-23

2-7. Bladder pressure versus time at continuous operation at $5 \%$ fuel void fraction ............... 2-24

2-8. Typical fuel snorkel vent design ............ 2-25

2-9. Tungsten approximate stress versus strain at $1700 \mathrm{~K}$. . . 2-27

2-10. LIFE4 lifetime analysis of SP-100 reference design . . . 2-30

2-11. Design concept of fueled emitter deformation capsule . . 2-31

2-12. Thermionic diode for fueled emitter test . . . . . 2-33

2-13. Cesium reservoir heater assembly . . . . . . . . 2-35

2-14. Assembly drawing of bottom of fueled emitter deformation capsule ................... . 2-37

2-15. TAC2D model for gap sizing . . . . . . . . . . . 2-40

2-16. Collector heat flow at $800 \mathrm{~K}$ versus primary gap thickness .... . . . . . . . . . . . 2 2-43

2-17. Collector temperature variation versus secondary gas composition .............. 2-. 2-46

2-18. TAC2D mode1 of capsule cell ............. 2-47

2-19. Capsule emitter temperature profile . . . . . . . 2-50

2-20. Core configuration giving specific fueled emitter test

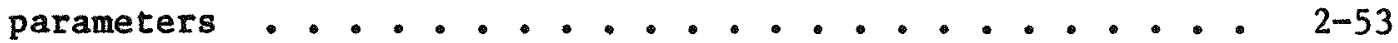

2-21. Fission power in single fuel/clad emitter . . . . . . . 2-58

2-22. Radial $\mathrm{P} / \overline{\mathrm{P}}$ at emitter/fuel $\mathrm{VO}_{2}$ interface ....... 2-59

2-23. Thermionic test device replacing three TRIGA fuel

2-24. Two-dimensional RZ configuration for TWOTRAN analysis for single thermionic device at radial center . . . . . . . 2-62

2-25. Vapor-deposited tungsten emitter prior to machining . . . 2-69

2-26. Process control diffusion bond sample ........ 2-70 
FIGURES (Continued)

2-27. Tantalum-tungsten diffusion bond ........... 2-71

2-28. Vanadium-niobium-brazed ceramic-to-metal seals before

final machining ..................... 2-73

2-29. Finish machined ceramic-to-metal seals . . . . . . . 2-74

2-30. $\mathrm{UO}_{2}$ fuel loading for in-pile capsule converter . . . . 2-75

2-31. Exploded view of thermionic diode . . . . . . . . 2-76

2-32. Collector: before and after brazing of collector lead adapters ............. 2- . . 279

2-33. Ceslum reservoir: before and after EB weld of collector reservoir adapter . . . . . . . . . . . 2 2-79

2-34. Collector-cesium reservoir: before and after EB weld of cesium reservoir to collector . . . . . . . . . . 2-80

2-35. Collector subassembly-insulator seal: before and after EB weld of insulator seal to collector subassembly . . . 2-80

2-36. Collector-emitter assembly: before and after EB weld of emitter assembly to collector assembly . . . . . . . . 2-81

2-37. Thermionic diode subassembly-collector end cap: before and after EB weld of collector end cap to diode subassembly ................ 2-81

2-38. Thermionic diode and cesium distillation assembly: ready for attachment to diode and ion pumping ..... . . 2-82

2-39. Thermionic diode in processing station: ready for outgassing, cesiation, and pinchoff .......... 2-82

2-40. Drawing of primary assembly fixture . . . . . . . . 2-87

2-41. CPM schedule for fueled emitter deformation capsule 1 . . 2-89

2-42. CPM schedule for fueled emitter capsule 2 . . . . . . 2-90

2-43. CPM schedule for fueled emitter deformation capsule 3 . . 2-91

2-44. CPM schedule for fueled emitter deformation capsule 4 . . 2-92

2-45. Photograph showing instrumentation for the in-core fueled emitter capsule tests . . . . . . . . . 2-95

2-46. Schematic of instrumentation system . . . . . . . 2-96

2-47. Sweep waveform calibration at 150-A operating condition ........................ 2-98

2-48. Sweep waveform calibration at maximum operating condition of $500 \mathrm{~A}$.......................... 2-99

2-49. Schematic of variable-resistance-load water cooling system .................. 2- 2100 


\section{FIGURES (Continued)}

2-50. Schematic of bus-bar water cooling system . . . . . . 2-102

2-51. Schematic of gas exchange system . . . . . . . . 2-104

2-52. Overview photo of TRIGA Mark F facility . . . . . . . 2-107

2-53. Schematic of TRIGA Mark F facility . . . . . . . . 2-108

2-54. Core configuration ................. 2-110

3-1. Metal-ceramic seal designs ........... 3-2

3-2. Scanning electron microscopy photomicrographs of a fractured section of $\mathrm{Y}_{2} \mathrm{O}_{3}$ cold pressed at $344.7 \mathrm{MPa}$ (50 ksi), then sintered for $30 \mathrm{~min}$ at $1600^{\circ} \mathrm{C} \ldots . . .3-7$

3-3. Scanning electron microscopy photomicrographs of hot-pressed, fractured $\mathrm{Y}_{2} \mathrm{O}_{3}$ surfaces . . . . . . . . 3-9

3-4. Advanced seal configuration ............. 3-13

3-5. 1972 metal-ceramic seal ............. 3-14

3-6. Vanadium-niobium-brazed polycrystalline $\mathrm{Al}_{2} \mathrm{O}_{3}$ to niobium seal joint ................ 3-15

3-7. Photomicrograph of alumina-niobium cermet ...... . 3-16

3-8. High-temperature, high-pressure autoclave . . . . . 3-18

3-9. Seal insulator test plan logic. . . . . . . . . 3-19

3-10. Conceptual drawing of cesium compatibility test stand . . . 3-21

4-1. Photomicrograph of yttria-niobium cermet . . . . . . 4-2

4-2. Sheath insulator test plan logic ........... 4-7

4-3. Photomicrograph of pentalayer-collector from 14,000-h
G-series converter . . . . . . . . . . 4-8

4-4. X-ray diffraction patterns of yttria-alumina compacts $4-11$

4-5. Equipment for fabrication of plasma-sprayed graded
trilayer . . . . . . . . . . . . . 4-13

4-6. Schematic diagram of graded trilayer sheath insulator . . 4-15

4-7. Test stand for inspecting trilayer bonding . . . . . . 4-17

4-8. Electrical conductivity of sheath insulator test stand - 4-18

4-9. Sheath sample in test oven ............... 4-20

4-10. Electrical conductivity and transference number for

4-11. Correlation model of ion transport . . . . . . . . . 4-25 
FIGURES (Continued)

4-12. Example of possible data to be obtained from accelerated electrolysis tests ................. 4-26

4-13. Generation of oxygen vacancies at the anode of $\mathrm{Nb}-\mathrm{Y}_{2} \mathrm{O}_{3}-\mathrm{Nb}$ cell ....................... 4-28

4-14. Comparison of the analytic solution and computed result for steady vacancy profile in $\mathrm{Y}_{2} \mathrm{O}_{3}$. . . . . . . . . . 4-29

5-1. Idealized task logic ............. . 5-3

5-2. Prototypic cylindrical converter . . . . . . . . 5-5

5-3. Variable spacing research converter . . . . . . . . 5-8

5-4. Electrical power density as a function of electrode spacing, parametric in current density ......... 5-9

5-5. Optimized current density voltage characteristics for emitter temperature of $1700 \mathrm{~K}$............ . 5-10

5-6. Electrical power density as a function of collector temperature, parametric in current density ....... 5-11

5-7. Output power density of converter 282 as a function of test period..................... 5-13

5-8. Current density versus voltage characteristics, parametric in test period at a collector temperature of $1075 \mathrm{~K}$. . . . 5-14

5-9. Variable spacing cesium-cesium oxide converter . . . . 5-15

5-10. Schematic of apparatus for cesium-cesium oxide converter tests................... 5-16

5-11. Cesium and cesium oxide pressure family of J-V curves . . 5-19

5-12. Variation of performance of cesium-cesium oxide converter with collector temperature . . . . . . . . . 5-20

5-13. Relative power distribution (local power/core average power) ................ 5-23

5-14. Composite axial TFE power profile . . . . . . . 5-24

5-15. Collector heat flux correlation with sheath (collector) temperature ........... 5-25

5-16. Correlation between input power, emitter temperature, and current density . . . . . . . . . . . . 5-26

5-17. Current-voltage characteristic of a test device provides estimators of operating condition......... 5-27

5-18. Thermionic performance comparison at a typical operating point . . . . . . . . . . . . . . . 5-29

5-19. Emitter temperature estimate errors observed using the obstructed mode................... 5-30 
FIGURES (Continued)

5-20. $\mathrm{T}_{\mathrm{E}}$ (ignition current): single parameter fit required . . 5-31

5-21. Emitter temperature estimate will be synthesized using several diagnostic tools ............. 5-33

5-22. Photomicrograph of electron beam weld between Mo-Re sleeve and tungsten emitter of $14,000-\mathrm{h}$ G-series converter ................. 5-36

\section{TABLES}

2-1. Fueled emitter test parameters ............ 2-5

2-2. Fueled emitter test matrix . . . . . . . . . 2-6

2-3. Capsule requirements . . . . . . . . . . . . 2-10

2-4. Instrumentation/data acquisition requirements . . . . . 2-11

2-5. Test reactor requirements ............. . 2-12

2-6. Previous GA thermionic experiments . . . . . . . . 2-15

2-7. Initial LIFE4 correlation with Zimmermann unconstrained swelling data... . . . . . . . . . . . 2-20

2-8. SP-100 TFE cell reference design .. . . . . . . . . 2-29

2-9. Heat flows for gap-sizing analysis . . . . . . . . 2-42

2-10. Primary and secondary gap sizes... . . . . . . 2-44

2-11. Cold fuel/emitter gaps for test capsules . . . . . . . 2-52

2-12. Neutron energy group structure . . . . . . . . . 2-55

2-13. Material description and dimensions of thermionic device and fueled emitter analytical model ...... 2- . . 27

2-14. TWOTRAN - RZ material configuration description . . . . . 2-63

2-15. Power requirements for fueled emitters . . . . . . . 2-64

2-16. Radial and axial power factors . . . . . . . . . 2-66

2-17. Final enrichment projection for fueled emitter thermionic device ................ . . 2- 2-67

2-18. Thermionic diode fabrication and processing procedure . . 2-77

2-19. Thermionic diode fabrication status . . . . . . . . 2-83

2-20. Primary assembly procedure . . . . . . . . . . 2-85

2-21. Alarm levels for computer-monttored parameters . . . . 2-106 


\section{TABLES (Continued)}

3-1. SP-100 thermionic reactor seal-insulator operating requirements .................. 3-3

3-2. Ranking of ceramic insulator materials by magnitude of radiation-induced dimensional change . . . . . . 3-5

3-3. Process information; $\mathrm{Y}_{2} \mathrm{O}_{3}$ ceramic hot pressing ..... . 3-11

4-1. SP-100 thermionic reactor sheath-insulator operating requirements .................. 4-4

4-2. Ranking of insulator materials relative to design and performance requirements .......... 4-5

4-3. Sheath insulator tests ................ 4-16

5-1. Converter diagnostics on G-series converter ...... . 5-35 


\section{INTRODUCTION/SUMMARY}

The thermionic technology program addresses the feasibility issues of a seven-year-1ife thermionic fuel element (TFE) for the SP-100 Thermionic Reactor Space Power System. During the 1970s, the TFE development program developed technology consistent with the $20,000-\mathrm{h}$ lifetime goal used at that time. Primary life-limiting factors were recognized to be (1) thermionic emitter dimensional increases due to swelling of the nuclear fuel and (2) electrical insulator structural damage from fast neutrons. Unrestricted emitter dimensional increases result in shorting of the converter electrodes, thereby reducing the output voltage of the shorted cell to near zero. Structural fallure of an insulator seal results in a mixing of the fission gases with the cesium vapor. Structural failure of the sheath insulator can result in increased collector temperatures and less than optimum performance.

The 1984-85 thermionic technology program is investigating the fueled emitter and insulator lifetime issues, both experimentally and analytically. This work is intended to analytically project the lifetime of the fueled emitter and insulator and to experimentally verify these projection methods. The SP-100 project plan calls for resolution of the lifetime issues by July 1985 .

\subsection{FUELED EMITTER DEFORMATION}

\subsubsection{Task Objectives/Approach/Requirements}

The analytical approach for resolving the emitter lifetime issue involves the following steps: (1) validate existing fuel deformation models [LIFE 4 and FASTGRASS codes developed for the liquid metal fast breeder reactor (LMFBR) program] for use in TFE fueled emitter design, (2) Identify dominant deformation mechanisms, and (3) calculate the 
expected lifetime as a function of the emitter temperature and geometry. The deformation mechanisms proposed are fuel swelling, thermal ratcheting, and the bladder effect. This latter phenomenon arises from the pressure of trapped fission gases within the central void of the fuel which is formed by a vaporization-condensation restructuring of the uranium oxide fuel.

The in-pile irradiations of prototype fueled emitters are intended to verify the dominant deformation mechanisms outlined above and to measure the amount of emitter deformation as a function of fuel burnup, temperature, and emitter thickness. To this end, 12 fueled emitters are being fabricated, encapsulated, and irradiated in the Mark F TRIGA reactor. Emitter deformation resulting from steady-state operation and thermal cycling will be measured by track-etch neutron radiography. Measurement of the pressure of fission gases released from the fuel will provide data on the amount of fission gases trapped in the fuel bladder.

\subsubsection{Emitter Deformation Analysis}

Existing analytical methods to predict emitter deformation were evaluated for their capabilities. The prime candidates were LIFE4, FASTGRASS, and MATPRO. LIFE4 was selected for the initial studies for its broad analytical capabilities, including fuel creep, swelling, sintering, restructuring, and fission gas release. It also performs thermal and elastic structural analysis. To this, GA Technologies Inc. (GA) added the capability to analyze structures undergoing plastic deformation, which is important in the analysis of thermal ratcheting. LIFE4 is a one-dimensional model. Future work will adapt the LIFE4 and FASTGRASS fuel models into a two-dimensional structural analytical code.

Work is underway at GA and Los Alamos National Laboratory (LANL) to validate the LIFE4 code to predict fueled emitter deformation. Prior experimental data on both unconstrained and constrained fuel swelling were compared against the predictions of LIFE4. The data base includes emitter deformation data from the series of TFE tests by GA as well as 
data from the U.S., England, and the Federal Republic of Germany (FRG). The LIFE4 code was used to predict the deformation observed in the Zimmermann and GA tests. Reasonably good correlation was found. The validation of LIFE 4 is continuing into FX-85 and will involve fine-tuning the code to the data.

Preliminary analysis of the bladder mechanism was done by Space Power Inc. (SPI) using the two-dimensional ANSYS code. The results to date indicate that, at $1700 \mathrm{~K}$ emitter temperature, about $68.9 \mathrm{MPa}$ (100 atm) bladder pressure would be required to create a significant rate of emitter deformation $(\sim 1 \mathrm{mil} / \mathrm{yr})$. Assuming that the bladder is $100 \%$ effective in retaining the fission gases and using the LIFE4 gas release model, such a rate of emitter deformation would not occur until about $20,000 \mathrm{~h}$. This is a very conservative result, since complete bladder containment is not likely due to the porocity and grain boundary channeling of the fuel, which are created by fission generation and transport. If the analysis eventually concludes that fission gases could accumulate and cause excessive emitter distortion, a snorkel vent will be incorporated into the top of the fuel cavity. The design and analysis of the snorkel vent tube were completed by SPI.

Analysis of the thermal ratcheting mechanism by GA has shown that the emitter-temperature-step increases of $4 \mathrm{~K}$ every $150 \mathrm{~h}$, which coincide with SP-100 reactivity insertions for fuel burnup, will not cause emitter deformation. This temperature increase is small enough that the emitter remains in the elastic strain region. Ramp cooling of the emitter by $4 \mathrm{~K}$ over the $150 \mathrm{~h}$ does not lead to the opening of a gap between the fuel and emitter, because fuel swelling more than offsets the differential expansion between the fuel and emitter. If a gap were allowed to open, a condition would be set up, where thermal ratcheting by fuel vaporization could occur.

At this point, the predominant deformation mechanism is concluded to most likely be fuel swelling. Using the LIFE4 model to calculate 
emitter deformation in the reference SP-100 reactor, the emitter-tocollector gap has been shown to decrease by only one-third of the initial gap after seven years of operation. Even for the most conservative extrapolation from the initial slope of the deformation-time curve, an approximate seven-year lifetime is still predicted.

As part of this analytical effort, emitter materials having superior creep strength were investigated. Dispersion-strengthened and composite emitters were concluded to offer the most promise. Stronger emitters allow operation at a higher emitter temperature, reduced emitter thickness, or a combination of both.

\subsubsection{Capsule Design}

1.1.3.1. Design Description. The fueled emitter deformation capsule is designed to provide data on the distortion of a chemical vapor-deposited (CVD) tungsten (deposited from WF $_{6}$ ) emitter as a function of (1) emitter thickness, (2) emitter temperature, and (3) irradiation time, and to monitor fission gas release. Each capsule consists of three thermionic diodes whose outputs can be measured individually. Every diode has its own cesium reservoir (with two heaters) and fission gas reservoir with a pressure gauge. The parameters to be measured are collector temperatures, cesium reservoir temperatures, output voltages and currents, and fission reservoir pressures. The emitter temperature will be inferred by comparing the output characteristics to those of an out-of-pile thermionic diode. The collector temperature can be adjusted by varying the gas composition in the gap between the primary and secondary containments. The outside diameter of the capsule inserted into the reactor core is $5.94 \mathrm{~cm}(2.34 \mathrm{in}$.), and the outside diameter of the secondary containment outside the core is $10.16 \mathrm{~cm}$ ( 4.0 in.) A hard seal separates the primary and secondary containments, and a soft seal is located at the top of the secondary containment. The design of the primary containment, including details and fixtures, has been completed by Thermo Electron (TE), and the secondary containment design is in progress. 
1.1.3.2. Analysis. Thermal and nuclear analyses were performed by GA to determine thermal inputs to the fuel, heat transfer gaps, temperature distributions, and fuel enrichments. The fuel heat generation rates were set at 987,1302 , and $1661 \mathrm{~W}$ for emitter temperatures of 1650,1750 , and $1850 \mathrm{~K}$, respectively, based on heat transfer analysis and correlations developed during the earlier program. These values are consistent with the $\mathrm{SP}-100$ system requirements. The heat transfer gas gaps surrounding the fueled emitter cells were sized using a one-dimensional TAC model, taking into consideration the fuel heat generation rates, the material gamma rates, collector temperature control requirements, and component differential expansions. Cold gap sizes between the collector and the primary containment ranged from 5.2 to $16.0 \mathrm{mils}$, depending upon the collector heating rates. The collector temperature will be controlled within $\pm 100 \mathrm{~K}$ by varying a helium-argon gas mixture between the primary and secondary containments. GA confirmed the gap sizing and determined the cell temperature distributions using a two-dimensional TAC heat transfer model. TE confirmed both the gap size and the emitter lead temperature using a similar model.

The fuel enrichments required for generation of the desired thermal power were calculated by GA using a one-dimensional transport model, then confirmed for a single case with TWOTRAN, a two-dimensional neutron transport model. The Mark F TRIGA is assumed to operate at its maximum licensed power of $1.5 \mathrm{MW}$ in order to minimize the fuel enrichments and therefore minimize the thermal peaking in the fuel. The fuel enrichments finally selected for the 12 emitters ranged between $5.8 \%$ and $17.5 \%$, depending on the fuel power generation rate, the emitter thickness, and the location of the fueled emitter within the reactor. These low enrichments permit a maximum-to-average radial power distribution of 1.5 or less in all of the fuel bodies. This will allow the fuel temperature distribution to very closely approximate that of the SP-100 fuel. 


\subsubsection{Capsule Fabrication}

1.1.4.1. Component Fabrication. Component fabrication efforts were initiated by a GA-funded effort to reestablish the needed thermionic fabrication technology. This work included laboratory and equipment setup and revitalization, fabrication procedure updating, and process verification for tungsten vapor deposition, ceramic-to-metal seal manufacture, tungsten-to-tantalum diffusion bonding, uranium dioxide fuel manufacture, chemical analytical methods, heat treating-degassing, and special machine shop operations.

GA chemically vapor-deposited tungsten emitters with controlled chemistry and microstructure for the 12 irradiation capsule converters and one electrically heated converter. GA also diffusion-bonded the tungsten emitters to a tantalum transition. TE performed most of the emitter machining. GA produced uranium dioxide fuel loadings having controlled stoichiometry and density for the 12 in-pile emitters. GA fabricated 16 high-temperature ceramic-to-metal seals and qualified them for capsule converter applications. The alumina ceramic is metallized with a tungsten-yttria metallizing mixture and brazed with a niobium-vanadium alloy. TE machined the parts for 16 collector subassemblies and the primary capsule components.

1.1.4.2. Capsule Assembly. Assembly of the capsule, through the primary containment, is being done by $\mathrm{TE}$. The first step in the capsule fabrication is the assembly of the thermionic diodes. In sequence, the following electron beam (EB) welds are made: (1) cesium tube to adaptor, (2) adaptor to collector, (3) insulator seal to collector, (4) emitter to insulator seal and, (5) end cap to collector. Next, the cesium distillation assembly is brazed to the diode. The diode is outgassed using an Ion pump, cesiated, and pinched off. After the diode is given an operational test, it is loaded with the fuel pellets, then the emitter flange is attached. The three diodes are assembled into a primary fixture and connections to the diode leads and fission gas tubes are completed. Then the cesium heaters, voltage probes, and thermocouples are attached. The 
primary containment is formed by fitting a stainless-steel tube around the diode assembly and the hard seal. The secondary containment will be installed at GA. The three diodes for the first capsule have been fabricated, outgassed, cesiated, pinched off, and operationally tested. The primary containment assembly fixtures are being fabricated. The fabrication of the diodes for the second capsule has been completed.

\subsubsection{Instrumentation}

Rasor Associates (RA) is fabricating the instrumentation for operation of four fueled emitter capsules in the Mark F TRIGA reactor. The input power to each fueled emitter device is determined by the power level of the TRIGA reactor and the location of the fueled emitter in the reactor. The emitter temperature, in turn, is established by controlling electron cooling (i.e., operating current). As in a thermionic converter, a low pressure of cesium vapor is used to obtain the proper electron emission characteristics for the emitter. The temperature of the collector is determined by the input power to the device and the thermal conductance of two gas gaps: (1) between the collector and primary containment can and (2) between the primary can and the water-cooled secondary containment can. The composition and pressure of the gas in the second gap is changed to adjust the collector temperature. Thus, the essential instrumentation needed for operation includes the TRIGA reactor, $12 \mathrm{dc}$ driving supplies ( $10 \mathrm{~V}, 500 \mathrm{~A})$ to establish the electron coo1Ing for each emitter, 12 cesium reservoir heater-coolers to establish the desired cesium pressures, and a secondary containment gas change system which can be used with each of the four capsules. This instrumentation has been fabricated and is presently undergoing burn-in tests.

The emitter temperature and input power of each device are inferred from current-voltage characteristics. These data are obtained by rapidly $(0.2 \mathrm{~s})$ varying the current through the dc driving supply and the test device, while recording the current-voltage waveform with an oscilloscope. Other recorded data include the collector and cesium reservoir temperatures from chromel-alumel thermocouples. To determine the amount 
of fission gas release, each fueled emitter has a separate fission gas collection volume. The pressure in this trap is monitored with pressure transducers. The transducers and their power supplies have been procured and are now being calibrated.

Three additional support systems are required:

1. A water flow system used to cool the high current bus bars connected to each test device. This system has been fabricated.

2. A reactor scram system to shut down the reactor in case of a loss of current or bus bar water flow to any test device or an excessively high primary containment temperature in any capsule. The scram system is complete and awaits final test following installation at GA.

3. A computerized data acquisition system to acquire, analyze, and store all pertinent operating parameters every minute. Included in the recorded data are the reactor power level, fission gas trap pressure, collector and cesium reservoir temperatures, operating current and output voltage for each test device, secondary containment pressures, impending scram conditions etc. A data acquisition system, based on an HP9816 microcomputer, has been built, and all the software needed for operation has been written.

\subsubsection{Test Reactor Preparation}

Preparation of the $G A$ reactor facility for the irradiation of the fueled emitter capsules includes (1) modifications to the Mark F TRIGA, (2) modifications to the neutron radiography unit, (3) an amendment to the reactor operating license, and (4) licensing of additional reactor operators. The Mark F TRIGA reactor uses 70\%-enriched uranium with erbium added to the fuel to serve as a burnable poison and to enable core 
operating lifetimes of $9 \mathrm{MW}-\mathrm{yr}$. This feature provides for unperturbed fueled emitter operation, since the reactor will be operated with very little control rod movement for extended durations and without the frequent refuelings normally experienced in fast test reactors. Modifications to the reactor included (1) fabrication of new core grid plates designed for accommodation of the fueled emitter capsules (larger than the TRIGA elements), (2) refinement of the nuclear instrumentation to allow accurate power and local relative flux measurements, (3) redesign of the reactor bridge structure to allow access to the neutron radiography unit and provide more room for the capsule electrical buses and instrumentation, and (4) replacement of the reactor coolant heat exchanger.

Modification of the neutron radiography unit, built for the earlier program, is required to (1) fit within the Mark F reactor pool, (2) accept the large-diameter capsule, and (3) switch to the more accurate track-etch radiographic method. These modifications are now in progress. An amendment was received to the existing Mark F TRIGA license to allow the four fueled emitter capsules to be tested. Additional reactor operators were hired for the long-term continuous operation of the TRIGA, as required for the fueled emitter irradiations. These operators were trained by GA and licensed by the Nuclear Regulatory Commission (NRC). other preparations included gaining approval of the capsule design by the GA Criticality and Safeguards Committee. The fueled emitter irradiations are now scheduled to start at the end of November.

\subsection{METAL CERAMIC SEAL}

\subsubsection{Task Objectives/Approach/Requirements}

The function of the metal-ceramic seal in the reference thermionic reactor design is to provide a hermetic seal between the cesium and fission gas spaces in individual converters within a TFE. The seal must electrically isolate the enitter from the collector. Specific requirements include the ability to fulfill these functions for the full seven 
years $(61,320 \mathrm{~h})$ design lifetime of the reactor, while operating at a peak temperature of $1230 \mathrm{~K}$ in cesium vapor ( 1 torr) with a peak steadystate applied voltage near $0.6 \mathrm{~V}$. The most severe requirement is to perform in this environment while exposed to a total fast neutron fluence of

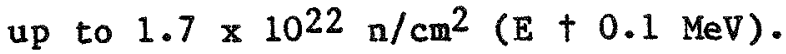

This task is intended to demonstrate that suitable ceramic materials and seal fabrication processes will be available to meet these requirements. Previous seal design experience and data from previous fast neutron irradiation tests will be used to identify potential ceramics and seal designs and seal degradation processes. The cesium compatibility of selected ceramics will be established in accelerated tests at higher than design temperatures and cesium pressures. Life-limiting degradation processes will be assessed analytically and life projections made for the selected design. For example, stress calculations for the seal designs will be performed to ensure that neutron-induced swelling of the ceramic can be accommodated by elastic deformation of the metal parts.

\subsubsection{Fabrication Development}

1.2.2.1. Solid-Body Ceramics. Single-crystal $\mathrm{Al}_{2} \mathrm{O}_{3}$, single-crystal and polycrystalline yttria aluminum garnet ( $Y A G$ ), and polycrystal $\mathrm{Y}_{2} \mathrm{O}_{3}$ were selected as ceramic candidates for the fabrication, development, and testing of solid-body metal-ceramic seals. As the first step, the laboratory facilities and processes for fabrication of polycrystalline alumina-niobium seals were reestablished by GA to provide a base from which to develop seals with different ceramics.

1.2.2.2. Cermets. Cermets of niobium spheres in an alumina matrix fabricated by TE have given good results in trilayer and pentalayer sheaths. The same technology can be used to make insulator seals. The rationale for the cermet approach is ( 1 ) a good thermal expansion match between niobium and alumina, (2) a strong interface between the insulator and the adjacent niobium electrode due to bonding of the spheres to the electrode, (3) a reduced modulus of the cermet, (4) crack stopping due to 
the spheres, and (5) higher thermal conductivity (relative to the ceramic). Based on a literature survey and evaluation of candidate ceramics with respect to radiation resistance, electrolytic degradation, thermal expansion match, and cesium compatibility, yttria and YAG have been selected as matrix materials for cermets with longer life potential than alumina. However, alumina is being used to reestablish the cermet technology.

\subsubsection{Testing}

A seal insulator test plan was proposed and approved. The plan calls for cesium compatibility tests on alumina, yttria, and YAG ceramic bodies at 800,1100 , and $1400 \mathrm{~K}$ in a cesium pressure of 60 torr. Sufficient thermal cycling of fabricated seals is planned to ensure their ability to meet TFE fabrication process requirements. An electrical test at $1 \mathrm{~V}$ at $300,900,1100$, and $1300 \mathrm{~K}$ will be used to confirm their electrical resistance at temperature. A cesium capatibility test stand has been fabricated at RA. The test stand has been operated with preliminary samples and early problems; a steel bell jar collapse and a leaky valve have been corrected. The preliminary tests suggest that YAG samples will darken after $200 \mathrm{~h}$ at temperature, possibly due to cesium exposure. Further testing in cesium will continue following preparation of new samples.

\subsection{METAL-CERAMIC SHEATH INSULATOR}

\subsubsection{Task Objectives}

The function of the metal-ceramic sheath insulator is to electrically isolate the collector of each converter in a TFE from the outer sheath tube which operates in contact with the reactor liquid metal coolant. The sheath insulator must also provide a high uniform thermal conductance between each collector and the sheath tube. These functions must be fulfilled for the seven-year $(61,320-h)$ design life of the reactor. 
Operating requirements include a peak steady-state temperature of $1130 \mathrm{~K}$, an applied voltage of up to $50 \mathrm{~V}$, and exposure to a fast neutron fluence of up to $1.7 \times 10^{22} \mathrm{n} / \mathrm{cm}^{2}(\mathrm{E}+0.1 \mathrm{MeV})$.

This task is intended to establish that metal-ceramic sheath insulators will be available to meet these requirements. A combined analytical and experimental approach is being used. The existing data base will first be used to identify important life-limiting degradation mechanisms and those ceramic materials which best withstand such degradation. The feasibility of fabricating sheath insulators with the selected ceramics wi11 be established. Tests will be conducted to examine the integrity of the interface bond between the metal and ceramic to determine its thermal conductance. Accelerated tests at temperatures and/or voltages higher than the design conditions will explore electrolytic degradation processes in selected sheath insulator designs.

The electrical performance characteristics of the sheath insulators w11l be modeled analytically and verified using the experimental data. The ability of each sheath design to meet the design requirements will then be projected from analytical calculations.

\subsubsection{Fabrication Development}

1.3.2.1. Plasma-Sprayed Graded Sheath Insulator. This type of insulator is made by plasma spraying mixtures of niobium and ceramic powders onto a niobium collector, then hot pressing a niobium sleeve over the plasmasprayed surface.

Polycrystalline $\mathrm{Y}_{2} \mathrm{O}_{3}$ and $\mathrm{YAG}\left(\mathrm{Y}_{3} \mathrm{Al}_{5} \mathrm{O}_{12}\right)$ are the prime candidates to meet the above requirements. These ceramics were selected based on their stability under fast neutron irradiation, close match of thermal expansion coefficient to surrounding structural materials, and resistance to ionic transport at the reference electrical potential and operating temperature. 
The first step was to reestablish and update laboratory facilities and processes for fabricating graded trilayer sheath insulators. The new GA-owned facilities include a computer-controlled plasma-spray system for controlled chemical composition and trilayer thicknesses.

High-purity $\mathrm{Y}_{2} \mathrm{O}_{3}$ and niobium powders were purchased and analyzed for trace impurities. Process conditions were selected to plasma-spray graded $\mathrm{Nb}-\mathrm{Y}_{2} \mathrm{O}_{3}-\mathrm{Nb}$ trilayers. Three trilayers were sprayed and prepared for hot isostatic pressing. One of these samples was hot isostatically hot pressed at $2000 \mathrm{~K}$ and made available for out-of-pile evaluation.

\subsubsection{Cermet Sheath Insulator. Cermet sheath insulators are tiny} niobium spheres in a matrix of ceramic material. The ceramics being used are alumina, yttria, and YAG. Initial compacts of the above ceramic materials with volume fractions of niobium spheres ranging from 0.25 to 0.40 have been fabricated at TE by (1) cold pressing [413.6 MPa $(60,000 \mathrm{psi})]$, (2) low-temperature sintering (1473 K), (3) machining, and (4) autoclaving at high pressure $[68.9 \mathrm{MPa}(10,000 \mathrm{psi})]$ and high temperature $(1820 \mathrm{~K})$. Compacts were made of all the foregoing combinations. Photomicrographs of these initial samples showed that agglomeration was a problem. As a consequence, the fabrication technique is being modified to minimize this problem.

\subsubsection{Testing}

Two primary types of tests will be performed at RA:

1. A thermal bond test will ensure insulator integrity. This will be accomplished using high-contrast photography with a centrally heated insulator operating at a surface temperature of $1350 \mathrm{~K}$ and a radial heat flux near $5 \mathrm{~W} / \mathrm{cm}^{2}$. Temperature cycling between 500 and $1200 \mathrm{~K}$ will be used to further confirm integrity. The vacuum system and data acquisitions system for this test are complete and awaiting test specimens. 
2. Electrical testing for each sheath will begin with a short $150-V$ voltage standoff test at $1200 \mathrm{~K}$, followed by electrical conductivity measurements at $50 \mathrm{~V}$ and $300,700,900$, and $1200 \mathrm{~K}$. Electrical life testing will be performed at 100 , 1250 , and $1400 \mathrm{~K}$ with samples at $10,25,50$, and $100 \mathrm{~V}$. Metallurgical examinations will be made on specimens that have operated 2000,5000 , and $8000 \mathrm{~h}$ to identify any possible mechanical degradation. The vacuum test stand for these tests has been completed. Ovens are being fabricated similar to those used for the cesium compatibility tests. They are larger and are modified to use all-refractory materials to avoid metal spray on electrical insulators.

\subsubsection{Analysis}

An analytical model has been developed to predict the timedependence of the electrical conductivity and material transport in the sheath insulator. Two levels of approximation are being used:

1. Ionic conductivity for the electrically stressed ceramic is expressed as a function of temperature, the activation energy for transport of an ion, and the electric field. For the temperature and electric field regime needed in the reference reactor design, the ionic current is expected to be approximately linear with electric field and to have an Arrhenius temperature dependence. The data obtained in the testing program are designed to establish the validity of this first-order approximation.

2. The analytical model is being extended by RA to a second order of approximation by treating the sheath insulator as a multilayer structure, with a central ceramic layer bounded by layers of metal. The transport of both ions and electrons through the structure is modeled with a numerical solution of transport continuity equations in each region and by matching boundary 
conditions at the interfaces and edges. The transport of electrons is treated with the band theory of insulators. Transport coefficients for the most mobile ions in the lattice will be obtained from calculations based on chemical equilibria involving the materials, the temperature, and oxygen pressure. A computer program, which solves finite difference forms of the continuity equations for vacancy transport, has been prepared and is being used for an initial parametric study.

Possible degradation mechanisms identified theoretically (i.e., oxygen anion loss from the cathode or an increase in lattice defects, leading to increased conductivity) will be compared to the experimental data to verify the model. This model will then be used to project the life characteristics of the sheath insulator and its acceptable operating environment.

\subsection{CONVERTER PERFORMANCE}

\subsubsection{Task Objectives/Approach/Requirements}

This task has three objectives:

1. Produce a reliable correlation between the emitter temperature and the electrical behavior of a test device similar to the fueled emitter capsule.

2. Select a suitable method for obtaining oxygenated performance, based on previous data and planar converter tests.

3. Measure thermal and electrical performance of an oxygenated converter cell that is prototypic of the SP-100 thermionic reactor designs and monitor performance stability with time.

The specific performance objectives are for an electrode power density of $2.5 \mathrm{~W} / \mathrm{cm}^{2}$ (corresponding to a current density of $5.9 \mathrm{~A} / \mathrm{cm}^{2}$ and 
an output electrode potential of $0.42 \mathrm{~V}$ ) at an emitter temperature of $1700 \mathrm{~K}$, a collector temperature of $1085 \mathrm{~K}$, and an interelectrode spacing of $0.5 \mathrm{~mm}$. This goal is understood to be subject to change, dependent on $\mathrm{SP}-100$ system requirements.

After a review of the converter performance data base, the two most promising technical approaches to achieve task objectives were chosen to be (1) use of molybdenum coatings sublimed onto a niobium collector in a low-pressure oxygen atmosphere and (2) use of a cesium-cesium oxide vapor in the interelectrode space. Encouraging results have been found using both technical approaches.

Two converters are being supplied by $\mathrm{TE}$ for testing at $\mathrm{RA}$ to meet these objectives. The first test device, $T D-1$, will be used for emitter temperature correlation testing. A test facility, including a vacuum system, driving supply, and heater-coolers, has been prepared for $\mathrm{TD}-1$. The same test stand equipment will then be used for performance testing of the second converter.

The techniques used in the previous program to measure in-pile emitter temperature based on electrical and thermal characteristics have been reviewed and the data required in the $\mathrm{TD}-1$ test identified. Two planar converters have been tested: (1) an oxygenated collector and (2) an external cesium oxide reservoir. Sections 5.2 and 5.3 describe the results.

\subsubsection{Converter Performance of Oxygenated-Collector Converter}

Tests at TE have demonstrated that thermionic converters built with a sublimed molybdenum coating on niobium collectors can provide significantly higher power output at interelectrode spacings of $0.5 \mathrm{~mm}$ than diodes with bare collectors. In such converters, oxygen transport to the emitter increases its current density at a given temperature and cesium pressure. Consequently, converters with oxide collectors can operate at lower cesium pressure (relative to those with bare collectors) and 
reduced potential losses in the plasma at high interelectrode spacings. Additional output can result from the lower collector work function of the oxide collector. A TE research converter with a sublimed molybdenum collector and an electropolished power metallurgy tungsten emitter has given a stable electrode output of $3 \mathrm{~W} / \mathrm{cm}^{2}$ at a spacing of $0.5 \mathrm{~mm}$ and emitter and collector temperatures of 1730 and $1075 \mathrm{~K}$, respectively. These test conditions closely approximate those of the SP-100 baseline design.

\subsubsection{Cesium-Cesium Oxide Converter}

An alternative with potential for longer life than the oxygenated collector approach described above is a converter having dual reservoirs of cesium and cesium oxide, both connected to the interelectrode volume. A converter of this type was recently built and tested at RA. The performance obtained with the dual reservoirs was comparable to an oxygenated collector converter. Good control of both vapors was maintained throughout the test. Some indications of very low collector work functions, such as high back emission, were observed, although the converter performance did not reflect the corresponding increase in output voltage. Operation of the cesium-cesium oxide converter with a high collector temperature resulted in a loss of performance. The operation was stable and repeatable throughout the duration of the test. 


\section{FUELED EMITTER DEFORMATION}

\subsection{TASK OBJECTIVES/APPROACH/REQUIREMENTS}

\subsubsection{Objectives}

Thermionic emitters fueled with uranium oxide will be tested in-pile to measure emitter deformation as a function of emitter temperature, thickness, and operating profile and to determine dominant deformation mechanisms. Candidate deformation mechanisms include the following:

1. Emitter creep induced by fuel swelling and restructuring.

2. Emitter creep from pressure buildup in the fuel central cavity formed by fuel vaporization/condensation.

3. Emitter thermal ratcheting from temperature transients and fuel redistribution.

The deformation data will be used to validate fuel models and viscoelastic analyses, which will establish the design of fueled emitters for seven-year operation in SP-100 reactor power systems. The prediction of a seven-year lifetime on the basis of these test results and viscoelastic analysis is a major milestone scheduled for July 1985.

\subsubsection{Approach}

The logic of the fueled emitter deformation task, shown in Fig. 2-1, is divided into two major activity lines: (1) analysis and (2) experiment. The starting point for both of these activities is the application of prior test experience and existing analytical methods. Prior in-pile test experience with fueled emitters allows the early establishment of 


\section{ANALYSIS}

VALIDATE EMITTER DEFORMATION MODELS

IDENTIFY DOMINANT DEFORMATION MECHANISMS

CALCULATE EXPECTED LIFETIME

TEMPERATURE

GEOMETRY

EVALUATE IMPROVED EMITTERS/FUELS

IN.PILE EXPERIMENTS

VERIFY DOMINANT DEFORMATION MECHANISMS
FUEL SWELLING
BLADDER
THERMAL RATCHETING
EXTRAPOLATE TO MINIMUM LIFETIME

ESTABLISH DESIGN METHOD

VERIFY ANALYTICAL MODEL

PREDICT LIFETIME

IDENTIFY IMPROVED EMITTERS

\section{OUT-OF-PILE EXPERIMENTS}

VERIFY CVD TUNGSTEN CREEP STRENGTH SCREEN IMPROVED EMITTER CONCEPTS

A17773

Fig. 2-1. Fueled emitter deformation/1ifetime experimental and analytical approach 
the basic capsule design. This same experience, plus preliminary emitter deformation analysis and SP-100 systems analysis, allows the establishment of the emitter geometries and the fabrication of the emitters. Specification of the detailed operating conditions and profiles for the experiment is derived from an extensive analytical effort in which the deformation analytical models are normalized to prior test experience, including the Zimmermann, Battelle Memorial Institute (BMI), and GA data bases. These analytical studies are expected to yield information on the potential deformation mechanisms and to guide the exact specification of emitter operating temperatures. Meanwhile, the fueled emitter capsules have been fabricated and made ready for testing.

The in-pile data obtained from these tests are used to confirm the analytical predictions of predominant deformation mechanisms and to verify the fuel analytical models and viscoelastic methods, therefore establishing the design methods for the fueled emitters in the SP-100.

The 1984-85 thermionic technology program is formulated on the fabrication of 12 fueled emitters. This number was selected to balance the cost of the fueled emitter deformation task with the costs of the other tasks within the program. The number is viewed to be adequate as long as the number and range of variables to be tested are maintained within reasonable bounds.

Direction from the SP-100 program office has been to tailor the technology program to the specific needs of the reference SP-100 system. Therefore, with the reference emitter at $2.79 \mathrm{~cm}(1.1 \mathrm{in}$ ) diameter, $5.08 \mathrm{~cm}$ (2 in.) long, $0.178 \mathrm{~cm}(0.070 \mathrm{in.})$ thickness, and $1700 \mathrm{~K}$, the range of parameters to be investigated should include and perhaps span these values. The other parameters, yet to be specified in the systems analysis, are related to the expected emitter temperature-time profile.

The degree to which these design parameters merit treatment as variables within the testing program depends on their perceived relative 
importance to the determination of dominant deformation mechanisms, the ability to verify the analytical methods, the ability to predict sevenyear life at the end of $7000 \mathrm{~h}$ of testing, and system constraints. In prior presentations of technology program planning, the emitter diameter and length have been proposed to be fixed and emphasis placed on determining how the emitter thickness, emitter temperature, and emitter temperature-time operating profiles impact fueled emitter lifetime. The rationale for fixing the diameter and length is that (1) the system design is based on data for a $2.79-\mathrm{cm}\left(1.1-\mathrm{in}_{0}\right)$ diameter and a $5.08-\mathrm{cm}$ (2-in.) length, and (2) two variables should be eliminated in an already complex analysis. Smaller diameters or shorter lengths are in the wrong direction as far as reactor criticality is concerned. Larger diameters are predicted to yield shorter lifetimes.

Table 2-1 specifies the characteristics of the 12 fueled emitters in the four capsules. Nine fueled emitters within three of the capsules are designated as steady-state reference cases where no intentional thermal cycling would be permitted. The other capsule is designated for thermal ratcheting experiments. All emitter fuel cavities will feature a means for sampling the fission gases to determine release-to-birth ratios, thereby obtaining an upper limit to the amount of fission gas that could be trapped in the restructured central fuel cavity. Hence, all capsule emitters will be capable of providing data on the impact of fuel swelling/restructuring and the bladder effect.

Tables 2-1 and 2-2 show the allocation of emitter temperature and thickness variables among the steady-state emitters. Six of the nine emitters will be operated at $1750 \mathrm{~K}$ to maximize data around the maximum expected emitter temperature in the $\mathrm{SP}-100$ system reference design. Three of these emitters at $1750 \mathrm{~K}$ will be at the reference $0.178 \mathrm{~cm}$ $(0.070 \mathrm{in.})$ thickness. Greater emphasis is placed on the $0.254-\mathrm{cm}$ (0.100-in.) thick emitters than on the $0.102-\mathrm{cm}(0.040-i n$.$) thick$ emitters to maximize the probability of achieving deformation rates consistent with seven-year lifetimes. 
TABLE 2-1

FUELED EMITTER TEST PARAMETERS(a)

\begin{tabular}{|c|c|c|c|c|}
\hline & \multicolumn{3}{|c|}{ Steady-State } & \multirow{2}{*}{$\begin{array}{l}\text { Transient } \\
\text { Capsule } 4\end{array}$} \\
\hline & Capsule 1 & Capsule 2 & Capsule 3 & \\
\hline \multicolumn{5}{|l|}{ Cell 1, top diode } \\
\hline Temperature, $\mathrm{K}$ & 1750 & 1650 & 1750 & 1650 \\
\hline Thickness, cm (in.) & $0.254(0.100)$ & $0.178(0.070)$ & $0.102(0.040)$ & $0.178(0.070)$ \\
\hline $\mathrm{U}-235$ loading, $\mathrm{g}$ & - & 11.65 & - & - \\
\hline \multicolumn{5}{|l|}{ Cel1 2, middle diode } \\
\hline Temperature, $\mathrm{K}$ & 1850 & 1850 & 1750 & 1850 \\
\hline Thickness, $\mathrm{cm}$ (in.) & $0.254(0.100)$ & $0.178(0.070)$ & $0.178(0.070)$ & $0.178(0.070)$ \\
\hline U-235 loading, $g$ & -- & 24.97 & - & -- \\
\hline \multicolumn{5}{|l|}{ Cel1 3, bottom diode } \\
\hline Temperature, $\mathrm{K}$ & 1750 & 1750 & 1750 & 1750 \\
\hline Thickness, cm (in.) & $0.254(0.100)$ & $0.178(0.070)$ & $0.178(0.070)$ & $0.178(0.070)$ \\
\hline $\mathrm{U}-235$ loading, $\mathrm{g}$ & - & 20.39 & -- & -- \\
\hline
\end{tabular}

(a) Emitter is $2.79 \mathrm{~cm}(1.1 \mathrm{in.})$ diam and $5.08 \mathrm{~cm}(2.0 \mathrm{in.}) 10 n g$. 
TABLE 2-2

FUELED EMITTER TEST MATRIX

\begin{tabular}{|c|c|c|c|c|c|c|}
\hline \multirow{2}{*}{$\begin{array}{c}\text { Emitter } \\
\text { Temperature, } \\
\mathrm{T}_{\mathrm{E}}\end{array}$} & \multicolumn{6}{|c|}{$\begin{array}{c}\text { Number of Steady-State Emitters } \\
\text { at Thickness [cm (in.)] }\end{array}$} \\
\hline & 0.102 & $(0.040)$ & 0.178 & $(0.070)$ & 0.254 & $(0.100)$ \\
\hline 1650 & & $-\infty$ & & 1 & & - \\
\hline 1750 & & 1 & & 3 & & 2 \\
\hline 1850 & & - & & 1 & & 1 \\
\hline
\end{tabular}


The specified temperatures are tentative until a greater level of understanding is obtained through detailed analysis of the impact of the temperature on lifetime. Temperatures are specified at this point to set the fuel enrichment needed for the design power level as a function of temperature. In actual in-pile operation, the temperature can be varied by adjusting the emitter electron cooling.

Emitters are generally located within the capsules to take advantage of the axial power profile in the test reactor. Emitters with the highest thermal power requirements are located in the axial center of the core. The other two off-center emitters operate at the lower thermal powers. Thus, the fuel enrichments can be the lowest possible values. This favors a better approximation to the fast reactor fuel temperature profiles.

A detailed analytical study of candidate operating profiles will define the ratcheting experiments for capsule 4. Figure 2-2 shows a logic diagram defining the analytical activities for deciding the kinds of ratcheting temperature-time profiles to perform. Optionally, out-ofpile testing may be undertaken if meaningful tests can be shown to be possible.

If the detailed fuel modeling and viscoelastic analysis shows the bladder effect to significantly contribute to emitter deformation, design variations for the fuel cavity may be in order. One option is to use snorkel devices to vent fission gases. This scheme has been used in the Soviet Tapaz program. Other variants for the design of the fuel cavity will be investigated as part of the fueled emitter analytical task. Variations in fuel cavity design are possible until the fuel is fabricated. 


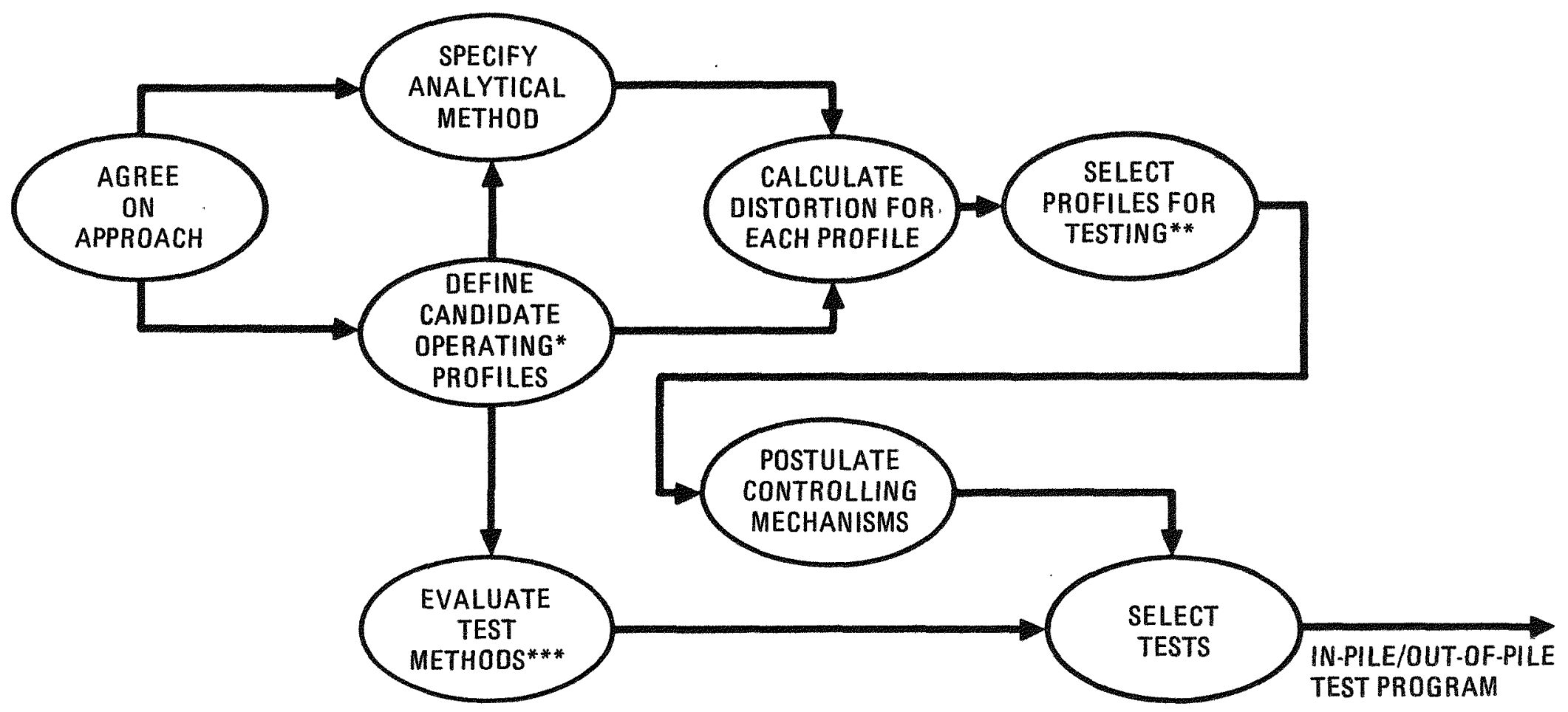

*INCLUDES ANTICIPATED SP-100 PROFILES AND IN-PILE TEST PROFILES

**DEFORMATION MUST BE MEASURABLE AND SIGNIFICANT

***DETERMINE WHICH TESTS CAN BE RUN OUT-OF-PILE OR IN-PILE

A17773

Fig. 2-2. Ratcheting experiment definition 


\subsubsection{Requirements}

Tables 2-3 through 2-5 list requirements for the design and fabrication of the test devices and capsules, instrumentation, and the test reactor.

\subsection{EMITTER DEFORMATION ANALYSIS}

Three mechanisms have been postulated to cause deformation of the thermionic fueled emitter: (1) fuel swelling, (2) bladder effect, and (3) thermal ratcheting. Each mechanism must be clearly understood and its contribution to the total emitter deformation estimated to assure that the seven-year lifetime of the SP-100 thermionic enfter can be safely and reliably achieved. Initial calculations were performed to assess the analytical means available to estimate the contribution from each effect and to use these methods to scope out their effect on emitter deformation. Initial validation and calibration of some of these methods were also begun. The results of these calculations are reported below.

\subsubsection{Fuel Swelling}

Emitter deformation due to fuel swelling was investigated using the LIFE4 (Ref. 2-1) computer code. LIFE4 is the national reference code for the integral modeling of fuel and blanket pins for both light water and fast breeder reactors. It is a one-dimensional, generalized-plane, strain analytical procedure, which investigates thermal and mechanical interaction associated with the major phenomenological models leading to deformation during irradiation. Figure 2-3 outlines the models considered in the LIFE 4 code. The code has been calibrated for use in the LMFBR program by using a broad material and fuel pin irradiation data base developed in that program. Use of the code for predicting the distortions in a thermionic emitter therefore requires the addition of tungsten material properties and an extrapolation of the LMFBR fuel data to the higher temperatures, larger diameters, and lower neutron flux 
TABLE 2-3

CAPSULE REQUIREMENTS

1. Emitter temperature accuracy within $\pm 50 \mathrm{~K}$

2. Real-time irradiations (at design power level)

3. Fuel power and temperature profiles approximately the same as in the SP-100 (lowest possible fuel enrichment)

4. Test device and capsule life greater than $7000 \mathrm{~h}$

5. Fluoride tungsten emitter of same quality as specified for the TFE

6. High-purity uranium oxide

7. Low-pressure fission gas over fuel

8. Fission gas sampling capability

9. Emitter temperature cycling capability

10. No increase in safety hazard or new hazard 
TABLE 2-4

INSTRUMENTATION/DATA ACQUISITION REQUIREMENTS

1. Emitter, emitter transition, collector, cesium reservoir, and fission product trap temperature measurements

2. Cesium reservoir power and control

3. Electrode bus power, control, and cooling

4. Device voltage and current measurements

5. Fission gas trap cooling

6. Fission gas sampling and spectroscopy

7. Secondary containment gas supply, pressure, and conductivity control

8. Data acquisition, including telephone modem

9. Safety circuitry for primary containment protection

10. No increase in safety hazard or new hazard 
TABLE 2-5

TEST REACTOR REQUIREMENTS

1. Accommodation of four fueled emitter test capsules, each containing $<100 \mathrm{~g}$ of $\mathrm{U}-235$ and each having a primary and secondary containment

2. Fueled emitter capsule diameter in-core of $6.03 \mathrm{~cm}(2.375 \mathrm{in.})$ [leaves $0.15 \mathrm{~cm}(1 / 16 \mathrm{in.)}$ clearance from TRIGA fuel]

3. Fueled emitter capsule diameter above-core of $12.7 \mathrm{~cm}$ (5 in.) (upper region contains primary containment instrumentation feedthroughs and fission gas traps)

4. Uninterrupted neutron source (motor-generator power to reactor control and scram circuitry)

5. Controllable and constant neutron source ( $<1 \%$ variation)

6. Neutron radiography capability (as in earlier tests)

7. Capability to safely move capsules to radiograph

8. Dedicated areas for capsule instrumentation racks and cabling channels

9. Continuous seven-day, 24-h operation

10. Unlimited thermionic operator access to reactor room during nonaccident conditions

11. Reactor available for thermionic operations on October 1, 1984 


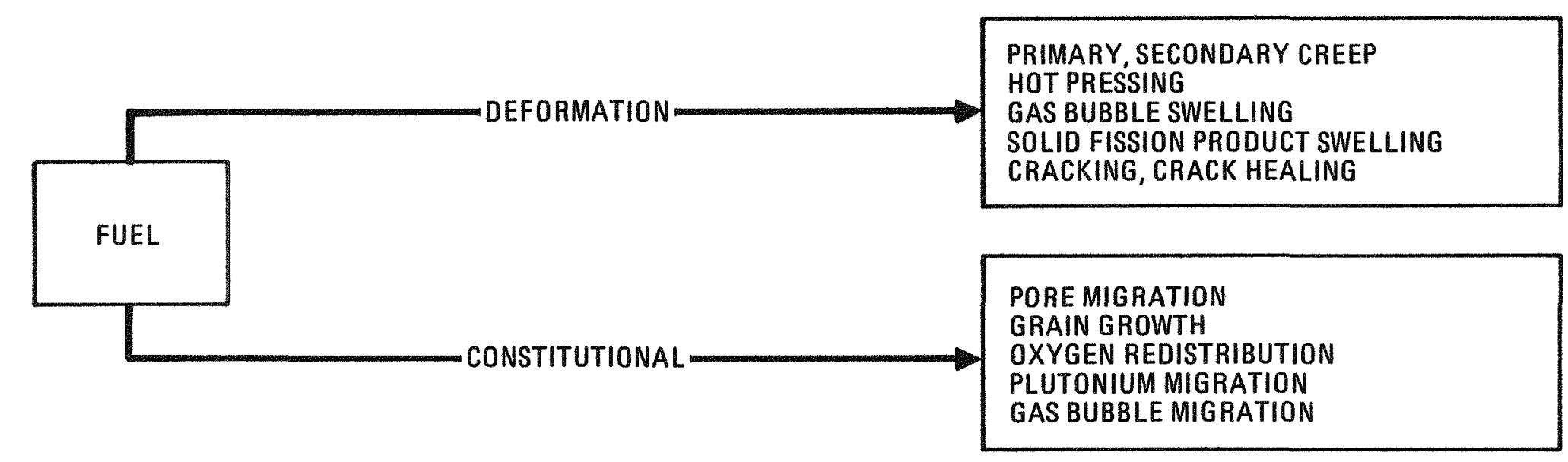

$\stackrel{N}{\omega}$

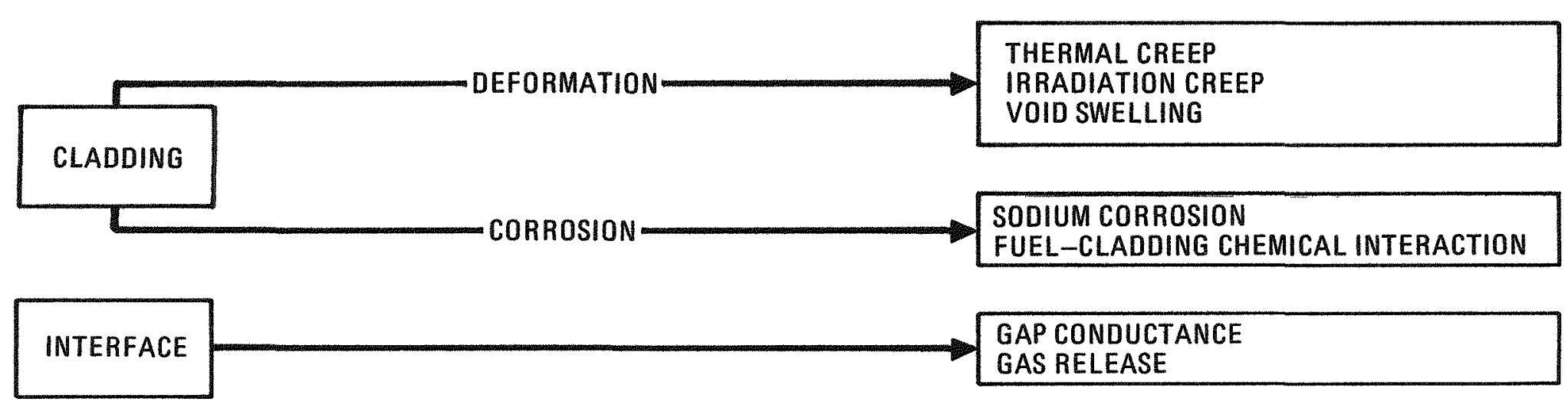

A17773

Fig. 2-3. LIFE4 phenomenological models 
associated with the thermionic emitter. Therefore, a process of code validation must precede final emitter deformation calculations.

2.2.1.1. Code Validation. Validation of the LIFE4 code for use in emitter deformation analyses proceeded along two fronts: (1) incorporation of tungsten emitter material properties and (2) investigation of fuel swelling modeling.

2.2.1.2. Tungsten Properties. LIFE4, as coded, includes material properties important to the LMFBR program, primarily those for 316 stainless steel. Tungsten material properties can be readily included through the input. The properties were obtained from previous work on thermionic tungsten. Great care was exercised in deriving the creep law, since this is a key parameter in predicting the emitter deformation. The creep law derived from TRW and Oak Ridge National Laboratory (ORNL) creep data (Ref. 2-2) using conservative estimates for the fluorine content is

$$
\varepsilon=1665 \sigma^{4.438} \mathrm{e}^{-120,000 / \mathrm{RT}}
$$

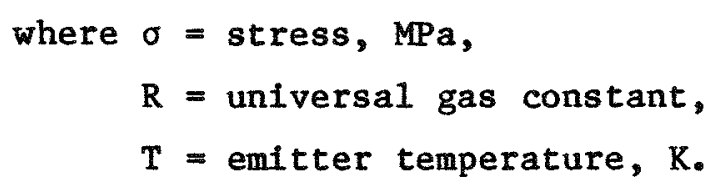

2.2.1.3. Fuel Swelling. Validation of the LIFE4 code for application to fuel emitters will be established primarily through investigating the previous irradiation experiments performed in the GA TRIGA reactor. These experiments included several irradiations with an emitter design that is very similar to the current design for the SP-100. Table 2-6 1ists the major parameters for the thermionic experiments which are applicable (i.e., $\mathrm{UO}_{2}$ fuel and tungsten emitter material). Of special interest are the $1 F 1$ and $6 F 3$ series which included $27.9 \mathrm{~cm}(11.0$ in.) $0 . d^{\text {. and }} 2.0 \mathrm{~cm}(0.79 \mathrm{in.})$ thickness for the emitter. The diameter is the same as and the thickness is slightly larger than $[2.0$ versus $1.8 \mathrm{~cm}$ ( 0.79 versus $0.71 \mathrm{in.})]$ that specified for the primary SP-100 design. 
TABLE 2-6

PREVIOUS GA THERMIONIC EXPERIMENTS

\begin{tabular}{cccccc}
\hline $\begin{array}{c}\text { Thermionic } \\
\text { Assemb1y }\end{array}$ & Ce11 & $\begin{array}{c}\text { Outside } \\
\text { Diameter } \\
(\mathrm{mm})\end{array}$ & $\begin{array}{c}\text { Emitter } \\
\text { Thickness } \\
(\mathrm{mm})\end{array}$ & $\begin{array}{c}\text { Emitter } \\
\text { Temperature } \\
(\mathrm{K})\end{array}$ & $\begin{array}{c}\text { Lifetime } \\
(\mathrm{h})\end{array}$ \\
\hline \multirow{2}{*}{ 2E1 } & E1 & 16.0 & 1.3 & 1,820 & 12,535 \\
& E2 & 16.0 & 1.3 & 1,820 & 12,535 \\
2 E2 & E3 & 16.0 & 1.3 & 1,820 & 11,084 \\
& E4 & 16.0 & 1.3 & 1,820 & 11,084 \\
& & & & & \\
1F1 & F1 & 27.9 & 1.0 & 1,780 & 8,560 \\
& & & & & \\
6 F3 & F18 & 27.9 & 2.0 & 1,750 & 8,062 \\
& F19 & 27.9 & 2.0 & 1,740 & 8,062 \\
& F20 & 27.9 & 2.0 & 1,820 & 8,062 \\
& F21 & 27.9 & 2.0 & 1,770 & 8,062 \\
& F22 & 27.9 & 2.0 & 1,770 & 8,062 \\
& F23 & 27.9 & 2.0 & 1,770 & 8,062 \\
& & & & & \\
\hline
\end{tabular}


A series of runs was performed using the LIFE 4 computer code to predict the performance of the various 6F3 experiments. Figure 2-4 shows the results which have been extrapolated to $61,000 \mathrm{~h}$. The two curves are the LIFE 4 predictions for the deformation of the lowest temperature cell, F22, and the highest temperature ce11, F20, for the experiment. It also shows the average deflections measured at each interim examination. The measured values fall within the LIFE4 predicted deflection band, giving credibility that within this range the code predicts the emitter performance reasonably well.

The deformation curves of Fig. 2-4 have been extrapolated beyond the 6F3 lifetime of $8062 \mathrm{~h}$ to the $61,000-\mathrm{h}$ 1ifetime of the SP-100. As can be seen, the LIFE code predicts the existence of a knee in the deformation curve which occurs after the last available measured data from the experiment. This knee is related to the behavior of the fission gases generated and their effect on the swelling of the $\mathrm{UO}_{2}$ fuel. As the amount of retained fission gases reaches its equilibrium value, the fuel swelling rate decreases, thus decreasing the interfacial pressure between the fuel and the emitter. The hoop stress in the emitter is directly proportional to the interfacial pressure. Therefore, a reduction in this pressure leads to reduced emitter creep strain rate; i.e., a knee is predicted in the emitter deformation curve beyond this saturation point. Figure 2-5 shows the relationship between emitter creep strain, fission gas retained, fuel swelling, and interface pressure, showing the onset of the knee in the deformation versus time plot for a typical emitter.

\subsubsection{Correlation of LIFE4 With other Experimental Data. Two other} sources of experimental data have been identified as possible calibration points for the LIFE4 code: (1) Zimmermannn data (Ref. 2-3) and (2) BMI data (Ref. 2-4). No attempts were made to use the LIFE code to predict the BMI experiments. This is because data consisted of $\mathrm{UO}_{2}$ fuel encapsulated in $W$ - 26Re - clad material. Material properties for this clad are not readily available. Therefore, trying to calibrate the swelling models in LIFE4 using these data may lead to many uncertainties. Pending 


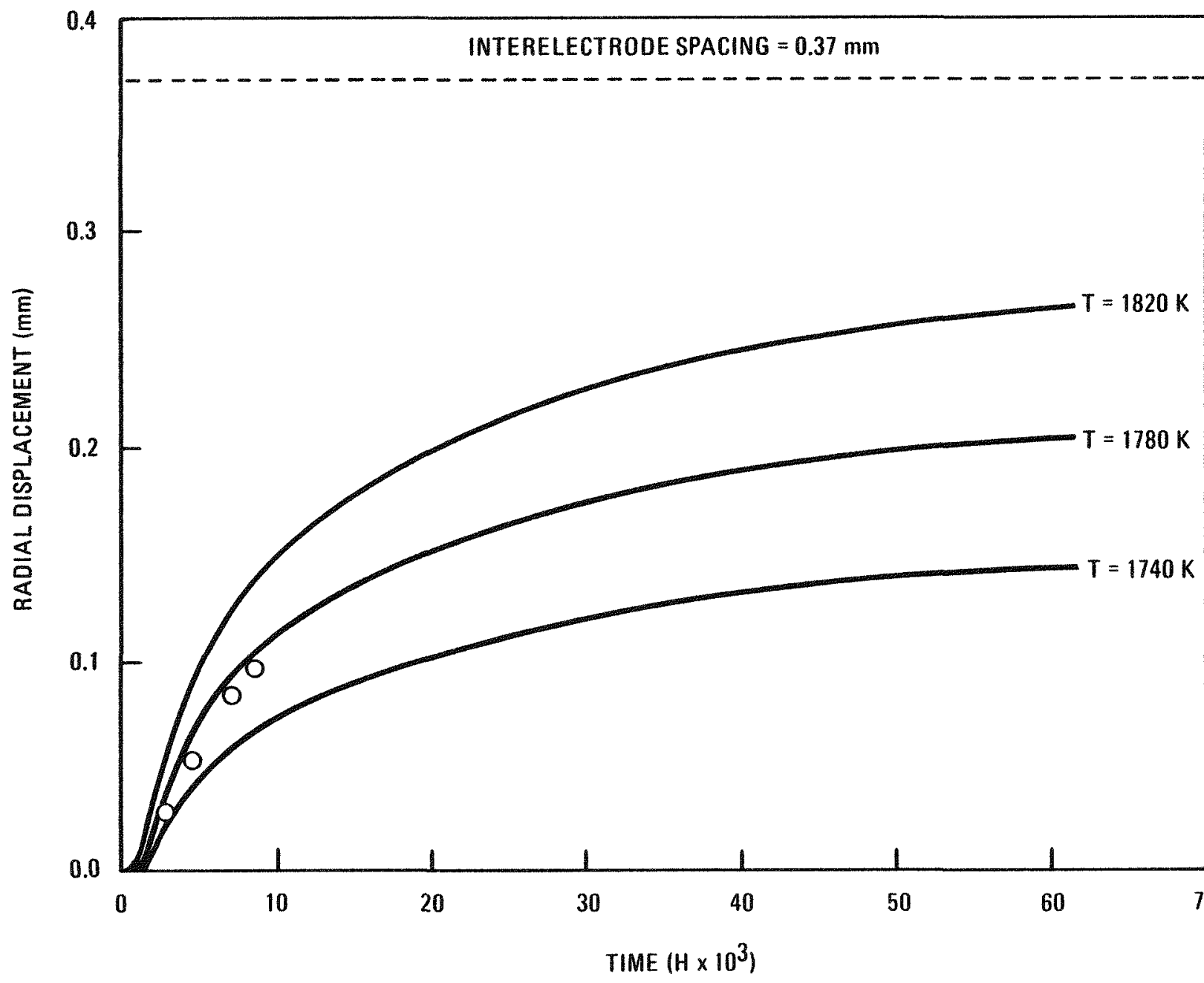

A17773

Fig. 2-4. LIFE4 deformation analysis of GA experiment 6 F3 


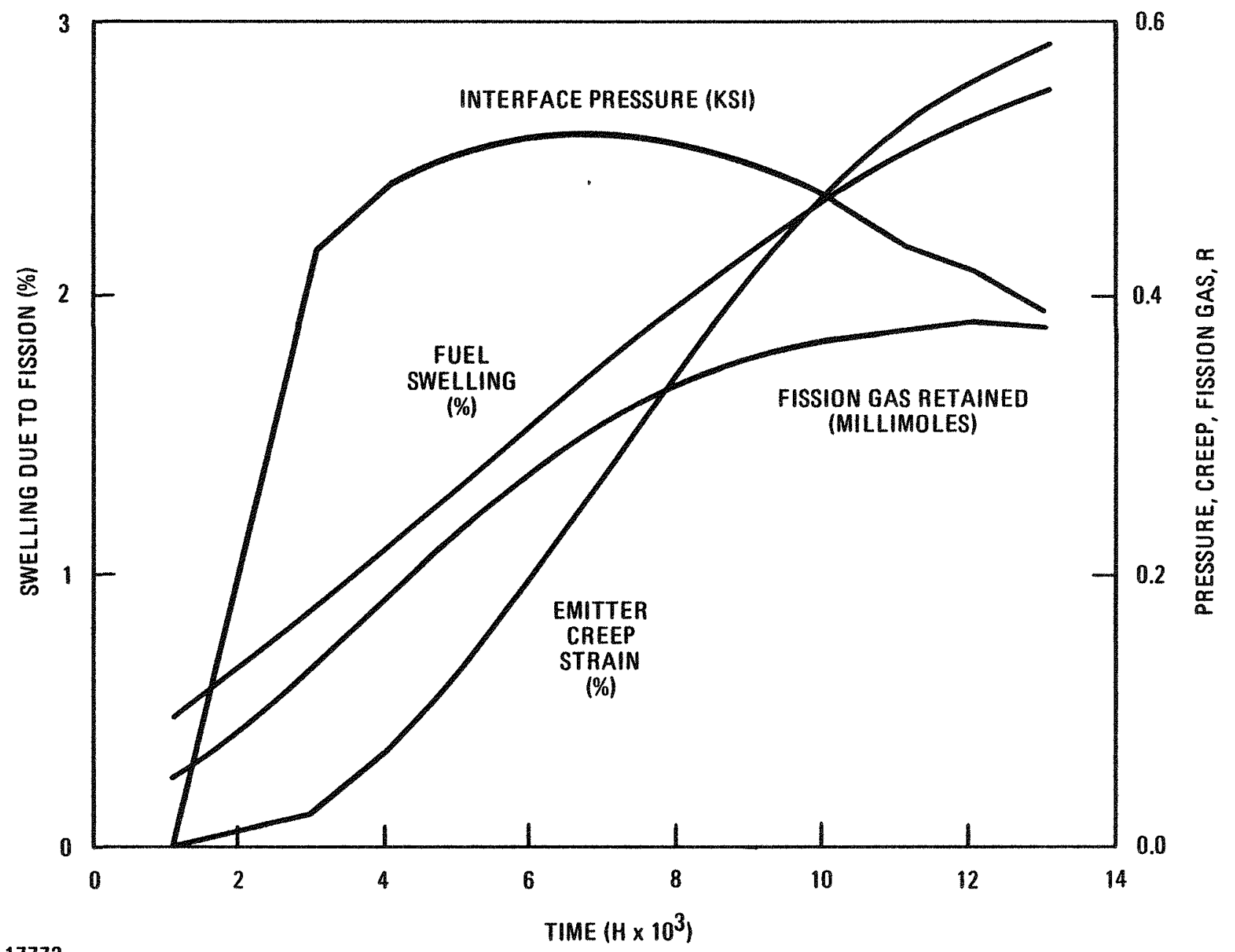

A17773

Fig. 2-5. Onset of knee in the emitter deformation analysis 
the availability of new materials data or prior calibration of LIFE4 with other data, the BMI data will be used only for check points.

Some attempts were made to utilize the Zimmermann data to calibrate LIFE4. These data have several shortcomings, however, which need to be considered:

1. The fuel was only lightly restructured, contrary to the highly restructured fuel in the thermionic case. Restructuring affects fission gas release, which in turn, affects the swelling characteristics of the fuel.

2. The data are for the most part at lower temperatures $(\sim 2100 \mathrm{~K})$, whereas this task investigates centerline temperatures of 2400 to $2500 \mathrm{~K}$. This lower temperature also affects the restructuring and swelling characteristics of the fuel.

3. The direction of heat flow in the wafers investigated by Zimmermann was axial, whereas in the emitter, it is radial.

Despite the shortcomings given above, several LIFE4 code runs were made to investigate the ability of the code to predict the unrestrained swelling data of Zimmermann. The initial results showed good agreement between the LIFE4 predictions and the Zimmermann data (see Table 2-7).

Subsequent analyses by GA and LANL have raised questions concerning the way in which LIFE4 defines unrestrained swelling. Discussions are being held continually between GA, LANL, General Electric, Space Power Inc., and Westinghouse Corp., the Department of Energy (DOE)-appointed developer of the code, concerning this issue, which will be resolved in the coming fiscal year. 
TABLE 2-7

INITIAL LIFE4 CORRELATION WITH ZIMMERMANN UNCONSTRAINED SWELLING DATA

\begin{tabular}{ccccc}
\hline Zimmermann & $\begin{array}{c}\text { Temperature } \\
\text { Data Point }\end{array}$ & $\begin{array}{c}\text { Burnup } \\
(\%)\end{array}$ & $\begin{array}{c}\text { Observed } \\
\text { Volumetric } \\
\text { Swelling } \\
(\%)\end{array}$ & $\begin{array}{c}\text { LIFE4 } \\
\text { Calculation } \\
\text { of Swelling } \\
(\%)\end{array}$ \\
\hline 15 & 1950 & 4 & 20 & 23 \\
19 & 1940 & 5 & 20 & 23 \\
22 & 2020 & 5 & 24 & 28 \\
\hline
\end{tabular}




\subsubsection{Bladder Effect}

Shortly after reactor startup, the pressed and sintered $\mathrm{UO}_{2}$ fuel redistributes within the emitter cavity, through vapor transport, leaving a central void. Fission gases diffusing out of the fuel may accumulate in this central void, causing the pressure to build up as fission gases accumulate over time. This pressure is resisted by the emitter and, in some cases, the fuel. The fuel can share, or at least delay, the transfer of the pressure load to the emitter, depending on its creep strength.

By resisting the pressure in the central void, the fuel may be put into tension circumferentially. These tensile stresses in the fuel may occur either early in life prior to the fuel contacting the emitter or later in life after pressure stress on the fuel has built up to a level in excess of the compressive stress due to the restraint by the emitter. At fuel temperatures in the SP-100 design, the fuel is almost all columnar grained. These long, slender grains are radially oriented, extending from the central void to the outer fuel surface. With this orientation, the bladder pressure causes a tensile load to act across the columnar grain boundaries, trying to pull them apart.

In time, voids nucleate on these columnar grain boundaries. In most materials, this void nucleation is caused when boundary sliding opens a hole on the edge of a single boundary. In fissioning $\mathrm{UO}_{2}$, void nucleation is greatly accelerated by the migration of gaseous fission products to the grain face and grain edge.

Because of the tensile load on the grain boundary, vacancies diffuse from the grain boundary to the void. The radial orientation of the grain boundary of this particular mechanism of grain boundary growth causes the fuel to creep in the circumferential direction. The tensile creep rate of $\mathrm{UO}_{2}$ to this mechanism has been calculated (Refs. 2-5 through 2-7) and found to be orders of magnitude higher than those $\mathrm{UO}_{2}$ compressive creep rates due to diffusion, dislocation, or irradiation. 
Figure 2-6 shows the average bladder pressure necessary to cause emitter distortion. If, for example, $1 \mathrm{mil}$ per year radial emitter distortion were permissible, $9.65 \mathrm{MPa}$ ( $1400 \mathrm{psia}$ ) average bladder pressure would be allowable using a $1700 \mathrm{~K}$ cVD-tungsten emitter with a $0.18-\mathrm{cm}$ (0.070-in.) wall.

Figure 2-7 shows the time of continuous operation necessary to achieve bladder pressure levels. As can be seen, the time necessary to reach $9.65 \mathrm{MPa}$ (1400 psia) depends on the percentage of fission gas that diffuses out of the central void, through the fuel skull, into the plenum. Xenon and krypton, the major constituents of $\mathrm{vO}_{2}$ fission gas in the central void, are virtually insoluble in $\mathrm{UO}_{2}$. Because of its high temperature, the fuel skull is entirely columnar grained. Postirradiation examination of previous in-core thermionic fuel elements showed the irradiated fuel to be highly porous in this entirely columnar-grained area. While the insolubility of the fission gases rules out a bulk diffusion action through the fuel, the existance of tunnel porosity in the skul1 may allow a pressure-driven Knudsen diffusion to occur through the fuel.

While the magnitude of the diffusion can presently be only postulated, instrumentation on the upcoming TRIGA test will attempt to measure the order of magnitude of gases leaving the central void during steadystate operation and at shutdown. With these data, the magnitude of the diffusion rate will be estimated.

Snorkel Design. If the accumulation of fission gases were concluded, causing excessive emitter distortion in the SP-100 designs, a snorkel vent can be incorporated into the TFE. The design and analysis of a typical snorkel vent (Fig. 2-8) has been completed. A snorkel design must satisfy the following criteria: (1) vent fission gas at a sufficient rate to prevent a large pressure buildup in the central void, (2) not become plugged with $\mathrm{UO}_{2}$ during the seven-year operating lifetime, and (3) remain structurally intact at the very high temperature of the fuel central void. 


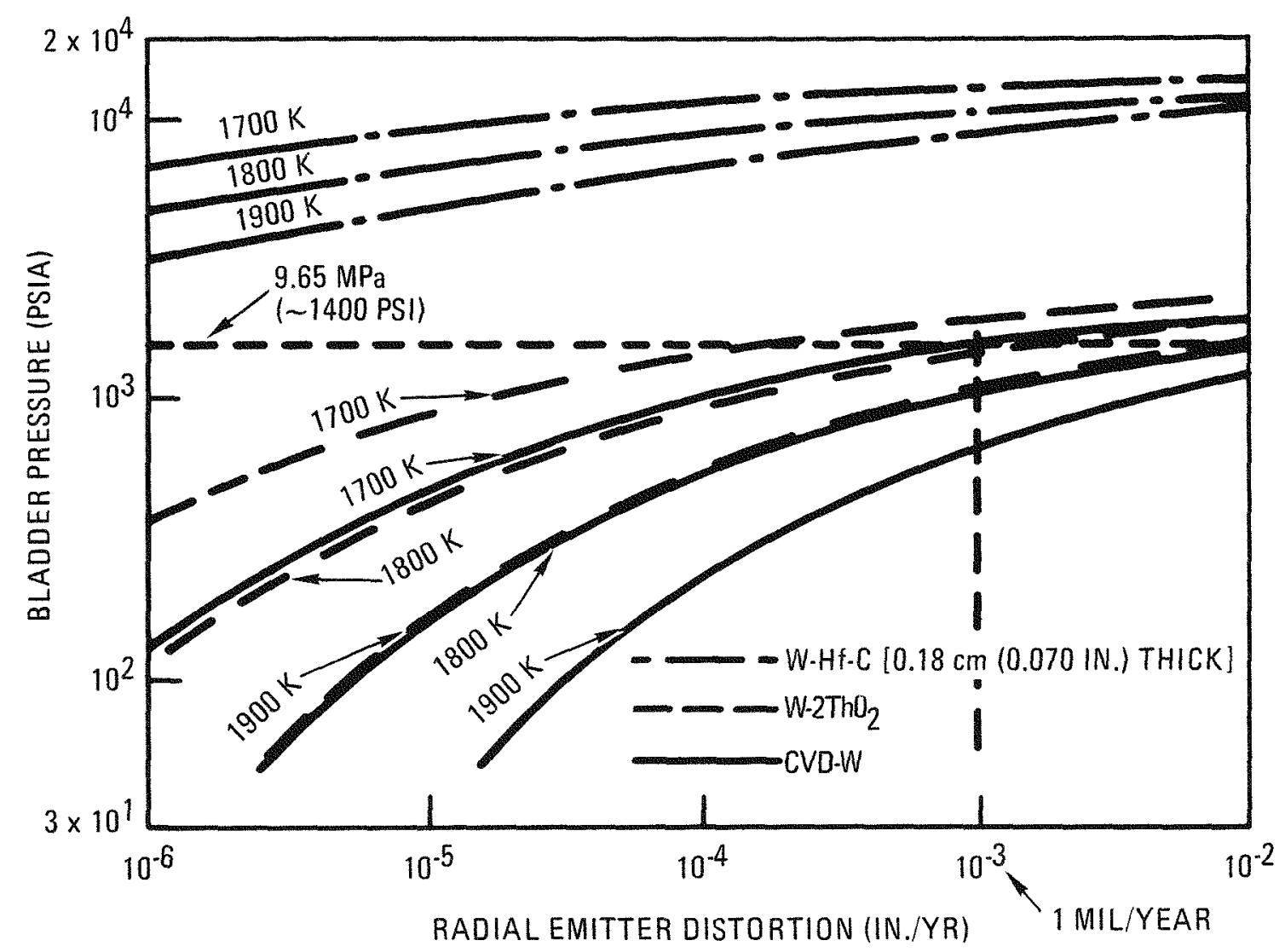

A17773

Fig. 2-6. Emitter distortion due to bladder pressure at $5 \%$ void fraction 


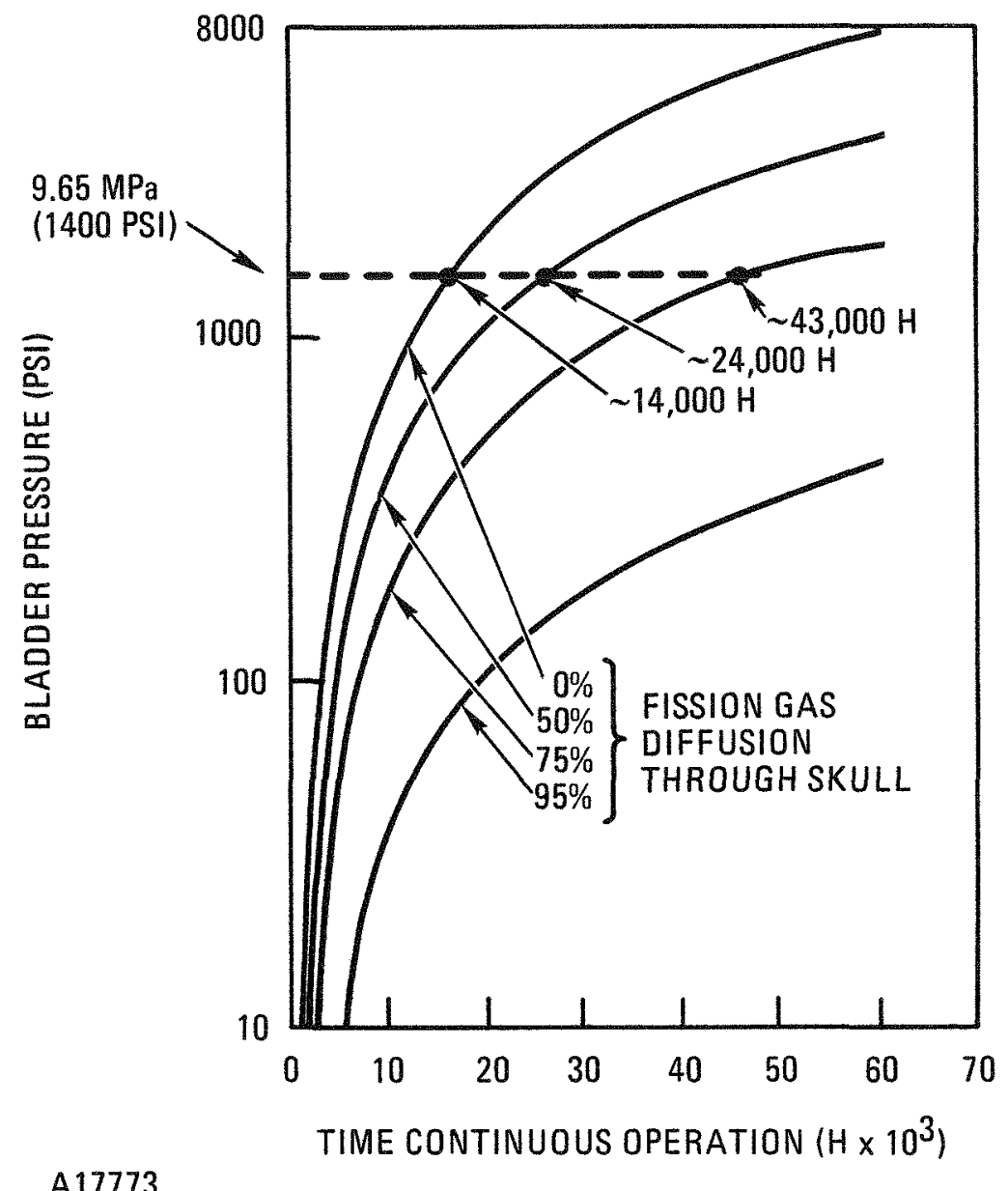

Fig. 2-7. Bladder pressure versus time at continuous operation at $5 \%$ fuel void fraction 


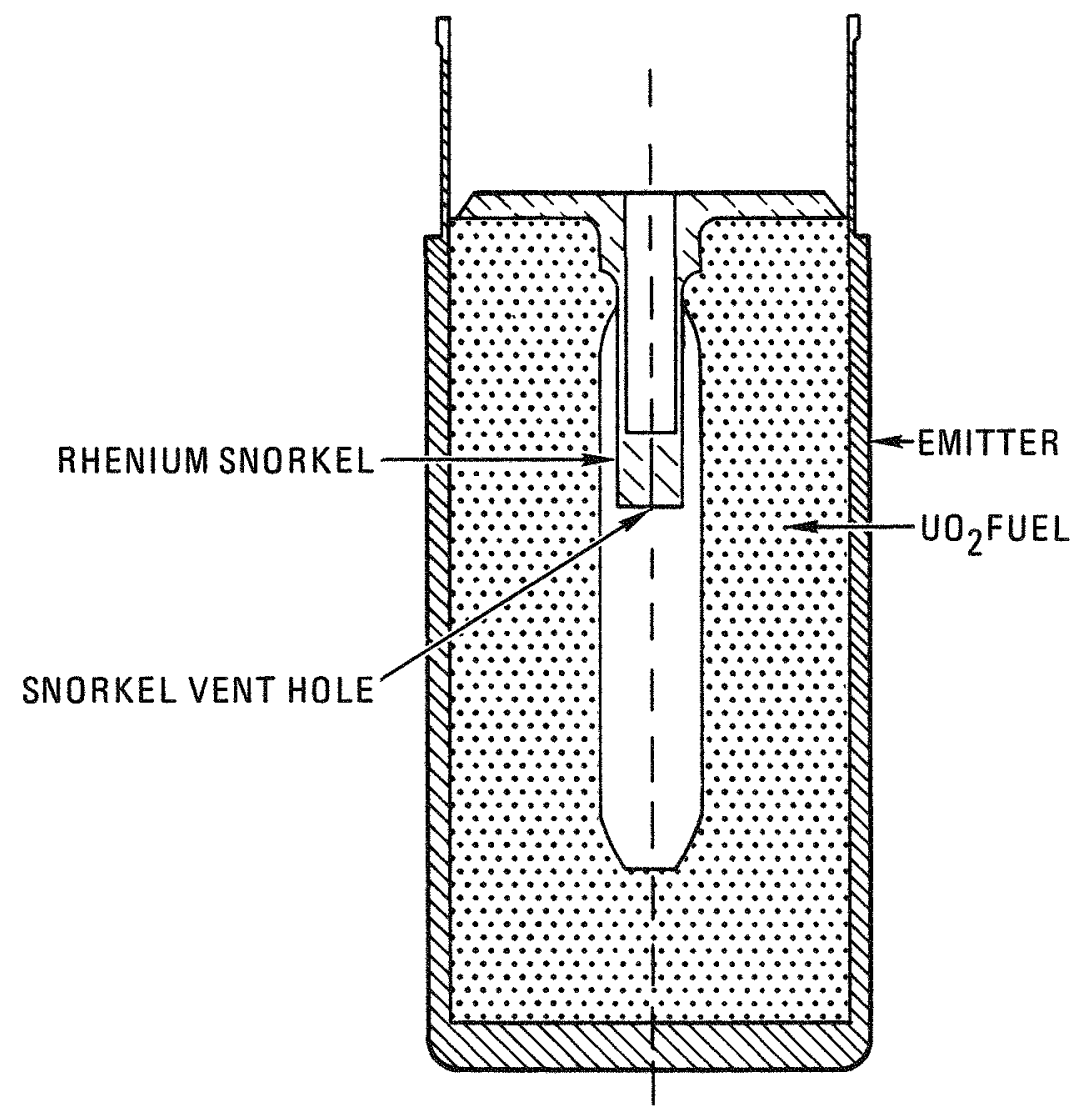

A17773

Fig. 2-8. Typical fuel snorkel vent design 
The snorkel design contains a $0.005-\mathrm{cm}\left(0.002-i n_{\bullet}\right)$ diameter orifice. It sits entirely in the central void and may be hotter than the fuel center temperature due to gamma heating of the rhenium material. The small diameter of the orifice allows the fission gas to vent, while limiting the loss of $\mathrm{UO}_{2}$ vapor through the snorkel. Because the entire orifice is at high temperature, it cannot plug with $\mathrm{UO}_{2}$. The center section of the snorkel is a thin-walled tube, reducing conduction heat loss from the orifice section. The inner diameter is made large $[0.318 \mathrm{~cm}(0.125 \mathrm{in.})]$ to reduce the chance of plugging in colder regions. The plate above the fuel has the dimensions of the existing fuel retainer plate. Rhenium was chosen as the snorkel material for its high strength, low thermal conductivity and vapor pressure, relatively good oxidation resistance in a $\mathrm{UO}_{2}$ environment, and ability to be formed using CVD.

\subsubsection{Thermal Ratcheting}

Conservative hand calculations were performed to determine the effect of temperature cycles on the emitter deformation. The cycles investigated arise due to the control drum reactivity insertions for maintenance of the reactor power level. The control swings for a $1.3 \%$ instantaneous power insertion cause an emitter temperature cycle of $4 \mathrm{~K}$ every $150 \mathrm{~h}$. The hand calculations were performed to determine the effect on emitter deformation of this $4 \mathrm{~K}$ temperature swing. The results showed that the circumferential stress in the emitter rises vary from 17.2 to $31.0 \mathrm{MPa}$ (2500 to $4500 \mathrm{psi}$ ) nominal. The resulting strain is within the elastic region of the stress-strain curve for CVD tungsten (Fig. 2-9), assuming yield stress of about $41.4 \mathrm{MPa}(6000 \mathrm{psi})$ at $1700 \mathrm{~K}$. Due to this high temperature, the stress quickly relaxes to its nominal value again. No plastic distortion is therefore expected due to this temperature cycling.

As a further check, a transient LIFE4 analysis of the reference SP-100 TFE cel1 was performed with a $4 \mathrm{~K}$ rise every $150 \mathrm{~h}$ for the entire lifetime of $61,000 \mathrm{~h}$. The results also showed no additional deformation due to this temperature cycle. 


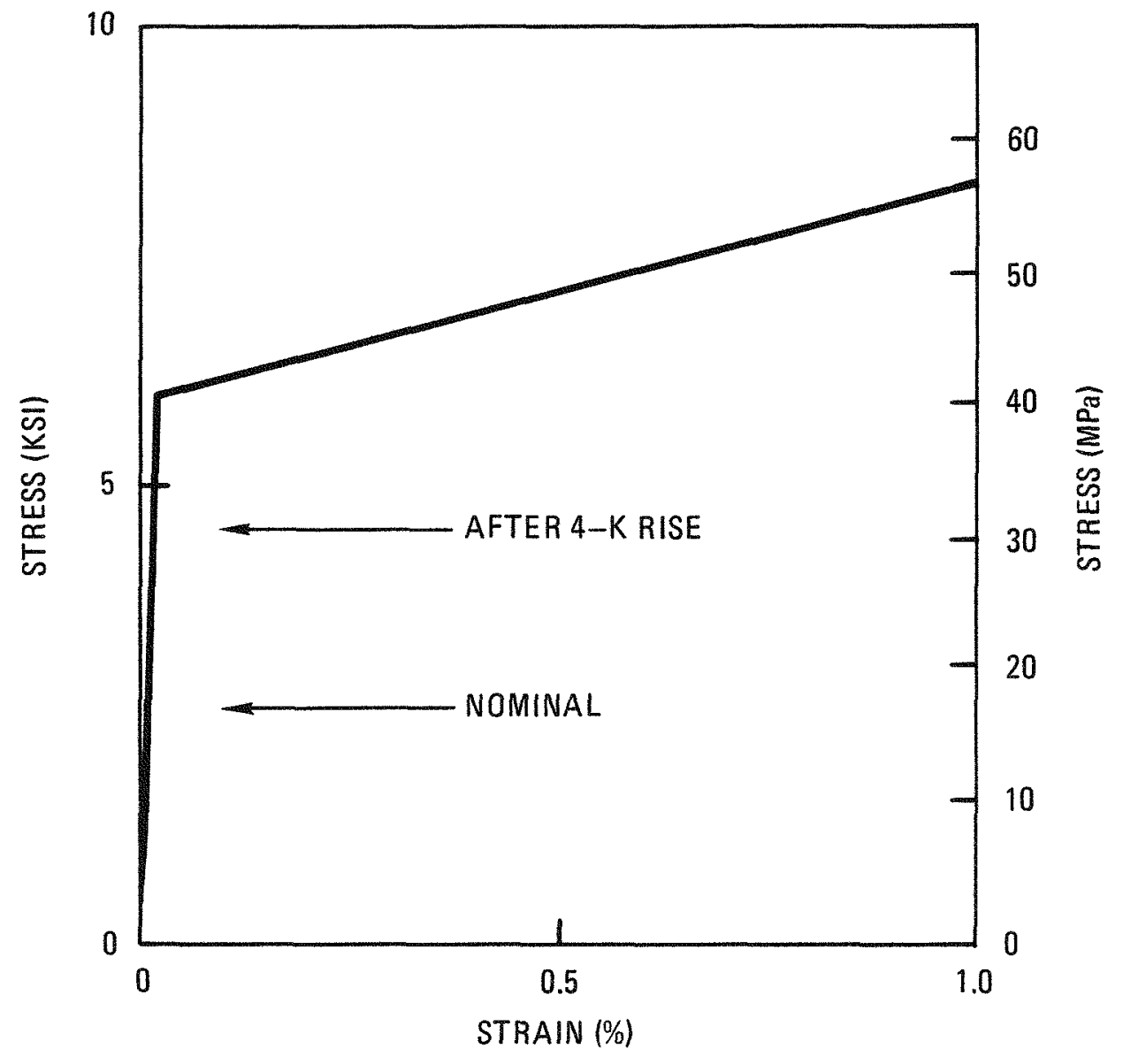

A17773

Fig. 2-9. Tungsten approximate stress versus strain at $1700 \mathrm{~K}$ 
2.2.4. Conclusions

Preliminary calculations were performed to access the deformation of a typical SP-100 thermionic emitter. Table 2-8 gives the major design parameters for the primary $\mathrm{SP}-100$ design. These initial calculations have shown the following:

1. Emitter distortion due to fuel swelling is currently the primary deformation mechanism. Using the LIFE4 code, the end-oflife distortion is currently estimated at $0.018 \mathrm{~cm}(0.007$ in.) Calibration of the LIFE4 code (shown in Fig. 2-10) is still an ongoing task and should be concluded in the coming fiscal year.

2. Deformation due to fission gas buildup in the fuel central void is currently not expected to lead to any significant contribution to the emitter distortion. A preliminary snorkel design has been completed, however, in the event that this effect is shown to be significant by later TRIGA experiments.

3. Ratcheting of the emitter due to power cycling is also not expected to lead to plastic deformation as long as temperature swings of less than $8 \mathrm{~K}$ are maintained. More detailed onedimensional and two-dimensional calculations will be performed to investigate the effect once a more definitive understanding of the capabilities of the control system is available.

\subsection{CAPSULE DESIGN}

\subsubsection{Design Description}

Figure 2-11 illustrates the design concept of the fueled emitter deformation capsule (FEDC). All four FEDCs contain three thermionic diodes whose electrical outputs can be individually monitored. Each 
TABLE 2-8

SP-100 TFE CELL REFERENCE DESIGN

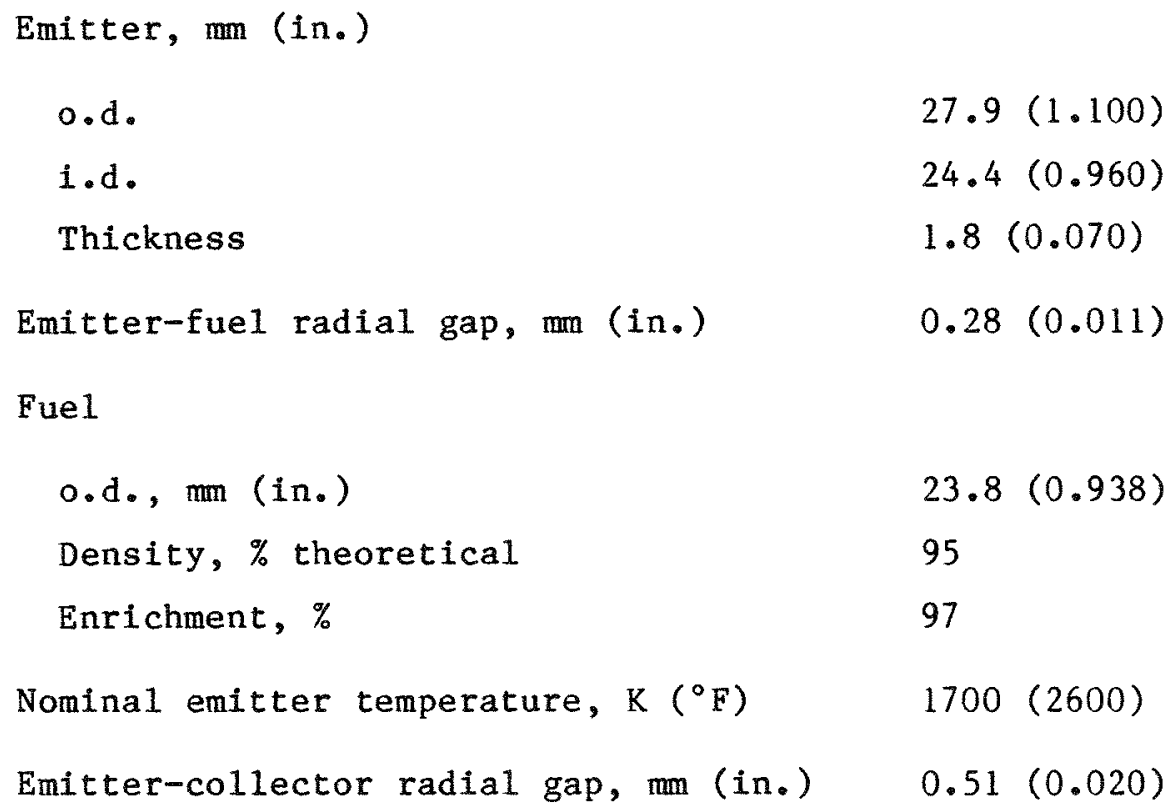

Fue1 


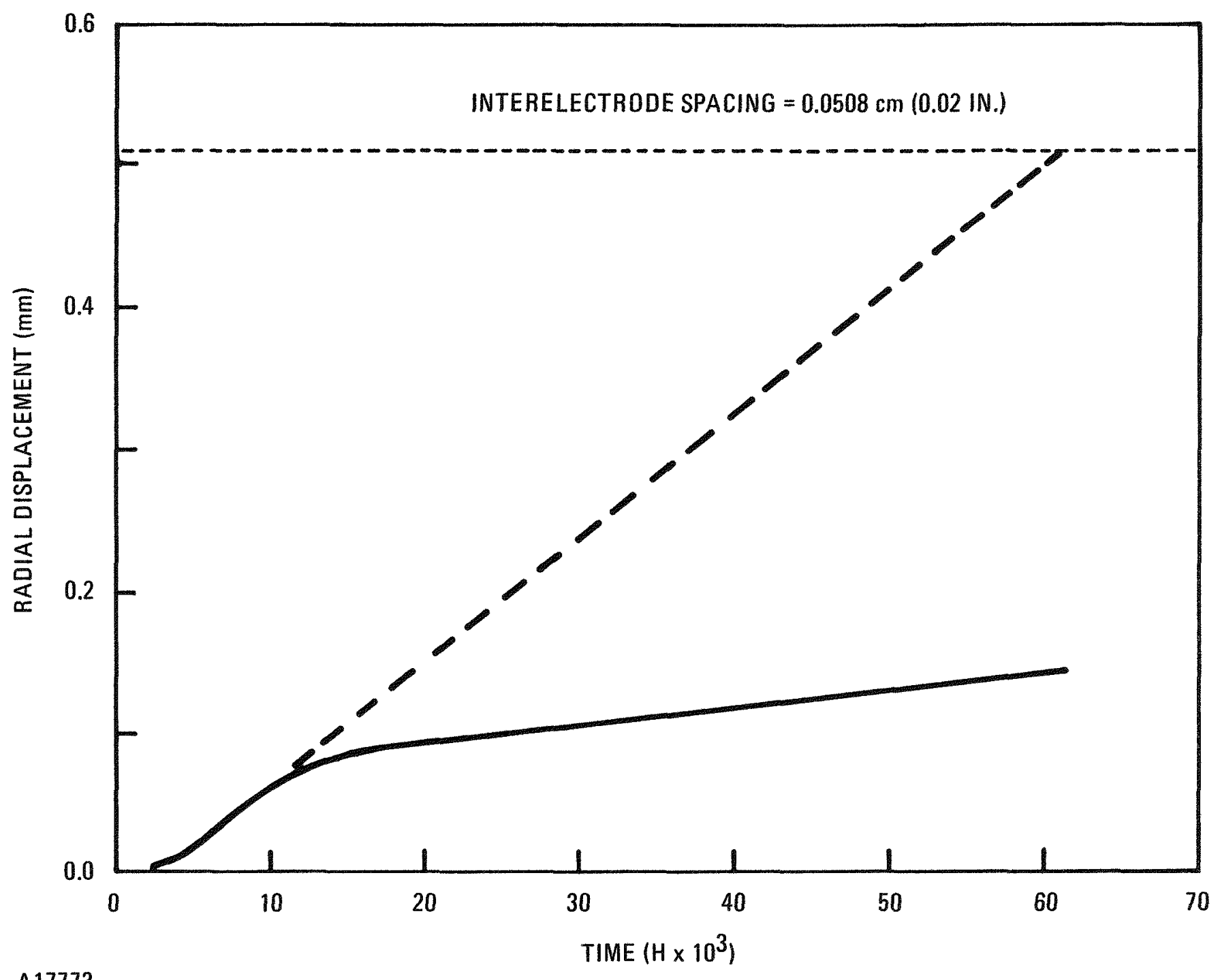

A17773

Fig. 2-10. LIFE4 1ifetime analysis of SP-100 reference design 


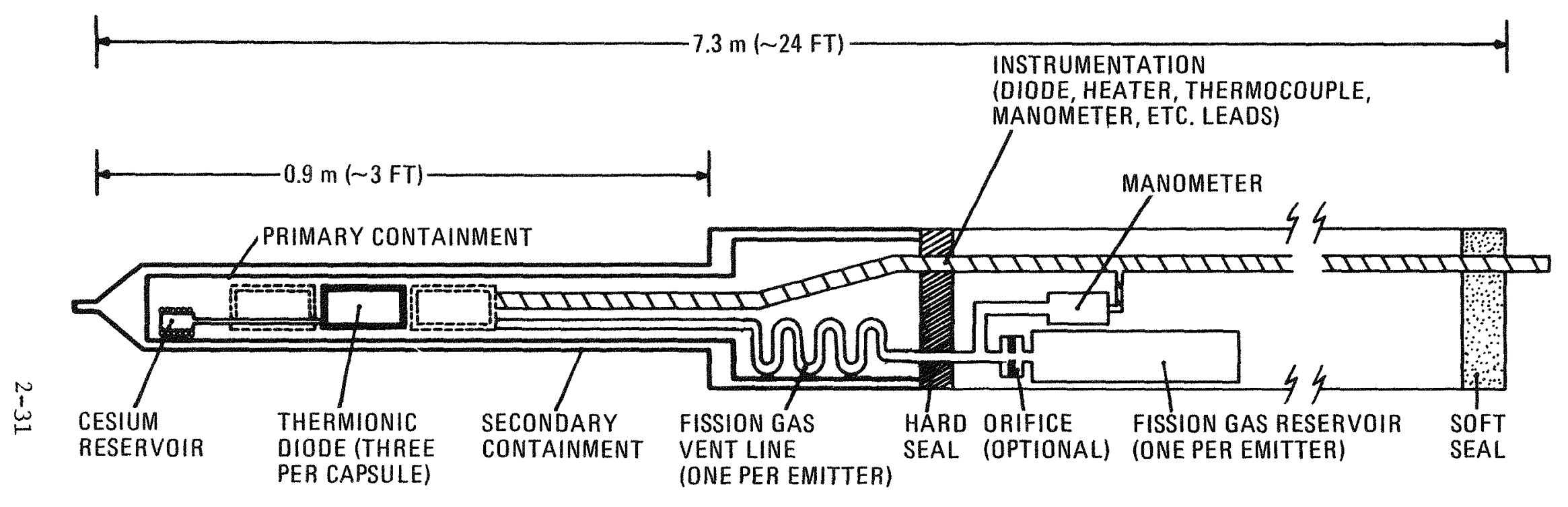

A 17773

Fig. 2-11. Design concept of fueled emitter deformation capsule 
thermionic diode functions as a fueled emitter, and its output characteristics will be used to infer the emitter temperature. Every diode has its own cesium reservoir and fission gas reservoir with a pressure gauge.

The primary containment includes the three fueled thermionic diodes and their cesium reservoirs which operate in a helium atmosphere to facilitate heat transfer. The primary stainless-steel containment tube is housed inside the stainless-steel secondary containment tube. The primary and secondary volumes are separated by a hard seal, which is penetrated by instrumentation leads and tubes to the fission gas reservoirs. The fission gas reservoirs and pressure gauges are located inside the secondary containment and operate in an inert gas atmosphere. A mixture of helium and argon is used to vary the thermal conductance across the gap between the primary and secondary containment tubes and thereby adjust the temperature of the components within the primary containment.

Figure 2-12 shows the design of the thermionic diode. The emitter is $2.79 \mathrm{~cm}(1.1 \mathrm{in.})$ in diameter and approximately $5.08 \mathrm{~cm}(2.0 \mathrm{in.})$ in length. It is made using CVD from $\mathrm{WF}_{6}$. This material has good strength, but the preferred (100) orientation gives a bare emitter work function which is significantly lower than that of the (110) orientation obtained from coating the fluoride tungsten with CVD from tungsten chloride, as in the F-series TFEs. Consequently, the output power of an FEDC thermionic diode will be quite low because of the low bare work function of the emitter and because of the wide emitter-collector spacing ( $1 \mathrm{~mm}$ to provide ample room for emitter deformation). The insulator sleeve is built from high-purity alumina and niobium sleeves. This component operates up to $1500 \mathrm{~K}$.

The thermal impedance of the FEDC is designed so that the bare niobium collector will operate around $800 \mathrm{~K}$. The periphery of the collector is penetrated by 23 holes for the output, heater, thermocouple, and instrumentation leads, as well as for cesium reservoir and fission gas tubes. The cesium reservoir tube, the emitter flange, and the 


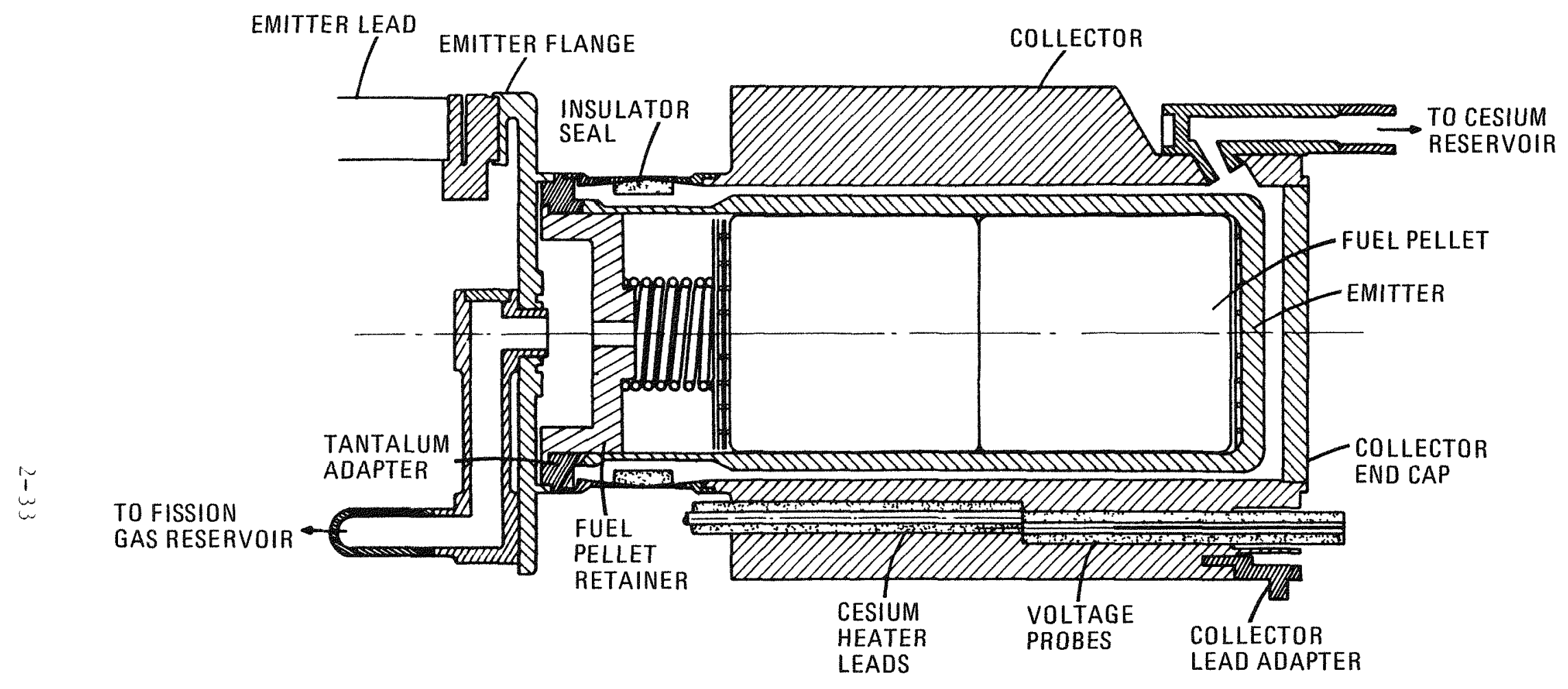

A17773

Fig. 2-12. Thermionic diode for fueled emitter test 
fission gas reservoir tubing are made from niobium. The collector lead adapter is copper.

The high-density $\mathrm{UO}_{2}$ fuel pellets are located inside the emitter using a niobium retainer in combination with a tungsten spring and tungsten radiation shields. The thermionic diode design permits emitter wall thicknesses of 40,70, and $100 \mathrm{mils}$, and by varying the fuel loading, emitter temperatures of 1650,1750 , and $1850 \mathrm{~K}$. Table 2-1 gives the emitter thicknesses, emitter temperatures, and fuel loadings for the 12 fueled emitters to be tested.

Figure 2-13 shows the design of the cesium reservoir heater. Section $B-B$ is an axial section, and Section AA is a cross section. An Inconel sheath heater is brazed into grooves machined from copper. Two heaters are bonded to each copper heater body for improved reliability. This heater is brazed to a copper radiator which can then be mechanically clamped to the niobium-cesium reservoir tubes. Each cesium reservoir has a separate heater assembly.

Figure 2-14 shows the assembly drawing of the bottom $0.46 \mathrm{~m}(1.5 \mathrm{ft})$ of the FEDC which goes into the TRIGA reactor. Most of the major components can be identified by referring to Figs. 2-11 through 2-13. The three fueled emitters are stacked as close as possible to the axial center of the reactor core to allow the lowest possible fuel enrichment and, thus, the flattest possible radial power distribution. The outer diameter of this section of the FEDC is $5.94 \mathrm{~cm}(2.34 \mathrm{in.})$. Hence, Fig. 2-14 is approximately full scale. This drawing shows that the FEDC is complex and that the components must be machined, fabricated, and assembled to close tolerances.

The FEDC design is complicated by the high temperatures and large temperature differences during capsule operation. To compensate for thermal expansion, the fission gas reservoir tubes are coiled in the primary after the FEDC diameter is increased to $10.16 \mathrm{~cm}$ ( 4.0 in.) Lead expansion is permitted by a compliant helix. 


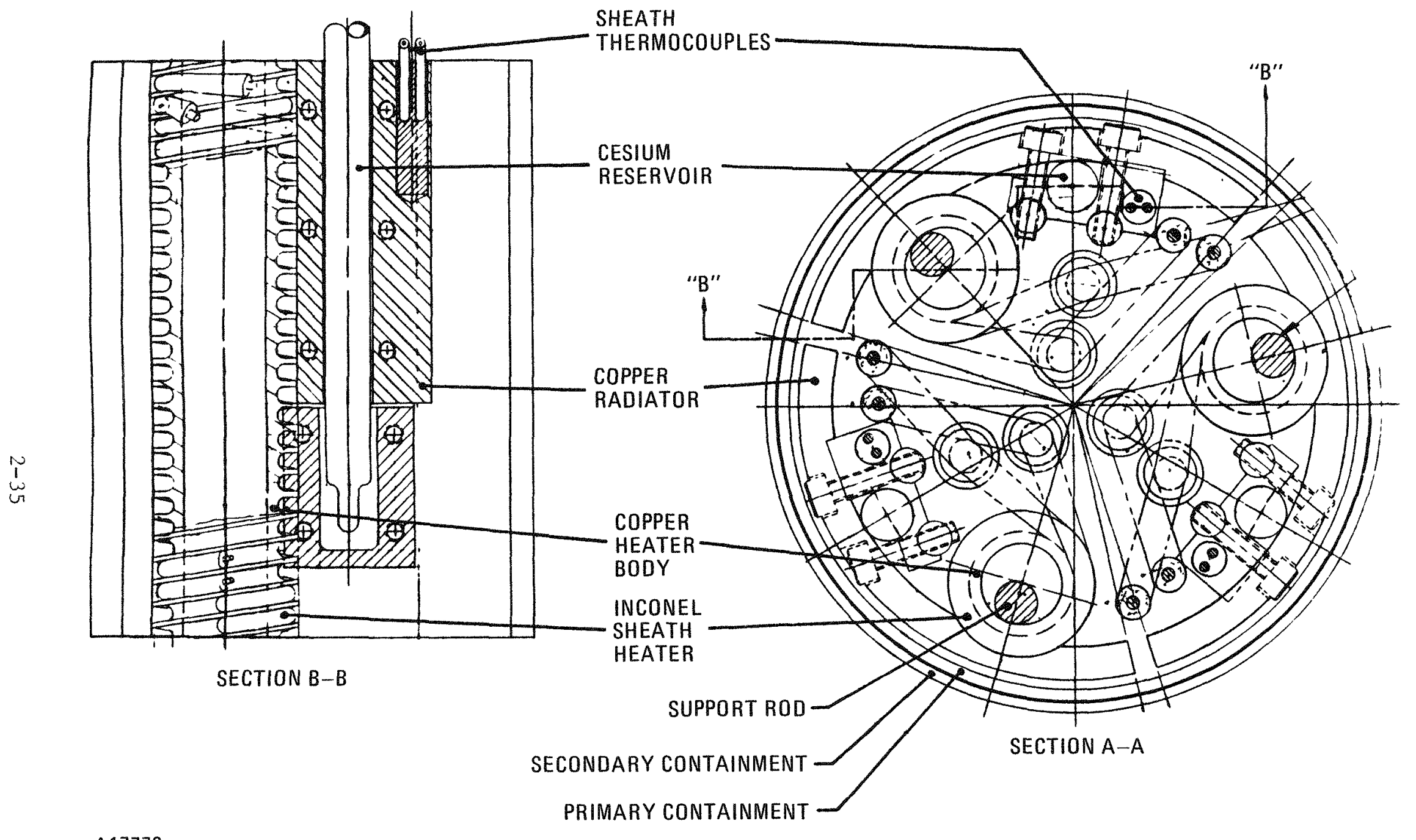

A17773

Fig. 2-13. Cesium reservoir heater assembly 
The secondary containment contains hermetically sealed stainlesssteel fission gas reservoirs, which are connected to the inside of each of the fueled emitters via small-diameter tubing. Although the initial design used refrigerated, activated charcoal in the reservoirs, subsequent analyses (see Section 2.3.2) have shown that an empty, nonrefrigerated reservoir permits the absolute fission gas release to be monitored over a long time while maintaining the gas pressure over the fuel in the low torr range. The use of a Leybold-Heraeus MEMBRANOVAC absolute pressure gauge (MAC 200) or equivalent allows accurate measurement of any fission gas release during operation and at shutdown. The secondary containment is closed at the top with a soft seal of cast epoxy.

\subsubsection{Capsule Design Analysis}

2.3.2.1. Thermal Analysis. This section summarizes the thermal analysis performed on the capsules. This effort had the following objectives:

1. Size the primary and secondary gaps as a function at emitter temperature, collector temperature, and capsule location in the TRIGA reactor.

2. Obtain a detailed two-dimensional steady-state temperature distribution for a capsule cell. (The particular cell selected was at the center of capsule 3.)

Method and Assumptions. The primary means of analysis was the computer program TAC2D (Thermal Analysis Code - 2 Dimensional) (Ref. 2-8). TAC2D is a code for calculating steady-state and transient temperatures in two-dimensional problems by the finite-difference method.

Pertinent assumptions are noted below:

1. All geometries are assumed to be cylindrical, i.e., RZ coordinates with no circumferential $(\vartheta)$ variation. 


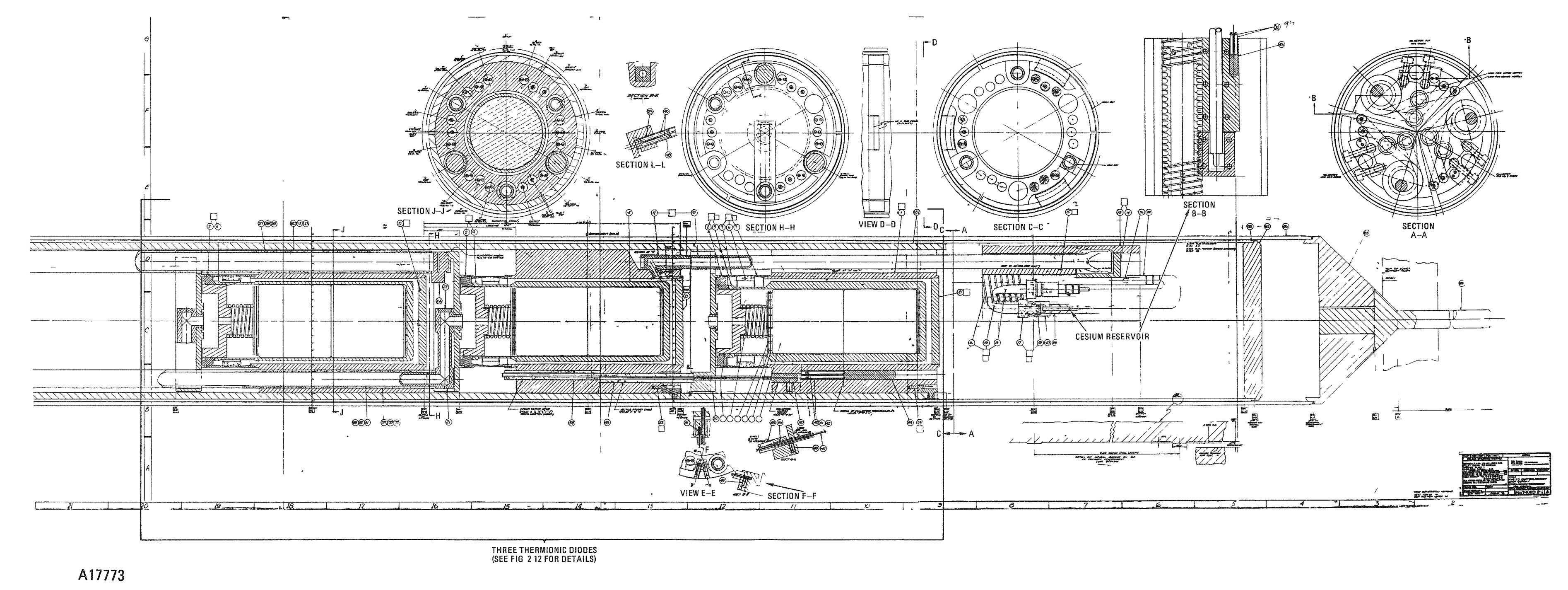

Fig. 2-14. Assembly drawing of bottom

of fueled emitter 
BLANK 
2. All analysis is steady state.

3. With the exception of the cesium-filled electrode gap, all heat transfer interior to the model is by conduction and onedimensional radiation. (The heat transfer across the electrode gap and the model boundary conditions are discussed later.)

4. Heat is generated uniformly in the $\mathrm{UO}_{2}$ fuel.

5. Where significant, thermal expansion is accounted for, but only in the radial direction.

6. Stress- or radiation-induced dimensional changes are not modeled directly. However, radial fuel swelling is accounted for in that the fuel/emitter gap is considered closed with a contact coefficient of $1 \mathrm{~W} / \mathrm{cm}^{2}-\mathrm{K}$.

Gap Sizing (One-Dimensional Analysis). As part of the specifications for each emitter cell, the gaps between the collector lead and the primary tube (primary gap) and between the primary and secondary tubes (secondary gap) must be determined. The nominal percentage of helium in the secondary gap control gas must also be specified. The control gas is a mixture of helium and argon. It is used to adjust the collector surface temperature, if necessary, to maintain a desired value, here assumed to be $800 \mathrm{~K}$.

A one-dimensional TAC model was constructed to calculate the gap sizes as functions of prescribed emitter temperature and cell position (see Fig. 2-15). Dimensions for the model were taken from the capsule design drawings (see Section 2.3.1). Since the niobium collector surface is assumed constant at $800 \mathrm{~K}$, this was taken as the boundary condition at the inner radius; $i . e .$, the fuel and emitter were not included. The boundary condition at the TRIGA water interface was taken as a constant surface temperature of $403 \mathrm{~K}$, derived by assuming nucleate boiling and applying the Jens-Lottes correlation. 


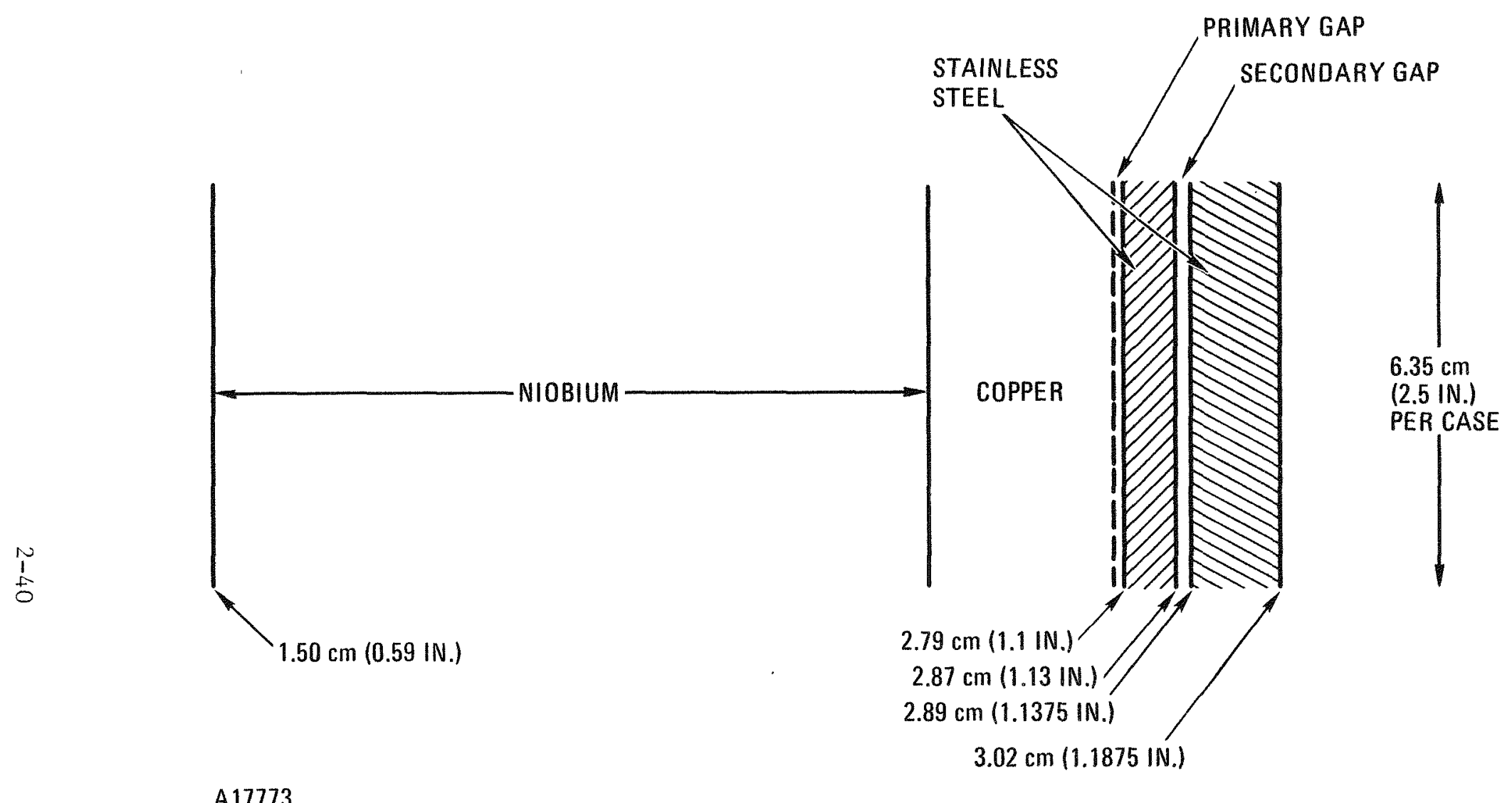

Fig. 2-15. TAC2D model for gap sizing 
The gamma-induced heating in the cells is a function of the TRIGA power level and the position of the cells in the core. A reactor power of 1.5 MW was assumed, and four different values of gamma heating were calculated, coresponding to the axial center and end cells of capsules $1 / 2$ and $3 / 4$. These values were input as local heat generation rates.

Since the model boundary conditions are fixed surface temperatures, a trial-and-error process is used to select the gap sizes that yield the desired cell heat flows. The cell heat flows were calculated independent of the TAC2D mode1, using simplified equations for the electron cooling, radiation, and cesium conduction heat transfers across the interelectrode gap. (The adequacy of these equations for gap sizing is confirmed later by the detailed two-dimensional analysis.) Emitter temperatures of 1650 , 1750 , and $1850 \mathrm{~K}$ were specified, with a collector temperature of $800 \mathrm{~K}$. Table 2-9 gives the resulting heat flows.

To expedite the trial-and-error process of finding the gap sizes corresponding to the desired heat flows of Table 2-9, the TAC2D model of Fig. 2-15 was repeated with one-dimensional radial layers stacked in 6.35-cm (2.5-in.) axial increments. (No axial heat flow was permitted.) Each layer represented one primary gap size trial in combination with one of the four gamma heating rates. The primary gap was varied through six values, while the secondary gap and mole fraction of helium were held at a single trial value for the whole problem. Thus, 24 separate cases (heat flows) were generated.

Figure 2-16 illustrates the results of this procedure, showing the variation in heat flow versus cold primary gap size for a single cold secondary gap size set at $8 \mathrm{mils}$ and a mole fraction of helium selected at 0.54 . The family of four curves results from the four gamma heating values. From Fig. 2-16, the cold primary gap sizes required to yield the heat flows (corresponding to the emitter temperatures of 1650, 1750, and $1850 \mathrm{~K})$ can be readily determined for each cel1. Table 2-10 summarizes these gap sizes and gives the gamma heating rates used. 
TABLE 2-9

HEAT FLOWS FOR GAP-SIZING ANALYSIS

\begin{tabular}{lccc}
\hline & \multicolumn{3}{c}{$\begin{array}{c}\text { Heat Flows at Emitter } \\
\text { Temperature (W) }\end{array}$} \\
\cline { 2 - 5 } & $1650 \mathrm{~K}$ & $1750 \mathrm{~K}$ & $1850 \mathrm{~K}$ \\
\hline Electron cooling & 638 & 834 & 1053 \\
Radiation & 202 & 270 & 354 \\
Cesium conduction & 23 & 34 & 44 \\
Total & $\mathbf{8 6 3}$ & 1138 & 1451 \\
\hline
\end{tabular}


COPPER THICKNESS (MILS)

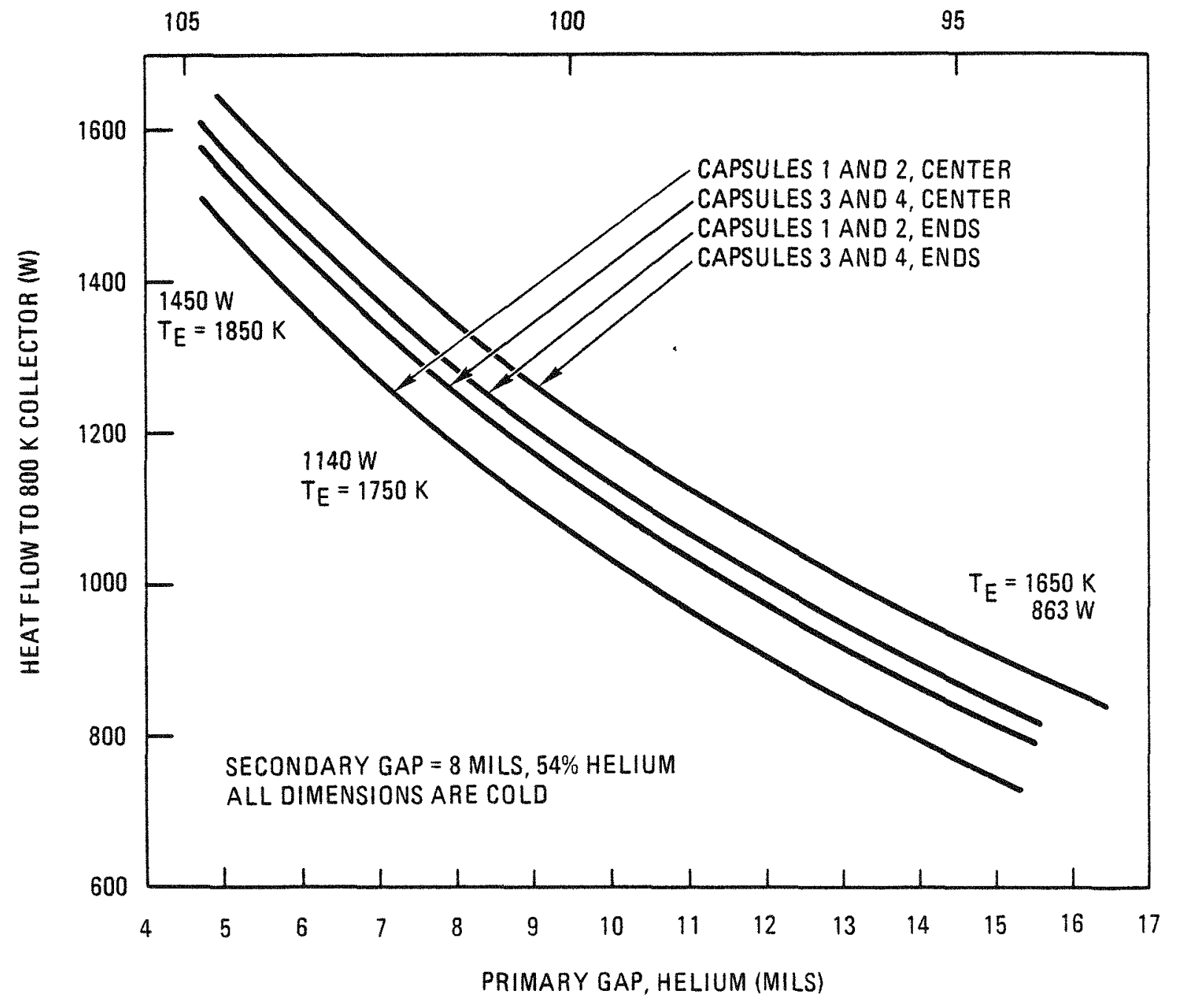

A17773

Fig. 2-16. Collector heat flow at $800 \mathrm{~K}$ versus primary gap thickness (gamma heating accounted for) 
TABLE 2-10

PRIMARY AND SECONDARY GAP SIZES(a)

\begin{tabular}{cccccc}
\hline Capsule & $\begin{array}{c}\text { Emitter } \\
\text { Temperature } \\
(\mathrm{K})\end{array}$ & $\begin{array}{c}\text { Gamma } \\
\text { Heating } \\
(\mathrm{W} / \mathrm{g})\end{array}$ & $\begin{array}{c}\text { Collector } \\
\text { Heat Flow } \\
(\mathrm{W})\end{array}$ & $\begin{array}{c}\text { Cell } \\
\text { Axial } \\
\text { Location }\end{array}$ & $\begin{array}{c}\text { Cold } \\
\text { Primary Gap } \\
\text { (mils) }\end{array}$ \\
\hline $1 / 2$ & 1850 & 0.76 & 1450 & Center & 5.2 \\
$3 / 4$ & 1850 & 0.68 & 1450 & Center & 5.8 \\
$1 / 2$ & 1750 & 0.76 & 1140 & Center & 8.5 \\
$3 / 4$ & 1750 & 0.68 & 1140 & Center & 9.4 \\
$1 / 2$ & 1750 & 0.64 & 1140 & Ends & 9.9 \\
$3 / 4$ & 1750 & 0.57 & 1140 & Ends & 10.8 \\
$1 / 2$ & 1650 & 0.64 & 863 & Ends & 14.6 \\
$3 / 4$ & 1650 & 0.57 & 863 & Ends & 16.0 \\
\hline
\end{tabular}

(a) Primary gap is helium. Secondary gap is $54 \%$ helium, $46 \%$ argon (mole fraction), 8 mils cold. The test plan does call for all of the above combinations of capsules and emitter temperatures. 
To establish the amount of control of collector temperature avai1able, the model was run with the cold primary gaps of Table 2-10 and heat flows corresponding to the emitter temperatures of 1650,1750 , and $1850 \mathrm{~K}$ imposed on the collector surface. The fraction of helium in the secondary gas mixture was set at 0 (all argon) and 1 (all helium). Figure 2-17 shows the degree of collector temperature control attainable. Note that the nominal mole fraction of helium of 0.54 is very nearly in the middle of the range.

No closing of the gaps or interference was indicated in any of the preceding analysis. At operating temperatures, the primary gap increases by about 1 to $2 \mathrm{mils}$, while the secondary gap drops to approximately half the cold value of 8 mils.

Temperature Distribution (Two-Dimensional Analysis). A second, more detailed TAC model was developed to predict the two-dimensional temperature distribution within a single cell. Figure 2-18 gives the geometry of the mode1. Dimensions are obtained from the design drawing (see Section 2.3.1). The particular cell chosen for consideration was the center cell of capsule 3 , having a specified average emitter temperature of $1750 \mathrm{~K}$. The emitter thickness of this cell is $70 \mathrm{mils}$, and the stem thickness was taken as $25 \mathrm{mils}$. Using the results of the previous section, the cold primary gap was taken as $9.4 \mathrm{mils}$, and the cold secondary gap, 8 mils. The mole fraction of helium in the control gas was 0.54 , based on the one-dimensional analysis. A third gap, between the emitter flange and copper collector lead at the cell top, was set at 20 mils. Total heat input was equal to $1196 \mathrm{~W}$ generated in the fuel plus gamma heating of $0.68 \mathrm{~W} / \mathrm{g}$ throughout the rest of the cell. The emitter stem also included current heating ( $I^{2} R$ heating). The value of $1196 \mathrm{~W}$ for the fuel was obtained by subtracting the gamma heating in the emitter (which contributes to the total heat flow to the collector) from $1302 \mathrm{~W}$ (the heat flow calculated for the gap sizing analysis, $1138 \mathrm{~W}$, augmented by estimated end losses). 


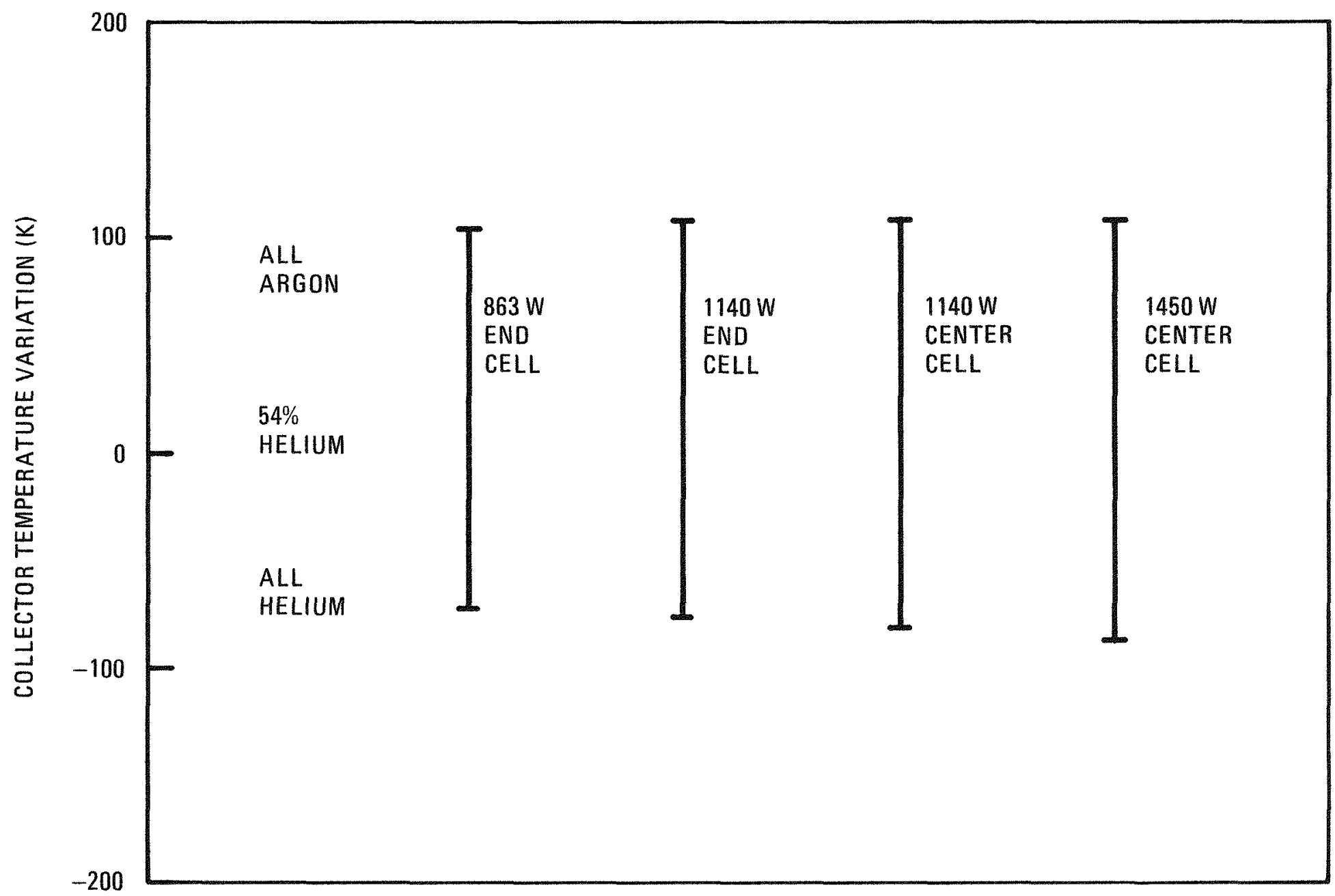

A17773

Fig. 2-17. Collector temperature variation versus secondary gas composition 


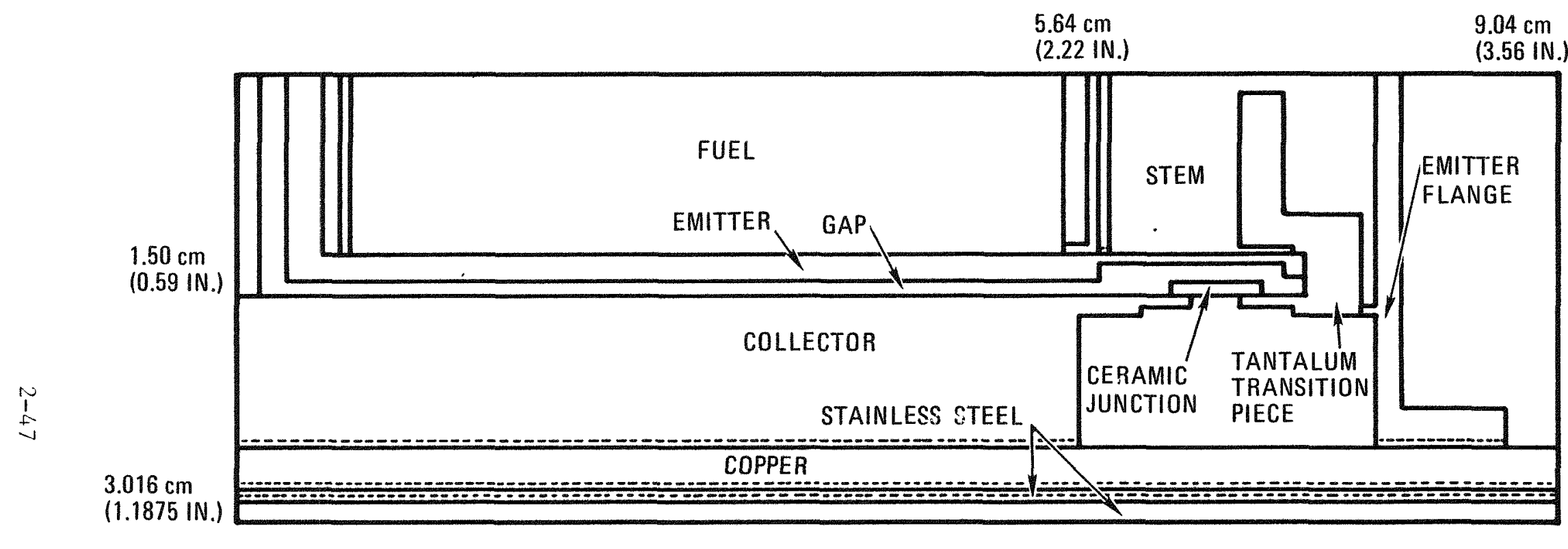

A17773

Fig. 2-18. TAC2D model of capsule cell 
Since this model includes the entire cell, the heat transfer across the electrode gap must be considered. Three mechanisms contribute to this heat transfer: (1) electron cooling resulting from emission of electrons from the emitter surface, (2) thermal radiation, and (3) conduction through the cesium gas. The simplified equations used in the gap sizing analysis were replaced with more general techniques.

For the electron cooling, the following equation was used:

$$
\mathrm{QEC}_{\mathrm{EC}}=\mathrm{J}\left(\phi+2 \mathrm{k} \mathrm{T}_{\mathrm{E}}\right),
$$

$$
\text { where } \begin{aligned}
\mathrm{Q}_{\mathrm{EC}}= & \text { electron cooling, } \mathrm{W} / \mathrm{cm}^{2} \text { (emitter area), } \\
\mathrm{J}= & \text { current density, } \mathrm{A} / \mathrm{cm}^{2}, \\
\phi= & \text { emitter work function, } \mathrm{eV}, \\
& 1.3\left(\mathrm{~T}_{\mathrm{E}} / \mathrm{T}_{\mathrm{R}}\right)-0.628 \phi_{\mathrm{O}}+1.6, \\
\mathrm{~T}_{\mathrm{E}}= & \text { local emitter temperature, } \mathrm{K}, \\
\mathrm{T}_{\mathrm{R}}= & \text { cesium reservoir temperature, } \mathrm{K}, \\
\phi_{\mathrm{O}}= & \text { bare work function, eV, } \\
\mathrm{k}= & \text { Boltzmann constant, } 8.625 \times 10^{-5} \mathrm{eV} / \mathrm{K} .
\end{aligned}
$$

To establish the current density $J$ as a function of local emitter temperature $T_{E}$ and to determine the cesium reservoir temperature $T_{R}$ and bare work function $\phi_{O}$, the performance characteristics of $\mathrm{TE}$ converter No. 42 were used. Thus, $\phi_{0}$ was taken as $4.6 \mathrm{eV}$. A J versus $\mathrm{T}_{\mathrm{E}}$ curve was derived for an average emitter temperature of $1700 \mathrm{~K}$ by assuming a current density of $6.0 \mathrm{~A} / \mathrm{cm}^{2}$ at this temperature, noting the electrode voltage and reservoir temperature along the optimum envelope, then reading the current densities at other temperatures ( 1600 to $2000 \mathrm{~K}$ ), while maintaining the voltage and reservoir temperature constant. A family of such curves was produced for all electrode spacings given in the data ( 1.25 to $20 \mathrm{mils}$ ) and extrapolated to yield a curve at a spacing of $40 \mathrm{mils}$. An analogous procedure was followed to give a similar curve for an average emitter temperature of $1800 \mathrm{~K}$ and assumed current density of $7.0 \mathrm{~A} / \mathrm{cm}^{2}$. 
Finally, these two curves were interpolated to yield a function representing $J$ versus $T_{E}$ with $6.5 \mathrm{~A} / \mathrm{cm}^{2}$ at $1750 \mathrm{~K}$. The cesium reservoir temperature was also interpolated and was taken as $628 \mathrm{~K}$.

Reference 2-9 gives the methods used to handle radiation and conduction through the cesium gas. The equations are not repeated here; however, the cesium vapor pressure was calculated according to

$$
P_{G}=2.45 \times 10^{8} \times \mathrm{e}^{-8910 / \mathrm{TR} / \sqrt{\mathrm{T}_{R}}}
$$

where $T R$ is the reservoir temperature in $K$, and $P_{G}$ is in torr.

The boundary condition at the secondary containment/water interface was the same as in the one-dimensional analysis (403 $\mathrm{K}$ surface temperature). The cell being modeled was assumed to be bounded on the top and bottom by identical cells. Therefore, the upper axial boundary temperature and heat flux were matched to the low axial boundary.

Figure 2-19 gives the emitter temperature profile determined by the TAC2D mode1. Note that the average emitter temperature of $1744 \mathrm{~K}$ is very close to the specified average value of $1750 \mathrm{~K}$. The average collector surface temperature is $801 \mathrm{~K}$ versus the $800 \mathrm{~K}$ used in the one-dimensional gap-sizing analysis. The heat transfer rates predicted across the interelectrode gap are 815,268 , and $26 \mathrm{~W}$ for the electron cooling, radiation, and cesium conduction, respectively. As Table 2-9 shows, these agree reasonably well with the values used in the gap sizing.

Other pertinent results from the TAC2D model are (1) temperature of tantalum transition piece, $1140 \mathrm{~K}$; (2) temperature drop across ceramic junction, 1070 to $910 \mathrm{~K}$; and (3) temperature of emitter flange at base of emitter lead, $900 \mathrm{~K}$.

Using the temperatures from this analysis, hand calculations were done to obtain the cold radial gap sizes needed between the fuel and 
DISTANCE ALONG EMITTER (cm)

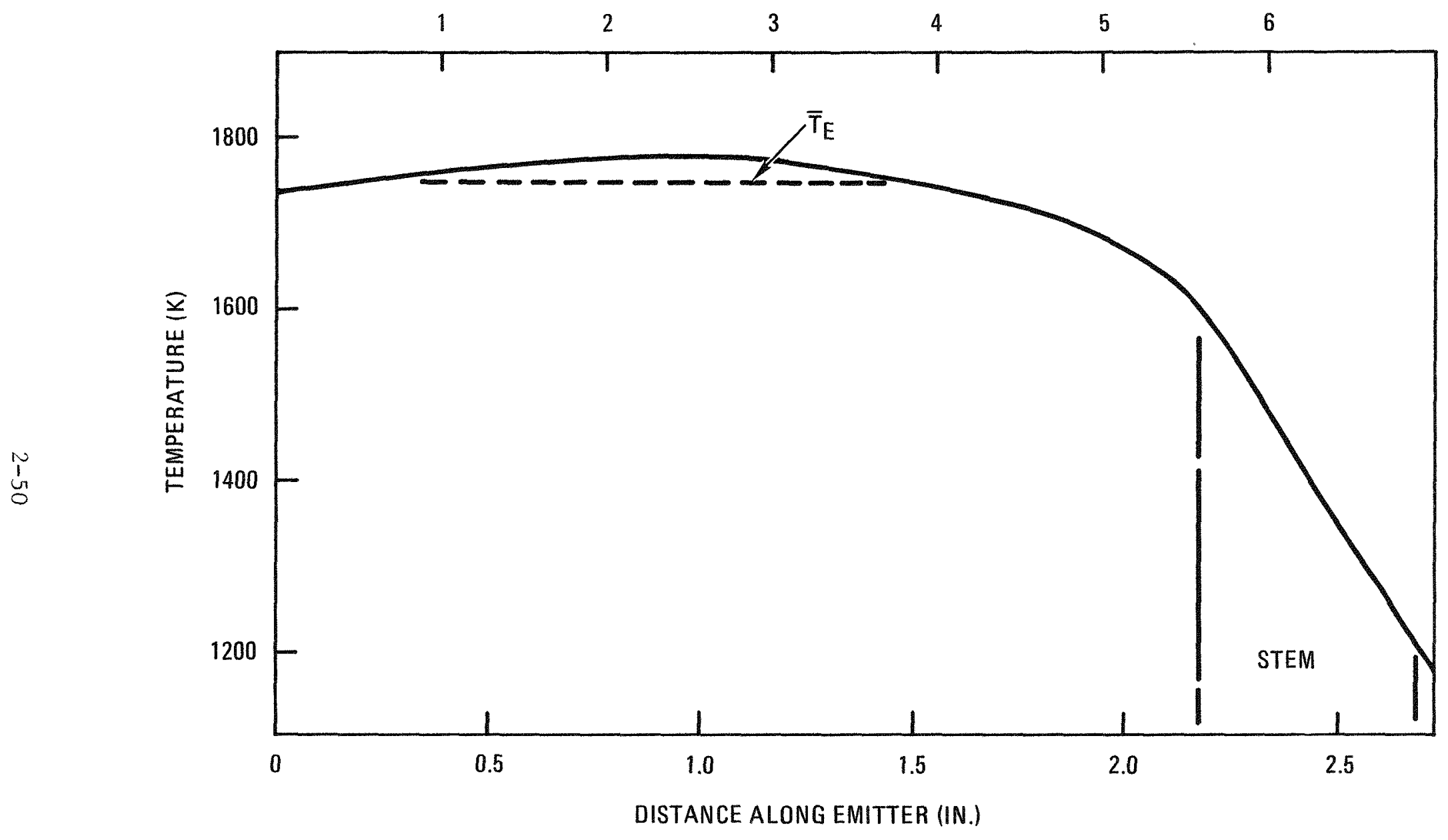

A17773

Fig. 2-19. Capsule emitter temperature profile 
emitter. At operating temperatures, the gap was assumed to just close with no interference. The nodal fuel temperatures were volume-averaged in the radial direction at the axial plane of maximum temperature, which gave $2160 \mathrm{~K}$. The maximum emitter temperature was $1779 \mathrm{~K}$. For the other cases with average emitter temperatures of 1650 and $1850 \mathrm{~K}$, the preceding temperatures were scaled using the heat flows of Table 2-9. Table 2-11 shows the cold fuel/emitter gaps for emitter thicknesses of 40,70, and $100 \mathrm{mils}$. Emitter thickness was assumed to have no effect on temperature.

2.3.2.2. Nuclear Analysis. This study was intended to determine the enrichment specified for each of the 12 fueled emitters for required performance. The four devices will be located in either the B-C or the $C-D$ ring of the hexagonal pitch TRIGA Mark $F$ reactor core, as indicated in Fig. 2-20. Axially, the middle fueled emitter in each device will be located at the midplane of the core, with one fueled emitter equidistant above and below the midplane. In order to locate each thermionic test device, three fuel elements are removed at each location. The analysis was initially done with a water channel present adjacent to the device in the location of the missing fuel elements. However, this was later modified so that aluminum filler pieces were located in those channels to minimize power peaking within the test device as well as the adjacent TRIGA FLIP fuel elements.

Three criteria were used for selecting the fuel enrichment for each of the fueled emitters:

1. Achieve the specified heat flux or power from each emitter at its specified location at a reactor power level of about $1.5 \mathrm{MW}$.

2. Achieve a power distribution within the fueled emitter that has a peak/average power of less than about $1.5 \mathrm{MW}$, which is the expected peak power in the SP-100 system. 
TABLE 2-11

COLD FUEL/EMITTER GAPS FOR TEST CAPSULES

\begin{tabular}{|c|c|c|c|}
\hline \multirow{2}{*}{$\begin{array}{c}\text { Emitter } \\
\text { Temperature } \\
\text { (K) }\end{array}$} & \multirow{2}{*}{$\begin{array}{l}\text { Emitter } \\
\text { Thickness } \\
\text { (mils) }\end{array}$} & \multicolumn{2}{|c|}{ Gap (mils) } \\
\hline & & Radial & Diametral \\
\hline 1650 & $\begin{array}{r}40 \\
70 \\
100\end{array}$ & $\begin{array}{l}6.4 \\
6.0 \\
5.6\end{array}$ & $\begin{array}{l}12.8 \\
12.0 \\
11.2\end{array}$ \\
\hline 1750 & $\begin{array}{r}40 \\
70 \\
100\end{array}$ & $\begin{array}{l}7.8 \\
7.3 \\
6.8\end{array}$ & $\begin{array}{l}15.6 \\
14.6 \\
13.6\end{array}$ \\
\hline 1850 & $\begin{array}{r}40 \\
70 \\
100\end{array}$ & $\begin{array}{l}9.4 \\
8.8 \\
8.3\end{array}$ & $\begin{array}{l}18.8 \\
17.6 \\
16.6\end{array}$ \\
\hline
\end{tabular}




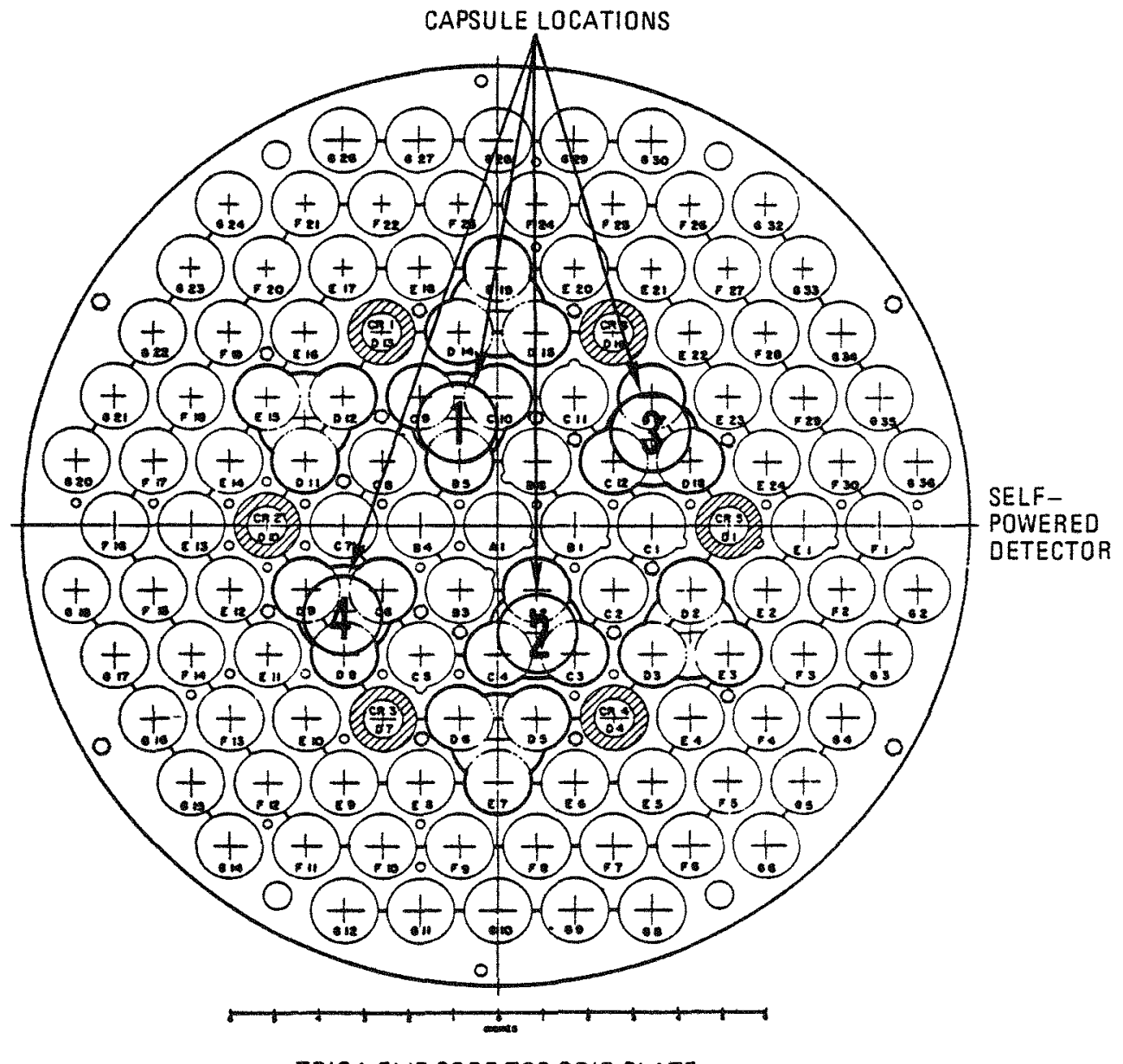

TRIGA FLIP CORE TOP GRID PLATE

\begin{tabular}{|c|c|c|c|c|}
\hline \multicolumn{5}{|c|}{ SPECIFIC FUELED EMITTER TEST PARAMETERS } \\
\hline & EMITTER TEMPERATURE (K)/THICKNESS (MIL) \\
\hline & CAPSULE 1 & CAPSULE 2 & CAPSULE 3 & CAPSULE 4 \\
\hline TOP CELL & $\begin{array}{c}1750 / \\
100\end{array}$ & $\begin{array}{c}1650 / \\
70\end{array}$ & $\begin{array}{c}1750 / \\
40\end{array}$ & $\begin{array}{c}1650 / \\
70\end{array}$ \\
\hline MIDDLE CELL & $1850 /$ & $1850 /$ & $1750 /$ & $1850 /$ \\
& 100 & 70 & 70 & 70 \\
\hline BOTTOM CELL & $1750 /$ & $1750 /$ & $1750 /$ & 70 \\
& 100 & 70 & $70 /$ \\
\hline
\end{tabular}

A 17773

Fig. 2-20. Core configuration giving specific fueled emitter test parameters 
3. Maintain the mass of U-235 in each device or capsule at less than $100 \mathrm{~g}$ for the sum of the three fueled emitters. This is a technical specification requirement for the TRIGA Mark F reactor.

The analysis was done in a similar manner to that used for previous thermionic devices irradiated in a TRIGA FLIP core, as described in Ref. $2-10$.

This study assumed that the 100-fuel-element TRIGA FLIP core was used for all of the analyses. The core configuration was assumed to be the hexagonal array, as shown in Fig. 2-20, with a center-to-center triangular pitch of $4.35 \mathrm{~cm}(1.714 \mathrm{in.})$. The atom densities used for the TRIGA FLIP core were those with 500 days burnup in the TRIGA Mark $F$ reactor.

Effective Broad-Group Cross Sections. Neutron cross sections used in this study were generated using the MICROX cross section code (Ref. 2-11). Table 2-12 gives the energy and lethargy intervals for each of the seven broad groups used in the analysis.

The TRIGA FLIP core cross sections were generated over a homogenized core spectrum, and the reflector cross sections were generated over a reflector spectrum.

The cross sections for all materials in the thermionic device (capsule) were generated over a homogenized TRIGA FLIP spectrum. Since tungsten, niobium, and uranium involve resonance structure, resonance cross sections were generated for these materials using the effective thickness for an equivalent cylinder. For tungsten, these resonance cross sections were generated as a function of emitter thickness; for uranium, they were generated as a function of enrichment.

One-Dimensional Radial Calculations. The power production from the fueled emitter within each thermionic device was initially calculated 
TABLE 2-12

NEUTRON ENERGY GROUP STRUCTURE

\begin{tabular}{cll}
\hline Group & \multicolumn{1}{c}{ Energy Interval } & Lethargy Interval \\
\hline 1 & $14.9 \times 10^{6}$ to $6.08 \times 10^{5}$ & -0.4 to 2.8 \\
2 & $6.08 \times 10^{5}$ to $9.12 \times 10^{3}$ & 2.8 to 7.0 \\
3 & $9.12 \times 10^{3}$ to 2.38 & 7.0 to 15.25 \\
4 & 2.38 to 0.4 & 15.25 to 17.0 \\
5 & 0.4 to 0.140 & 17.0 to 18.08 \\
6 & 0.140 to 0.050 & 18.08 to 19.11 \\
7 & 0.050 to 0.0 & 19.00 to 0.0 \\
\hline
\end{tabular}


from a radial calculation with the device at the core centerline. This calculation was done using the seven group cross sections described and the one-dimensional transport code DTFX (Ref. 2-12). An $S_{4}$ approximation was used for the neutron flux anisotropy, and the $P_{1}$ approximation was used for the scattering anisotropy. Table 2-13 gives the material description and radial dimensions used within the device and for the core and reflector.

The power production and the power distribution within the fueled emitter were calculated as a function of fuel enrichment, since the power production requirements vary depending on the location in the core and the experimental temperature desired. In addition, they were calculated as a function of emitter thickness, since this is an additional variable in the experiment.

Figures 2-21 and 2-22 summarize the results of this analysis. Figure 2-21 gives the calculated fission power from a single fueled emitter located at the radial centerline at $1.5 \mathrm{MW}$ and for an average axial power position as a function of enrichment and emitter thickness. For enrichments greater than $10 \%$, cel1 power and the U-235 enrichment have a nonlinear relationship. This is due to the self-shielding in the $\mathrm{UO}_{2}$ fuel pellets as the enrichment increases. Figure 2-22 shows the radial peak/ average power within the fuel pellet for the same enrichment and emitter thickness. Since maintenance of the power peaking within the fueled emitter at a value less than 1.5 (the expected power for the SP-100 system) is desirable, the enrichment must be maintained below $20 \%$.

As noted earlier, the thermionic device was installed in the core location vacated by three TRIGA FLIP fuel elements. The analysis was initially performed by homogenizing the three water channels created by the absence of the fuel elements into an annular cylinder around the device. However, this was later modified by adding three aluminum filler pieces in the water channels which were also homogenized into an annular channel. Table 2-13 and Fig. 2-23 give the dimensional details of this homogenization. These filler pieces were inserted to remove the effects 
TABLE $2-13$

MATERIAL DESCRIPTION AND DIMENSIONS OF THERMIONIC DEVICE AND FUELED EMITTER ANALYTICAL MODEL

Radial Dimensions of Thermionic Device

\begin{tabular}{|c|c|c|c|c|}
\hline Material Description & {$[\mathrm{cm}$} & $\left.\left(i n_{\bullet}\right)\right]$ & $\begin{array}{l}\text { Outside } \\
\text { Radius } \\
\text { ( } \mathrm{cm})\end{array}$ & $\begin{array}{l}\Delta \mathrm{R} \\
(\mathrm{cm})\end{array}$ \\
\hline \multicolumn{5}{|l|}{$\mathrm{UO}_{2}$ fuel } \\
\hline $\begin{array}{l}40-\text { mil emitter } \\
70-\text { mil emitter } \\
100 \text {-mil emitter }\end{array}$ & $\begin{array}{l}2.59 \\
2.44 \\
2.29\end{array}$ & $\begin{array}{l}(1.02) \\
(0.96) \\
(0.90)\end{array}$ & $\begin{array}{l}1.2954 \\
1.2192 \\
1.1430\end{array}$ & $\begin{array}{l}0.1016 \\
0.1778 \\
0.2540\end{array}$ \\
\hline Tungsten emitter & 2.79 & $(1.10)$ & 1.397 & -- \\
\hline Void & 3.00 & $(1.18)$ & 1.4986 & 0.1016 \\
\hline Niobium collector & 5.13 & $(2.02)$ & 2.5654 & 1.0668 \\
\hline Niobium and copper bus & 5.45 & $(2.145)$ & 2.7242 & 0.1588 \\
\hline $\begin{array}{l}\text { Primary containment (stainless } \\
\text { steel) }\end{array}$ & 5.55 & $(2.185)$ & 2.7749 & 0.0507 \\
\hline Void & 5.72 & $(2.252)$ & 2.8606 & 0.0857 \\
\hline $\begin{array}{l}\text { Secondary containment (stainless } \\
\text { steel) }\end{array}$ & 6.04 & $(2.375)$ & 3.016 & 0.1524 \\
\hline Homogenized aluminum filler prices & 7.13 & $(2.807)$ & 3.565 & -- \\
\hline Water annulus & 7.92 & $(3.117)$ & 3.959 & -- \\
\hline TRIGA FLIP correlation & & -- & 22.858 & -- \\
\hline Water reflector & & -- & 32.858 & -- \\
\hline
\end{tabular}

Axial Dimensions of Fueled Emitter

\begin{tabular}{lcc}
\hline \multicolumn{1}{c}{ Material Description } & $\begin{array}{c}\text { Distance from Midplane } \\
(\mathrm{cm})\end{array}$ & $\begin{array}{c}\Delta Z \\
(\mathrm{~cm})\end{array}$ \\
\hline UO $_{2}$ fuel & 2.50 & - \\
Tungsten emitter & 2.6778 & 0.1778 \\
Cap (niobium + void + tungsten) & 4.812 & 2.1342 \\
Plate (niobium) & 5.3945 & 0.5825 \\
Void & 5.9827 & 0.5882 \\
Niobium collector & 6.1552 & 0.1725 \\
Void & 6.3622 & 0.2110 \\
Tungsten emitter & 6.540 & 0.1778 \\
Fuel at axial center & $9.043(3.56$ in.) & 2.50 \\
\hline
\end{tabular}




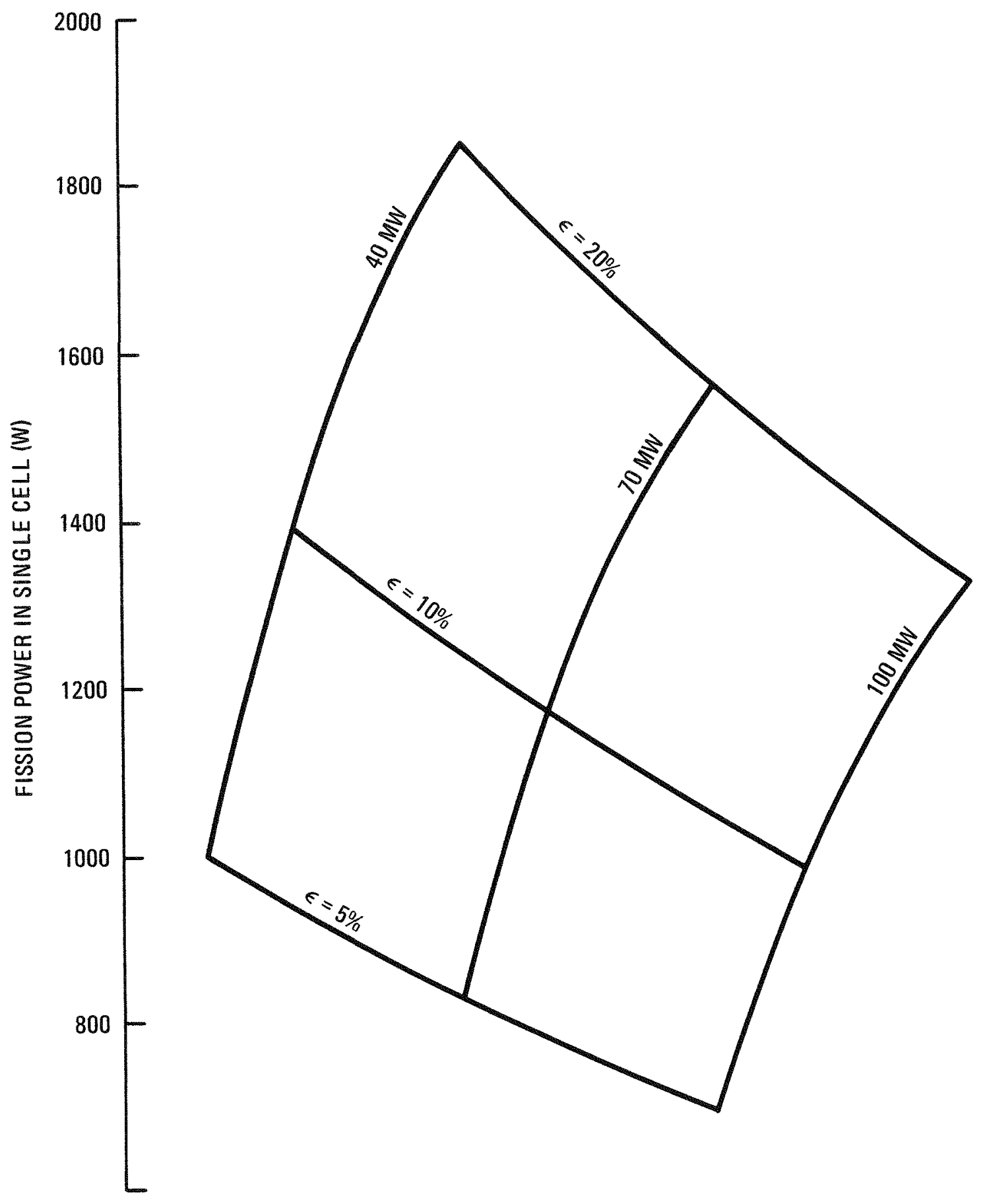

A 17773

Fig. 2-21. Fission power in single fuel/clad emitter. Radial center/average axial - FLIP TRIGA core (97 FE +

$T_{N}$ Dev) flux trap with three partial filler pieces. Reactor power $=1.5 \mathrm{MW}(t)$. 

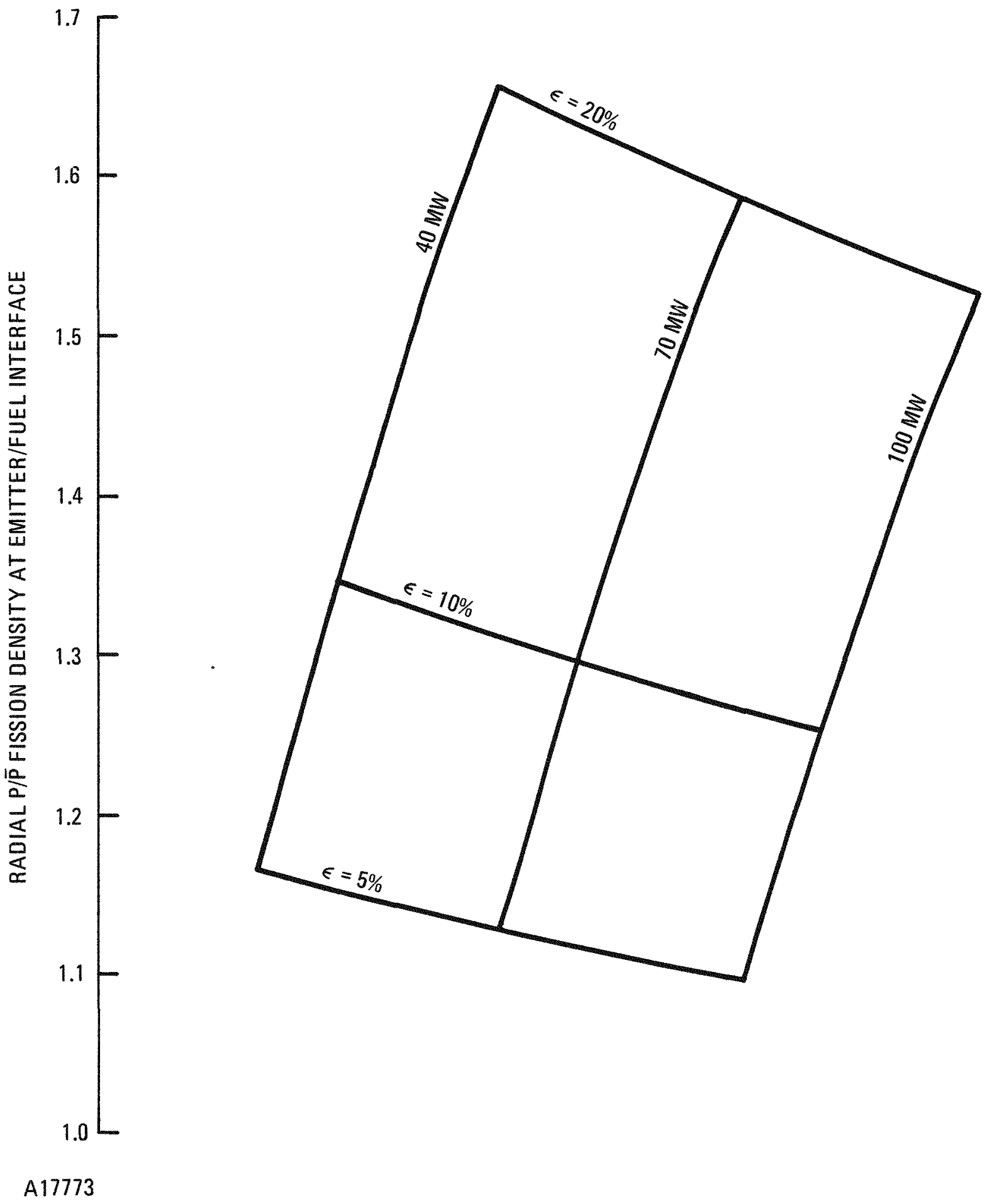

Fig. 2-22. Radial $\mathrm{P} / \overline{\mathrm{P}}$ at emitter/fuel $\mathrm{UO}_{2}$ interface. Reactor power $=1.5 \mathrm{MW}(t)$. Three partial filler pieces in flux trap. 


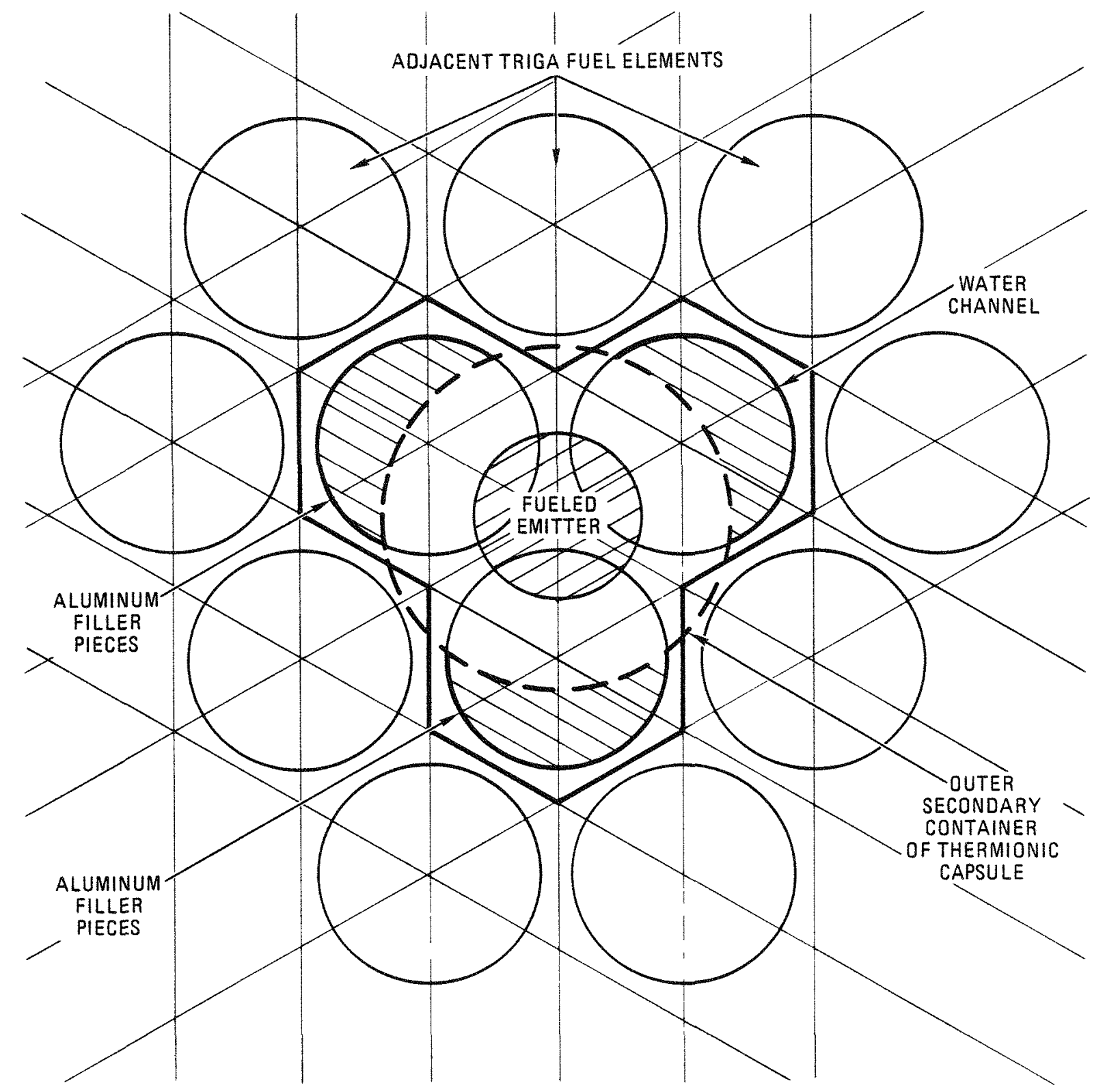

A 17773

Fig. 2-23. Thermionic test device replacing three TRIGA fuel elements 
of a flux trap and to reduce power peaking in both the emitter and the adjacent TRIGA fuel elements.

Two-Dimensional RZ TWOTRAN Analysis. The preliminary analysis for the power generated within the fueled emitters was done using the onedimensional radial calculations already described. In that analysis, explicit variations in the axial direction cannot be accounted for, and each material was considered axially homogeneous.

To correct this deficiency a two-dimensional analysis was performed in the $R Z$ geometry with a single thermionic device located at the radial centerline. This device contained three separate fueled emitters, axially located as shown in Fig. 2-24. The analysis was performed with the two-dimensional transport code TWOTRAN (Ref. 2-13), using the same flux and scattering approximations for anisotropy. Table 2-14 and Fig. 2-24 give the material and mesh description used in that analysis. The core was assumed to be symmetric about the axial midplane.

Since that analysis is limited regarding the mesh point configuration, more detail was provided in the vicinity of the thermionic device and its internal fueled emitters than in the uniformly homogenized core and reflector. To alleviate calculational deficiencies due to reduced mesh assignment, variable mesh spacing was used adjacent to material interfaces. The same seven-group cross sections used in the radial analysis were utilized.

Specification of Enrichment. In selecting the uranium enrichment for each of the 12 fueled emitters, the following procedure was used:

1. A thermal analysis was performed to define the fueled emitter power requirements to satisfy the desired emitter temperatures (see Table 2-15). This analysis contained about $12 \%$ for end losses and ignored the effect of gamma heating in the tungsten emitter. It was performed by the thermal analysis group. 


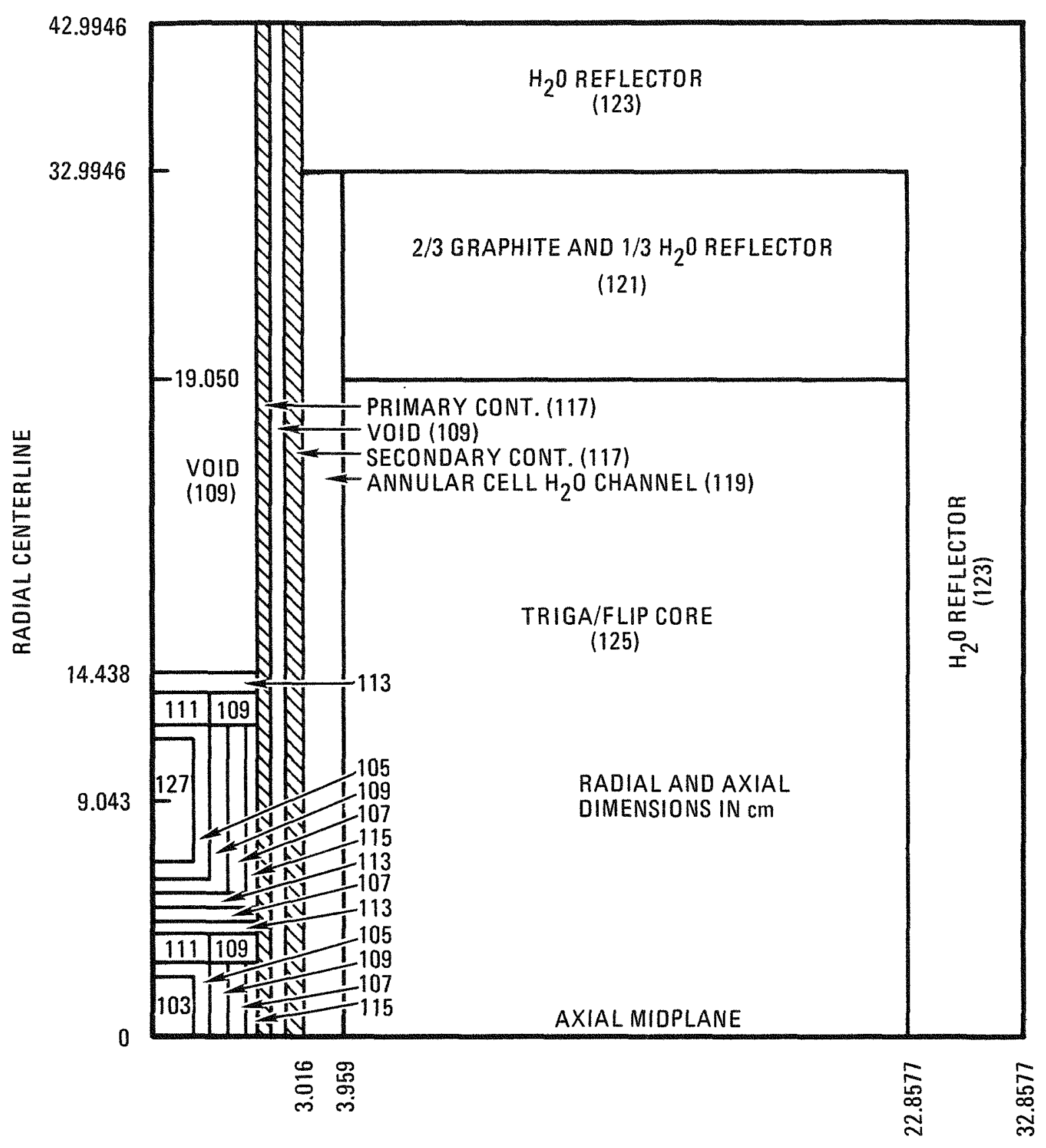

A17773

Fig. 2-24. Two-dimensional RZ configuration for TWOTRAN analysis for single thermionic device at radia1 center 
TABLE $\quad 2-14$

TWOTRAN - RZ MATERIAL CONFIGURATION DESCRIPTION(a)

\begin{tabular}{|c|c|c|c|c|c|c|c|c|c|c|}
\hline \multirow[b]{2}{*}{ Material Description } & \multirow{2}{*}{$\begin{array}{l}\text { Zone } \\
\text { No. }\end{array}$} & \multicolumn{9}{|c|}{ Volume Fraction } \\
\hline & & $w_{\text {nat. }}$ & Niobium & Copper & Stainless & Stee1 & Void & $\mathrm{UO}_{2}(\mathrm{~b})$ & $\mathrm{H}_{2} \mathrm{O}^{(\mathrm{c})}$ & Carbon \\
\hline Central fuel & 103 & & & & & & & 1.00 & & \\
\hline Emitter & 105 & 1.0 & & & & & & & & \\
\hline Collector & 107 & & 0.85 & & & & 0.15 & & & \\
\hline Void & 109 & & & & & & 1.00 & & & \\
\hline Emitter cap & 111 & 0.05 & 0.45 & & & & 0.50 & & & \\
\hline Niobium plate & 113 & & 1.00 & & & & & & & \\
\hline Niobium and copper bus & 115 & & 0.38 & 0.62 & & & & & & \\
\hline Stainless steel container & 117 & & & & 1.00 & & & & & \\
\hline $\mathrm{H}_{2} \mathrm{O}$ annulus & 119 & & & & & & & & 1.0 & \\
\hline Top reflector & 121 & & & & & & & & 0.67 & 0.33 \\
\hline $\mathrm{H}_{2} \mathrm{O}$ reflector & 123 & & & & & & & & 1.0 & \\
\hline TRIGA/FLIP core $(\mathrm{d})$ & 125 & & & & 0.036 & & & & 0.328 & \\
\hline Top/bottom fuel & 127 & & & & & & & 1.00 & & \\
\hline
\end{tabular}

(a) See Fig. 2-22 for location in RZ model.

(b) The uranium enrichment for the central fuel emitter was $11.3 \%$; for the top fueled emitter, $4.0 \%$

(c) The water cross sections in the core and annulus were averaged over the core flux spectrum.

(d) The TRIGA/FLIP atom densities are for 500 days burnup in the Mark F reactor. 
TABLE 2-15

POWER REQUIREMENTS FOR FUELED EMITTERS

\begin{tabular}{ccc}
\hline $\begin{array}{c}\text { Emitter } \\
\text { Temperature } \\
(\mathrm{K})\end{array}$ & $\begin{array}{c}\text { Total Power } \\
(\mathrm{W})\end{array}$ & $\begin{array}{c}\text { Surface Heat Flux } \\
\left(\mathrm{W} / \mathrm{cm}^{2}\right)\end{array}$ \\
\hline 1650 & 987 & 22.1 \\
1750 & 1302 & 29.2 \\
1850 & 1661 & 37.3 \\
\hline
\end{tabular}


2. Relative radial and axial power factors were computed for the emitters located within the specific device in either the $B-C$ or C-D rings (see Fig. 2-20). The radial factors were obtained using a one-dimensional radial calculation with all TRIGA/FLIP fuel elements as the basis. The axial factor for the top and bottom emitter in each device was obtained from an RZ calculation with a water channel at the core centerline. The radial factors compared favorably with those used previously. These factors are shown in Table 2-16. All of these determinations assumed radial and axial flux separability.

3. Using the fueled emitter locations and temperatures from Fig. 2-20, the power requirement data from Table 2-15, the axial and radial power factors from Table 2-16, and the power versus enrichment data from Fig. 2-21, the uranium enrichment for each of the fueled emitters was estimated. Table 2-17 gives these estimated data.

4. To confirm the adequacy of these estimated data, a two-dimensional power distribution calculation was made using TWOTRAN (Ref. 2-13) and the analytical model described earlier.

A11 of these analyses assumed that the experimental devices were neutronically decoupled and that control rod insertion effects were negligible.

\subsection{CAPSULE FABRICATION}

\subsubsection{Component Fabrication}

Component fabrication involved the procurement of centrified materials, the machining of parts, subassembly bonding operations, final machining, chemical analysis, and degassing. In the case of tungsten emitter components, tungsten was produced by the thermochemical 
TABLE 2-16

RADIAL AND AXIAL POWER FACTORS

\begin{tabular}{lcc}
\hline $\begin{array}{c}\text { Radial } \\
\text { Core Location }\end{array}$ & $\begin{array}{c}\text { Emitter at } \\
\text { Axial Midplane }\end{array}$ & $\begin{array}{c}\text { Top or } \\
\text { Bottom Emitter }\end{array}$ \\
\hline Radial center & 1.000 & 0.860 \\
B-C ring & 0.924 & 0.795 \\
C-D ring & 0.830 & 0.714 \\
\hline
\end{tabular}


TABLE 2-17

FINAL ENRICHMENT PROJECTION FOR FUELED EMITTER THERMIONIC DEVICE(a)

\begin{tabular}{|c|c|c|c|c|}
\hline & $\begin{array}{l}\text { B-C Ring } \\
\text { Cap No. } 1\end{array}$ & $\begin{array}{l}\text { B-C Ring } \\
\text { Cap No. } 2\end{array}$ & $\begin{array}{l}\text { C-D Ring } \\
\text { Cap No. } 3\end{array}$ & $\begin{array}{l}\text { C-D Ring } \\
\text { Cap No. } 4\end{array}$ \\
\hline \multicolumn{5}{|l|}{ Top } \\
\hline $\begin{array}{l}\text { Temperature, }{ }^{\circ} \mathrm{C} \text { at } \mathrm{mil} \\
\varepsilon, \%\end{array}$ & $\begin{array}{l}1750 \text { at } 100 \\
14.3\end{array}$ & $\begin{array}{l}1650 \text { at } 70 \\
5.8\end{array}$ & $\begin{array}{l}1750 \text { at } 40 \\
9.2\end{array}$ & $\begin{array}{l}1650 \text { at } 70 \\
7.3\end{array}$ \\
\hline$M_{25}, \mathrm{~g}$ & 27.4 & 12.6 & 22.6 & 15.9 \\
\hline$\overline{\mathrm{P}}, \mathrm{W}$ & 1302 & 987 & 1302 & 987 \\
\hline $\mathrm{P} / \overline{\mathrm{P}}$ & 1.51 & 1.27 & 1.44 & 1.33 \\
\hline
\end{tabular}

Middle

Temperature, ${ }^{\circ} \mathrm{C}$ at mil 1850 at $100 \quad 1850$ at $70 \quad 1750$ at $70 \quad 1850$ at 70

$\begin{array}{lllll}\varepsilon, \% & 17.5 & 12.5 & 9.4 & 16.0\end{array}$

$\begin{array}{lllll}\mathrm{M}_{25}, \mathrm{~g} & 33.4 & 27.1 & 20.4 & 34.7\end{array}$

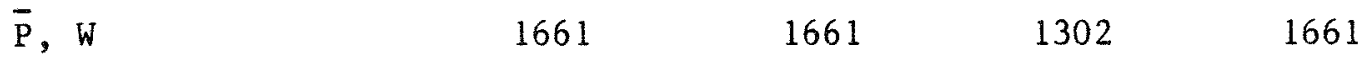

$\begin{array}{lllll}\mathrm{P} / \overrightarrow{\mathrm{P}} & 1.53 & 1.44 & 1.34 & 1.54\end{array}$

Bottom

$\begin{array}{llrrrr}\text { Temperature, }{ }^{\circ} \mathrm{C} \text { at mil } & 1750 \text { at } 100 & 1750 \text { at } 70 & 1750 \text { at } 70 & 1750 \text { at } 70 \\ \varepsilon, \% & 14.3 & 10.2 & 12.8 & 12.8 \\ M_{25}, \mathrm{~g} & 27.4 & 22.1 & 27.8 & 27.8 \\ \overline{\mathrm{P}}, \mathrm{W} & 1302 & 1302 & 1302 & 1302 \\ \mathrm{P} / \overline{\mathrm{P}} & 1.51 & 1.43 & 1.52 & 1.52\end{array}$

(a) Filler pieces are adjacent to capsule outer container. Critera:

Reactor power: $1.5 \mathrm{MW}(\mathrm{t})$.

Gamma heating in tungsten emitter: $0 \%$ to $5 \%$ from TRIGA fuel.

Power location factors:

$$
\begin{array}{lll}
B-C \text { ring } & C_{L} \text { No. } 2=0.924 & C_{L} \text { Nos. } 1 \text { through } 13=0.795 \\
C-D \text { ring } & C_{L} \text { No. } 2=0.830 & C_{L} \text { Nos. } 1 \text { through } 13=0.714
\end{array}
$$


decomposition of tungsten hexafluoride on a molybdenum mandrel in the presence of hydrogen gas.

At GA, component fabrication efforts were initiated by a GA-funded effort to reestablish the needed thermionic fabrication technology. This work included laboratory and equipment setup and revitalization, fabrication procedure updating, and process verification for tungsten vapor deposition, ceramic-to-metal seal manufacture, tungsten-to-tantalum diffusion bonding, uranium dioxide fuel manufacture, chemical analytical methods, heat treating-degassing, and special machine shop operations.

Tungsten Emitters. For tungsten deposition, control of the microstructure and fluorine content yielded fine-grained deposits with fluorine contents ranging from 5 to $15 \mathrm{ppm}$. The deposition system allows for infrared spectroscopic analyses of the gas feedstream to the deposition system and weight-based flow control of the tungsten feed.

Thirty vapor-deposited tungsten emitter blanks were prepared to provide raw material for the 12 irradiation capsule converters and one electrically heated converter. Figure 2-25 shows a tungsten emitter deposit for an in-pile converter. Emitters typically were heat treated and analyzed at GA, machined for diffusion bonding to tantalum transition pieces at TE, diffusion bonded at GA, and finish machined and degassed at $T E$.

Diffusion bonding procedures were validated in tests prior to initiating the capsule hardware fabrication. A process-controlled evaluation sample was prepared after several capsule emitters were bonded. Figure 2-26 shows the tungsten-to-tantalum sample piece. Figure 2-27 shows a cross section of the bonded joint.

Ceramic-to-Metal Seals. Sixteen ceramic-to-metal seals were prepared for the capsule applications. The seals were prepared by brazing preliminary machined niobium skirts to machined Lucalox $\mathrm{Al}_{2} \mathrm{O}_{3}$ ceramic rings that were metallized with a tungsten-yttria metallizing mixture. Brazing was performed in high vacuum with vanadium-niobium alloy. 


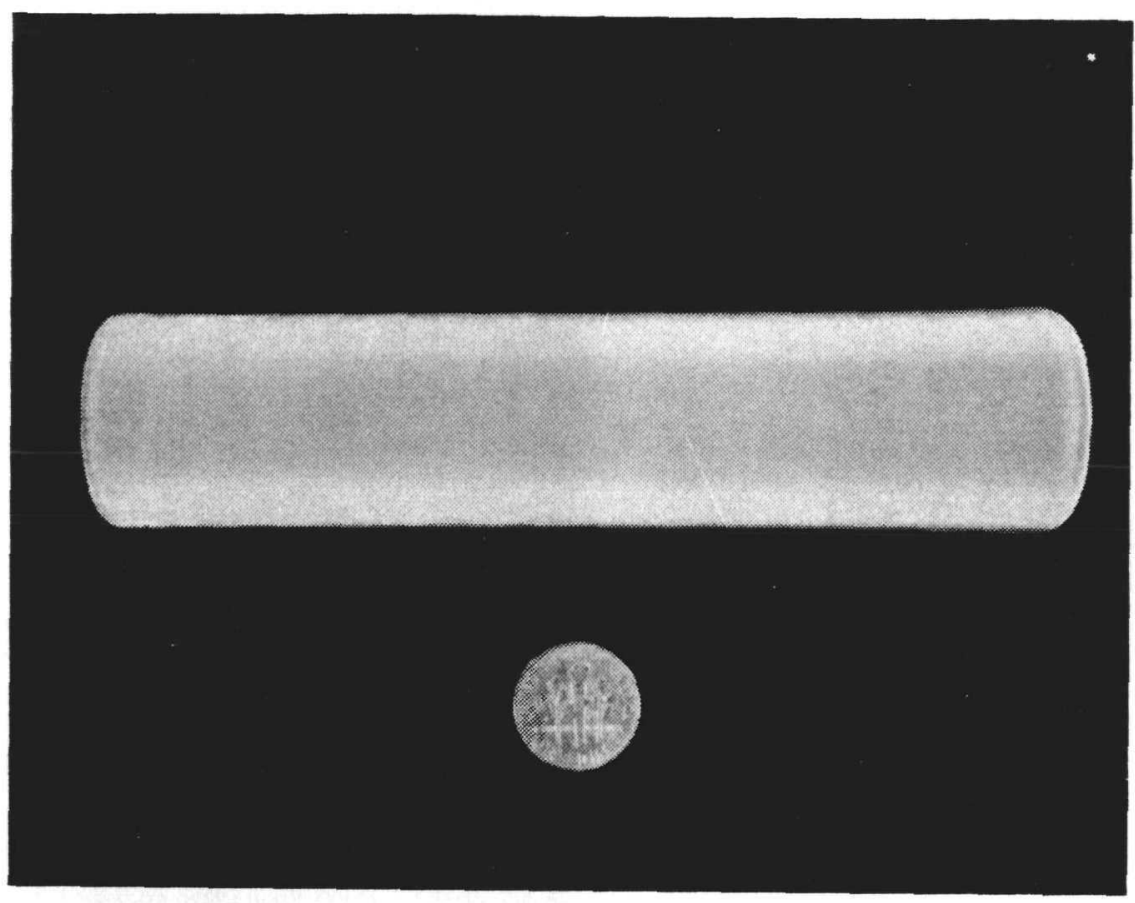

A17773

Fig. 2-25. Vapor-deposited tungsten emitter prior to machining 


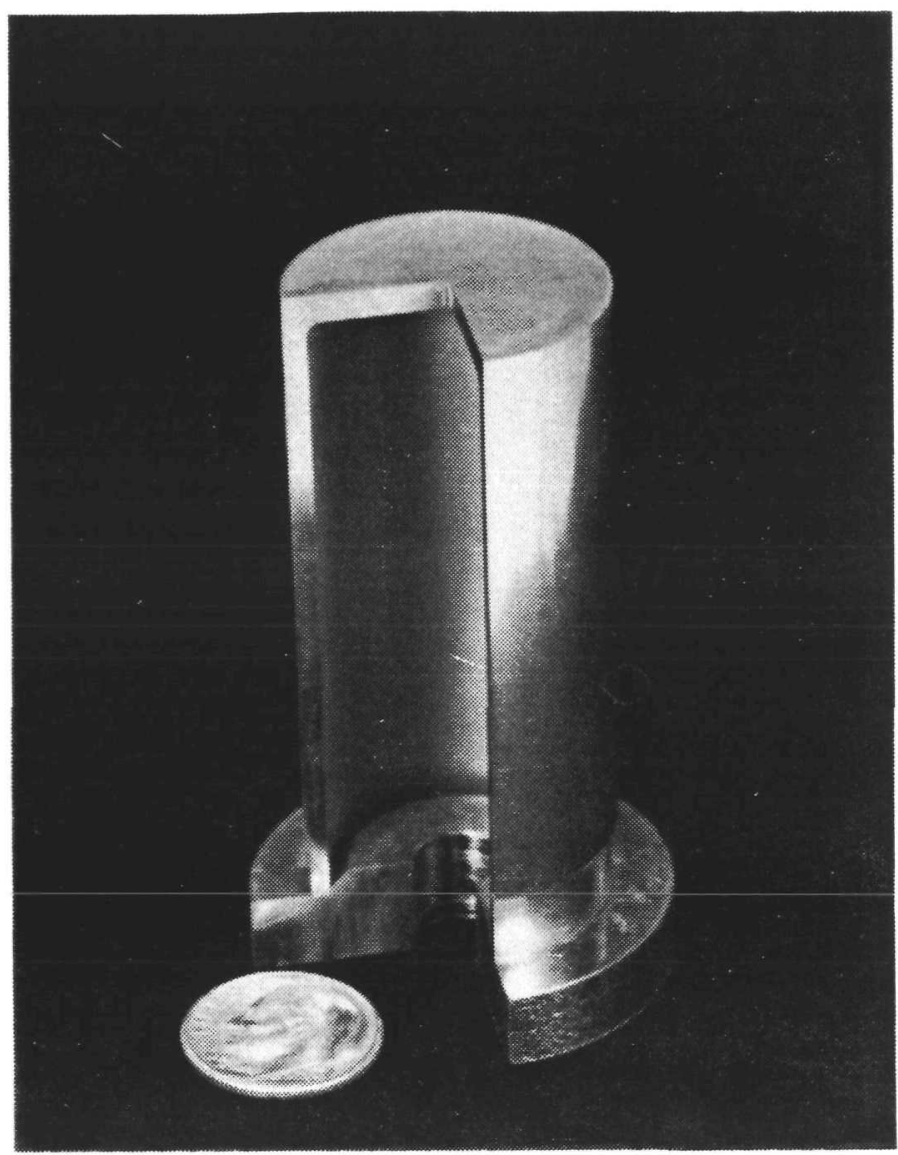

A17773

Fig. 2-26. Process control diffusion bond sample 


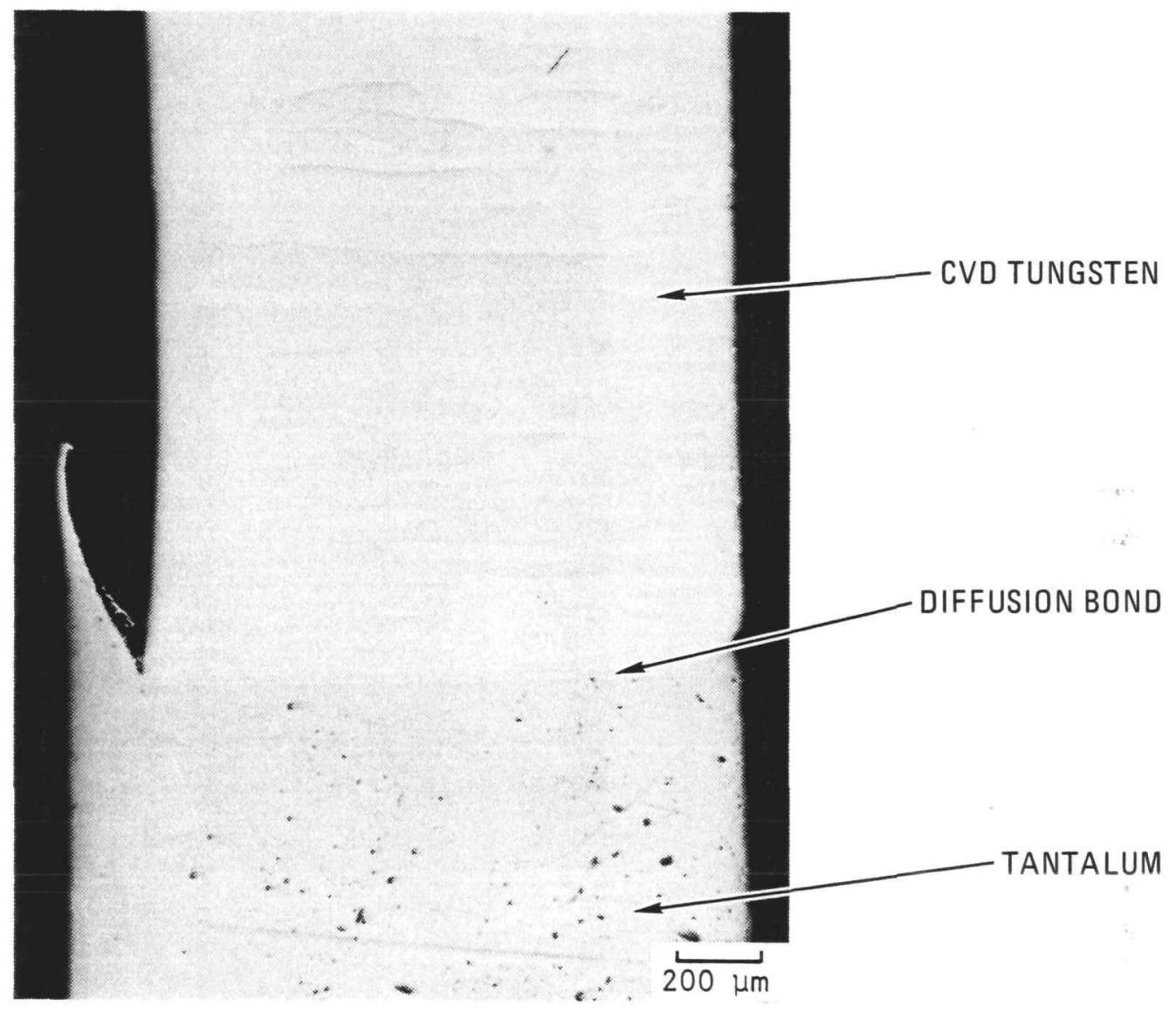

A17773

Fig. 2-27. Tantalum-tungsten diffusion bond 
Figure 2-28 shows a group of nine seals before machining. Figure 2-29 shows finish-machined seals.

Fuel. GA produced uranium dioxide fuel loadings having controlled stoichiometry and density for the 12 in-pile emitters. Enrichment of each fuel loading varied depending upon capsule position and emitter wall configuration. Figure 2-30 shows the appearance of a finished, degassed fuel loading.

Diode and Capsule Components. TE machined the parts for 16 collector subassemblies. The extent of this effort can be appreciated by considering that each collector subassembly consists of a collector - cesium tube and adaptor - collector end cap and components for the cesium distillation assembly.

TE has also prepared or procured the components for the primary capsule assemblies. These include emitter and collector leads and insulation, the primary capsule seal plate and associated feed-through fittings and insulators, thermocouples and thermocouple well components, heaters, and cesium reservoir components. TE also procured tubing for the capsule primary and secondary containment.

\subsubsection{Assemb1y}

The assembly of the FEDC starts with the fabrication and processing of the thermionic diode. The bond sequences can be visualized from the exploded view of the thermionic diode given in Fig. 2-31. Table 2-18 outlines the diode fabrication and processing procedure. Figures 2-32 through 2-39 are photographs of selected fabrication steps. The captions on the figures are self-explanatory and are keyed to the fabrication steps given in Table 2-18. Table 2-19 summarizes the fabrication status of the thermionic diodes for FEDCs 1 and 3 . Special nuclear material license SNM-1935 has been obtained so that the diode can be loaded with low-enriched fuel at TE. 


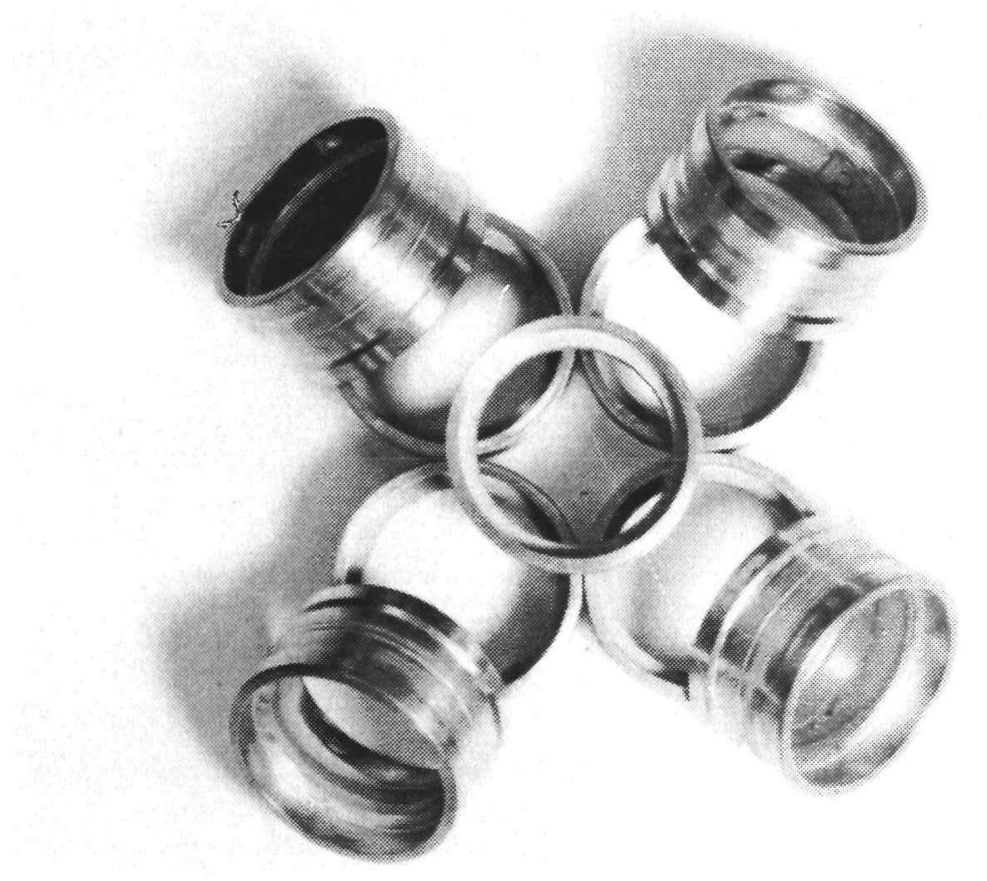

A17773

Fig. 2-28. Vanadium-niobium-brazed ceramic-to-metal seals before final machining 


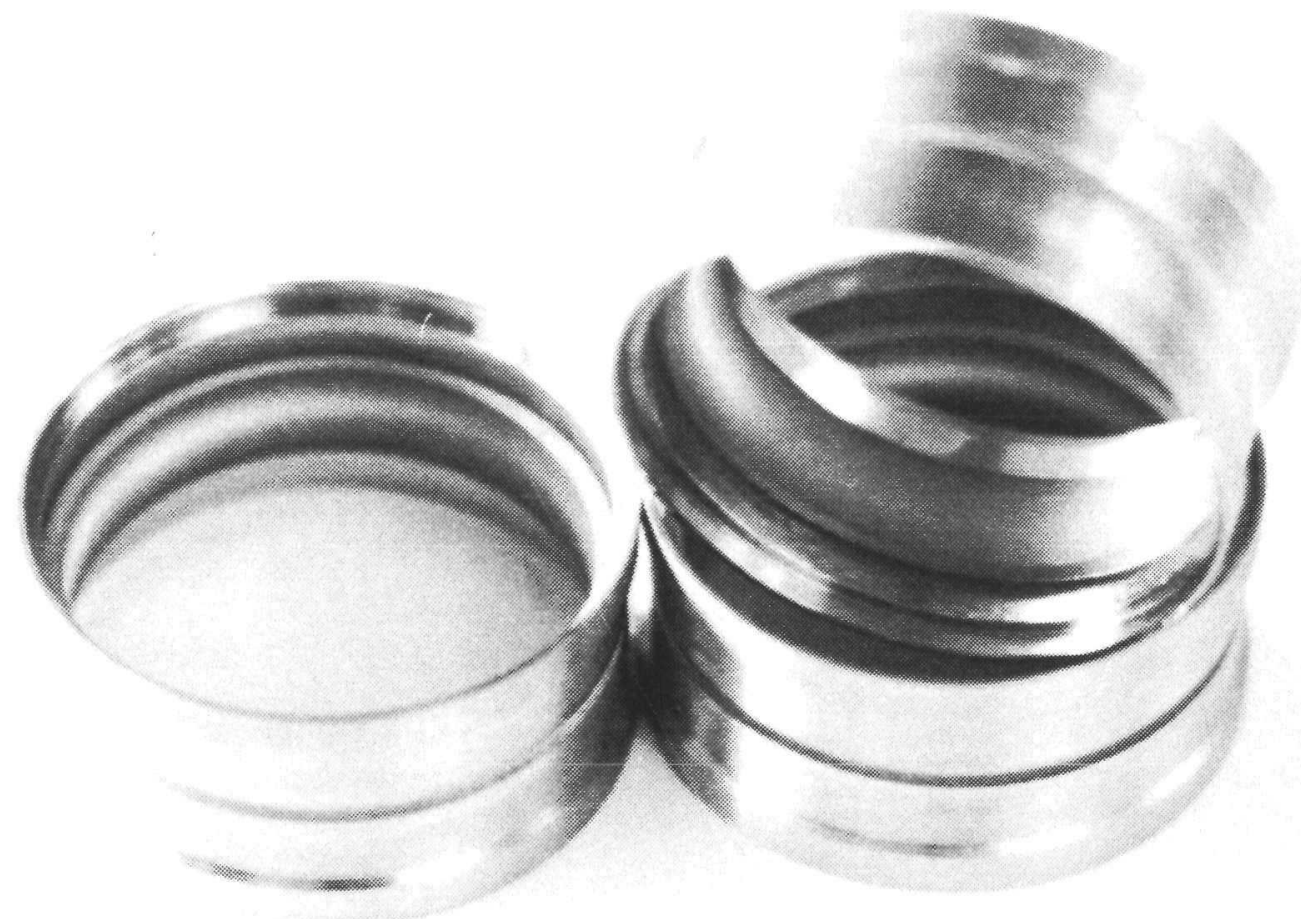

$840347-1$

A17773

Fig. 2-29. Finish machined ceramic-to-metal seals 


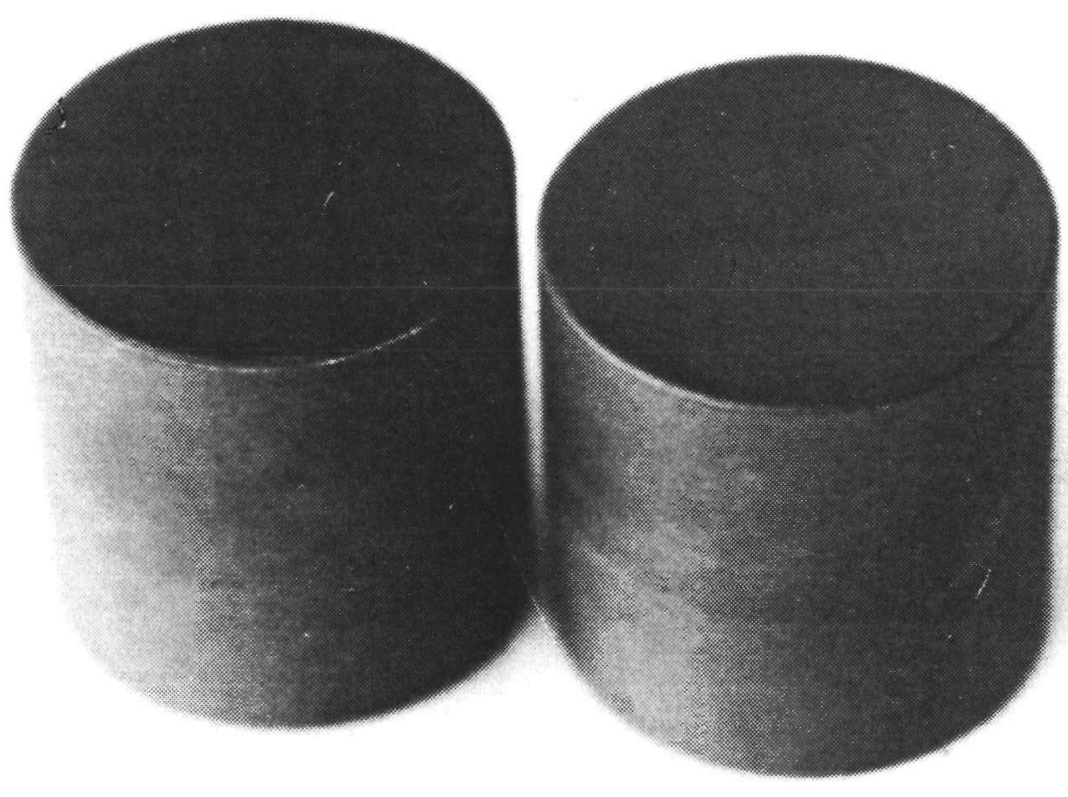

840347-2

A17773

Fig. 2-30. $\mathrm{UO}_{2}$ fuel loading for in-pile capsule converter 


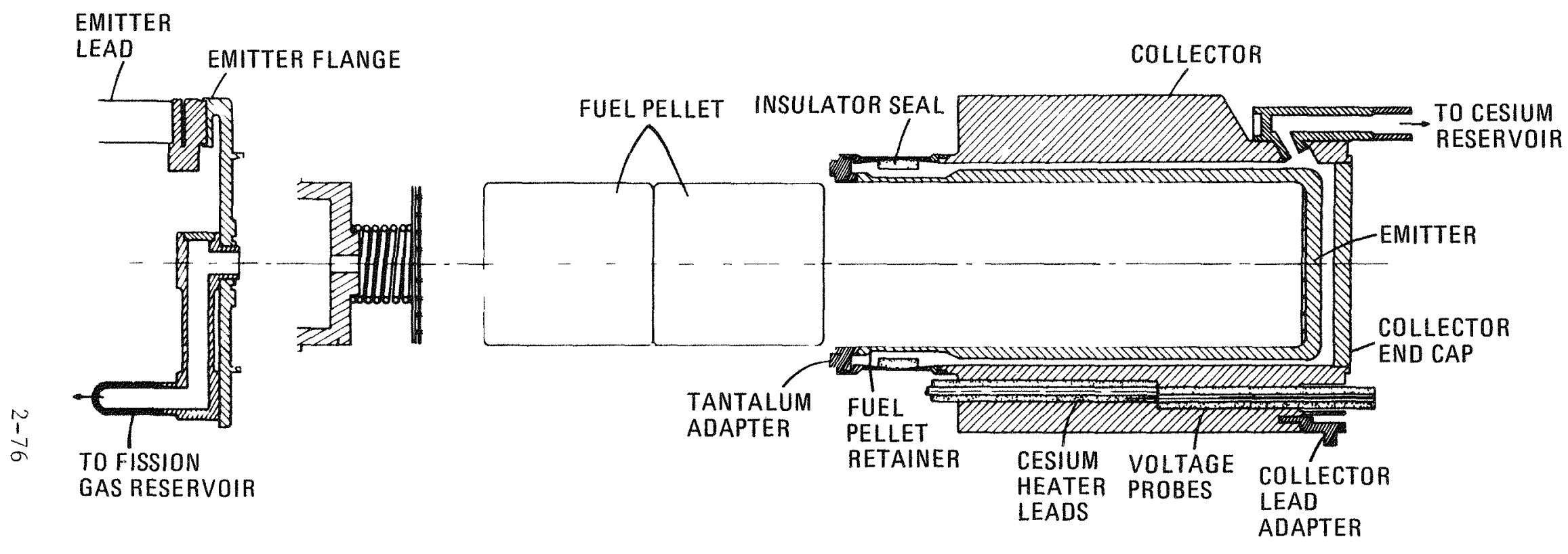

A17773

Fig. 2-31. Exploded view of thermionic diode 
TABLE 2-18

THERMIONIC DIODE FABRICATION AND PROCESSING PROCEDURE

1. Fabricate outgassing-distillation assembly

2. Fabricate emitter flange assembly

3. Fabricate insulator seal

4. Fabricate emitter assembly

a. Machine molybdenum mandre1

b. CVD tungsten onto mandrel

c. Dissolve molybdenum mandrel

d. Anneal $\left(1800^{\circ} \mathrm{C}\right.$ for $\left.6 \mathrm{~h}\right)$

e. Preliminary machine CVD tungsten emitter

f. Diffusion-bond tantalum transition piece to tungsten emitter to make emitter subassembly

g. Finish machine emitter subassembly to make emitter assembly

5. Fabricate emitter lead

6. Fabricate fission gas tube

7. Chemically clean all diode components and assemblies

8. Pre-degas selected components and assemblies

9. Braze copper collector lead adapters onto niobium collector

10. EB weld cesium reservoir adapter to tube

11. EB weld cesium reservoir to collector to make collector subassembly

12. EB weld collector subassembly to insulator seal to make collector subassembly

13. EB weld collector assembly to emitter assembly to make thermionic diode subassemb1y

14. EB weld collector end cap to thermionic diode subassembly to make thermionic diode assembly

15. Braze cesium out-gassing-distillation assembly to thermionic diode assembly and ion pump

16. Set up thermionic diode in processing station 
TABLE 2-18 (Continued)

17. Out-gas thermionic diode

18. Cesiate thermionic diode using double distillation

19. Pinch off thermionic diode

20. Check operation of thermionic diode

21. EB weld uranium oxide fuel pellets into thermionic diode

22. EB weld emitter flange assembly to thermionic diode

23. Braze emitter lead to emitter flange assembly

24. EB weld fission gas tube to emitter flange assembly 


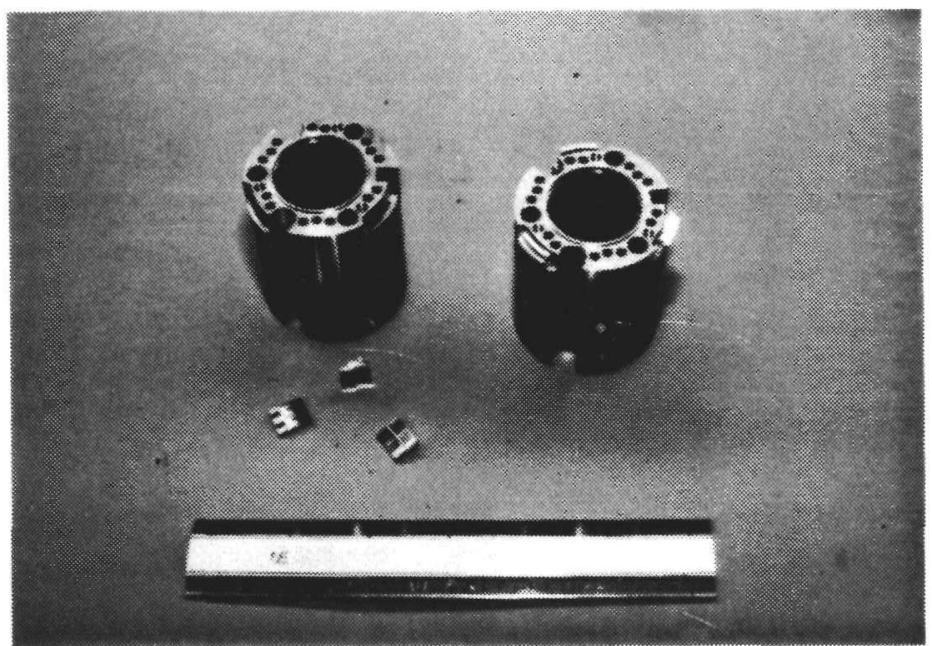

A17773

Fig. 2-32. Collector: before and after brazing of collector lead adapters (step 9, Table 2-9)

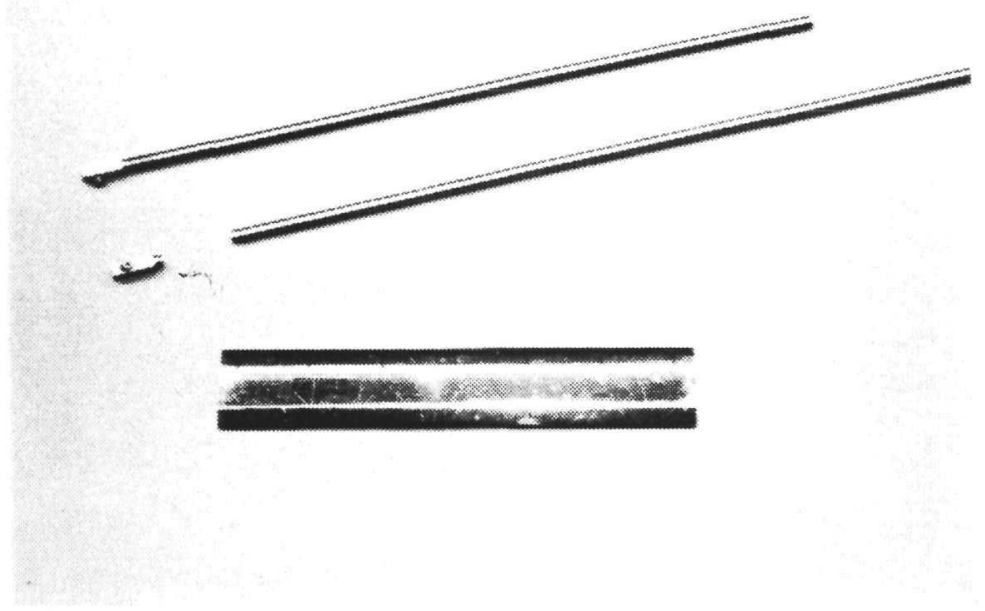

A17773

Fig. 2-33. Cesium reservoir: before and after EB weld of collector reservoir adapter (step 10, Table 2-9) 


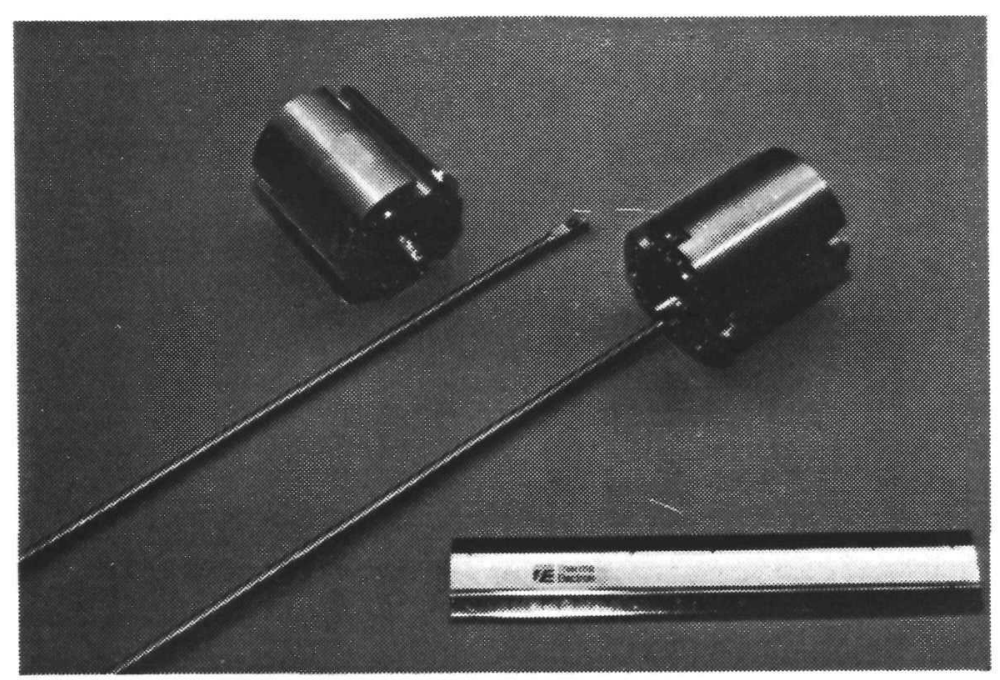

\section{A17773}

Fig. 2-34. Collector-cesium reservoir: before and after EB weld of cesium reservoir to collector (step 11, Table 2-9)

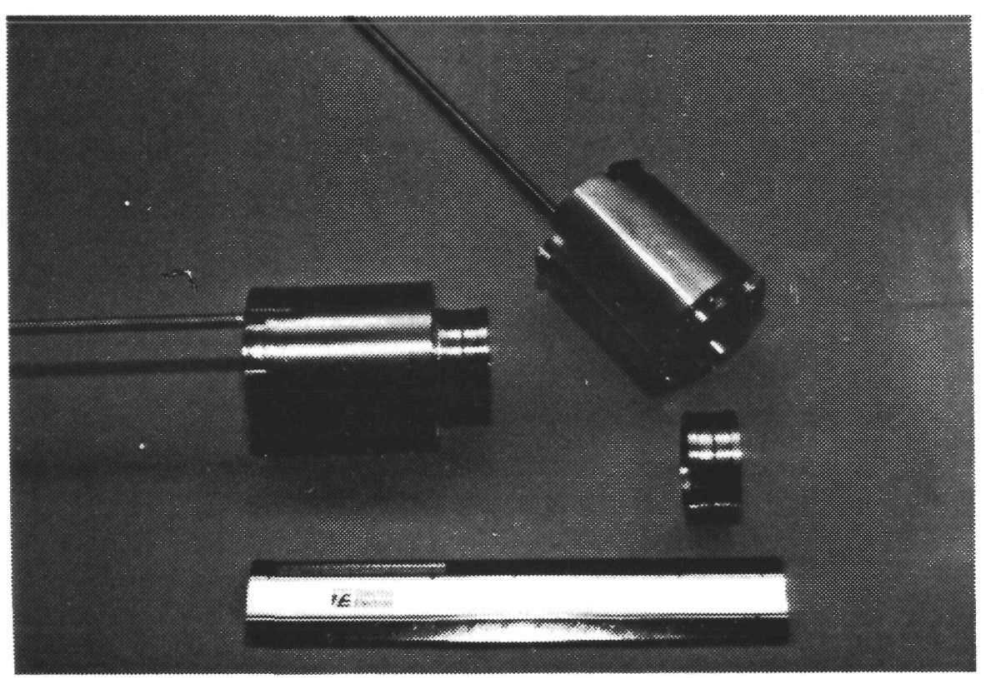

A17773

Fig. 2-35. Collector subassembly-insulator seal: before and after EB weld of insulator seal to collector subassembly (step 12, Table 2-9) 


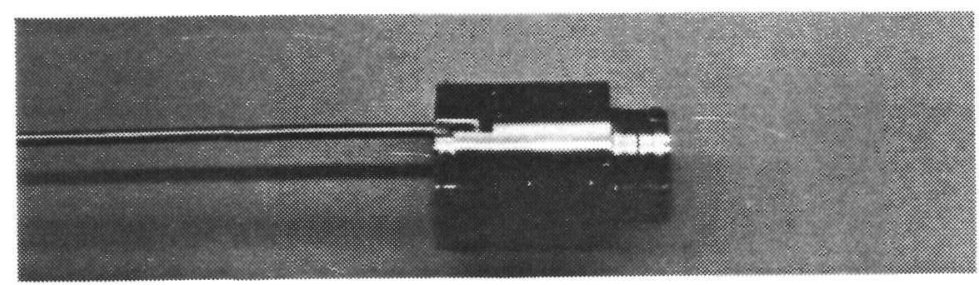

A17773

Fig. 2-36. Collector-emitter assemblies: before and after EB weld of emitter assembly to collector assembly (step 13, Table 2-9)

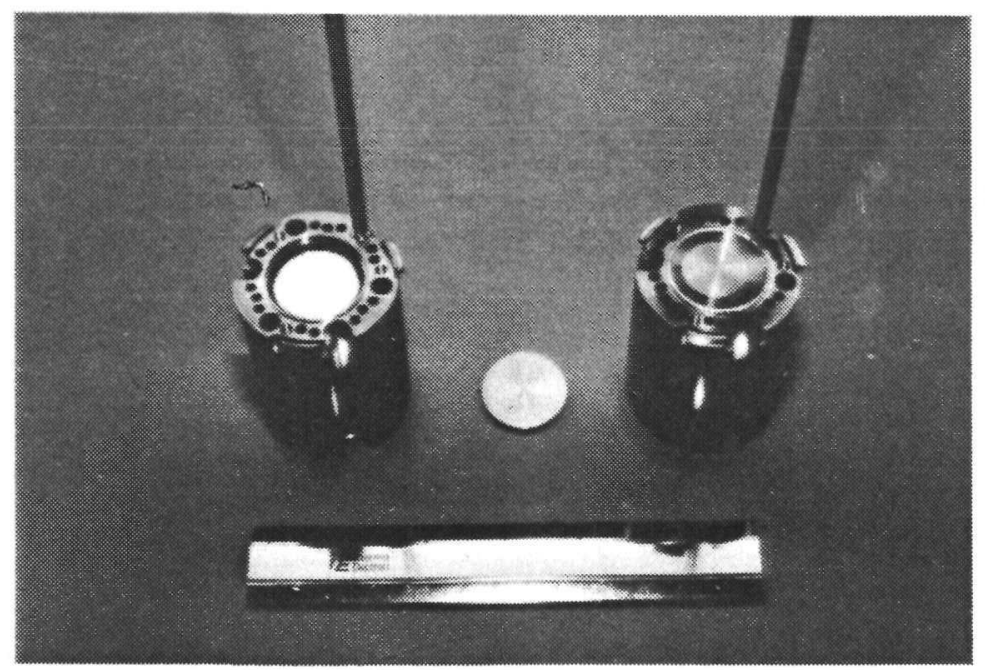

A17773

Fig. 2-37. Thermionic diode subassembly-collector end cap: before and after EB weld of collector end cap to diode subassembly (step 14, Table 2-9) 


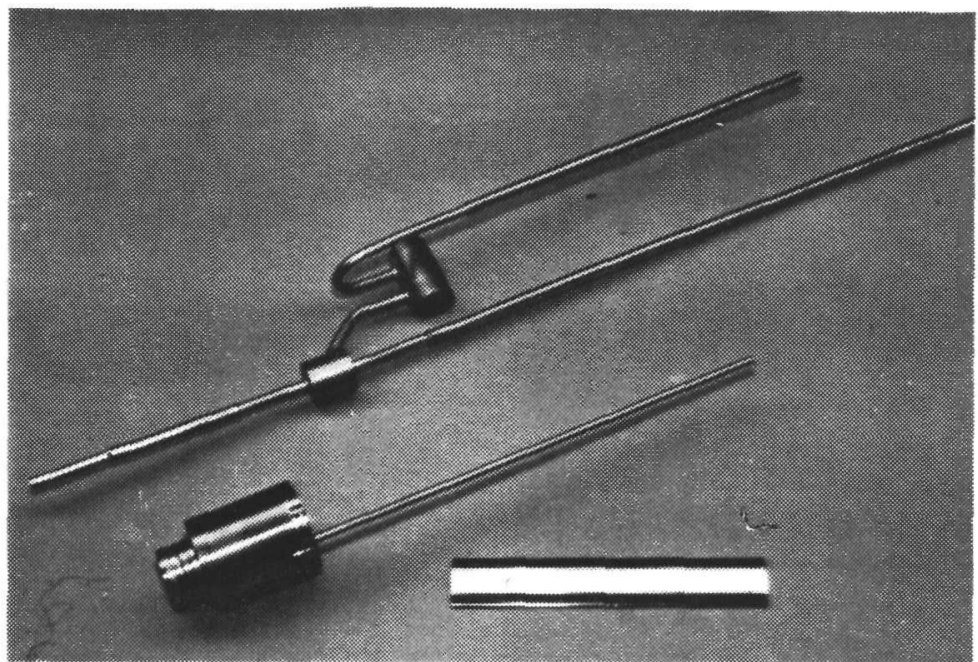

A17773

Fig. 2-38. Thermionic diode and cesium distillation assembly: ready for attachment to diode and ion pumping (step 15, Table 2-9)

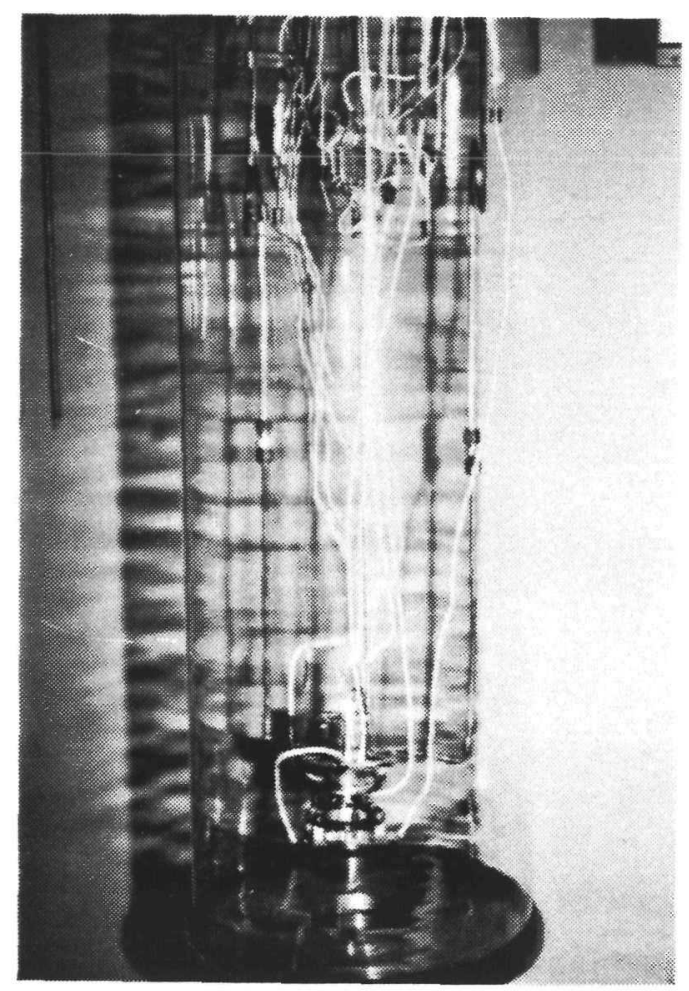

A17773

Fig. 2-39. Thermionic diode in processing station: Ready for outgassing, cesiation, and pinchoff (step 16, Table 2-9) 
IABII 19

IIII RMIONIT DIOIDI FABRIIAIION SIAIIIS

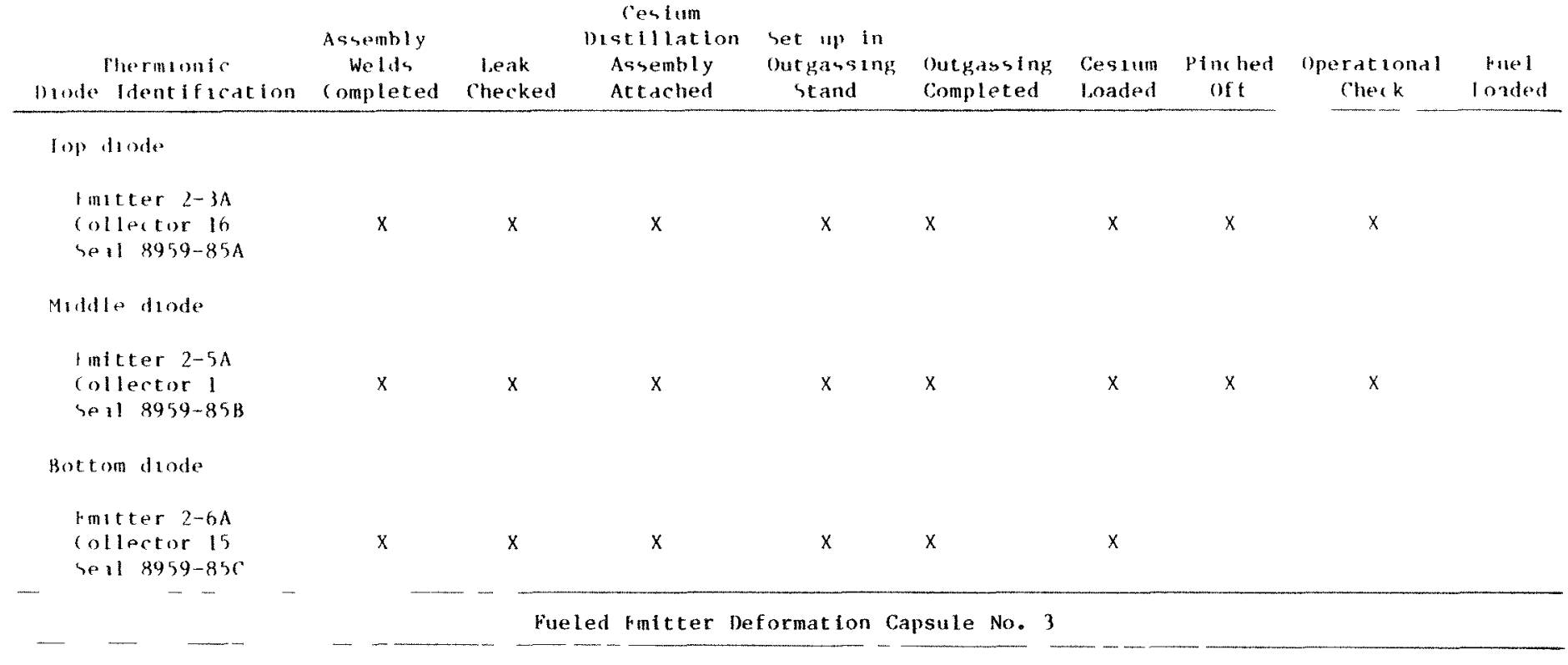

Fop dinde

Hintecer $6 \mathrm{~A}-8$

collector 12

Sell $9959 \quad 127 \mathrm{~A}$

Mudile diode

Imitter) 8

folloctor 5

seil 89,91314

Botton hade

fnitter (A a

ollertor 13

sen1 $9959 \quad 1318$

Fueled tintter Deformation apmalo No.

Fibricition operation 
Table 2-20 outlines the procedure for assembly of the primary containment (see Figs. 2-11 and 2-14). This assembly procedure can be more readily understood by referring to Fig. 2-40, which shows the primary assemb1y fixture. The space frame consists of concentric rings mounted on an array of rigid rods. Various fixtures fit into the space frame to facilitate assembly of the primary containment: (1) hard seal plate fixture, (2) fission gas tube coil fixture, (3) emitter lead expansion device fixture, (4) emitter lead-fission tube fixture, and (5) diode support fixtures. The parts for the primary assembly fixture are being machined.

After completion of the primary containment at TE, it and the secondary components will be shipped to GA in an electronics van. The primary containment will be mounted vertically in an existing, licensed, 7A shipping container. The mating of the primary and secondary containments will be performed at GA. These procedures are now being formulated.

Figures 2-41 through 2-44 give the status summaries of the four FEDCs for capsules 1, 2, 3, and 4, respectively. These Critical Path Method (CPM) network/schedule charts represent the status as of September $29,1984$.

\subsection{INSTRUMENTATION}

The input power to each fueled emitter device is determined by the power level of the TRIGA reactor and the location of the fueled emitter in the reactor. The emitter temperature, in turn, is established by controlling electron cooling (i.e., operating current). As in a thermionic converter, a low pressure of cesium vapor is used to obtain the proper electron emission characteristics for the emitter. The temperature of the collector is determined by the input power to the device and the thermal conductance of two gas gaps: (1) between the collector and primary containment can and (2) between the primary can and the water-cooled secondary containment can. The composition and pressure of the gas in 
TABLE $2-20$

PRIMARY ASSEMBLY PROCEDURE

1. Assemble space frame

2. Check alignment

3. Insert emitter lead/fission tube fixture

4. Insert top diode fixture

5. Install top diode

6. Insert middle diode fixture

7. Install middle diode

8. Insert bottom diode fixture

9. Install bottom diode

10. Insert fission tube coil fixture

11. Insert emitter lead/fission tube fixture

12. Thread three fission tubes to mate with diode assembly

13. Insert emitter expansion fixture

14. Feed three emitter leads to mate with diode assembly

15. Transfer space frame to horizontal furnace

16. Filament braze three fission tubes and three emitter leads

17. Insert hard seal fixture

18. Install hard seal plate

19. Feed three emitter lead extensions through hard seal

20. Feed three fission gas tube extensions through hard seal

21. Heliarc weld three emitter leads to three emitter lead extensions at hard seal plate

22. Heliarc weld three fission gas tubes to three fission gas tube extensions at hard seal plate

23. Mechanically clamp three cesium reservoir heaters to three cesium reservoirs

24. Feed 18 sheath thermocouples through hard seal plate to proper locations

25. Transfer space frame to horizontal furnace

26. Braze six sheath thermocouples into place

27. Braze six sheath thermocouples into place

28. Braze six sheath thermocouples into place

29. Leak-check sheath thermocouples

30. If necessary, repair leaky or shorted sheath thermocouples 
TABLE 2-20 (Continued)

31. Insert six voltage probes through ceramic insulators to proper locations

32. Crimp six voltage probe connections

33. Insert six cesium heater wires

34. Crimp six cesium heater wires at hard seal plate and at cesium heater

35. Install four collector lead segments

36. Transfer space frame to dry box

37. Heliarc three collector lead segments to three collectors

38. Remove space frame from primary assembly

39. Slip on primary containment

40. Transfer primary assembly to dry box

41. Heliarc weld primary containment to hard seal plate

42. Out-gas primary containment, including three fission gas reservoir tubes

43. Pinch off primary containment and three fission gas reservoir tubes (with reopenable pinchoffs)

44. S1ip on secondary containment

45. Transfer to dry box

46. Heliarc weld secondary containment to hard seal plate

47. Transfer to Department of Transportation 7A shipping cask

48. Pack to minimize vibration

49. Ship to GA 

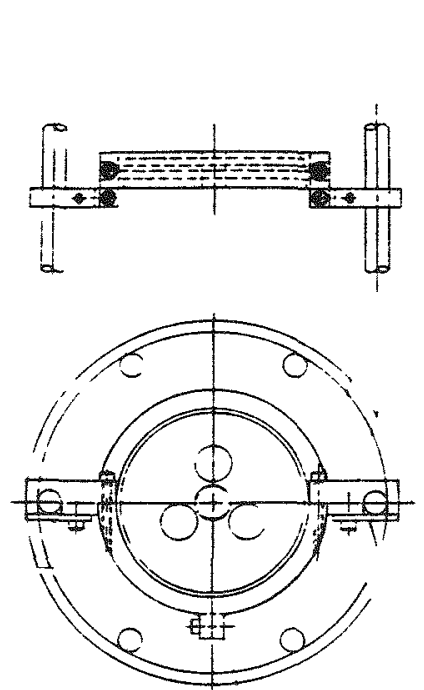

VIEW E-E HARDSEAL (1) PLACE) PLATE FIXTURE

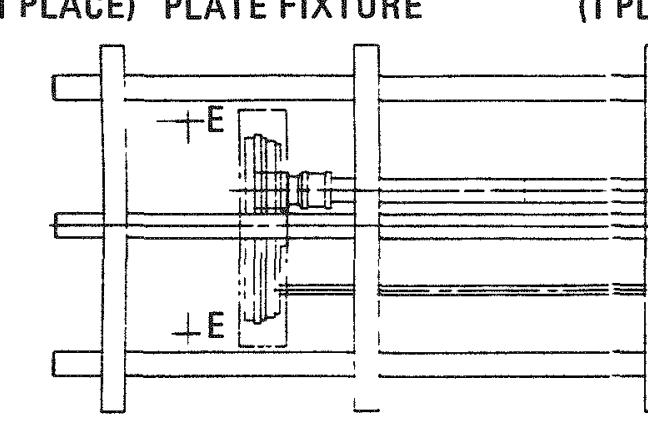

A17773
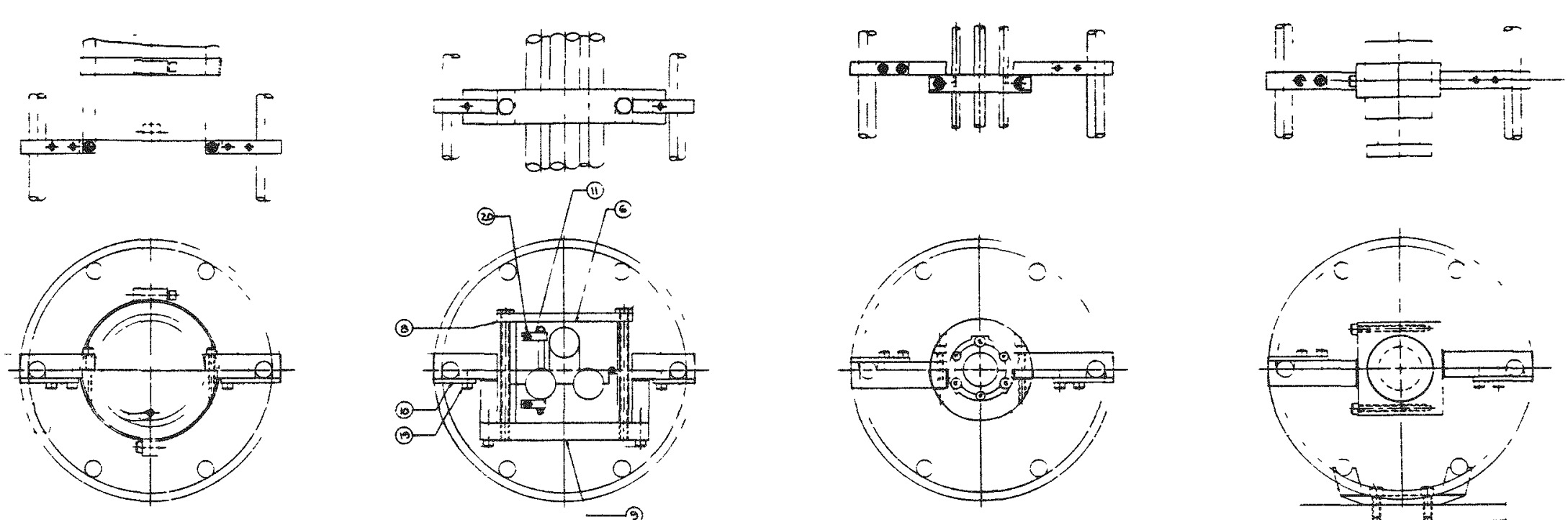

EW D-D FISSION TUBE

VIEW C.C

?

(1) PLACE) EXPAITTER LEAD

VIEW B-B EMITTER LEAD/FISSION

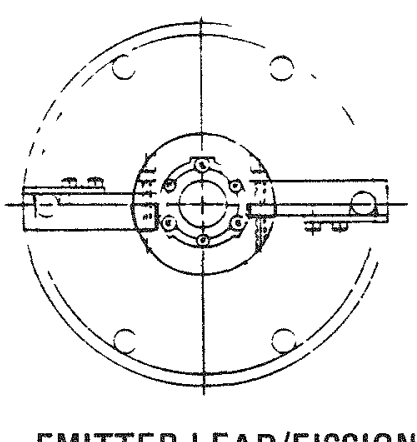

TUBE FIXTURE

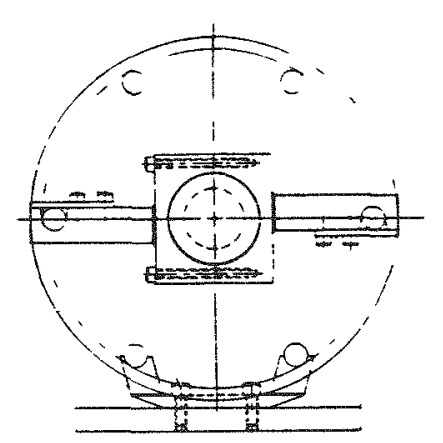

VIEW A-A DIODE SUPPORT

(3 PLACES FIXTURE
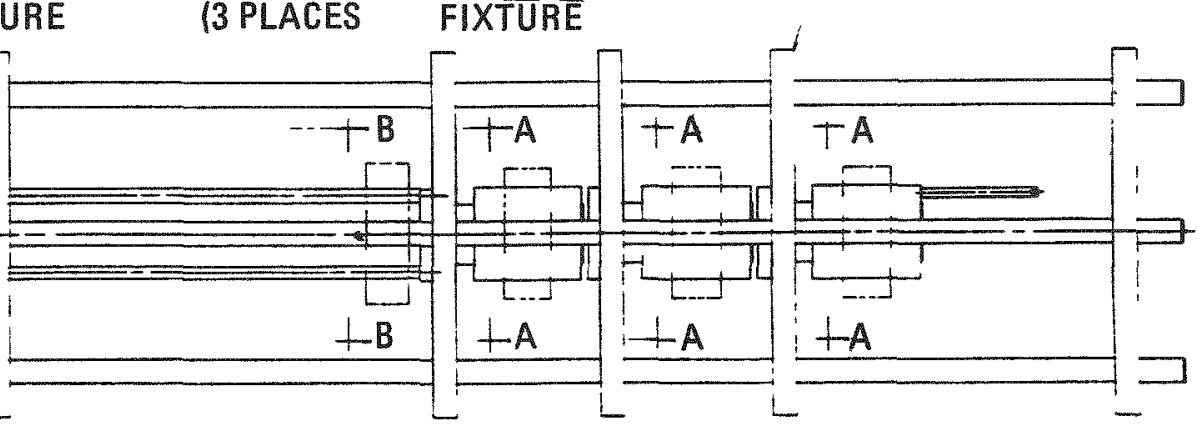

Fig. 2-40. Drawing of primary assembly fixture 


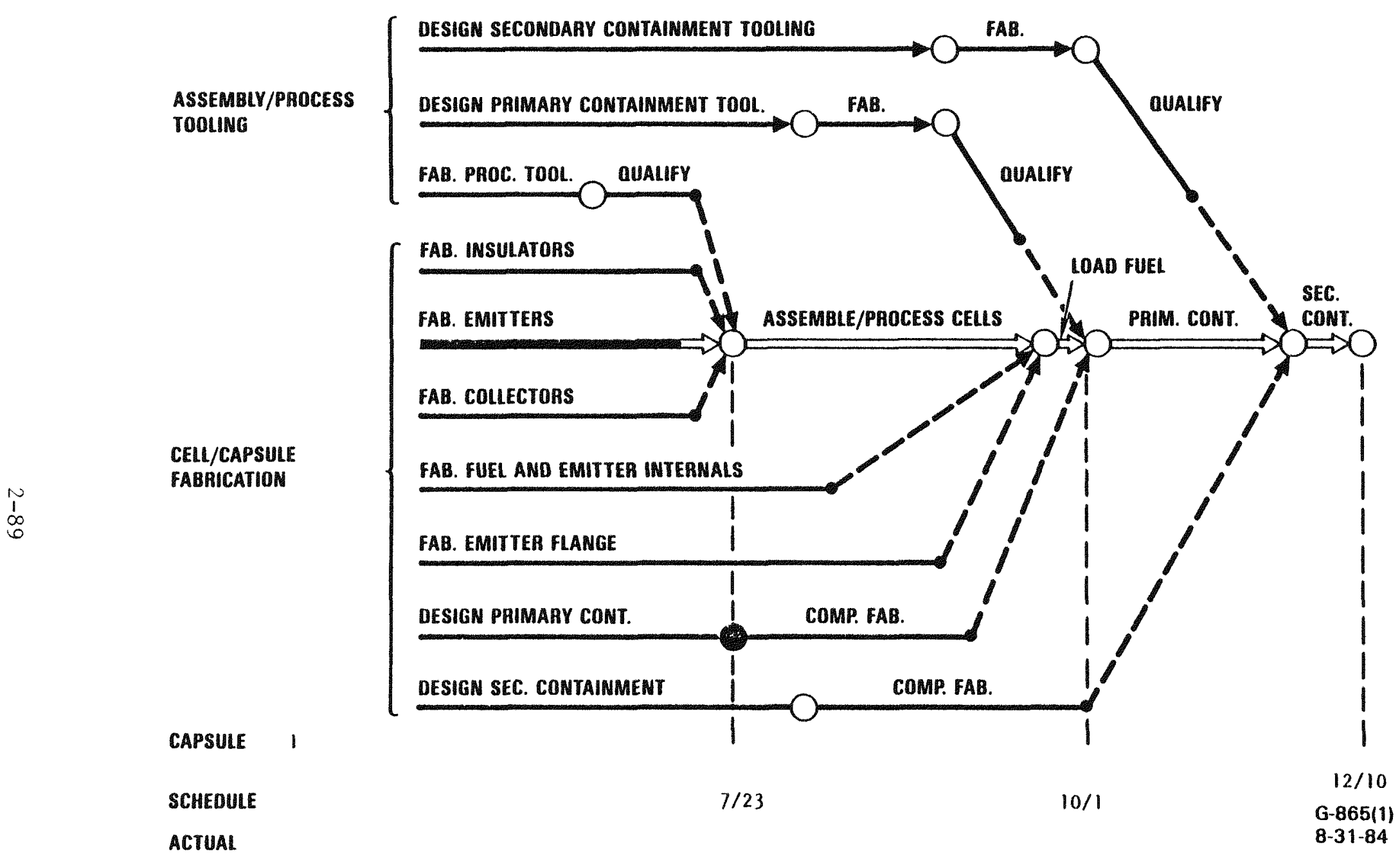

Fig. 2-41. CPM schedule for fueled emitter deformation capsule 1 


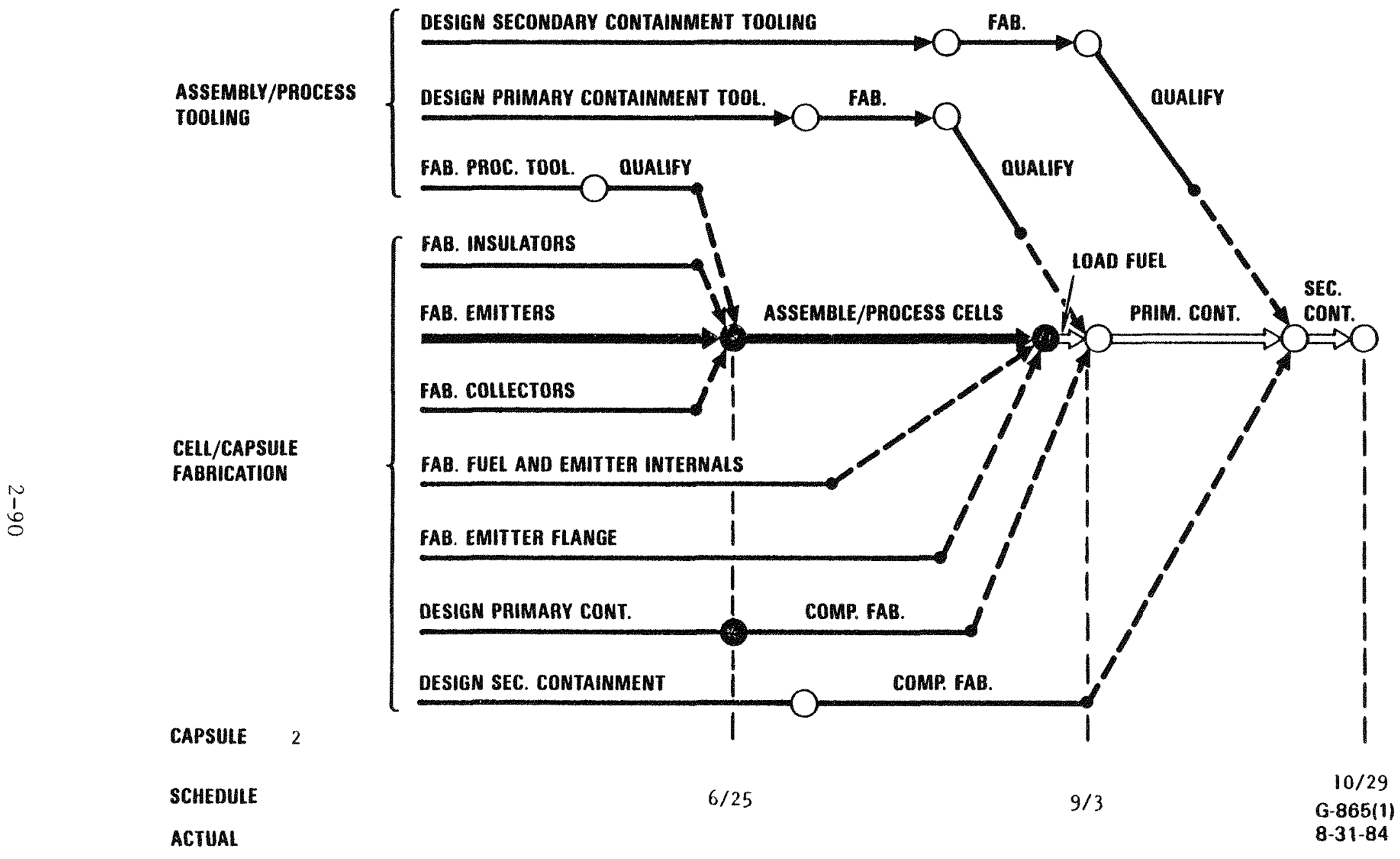

Fig. 2-42. CPM schedule for fueled emitter capsule 2 


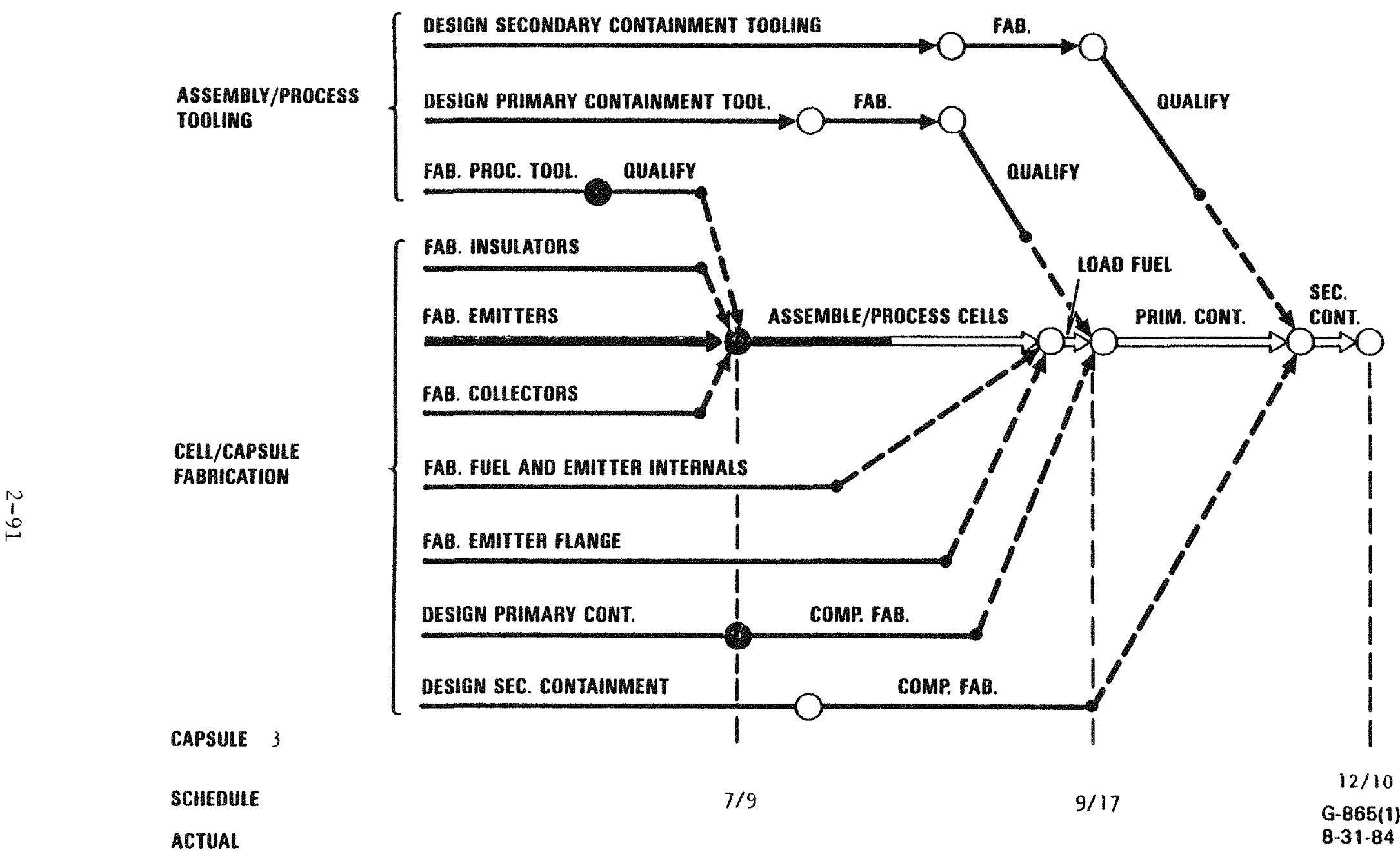

Fig. 2-43. CPM schedule for fueled emitter deformation capsule 3 


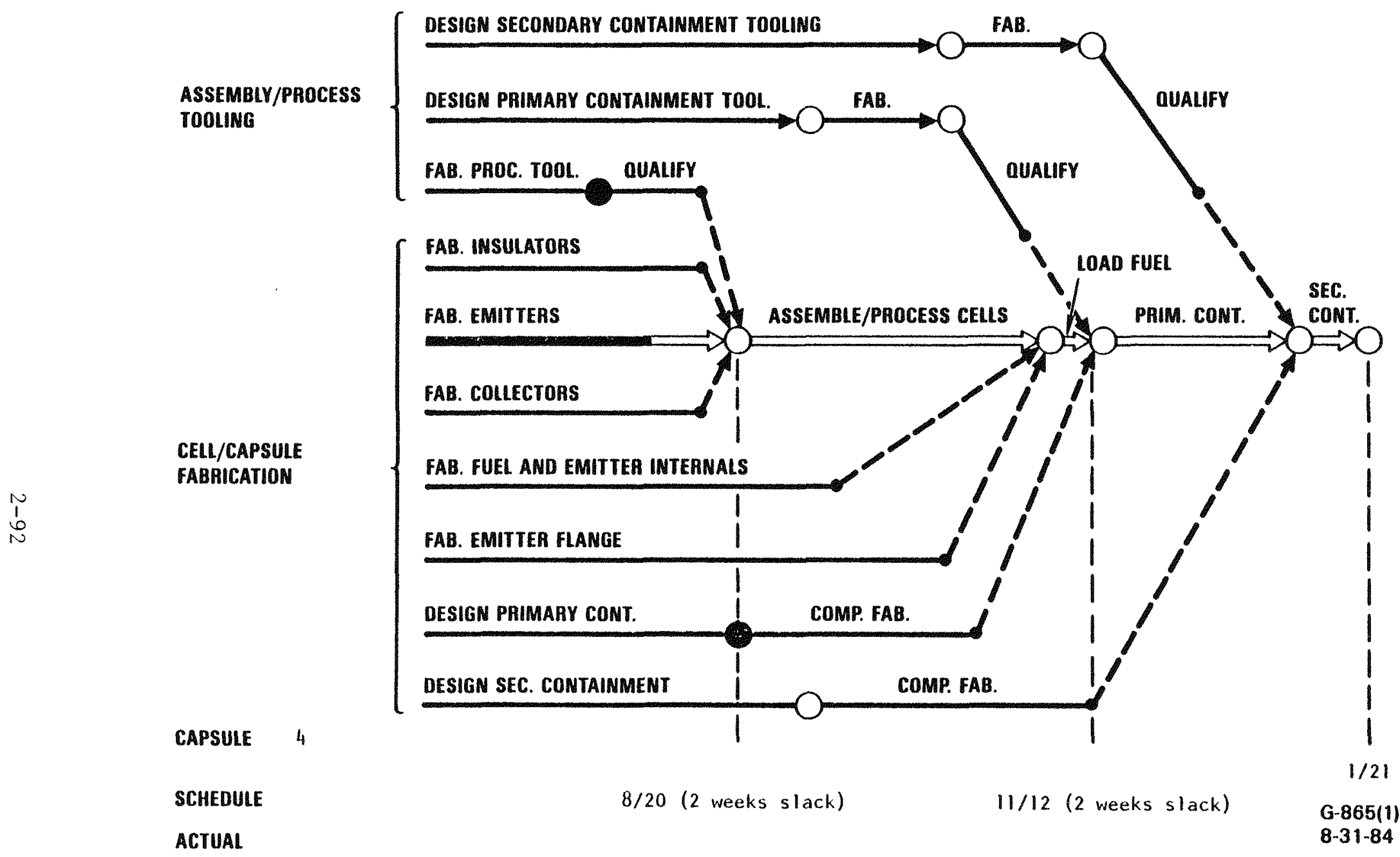

Fig. 2-44. CPM schedule for fueled emitter deformation capsule 4 
the second gap are changed to adjust the collector temperature. Thus, the essential instrumentation needed for operation includes the TRIGA reactor, $12 \mathrm{dc}$ driving supplies $(10 \mathrm{~V}, 500 \mathrm{~A})$ to establish the electron cooling for each emitter, 12 cesium reservoir heaters to establish the desired cesium pressures, and a secondary containment gas change system, which can be used with each of the four capsules. This instrumentation has been fabricated and is presently undergoing burn-in tests and calibration.

A number of measurements are made on the in-pile capsules. The data acquisitions system (DAS) monitors and maintains 62 separate temperatures, 22 gas and water pressures, and 12 thermionic device currents and voltages. The DAS also records reactor power, hour on-line for each capsule, and time of day. In all, it continuously collects 114 pieces of analog data. Panel-mounted meters display some of the pertinent information directly. A high-temperature meter relay sensor monitors one collector temperature in each capsule. Additional panel meters consist of four secondary gas pressures and 12 cesium reservoir temperature and heater currents.

The emitter temperature and input power of each device is inferred from its current-voltage characteristics. These data are obtained by rapidly $(0.2 \mathrm{~s})$ varying the current through the dc driving supply and the test device, while recording the current-voltage waveform with an oscilloscope. Other data that are recorded include the collector and cesium reservoir temperatures, as determined with chrome1-alumel thermocouples. To determine the amount of fission gas release, each fueled emitter has a separate fission gas trap, and the pressure in this trap is monitored with a pressure transducer. Three transducers and their power supplies have been obtained and are being calibrated. 
Three additional support systems are required:

1. The water flow system to cool the high-current bus bars.

2. A reactor scram system to shut down the reactor in case of a problem in certain areas. This scram system is complete and awaits only final tests following installation at GA.

3. The computerized DAS which acquires, analyzes, and stores al1 pertinent operating parameters on a 1 -min basis. The recorded data include reactor power level, fission gas trap pressure, collector and cesium reservoir temperatures, operating current and output voltage for each test device, secondary containment pressures, impending scram conditions, time of day, and elapsed time run. The system, based on a Hewlett Packard 9816 microcomputer, is complete and ready to run.

The complete instrumentation system, except for the DAS, is housed in nine separate racks, roughly $1.8 \mathrm{~m}$ (6 ft) tall, covering $3.7 \mathrm{~m}^{2}$ (40 $\mathrm{ft}^{2}$ ) (see Fig. 2-45). The entire instrumentation system, except for the DAS, is rack-mounted in eight cabinets $0.6 \mathrm{~m}(2 \mathrm{ft})$ wide, $0.76 \mathrm{~m}$ $(2-1 / 2 \mathrm{ft})$ deep, $1.8 \mathrm{~m}(6 \mathrm{ft})$ tall. This system combines several subsystems, as shown schematically in Fig. 2-46. The DAS monitors pressures, voltages, electrical current, and temperatures. Fabrication and assembly are now complete and undergoing final checkout and calibration. The scram and alarm capabilities provided are totally independent. Only three measurements can cause a scram situation generated by the converter/instrumentation system:

1. Excessively high primary containment temperatures, which can trigger any of four high-temperature meter relays.

2. Loss of bus bar water cooling, detected by a flowmeter optical sensor. 


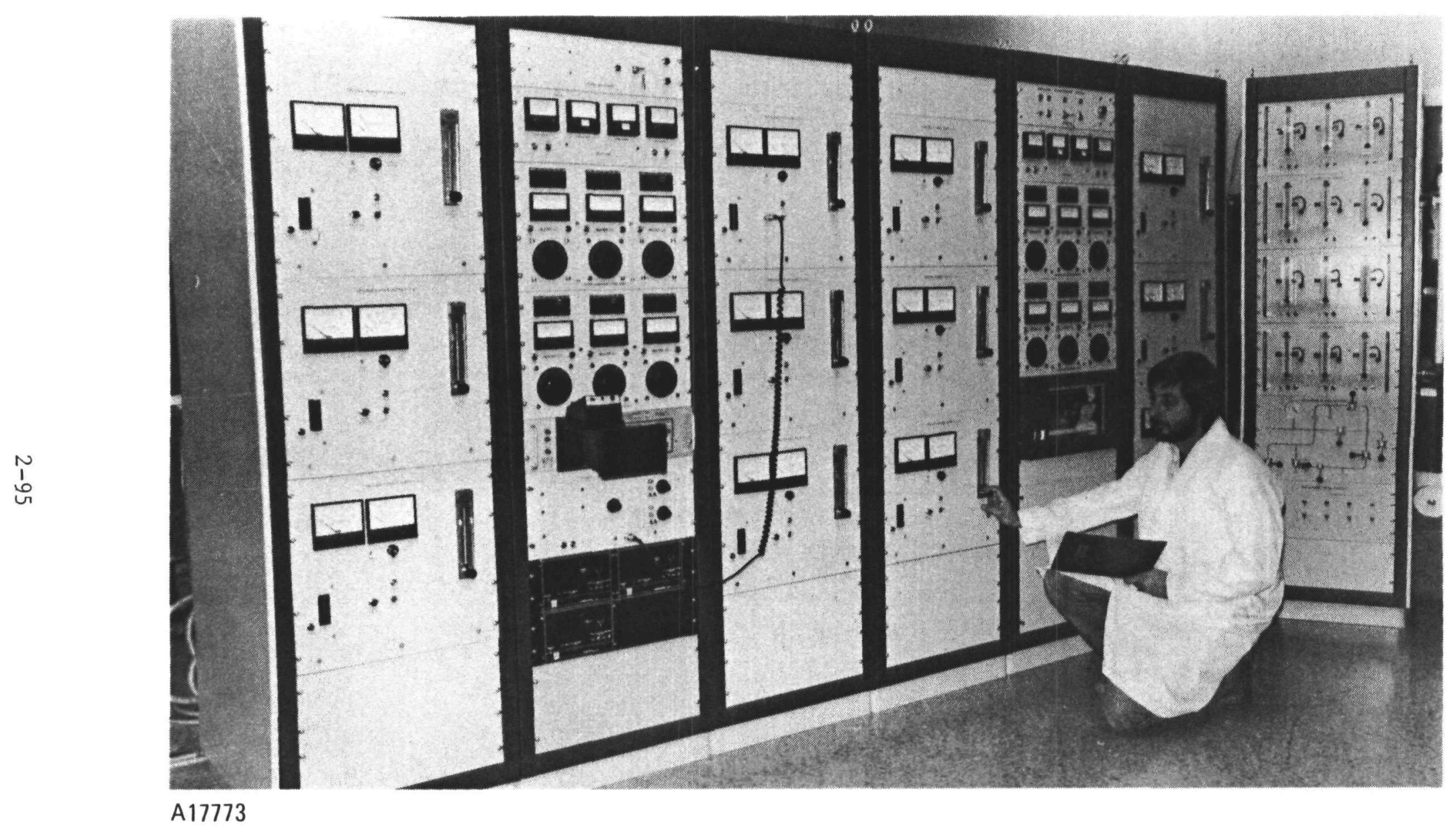

Fig. 2-45. Photograph showing instrumentation for the in-core fueled emitter capsule tests 


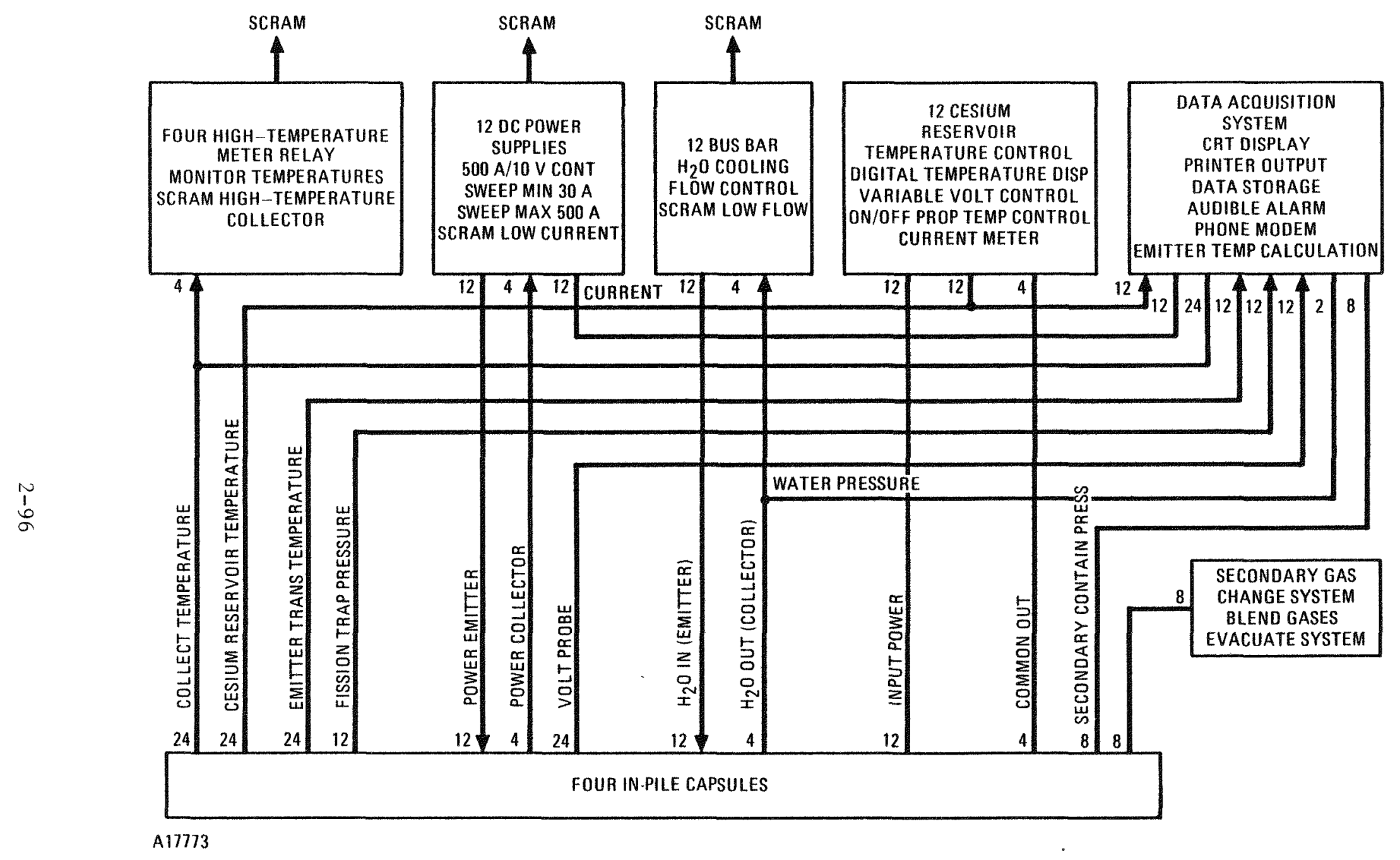

Fig, 2-46. Schematic of instrumentation system 
3. Low electrical current flow in a capsule, which can trigger a meter relay on the power supply.

The alarm system is independent of the scram system and has much broader capabilities because it is controlled by the microcomputer DAS. It can issue an alarm for the minimum or maximum value, except for water flow rate. An alarm condition will most likely precede an instrumentgenerated scram.

The instrument panel and the DAS are designed so that the scram and alarm levels can be varied. The values for both systems will be initially determined by out-of-pile tests (see Sections 5.1 and 5.4).

\subsubsection{Emitter Power Supply}

The emitter power supply is intended primarily to supply dc power to the converter and to provide voltage sweep capabilities so that the $J-V$ curves can be collected on each device. The system consists of the power supply unit and an adjustable resistance load. Current from the power supplies is carried to the capsule through an adjustable-resistance load (located near the power supplies in series with the cable), through the capsule bus bars, and back by power cables. A closed-loop water system cools the resistance 1oad. The power supply was designed for this specific application. It provides up to $500 \mathrm{~A}$ of regulated direct current at $10 \mathrm{~V}$ of continuous operation up to $8000 \mathrm{~h}$. In the sweep mode, it can provide up to $500 \mathrm{~A}$ and $20 \mathrm{~V}$ operation. The cycle sweep time is nominally $200 \mathrm{~ms}$.

Calibration of the power supply is now complete. Figures 2-47 and 2-48 present typical waveforms and show that the onset and termination of the sweep are completed before $200 \mathrm{~ms}$.

Adjustable resistance loads adjust the total resistance of the power supply circuit. Figure 2-49 shows the setup schematically. Resistance adjustments can only be performed under no-load conditions. The loads 


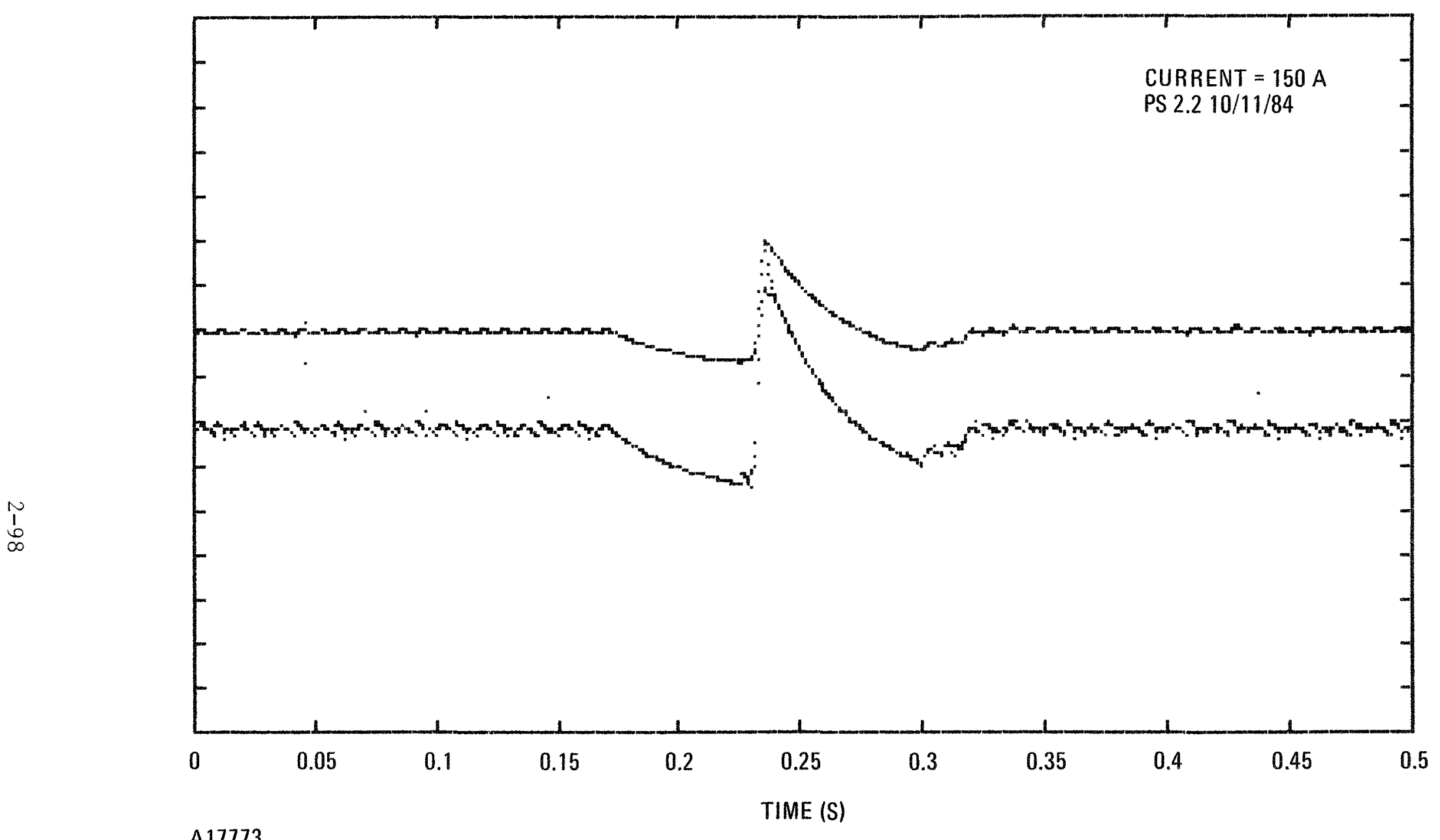

Fig. 2-47. Sweep waveform calibration at 150-A operating condition 


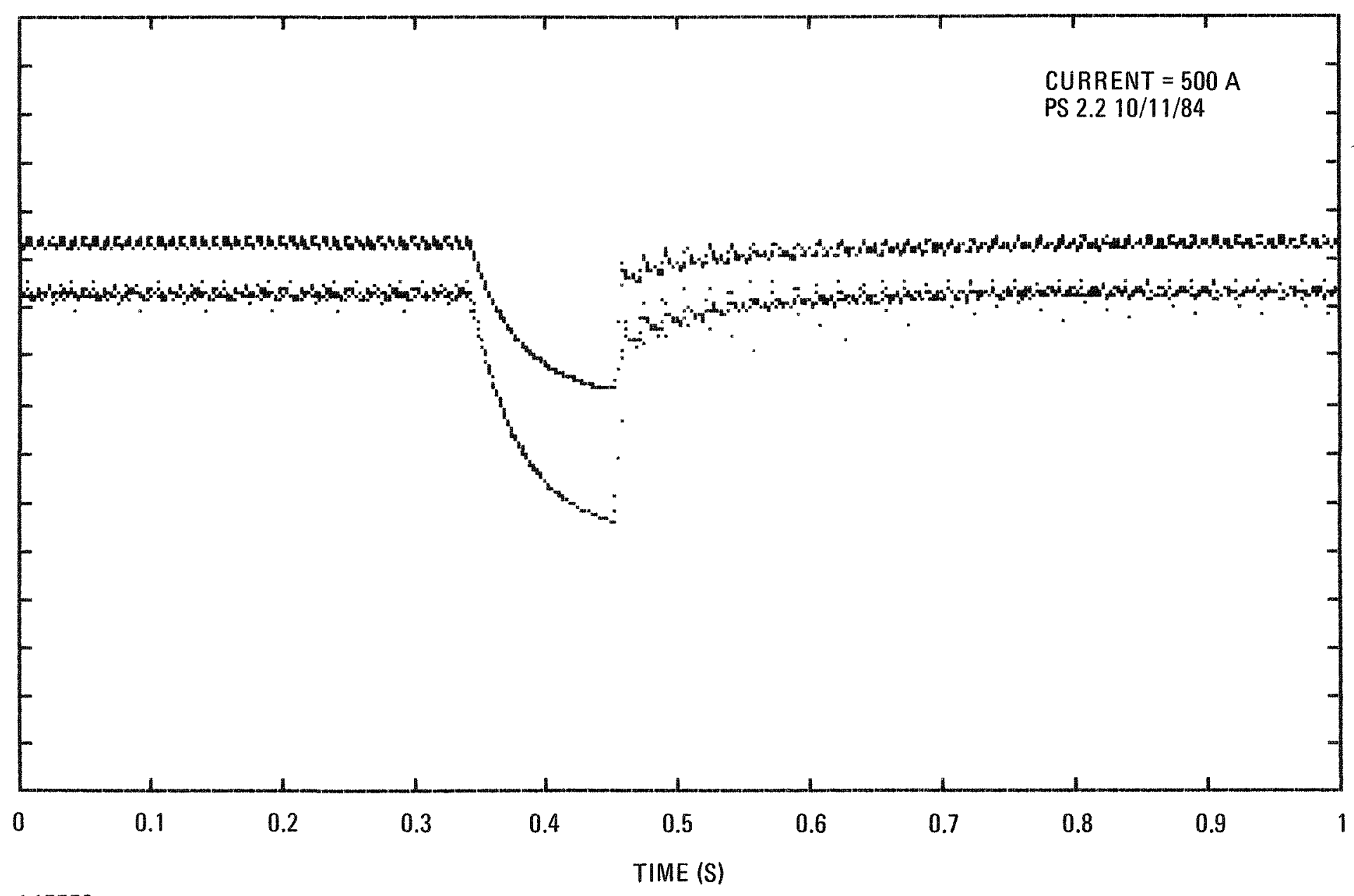

A17773

Fig. 2-48, Sweep waveform calibration at maximum operating condition of $500 \mathrm{~A}$ 


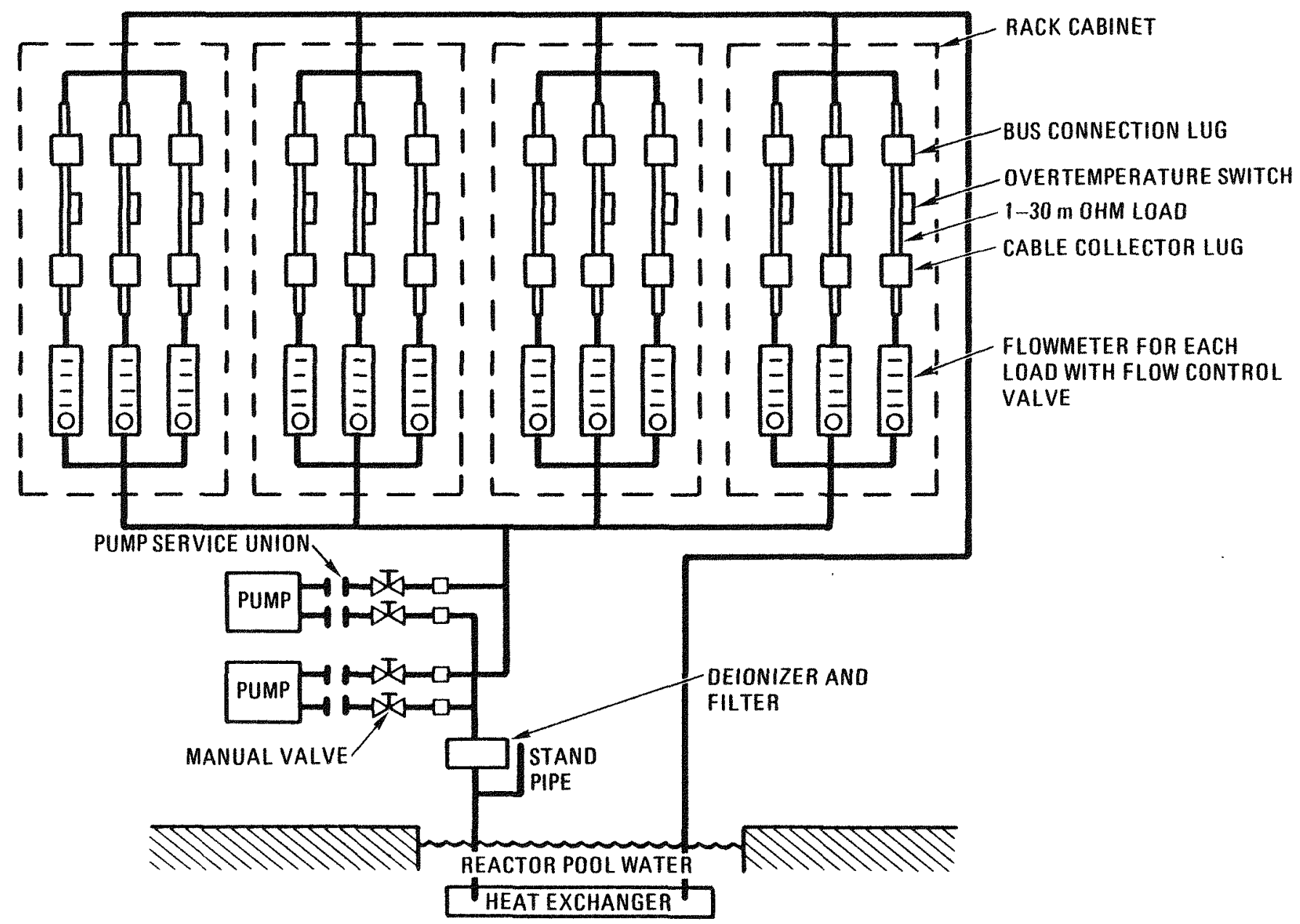

A17773

Fig. 2-49. Schematic of variable-resistance-load water cooling system 
are made from stainless-steel tubing connected to copper clamp blocks (two per tube). One block is connected to the power supply bus. The other block is used for power cable connection. Water is pumped through the stainless-steel tubes to cool them. Two pumps, operating in para1lel, provide the flow. Each pump can provide all of the required flow in case either fails. Water is pumped through the load, where it is heated, then into a heat exchanger, where it is cooled. The closed loop then returns to the pump. The heat exchanger is located in the reactor pool. A deionizer/filter continually cleans the water. Temperature switches mounted on the load tubes activate an alarm in the event of an overtemperature condition $\left(\mathrm{H}_{2} \mathrm{O}\right.$ temperature will not exceed $90^{\circ} \mathrm{C}$ ). Water flowmeters are mounted on the power supply front panels and connected to the system via nylon-braided, plastic hose.

\subsubsection{Bus Bar Cooling}

The capsule bus bars carry the electrical current from the test devices. Current levels are expected to be high (several hundred amps), and consequently, bus bar heating is required. The cooling is intended to remove this heat load. Due to the importance of this cooling, a scram situation can exist with the loss of flow.

Water-cooled bus bars have three inlets for each capsule (one for each device) and one common outlet (see Fig. 2-50). Flows are monitored for each device by panel meters, and each meter is equipped with an optical sensor that can activate a scram situation when the flow falls below the set point. The system is a closed-loop system, nearly identical to, but totally independent of, the load cooling system. It also has a double pump design.

\subsubsection{Cesium Reservoir Control}

The temperatures of each cesium reservoir are individually controlled by a time-proportional controller using a $\mathrm{K}$-type thermocouple monitor. Each reservoir heater is individually controlled to an accuracy 


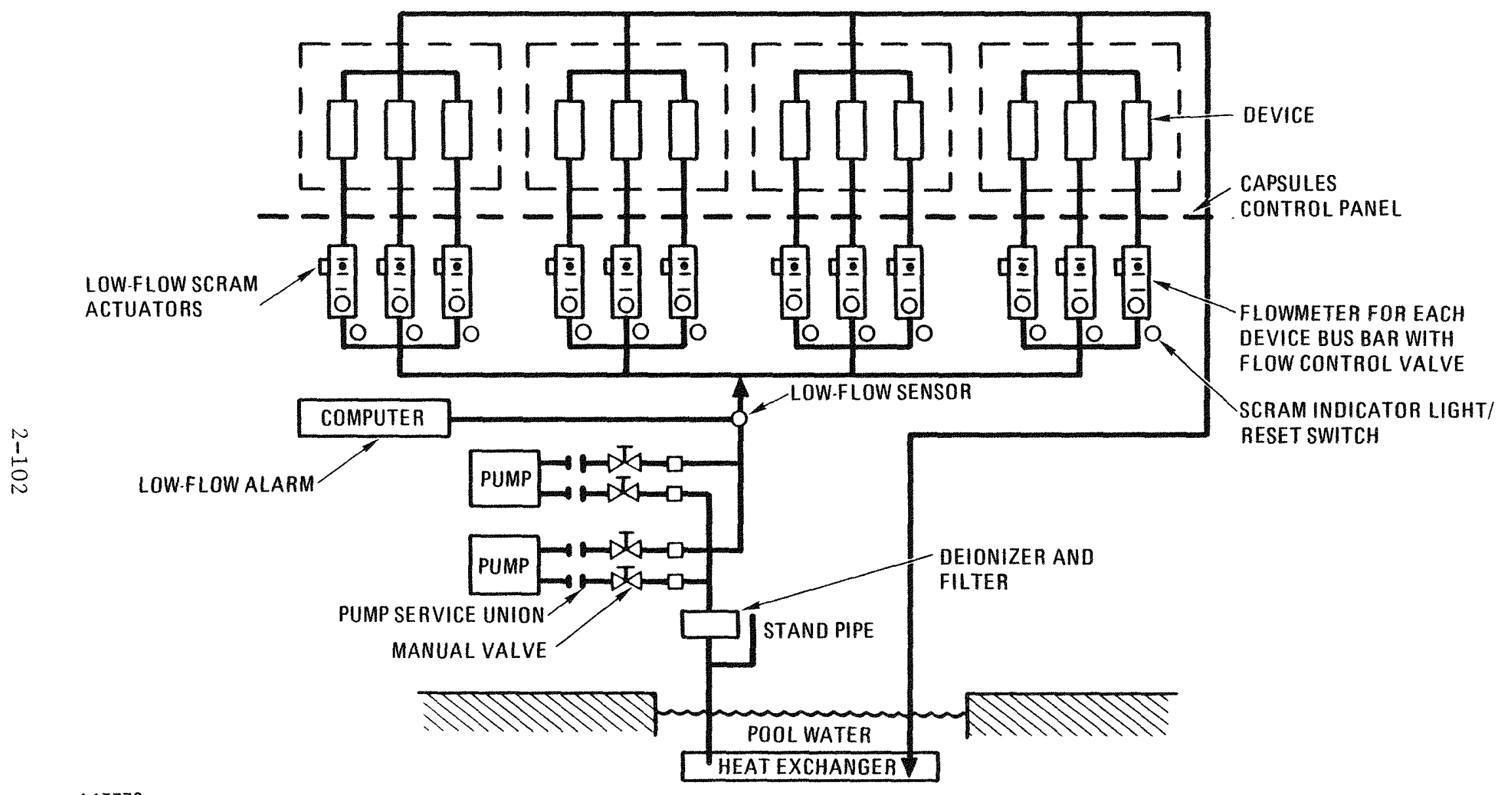

Fig. 2-50. Schematic of bus-bar water cooling system 
of $1^{\circ} \mathrm{C}$. This temperature is read out on a digital panel meter for each cesium heater assembly.

\subsubsection{Gas Exchange System}

The secondary gas exchange system, which partially establishes collector temperature, is intended to alter the heat transfer rate between the collector and the reactor pool water. A mixture of helium and/or argon is used for this purpose. The system is designed to use either gas or any mixture of the two. Figure 2-51 shows the system schematic. A vacuum pump removes the secondary containment gas, cleans it, and discharges it to the stack. The desired prepared mixture is obtained by repeatedly emptying and filling the capsule.

\subsubsection{Data Acquisition System}

The DAS is the major source of data collection. All 109 channels of data are input to a Hewlett Packard HP 3495 scanner. The scanner switches the analog data to a digital voltmeter sequentially. The scanner accepts thermistor, thermocouple, strain gauge, and voltage inputs. Figure 2-46 shows the sources of input to the DAS. The signals are digitized by a Keithley digital voltmeter. The heart of the system is a Hewlett Packard HP 9816 minicomputer, which accepts voltmeter data, processes the data, and stores the data in memory and on disk. A dual floppy disk drive and inkjet printer constitute the remainder of the DAS.

The computer has been programmed to convert each channel into usable form (temperature, pressure, etc.) and to examine the data from each channel for acceptability. If the data do not fall within acceptable levels, an alarm is generated. The alarm alerts the reactor operator with a blinking light and a printed meassage. It also creates an audible beep at the computer and causes the cathode ray tube (CRT) to blink the alarm message. 


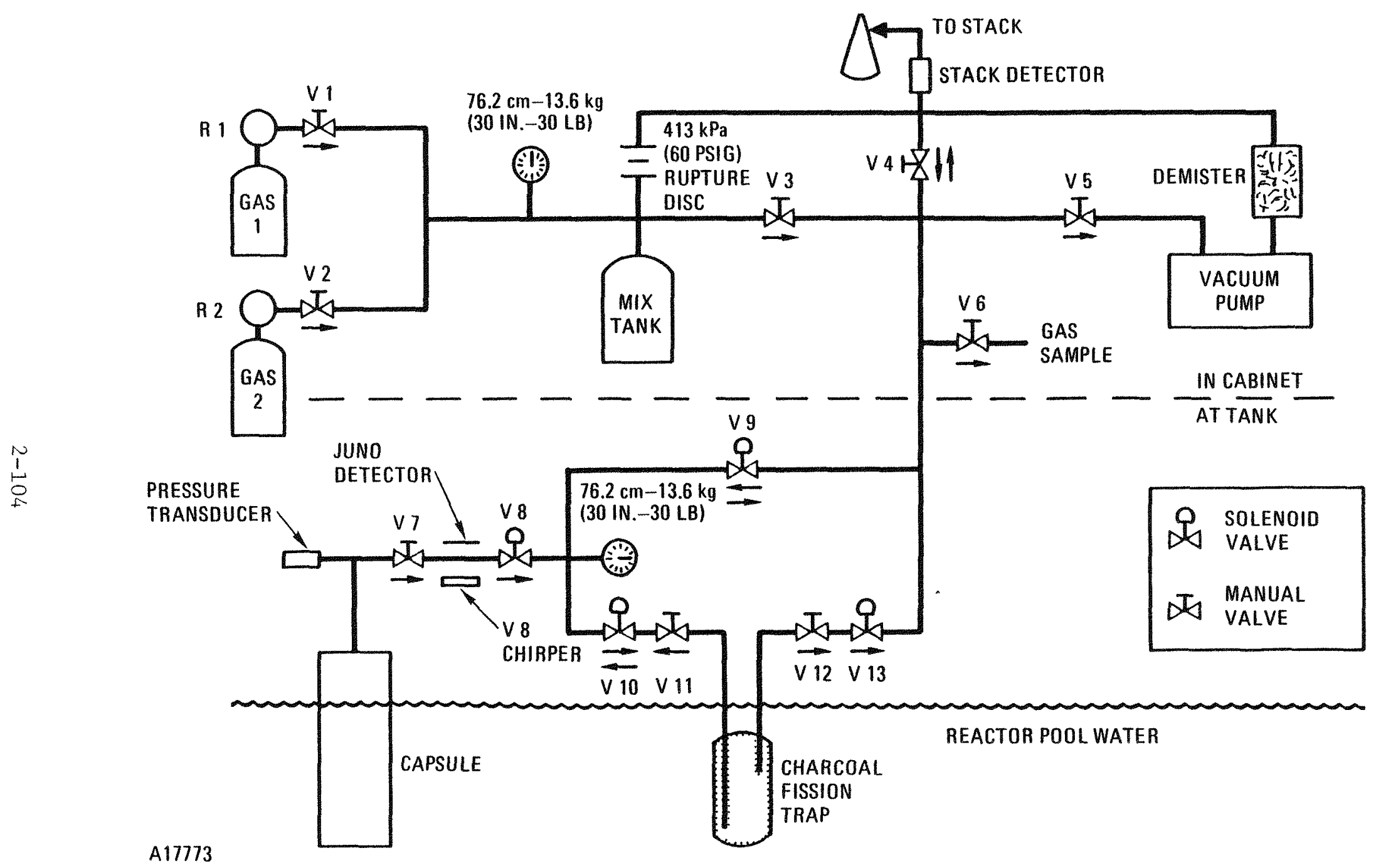

Fig. 2-51. Schematic of gas exchange system 
If the sample exceeds the preassigned value, it causes a highcondition alarm. Similarly, it can fall below the preassigned lower value to create a low-condition alarm. Table 2-21 presents alarm levels and other parameters monitored or generated by the computer. The values listed are tentative. In some instances, out-of-pile studies must be performed before these limits can be established.

\subsubsection{Scram Instrumentation}

A scram situation is where any one of three basic conditions exist to cause the reactor to shut down. The scram instrumentation senses abnormal conditions through meter relay switches mounted on the instrumentation cabinets. As mentioned before, the conditions that can cause a scram are (1) excessive primary temperature, (2) low dc current in any of the power supply, and (3) loss of bus bar water cooling, as indicated by low flow. Al1 scram circuitry is analog with continuous monitoring. All systems are designed fail safe.

\subsection{TEST REACTOR PREPARATION}

The fueled emitter capsules will be irradiated in the Mark F TRIGA reactor shown in Figs. 2-52 and 2-53. The reactor has special characteristics for testing thermionic emitters. These features include the following:

1. A nearly constant neutron source, made possible by the use of a burnable poison.

2. Shutdown required only once per year for reactor inspection, giving a $99 \%$ availability.

3. Neutron radiography for nondestructive measurements of fueled emitter geometries.

4. Simulation of the SP-100 fast neutron environment. 
TABLE 2-21

ALARM LEVELS FOR COMPUTER-MONITORED PARAMETERS

\begin{tabular}{|c|c|c|c|c|c|c|}
\hline Quantity & Description & High Alarm & Low Alarm & Input & Range & $\begin{array}{c}\text { Strip } \\
\text { Chart Span }\end{array}$ \\
\hline 1 & Reactor power & No & No & 0 to $1 \mathrm{~V}$ & $0.00 \mathrm{~mW}$ & $500 \mathrm{~kW}$ \\
\hline 24 & $\begin{array}{l}\text { Collector temperature } \\
\text { (display both readings) }\end{array}$ & $950^{\circ} \mathrm{C}$ & Burnout & $\mathrm{K}$ type & $40^{\circ} \mathrm{C}$ & $\begin{array}{l}300^{\circ} \mathrm{C} \\
\left(500^{\circ} \text { to } 800^{\circ} \mathrm{C}\right)\end{array}$ \\
\hline 24 & $\begin{array}{l}\text { Emitter transition temper- } \\
\text { ature (switch for } 3 \text { to MR) }\end{array}$ & $950^{\circ} \mathrm{C}$ & No & K type & $40^{\circ} \mathrm{C}$ & $300^{\circ} \mathrm{C}$ \\
\hline 12 & Current $\left(A / \mathrm{cm}^{2} \sim 50 \mathrm{~cm}^{2}\right)$ & $500 \mathrm{~A}$ & $\begin{array}{l}20 \text { A below } \\
\text { set }\end{array}$ & 0 to $50 \mathrm{mV}$ & $30 \mathrm{~A}$ & $50 \mathrm{~A}$ \\
\hline 2 & $\begin{array}{l}\text { Temperature } \mathrm{H}_{2} \mathrm{O} \text { at exit of } \\
\text { heat exchanger }\end{array}$ & $95^{\circ} \mathrm{C}$ & No & K type & $30^{\circ} \mathrm{C}$ & $50^{\circ} \mathrm{C}$ \\
\hline 1 & $\begin{array}{l}\text { Time day, month, year, } \\
\text { hour, minute, second }\end{array}$ & No & On startup & $\begin{array}{l}\text { Internal } \\
\text { clock }\end{array}$ & - & - \\
\hline 4 & Hours on line (capsule) & No & No & $\begin{array}{l}\text { Internal } \\
\text { clock }\end{array}$ & $50.0 \mathrm{~h}$ & - \\
\hline 114 & Total & & & & & \\
\hline
\end{tabular}




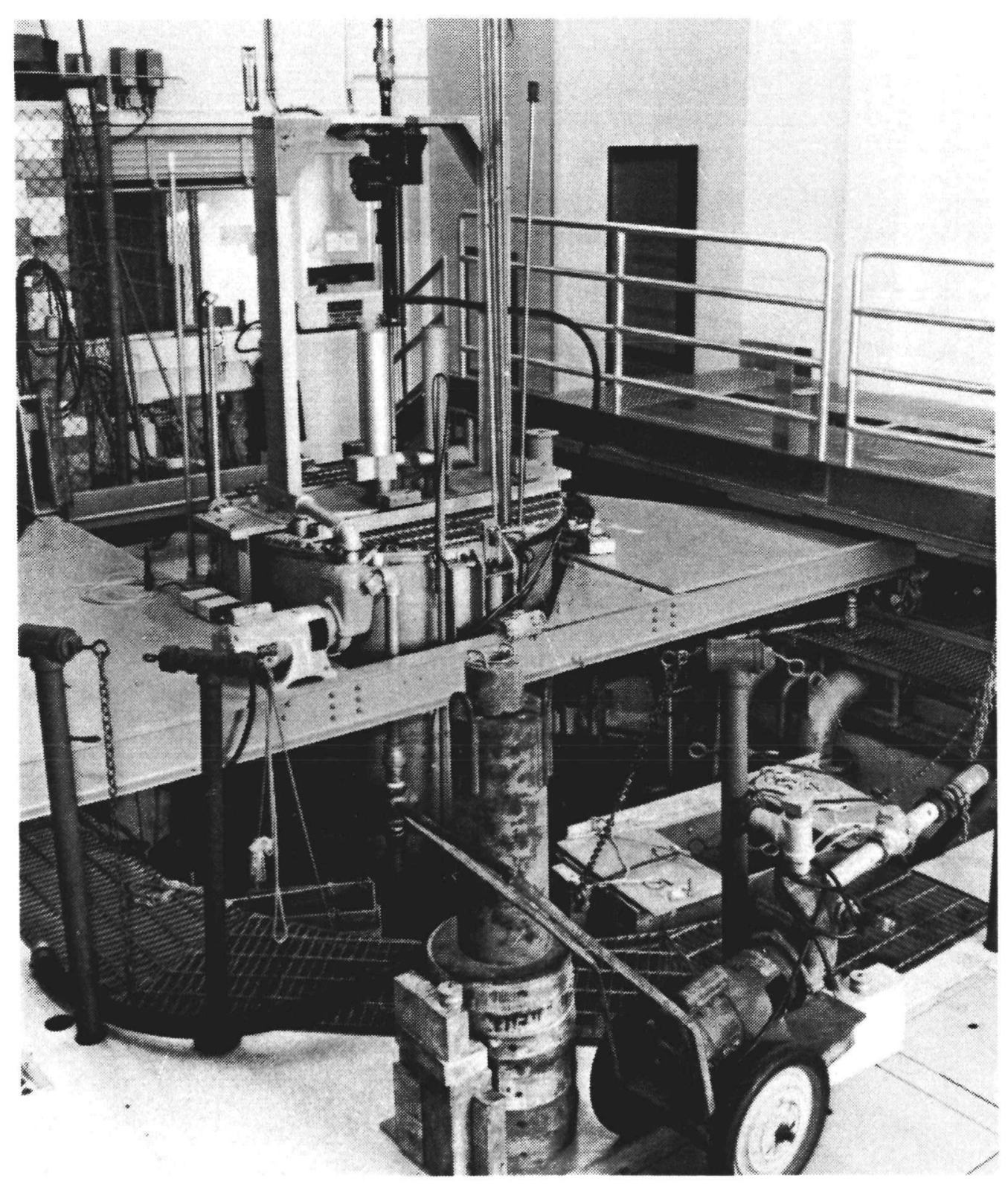

A17773

Fig. 2-52. Overview photo of TRIGA Mark F facility 

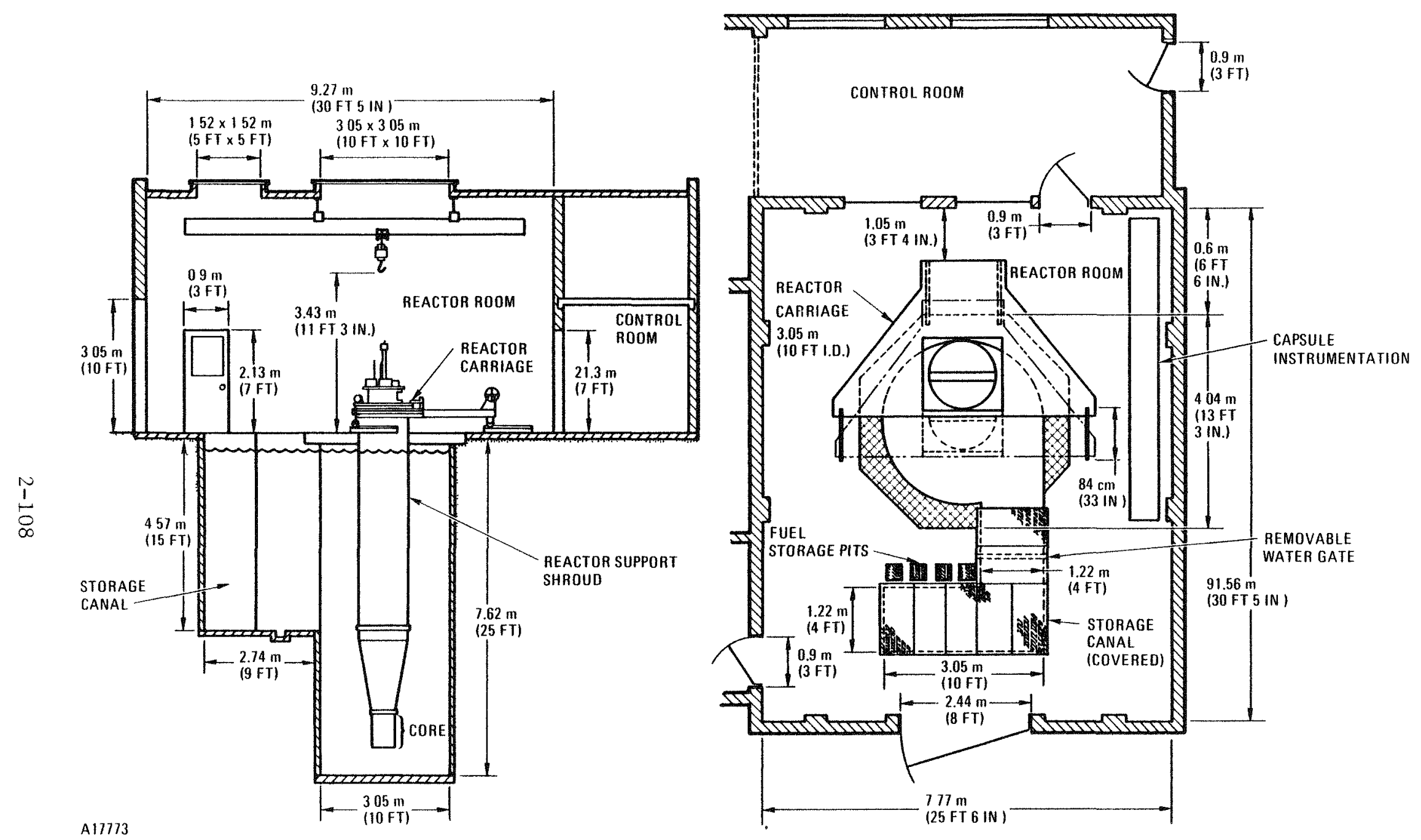

Fig. 2-53. Schematic of TRIGA Mark F faciljty 
The capsules will be located in the core positions indicated in Fig. 2-54. These locations take advantage of the special cutouts in the upper reactor grid plate to accommodate $5.8-\mathrm{cm}(2.3-\mathrm{in}$ ) diameter capsules.

The reactor will be operated at $1.5 \mathrm{MW}(t)$ to lower the enrichments in the thermionic fuel to on the order of $10 \%$. These low enrichments provide for high penetration of the thermal neutrons into the thermionic fue1, which simulates the flat power distribution in a fast reactor. At the 1.5-MW reactor power level, the fast neutron fluence $(>0.1 \mathrm{MeV})$ in the thermionic fuel is the same as the average fast fluence in the $\mathrm{SP}-100$ reactor. Hence, the materials fast neutron damage is also experienced in these tests.

Preparations for the TRIGA irradiations involved the following actions:

1. Train and license seven reactor operators to form a complement of 12 licensed operators at GA for the continuous operations.

2. Receive a license amendment to allow operation of four capsules.

3. Install a new 2-MW-capacity reactor heat removal system.

4. Modify reactor bridge, control rod support structure, core grid plates, and shroud to facilitate capsule testing.

5. Modify control console.

6. Install a two-channel recorder to measure reactor power.

7. Install in-core flux monitoring.

8. Update stack monitoring system. 


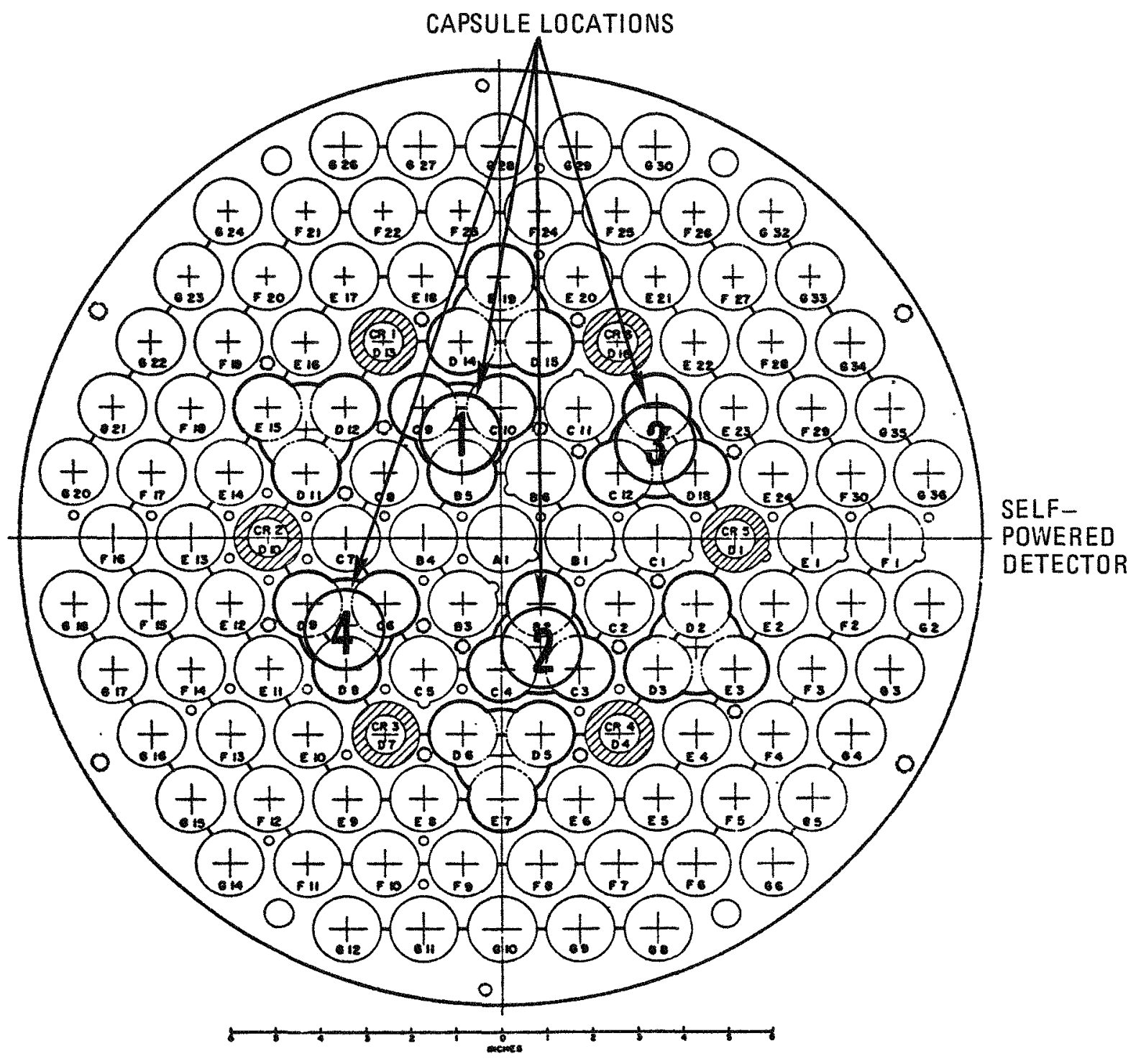

TRIGA FLIP CORE TOP GRID PLATE

A17773

Fig. 2-54. Core configuration 
9. Modify electronics for radiation monitoring.

10. Upgrade water treatment system.

11. Upgrade room ventilation system.

12. Install uninterruptable power supply to prevent reactor scrams from momentary power outages.

13. Build platform for instrumentation.

14. Build temperature-controlled room for computer DAS.

15. Install power for thermionic operations.

16. Install bottled gas supply for operations.

17. Upgrade neutron radiography unit to include etch track capability.

\subsection{REFERENCES}

2-1. "LIFE-4 (Rev. 0) Users and Programmers Manua1," Westinghouse Corporation Report WARD-0X-94000-12, v. 1 and 2.

2-2. "Final Summary Report - Thermionic Reactor Space Power System," DOE Report GA-A12608, June 30, 1973.

2-3. Zimmermann, $H_{\bullet}$, "Investigation on Swelling and Fission Gas Behavior in Oxide Fuels Under Neutron Irradiation," Kernforschungs Karlsruhe Report KFK 2467, June 1977.

2-4. Keller, D. L., "Progress in Development of Fuels and Technology for Advanced Reactors," Battelle Memorial Institute Report BMI 1886, July 1970.

2-5. Burton, B., "Diffusional Creep of Polycrystalline Materials," Trans Tech Publications, Bay Village, Ohio, 1977. 
2-6. Hu11, D., and D. E. Rimmer, "The Growth of Grain-Boundary Voids Under Stess," Phil. Mag. 4, 673-687 (1959).

2-7. Harris, J. E., M. O. Tucker, and G. W. Greenwood, "The Diffusional Creep Strain Due to the Growth of Intergranular Voids," J. Met. Sci. 8, 311-314 (1974).

2-8. Boonstra, R., "TAC2D - A General Purpose Two-Dimensional Heat Transfer Computer Code," GA Report GA-A14032, July 15, 1976.

2-9. Gietzen, A. J., "CPOP - A Program for Thermionic Converter Performance Analysis and Optimization," GA Report GA-8873, April 30, 1969.

2-10. Hackney, M. R., "Nuclear Analysis of Experiment 6F1 for Irradiation in a TRIGA FLIP Reactor," GA unpublished data, January 20, 1970.

2-11. Walti, P., and P. Koch, "MICROX - A Two Region Flux Spectrum Code for the Efficient Calculation of Group Cross Sections," GA Report GA-A10827, Apri1 1972.

2-12. Archibald, R., K. Lathrop, and D. Mathews," DTFX - A Revised Version of the IDF (DTF-IV) $S_{N}$ Transport Theory Code," GA Report GA-B10820, September 27, 1971.

2-13. Lathrop, K., "TWOTRAN, A FORTRAN Program for Two-Dimensional Transport," GA Report GA-8747, July 22, 1968. 


\section{METAL-CERAMIC SEAL}

\subsection{TASK OBJECTIVES/APPROACH/REQUIREMENTS}

\subsubsection{Insulator Seal Functional Requirements}

The metal-ceramic seal in the reference thermionic reactor design is intended to provide a hermetic seal between the cesium and fission gas spaces in individual converters within a TFE. The seal must electrically isolate and physically separate the emitter from the collector. Those types of seals are considered for SP-100 applications (see Fig. 3-1). The taper seal design with $\mathrm{Al}_{2} \mathrm{O}$ was used in previous TFE tests. The butt and multilayer designs yield a smaller intercell void space in the TFE. The pentalayer seal is a cermet structure that may act as both seal and sheath insulator.

\subsubsection{Seal Operational Requirements}

The operational requirements for the metal ceramic seals include the ability to fulfill these functions for the full seven-year $(61,320-h)$ design lifetime of the reactor while operating at a peak temperature of $1230 \mathrm{~K}$ in cesium vapor ( 1 torr) with a peak steady-state applied voltage near $0.6 \mathrm{~V}$. The most severe requirement is to achieve these conditions while exposed to a total fast neutron fluence of up to $1.7 \times 10^{22} \mathrm{n} / \mathrm{cm}^{2}$ (E $>0.1 \mathrm{MeV})$. Table $3-1$ summarizes these requirements.

\subsubsection{Candidate Materials for the Seal}

For the seal insulator, the primary concerns are radiation effects and cesium compatibility, both of which are controlled by materials selection. Crystal structure can also influence the extent of radiation damage through preferential nucleation of defect clusters. Typically, 


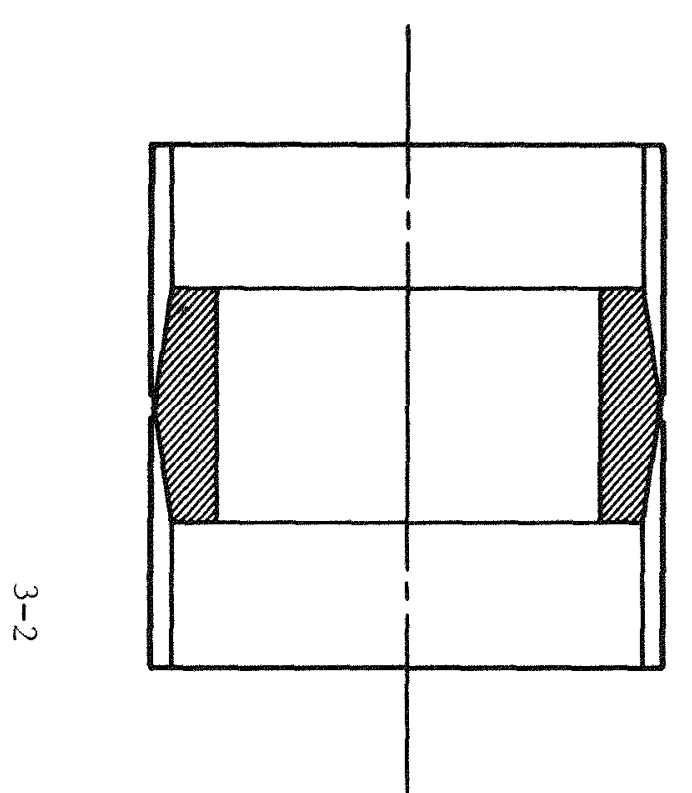

TAPER

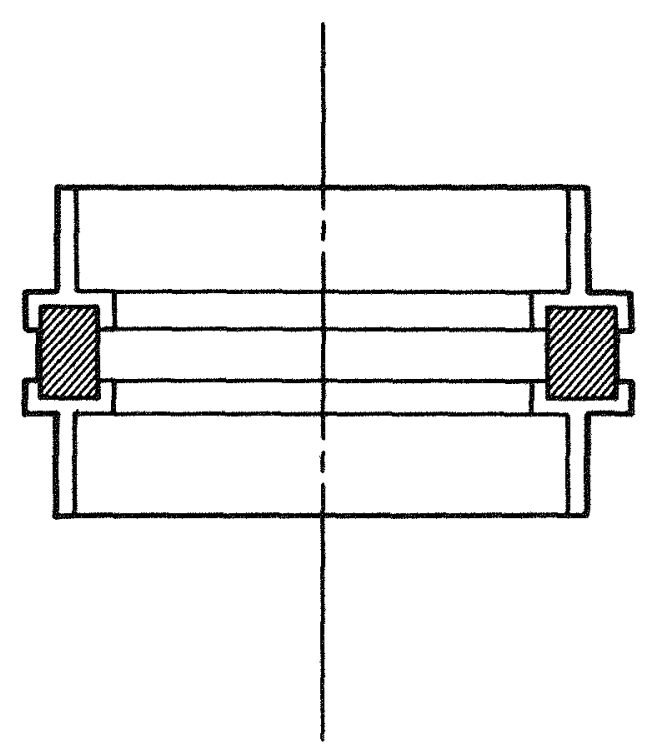

BUTT

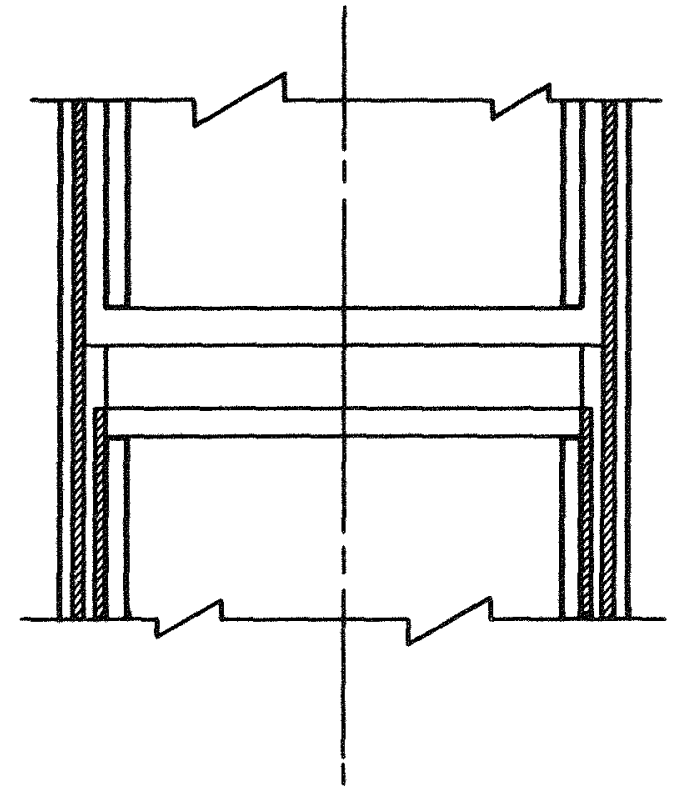

MULTILAYER

A17773

Fig. 3-1. Metal-ceramic seal designs 
TABLE 3-1

SP-100 THERMIONIC REACTOR SEAL-INSULATOR

OPERATING REQUIREMENTS

\begin{tabular}{ll}
\hline & \multicolumn{1}{c}{ Range } \\
\hline Metal-ceramic seal & \\
Neutron fluence, $\mathrm{n} / \mathrm{cm}^{2}(>0.1 \mathrm{MeV})$ & Maximum $1.7 \times 10^{22}$ \\
Potential, $\mathrm{V}$ & Average $1.0 \times 10^{22}$ \\
& Maximum 0.6 \\
Temperature, $\mathrm{K}$ & Average 0.6 \\
& Maximum 1230 \\
Cesium environment, tor & Average 1180 \\
& Normal $\mathrm{i}$ \\
\hline
\end{tabular}


defect clusters, such as dislocation loops, form selectively on certain crystallographic planes, causing preferential dimensional change, expansion for interstitial dislocation loops, and contraction for vacancy loops. In an anisotropic crystal structure, this can result in substantial differential dimensional changes in different crystallographic directions. This is important for sapphire $\left(\mathrm{Al}_{2} \mathrm{O}_{3}\right)$. Polycrystalline anisotropic materials have been observed to separate at grain boundaries due to radiation-induced, anisotropic dimensional changes. This can result in loss of leak tightness, which is a particular concern for the insulator sea1. Cubic structure ceramics perform much better in this respect.

Radiation damage studies have resulted in the ranking according to volumetric swelling shown in Table 3-2. Table 3-2 shows that materials with anisotropic crystal structures, such as $\mathrm{Al}_{2} \mathrm{O}_{3}$ and $\mathrm{BeO}$, exhibit the largest dimensional changes, while the complex-structure mixed-oxide materials, such as $\mathrm{MgAl}_{2} \mathrm{O}_{4}$ and $\mathrm{Y}_{3} \mathrm{Al}_{5} \mathrm{O}_{12}$, exhibit the smallest dimensional change. The covalently bonded ceramics also tend to be quite resistant to radiation damage. Yttria and YAG have been selected as prime candidates for the seal insulators, based on electrical properties and compatibility with the TFE environment. More radiation stable forms of $\mathrm{Al}_{2} \mathrm{O}_{3}$ are also candidates for the seal insulator.

\subsubsection{Objectives for Insulator Seal Tests}

The cesium compatibility of selected ceramics will be established in accelerated tests at higher-than-design temperatures and cesium pressures. Life-limiting degradation processes will be assessed analytically and life projections made for the selected design. For example, stress calculations for the seal designs will be performed to ensure that neutron-induced swelling of the ceramic can be accommodated by elastic deformation of the metal parts. Fabrication technology of ceramics is well known. However, its ability to produce the required geometrical and physical characteristics in candidate materials must be demonstrated. 
TABLE 3-2

RANKING OF CERAMIC INSULATOR MATERIALS BY MAGNITUDE OF RADIATION-INDUCED DIMENSIONAL CHANGE

\begin{tabular}{cl}
$\begin{array}{c}\text { Volumetric } \\
\text { Swelling Range (a) } \\
(\%)\end{array}$ & \multicolumn{1}{c}{ Insulator Material } \\
\hline 3 to 10 & $\mathrm{Al}_{2} \mathrm{O}_{3}, \mathrm{BeO}$ \\
0.5 to 1.5 & $\mathrm{Si}_{3} \mathrm{~N}_{4}, \mathrm{Y}_{2} \mathrm{O}_{3}, \mathrm{Y}_{2} \mathrm{O}_{3}-1 \% \mathrm{ZrO}_{2}$ \\
$<0.5$ & $\mathrm{MgAl}_{2} \mathrm{O}_{4}, \mathrm{Y}_{3} \mathrm{Al}_{5} \mathrm{O}_{12}, \mathrm{Si}_{2} \mathrm{ON}_{2}, \mathrm{Si}_{4} \mathrm{Al}_{2} \mathrm{O}_{2} \mathrm{~N}_{6}-5 \% \mathrm{Y}_{2} \mathrm{O}_{3}$ \\
\hline
\end{tabular}

(a) Irradiation to 1 to $2 \times 10^{22} \mathrm{n} / \mathrm{cm}^{2}$ at 925 to $1100 \mathrm{~K}$. 


\subsection{FABRICATION DEVELOPMENT}

\subsubsection{Solid-Body Ceramics}

Single-crystal $\mathrm{Al}_{2} \mathrm{O}_{3}$, single-crystal $\mathrm{XAG}$, and polycrystal $\mathrm{Y}_{2} \mathrm{O}_{3}$ were selected as ceramic candidates for the fabrication development and testing of solid-body metal-ceramic seals. Two sources of single-crystal $\mathrm{Al}_{2} \mathrm{O}_{3}$ were contacted: (1) Crystal Systems of Salem, Massachusetts, and (2) Kyocera of America. Samples from both companies were received." Samples from Crystal Systems were sent to RA for further evaluation. Single-crystal $\mathrm{Y}_{3} \mathrm{Al}_{5} \mathrm{O}_{12}$ was purchased from ICT, Inc. of Shelby, Michigan, and sent to RA.

No source of high-purity, high-density $\mathrm{Y}_{2} \mathrm{O}_{3}$ was commercially found. To obtain suitable $\mathrm{Y}_{2} \mathrm{O}_{3}$, GA purchased high-purity $\mathrm{Y}_{2} \mathrm{O}_{3}$ powder from Moly Corporation and is now examining processes for fabricating high-purity, high-density $\mathrm{Y}_{2} \mathrm{O}_{3}$ bodies.

One process tried was cold pressing powder with a stearic acid binder at $344.7 \mathrm{MPa}(50,000 \mathrm{psi})$, then sintering at $2 \times 10^{-5}$ torr for 30 min at $1600^{\circ} \mathrm{C}$. The ceramic fabricated this way (Fig. 3-2) had large and small porosity uniformly distributed throughout the sample.

An improvement in the quality of the sintered $\mathrm{Y}_{2} \mathrm{O}_{3}$ resulted from hot pressing trials. Hot pressing was done with high-purity $\mathrm{Y}_{2} \mathrm{O}_{3}$ powder at 15.2 to $53.1 \mathrm{MPa}$ (2200 to $7700 \mathrm{psi}$ ) from $1600^{\circ}$ to $1800^{\circ} \mathrm{C}$ for 0.5 to $2 \mathrm{~h}$. Several of the resulting $\mathrm{Y}_{2} \mathrm{O}_{3}$ ceramics (Fig. 3-3) had very few pores and were qualitatively equivalent to high-density $\mathrm{Al}_{2} \mathrm{O}_{3}$ in appearance and resistance to mechanical stress damage. Six of these samples were sent to RA for further evaluation. Table 3-3 shows the process conditions used in the preparation of these ceramics. 


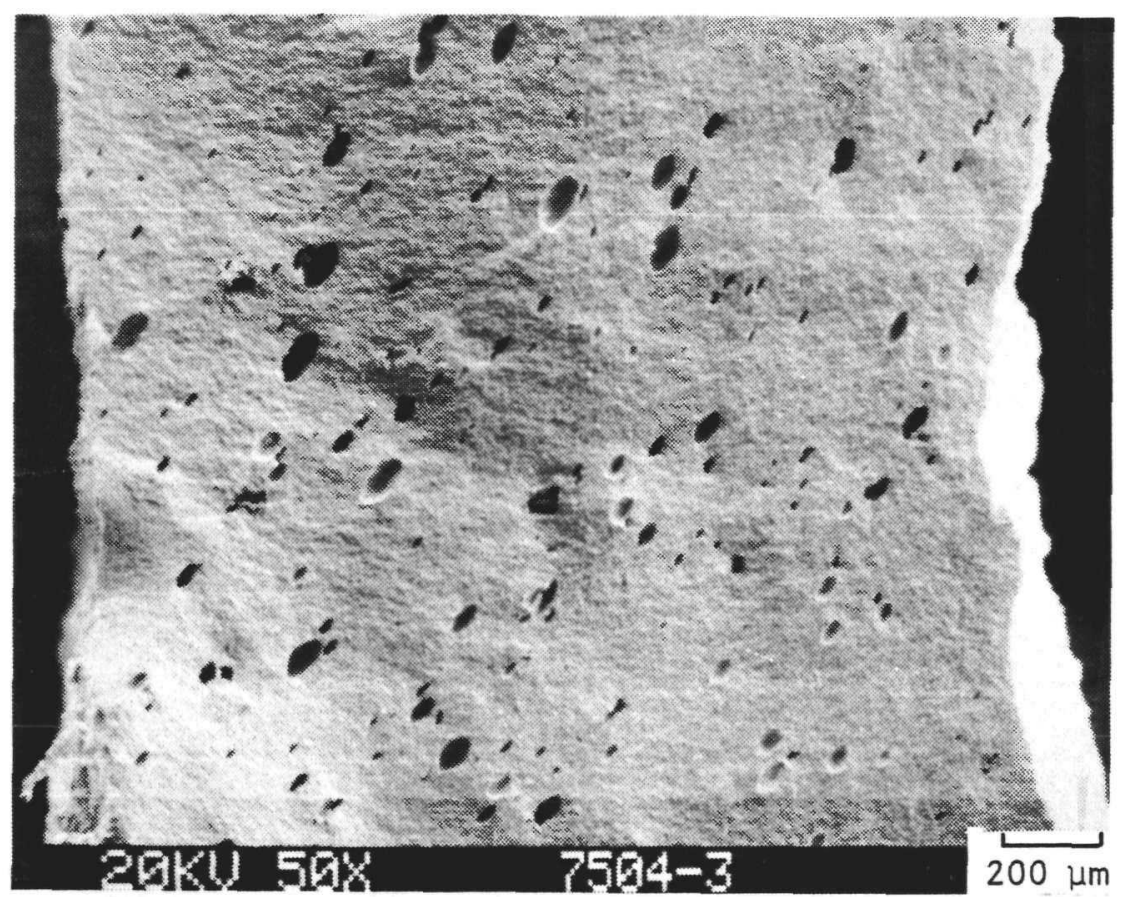

(a)

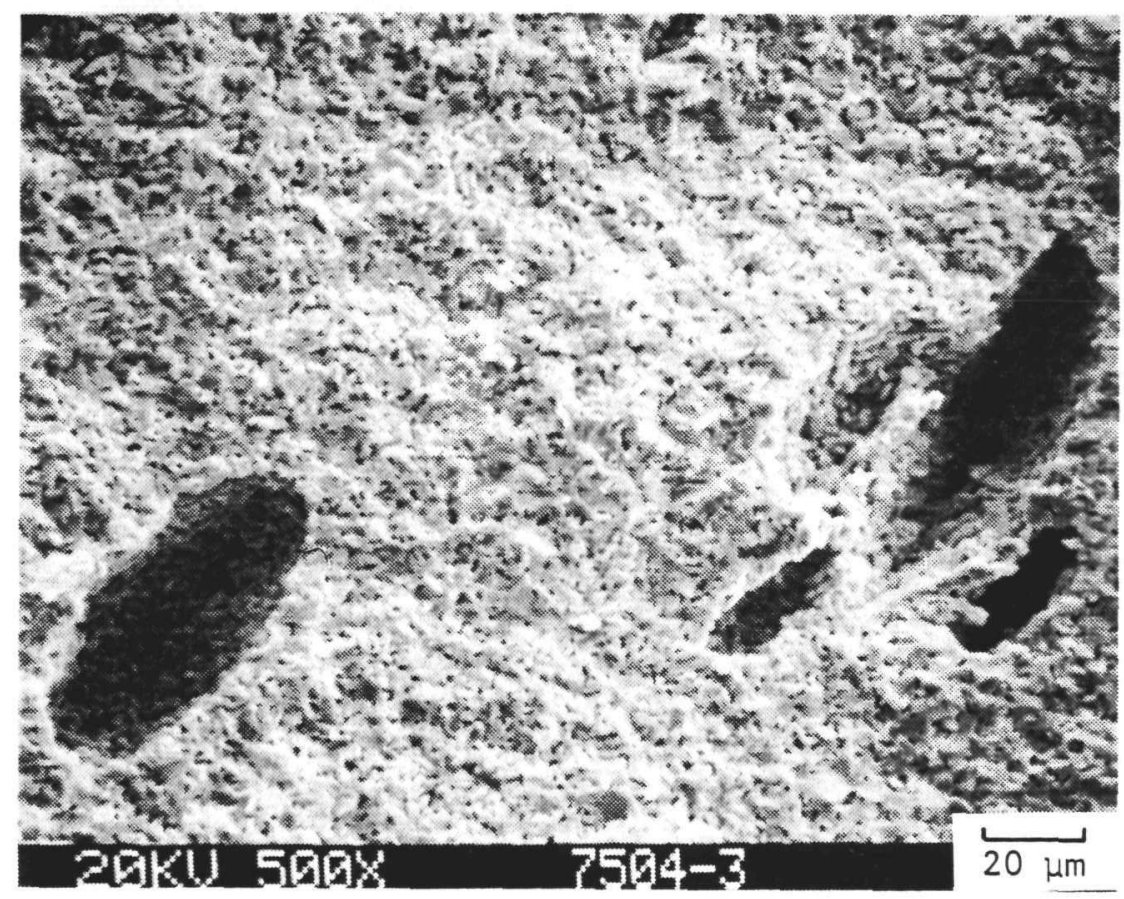

A17773

(b)

Fig. 3-2. Scanning electron microscopy photomicrographs of a fractured section of $\mathrm{Y}_{2} \mathrm{O}_{3}$ cold pressed at $344.7 \mathrm{MPa}$ (50 ksi), then sintered for $30 \mathrm{~min}$ at $1600^{\circ} \mathrm{C}$ : (a) $50 \mathrm{X}$, (b) $500 \mathrm{X}$ (sheet 1 of 2) 


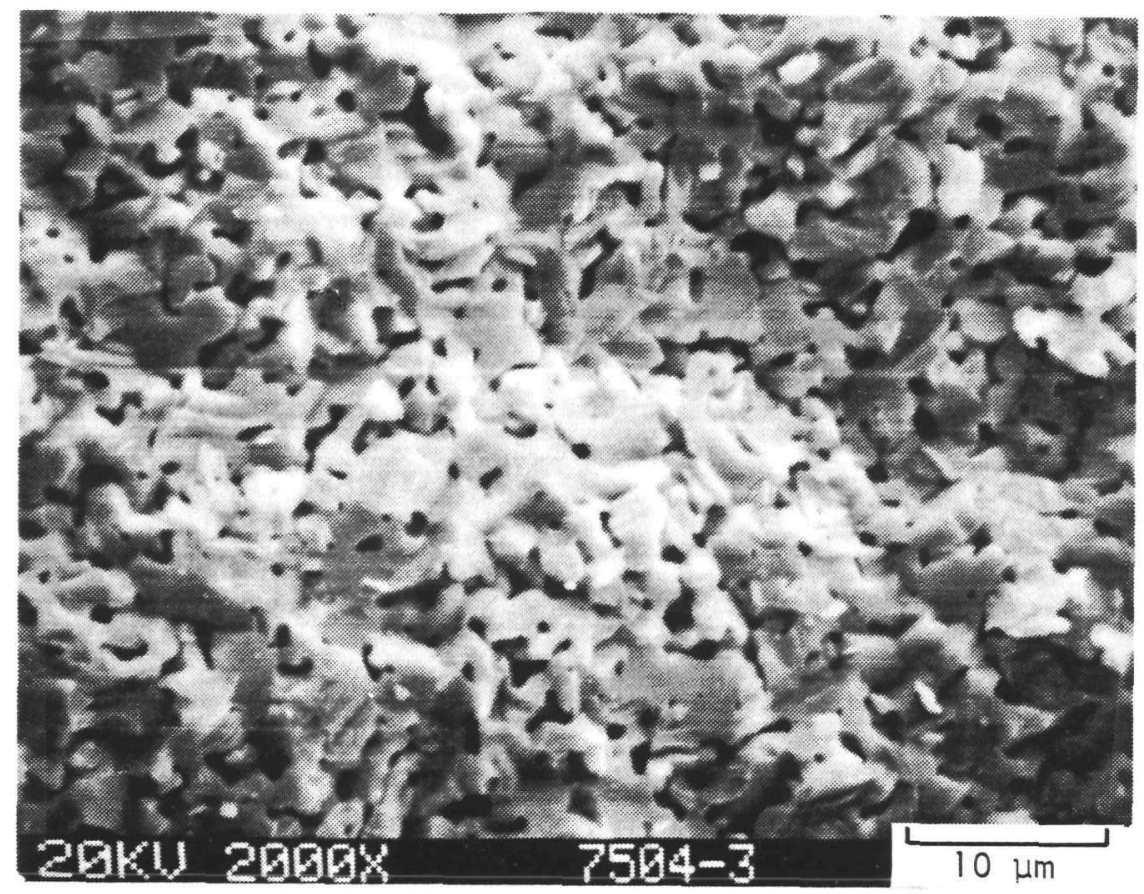

A17773

(c)

Fig. 3-2. Scanning electron microscopy photomicrographs of a fractured section of $\mathrm{Y}_{2} \mathrm{O}_{3}$ cold pressed at $344.7 \mathrm{MPa}$ (50 ksi), then sintered for $30 \mathrm{~min}$ at $1600^{\circ} \mathrm{C}$ : (c) $2000 \mathrm{X}$ (sheet 2 of 2) 


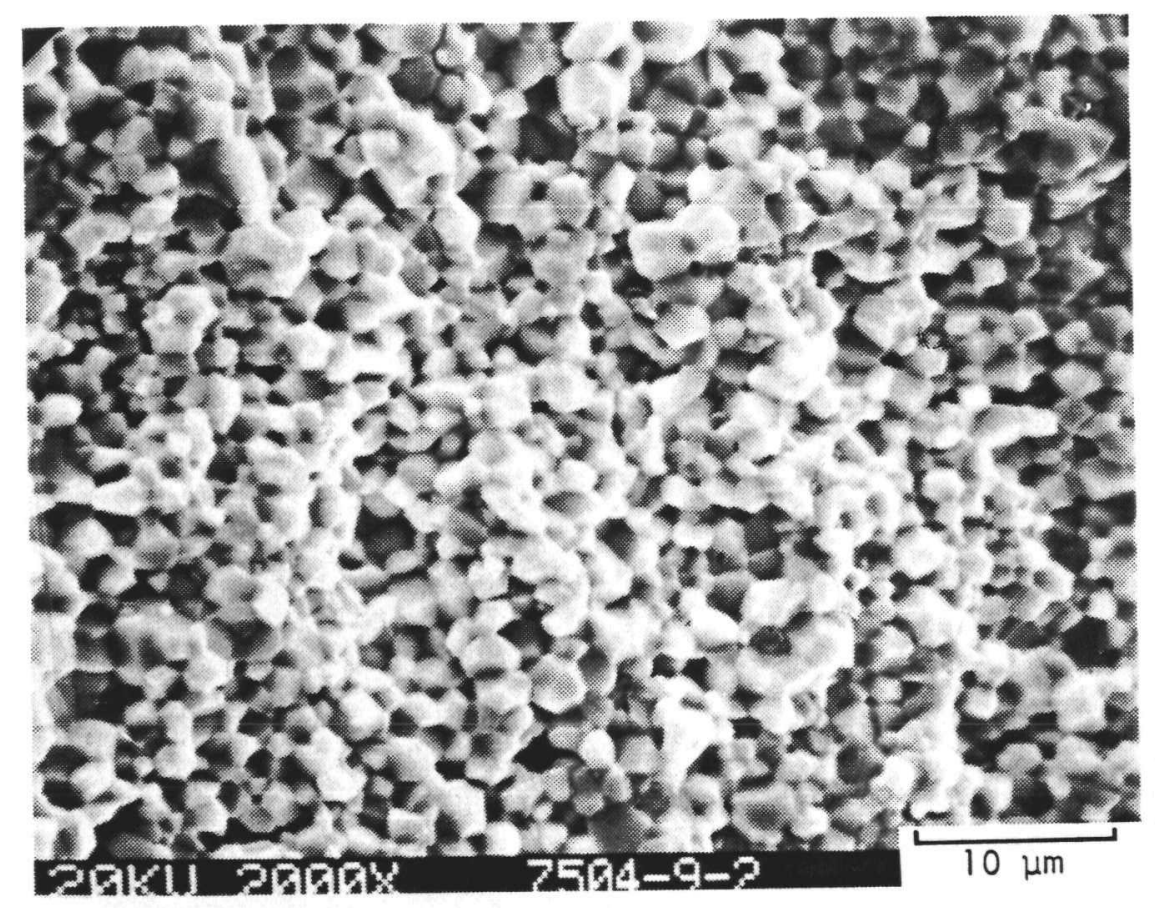

(a)

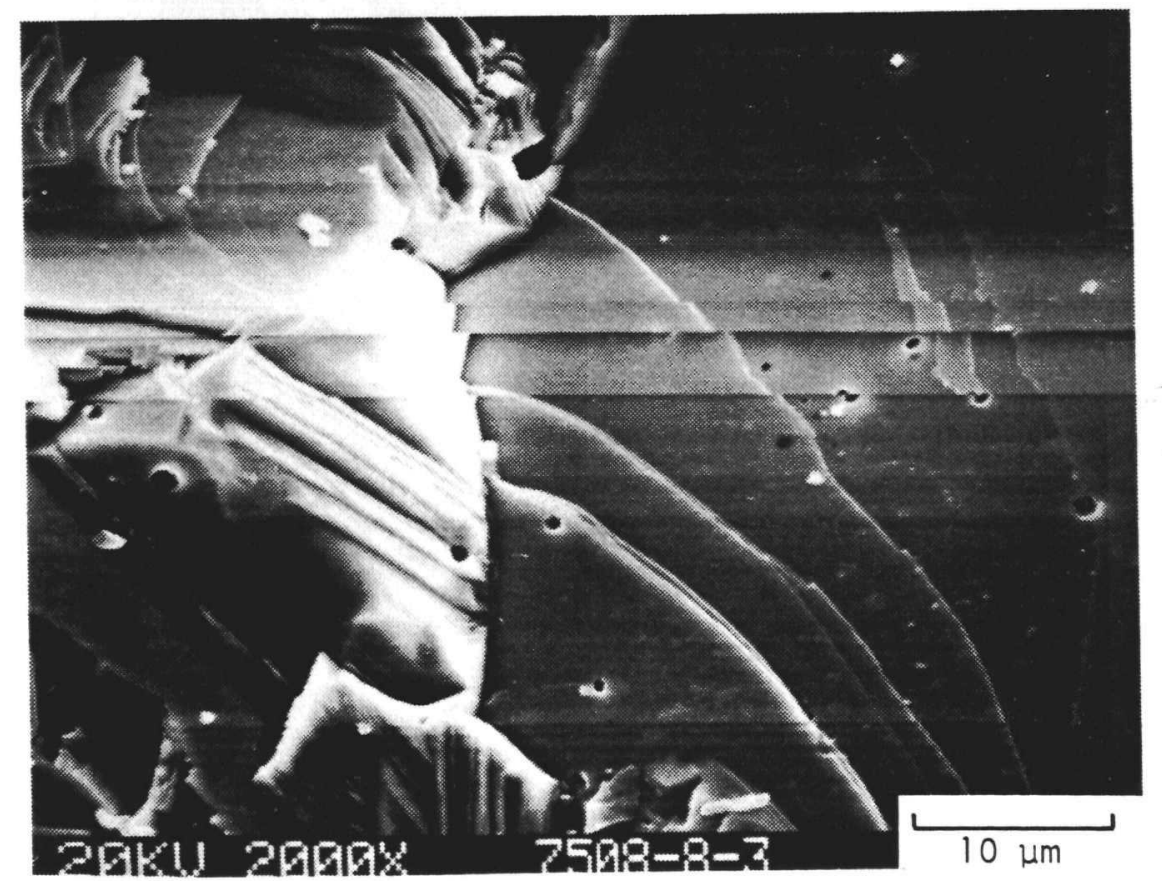

(b)

A17773

Fig. 3-3. Scanning electron microscopy photomicrographs of hot-pressed, fractured $\mathrm{Y}_{2} \mathrm{O}_{3}$ surfaces: (a) $1800^{\circ} \mathrm{C}$ and $15.8 \mathrm{MPa}(2300 \mathrm{psi})$, (b) $1800^{\circ} \mathrm{C}$ and $24.1 \mathrm{MPa}(3500 \mathrm{psi}$ ) (sheet 1 of 2) 


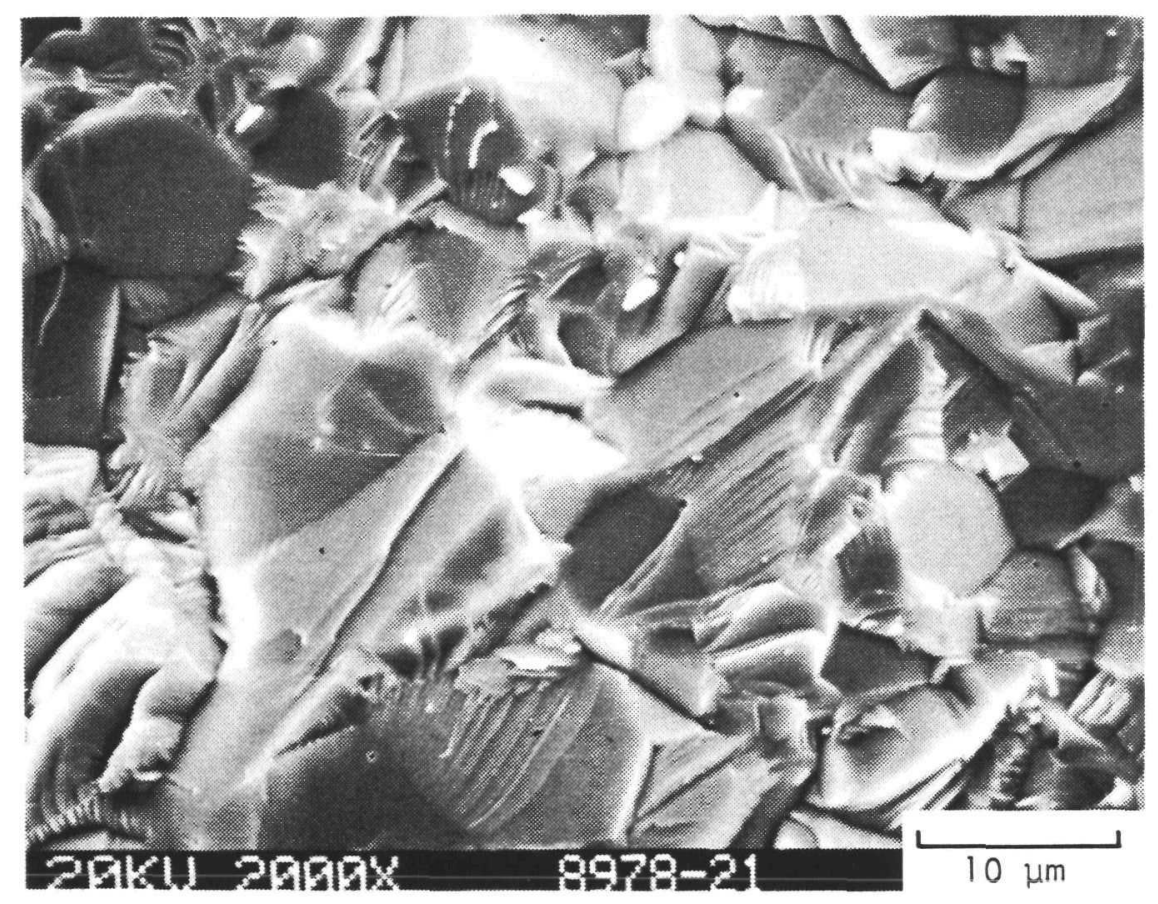

(c)

A17773

Fig. 3-3. Scanning electron microscopy photomicrographs of hot-pressed, fractured $\mathrm{Y}_{2} \mathrm{O}_{3}$ surfaces: (c) $1800^{\circ} \mathrm{C}$ and $53.1 \mathrm{MPa}$ (7700 psi) (sheet 2 of 2) 
TABILE , 1-3

PROCESS INFORMATION; $\mathrm{Y}_{2} \mathrm{O}_{3}$ CERAMIC, HOT PRESSING

\begin{tabular}{|c|c|c|c|c|c|c|c|c|}
\hline $\begin{array}{l}\text { Sample } \\
\text { No. }\end{array}$ & $\begin{array}{l}\text { Low- } \\
\text { Temperature } \\
\text { Hold } \\
\left({ }^{\circ} \mathrm{C}\right)\end{array}$ & $\begin{array}{l}\text { Pressure } \\
\text { During } \\
\text { Heating } \\
{[\mathrm{MPa} \text { (psi)] }}\end{array}$ & $\begin{array}{c}\text { Time } \\
\text { at low } \\
\text { Temperature } \\
\text { (min) }\end{array}$ & $\begin{array}{l}\text { Heating } \\
\text { Rate } \\
\left({ }^{\circ} \mathrm{C} / \mathrm{min}\right)\end{array}$ & $\begin{array}{c}\text { High } \\
\text { Temperature } \\
\left({ }^{\circ} \mathrm{C}\right)\end{array}$ & $\begin{array}{l}\text { Pressure at } \\
\text { Temperature } \\
{[\mathrm{MPa}(\text { psi)] }}\end{array}$ & $\begin{array}{c}\text { Time at } \\
\text { Temperature } \\
(\text { min })\end{array}$ & Remarks \\
\hline $8978-21$ & None & $3.1(450)$ & -- & 20 & 1800 & $\begin{array}{c}53.1 \\
(7700)\end{array}$ & 5 & Closed pores \\
\hline $8978-22$ & None & $1.7(250)$ & -- & 20 & 1700 & $\begin{array}{l}26.2 \\
(3800)\end{array}$ & 10 & Closed pores \\
\hline $7504-8-1$ & None & 0 & -- & 20 & 1700 & $\begin{array}{c}26.2 \\
(3800)\end{array}$ & 10 & Sample broke, few pores \\
\hline $7584-8-2$ & None & 0 & - & 20 & 1800 & $\begin{array}{c}24.1 \\
(3500)\end{array}$ & 30 & Sample broke, few pores \\
\hline $7504-8-3$ & None & 0 & -- & 20 & 1800 & $\begin{array}{l}24.1 \\
(3500)\end{array}$ & 30 & Sample broke, few pores \\
\hline $7504-9-1$ & 1000 & $17.9(2600)$ & 45 & 70 & 1700 & $\begin{array}{l}17.9 \\
(2600)\end{array}$ & 30 & Porous, weak \\
\hline $7504-9-2$ & 1000 & 0 & 60 & 80 & 1800 & $\begin{array}{l}15.9 \\
(2300)\end{array}$ & 60 & $\begin{array}{l}\text { Few pores, unt form } \\
\text { grains }\end{array}$ \\
\hline $7504-10-1$ & 1200 & 0 & 60 & 60 & 1800 & $\begin{array}{l}17.9 \\
(2600)\end{array}$ & 60 & $\begin{array}{l}\text { Few pores, } \\
\text { discontinuous growth }\end{array}$ \\
\hline $7504-10-2$ & 1200 & 0 & 60 & 60 & 1800 & $\begin{array}{l}25.5 \\
(3700)\end{array}$ & 60 & $\begin{array}{l}\text { Few pores, } \\
\text { discontinuous growth }\end{array}$ \\
\hline $7504-11-1$ & 1200 & 0 & 60 & 60 & 1800 & $\begin{array}{l}26.5 \\
(3700)\end{array}$ & 60 & $\begin{array}{l}\text { Few pores, } \\
\text { discontinuous growth }\end{array}$ \\
\hline $7504-11-2$ & 1300 & 0 & 120 & 40 & 1600 & $\begin{array}{l}17.9 \\
(2600)\end{array}$ & 120 & Connected pores \\
\hline
\end{tabular}


The seal shown in Fig. 3-4 differs from the seal used in the earlier TFEs (Fig. 3-5) in the size and shape of the ceramic and metal interface. This more compact seal is intended to reduce the unfueled volume of the TFE. Polycrystalline $\mathrm{Al}_{2} \mathrm{O}_{3}$ ceramic rings are being used to develop the technique for fabricating these seals. Modifications in both the metallizing and brazing processes to fabricate these seals have been necessary. An advanced $\mathrm{Nb}-\mathrm{Al}_{2} \mathrm{O}_{3}-\mathrm{Nb}$ seal has been made, but was not leak tight. The ceramic distorted during metallizing. The niobium ring used to retain the ceramic was machined to accommodate the distortion. This created the gap seen in Fig. 3-6.

The support of the ceramic during metallizing is being modified to overcome the ceramic distortion. Metallizing temperatures are being lowered to minimize dimensional changes in the metallized ceramics.

Dies are being made to hot press $\mathrm{Y}_{2} \mathrm{O}_{3}$ rings for advanced $\mathrm{Nb}-\mathrm{Y}_{2} \mathrm{O}_{3}-\mathrm{Nb}$ seal fabrication.

\subsubsection{Cermet}

Cermets of tiny niobium spheres in an alumina matrix fabricated by $\mathrm{TE}$ have given good results in trilayer (Ref. 3-1) and pentalayer (Ref. 3-2) sheaths. The same technology can be used to make compact insulator seals by a straightforward modification of the trilayer configuration.

Figure 3-7 shows a photomicrograph of an niobium-alumina cermet. The niobium spheres are typically around $1 \mathrm{mil}$ in diameter. The fabrication procedure is such that the niobium spheres in the ceramic matrix are diffusion bonded to the adjacent niobium walls that interlock the cermet and the walls to provide a high-strength interface. Stresses due to differential thermal expansion are quite small because of the excellent match in thermal expansion between the niobium and alumina. The incorporation of the low-modulus niobium spheres in the high-modulus ceramic 


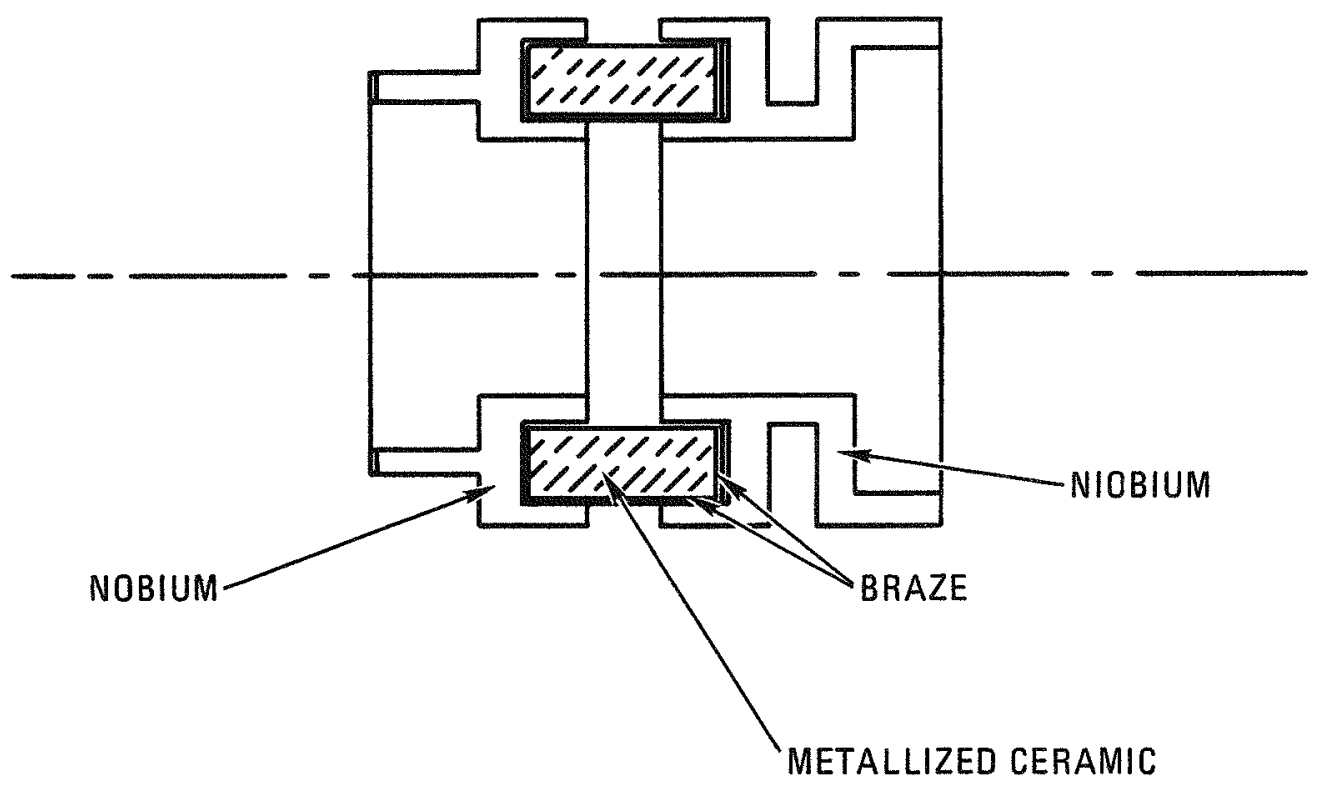

A17773

Fig. 3-4. Advanced seal configuration 

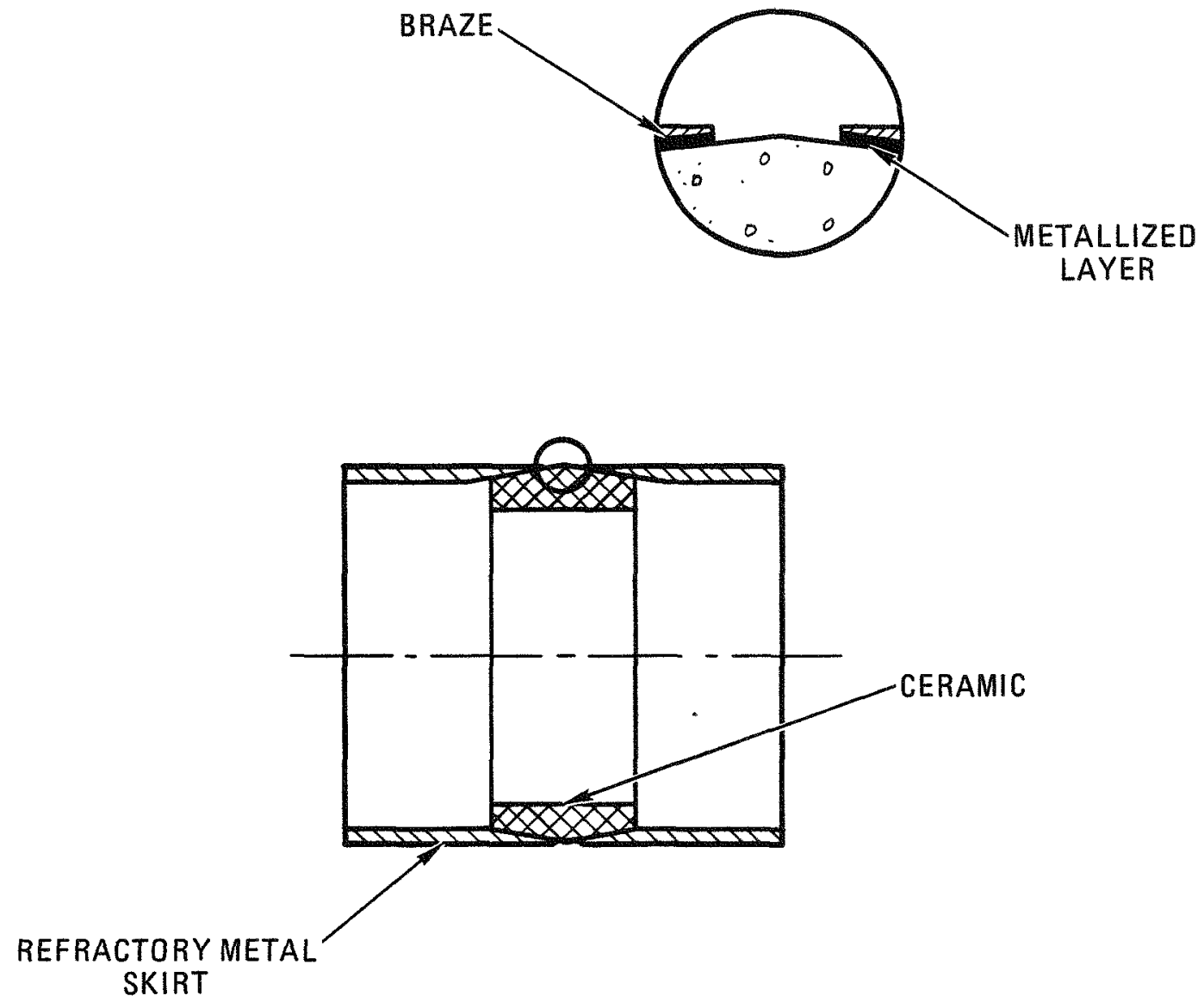

A17773

Fig. 3-5. 1972 metal-ceramic seal 


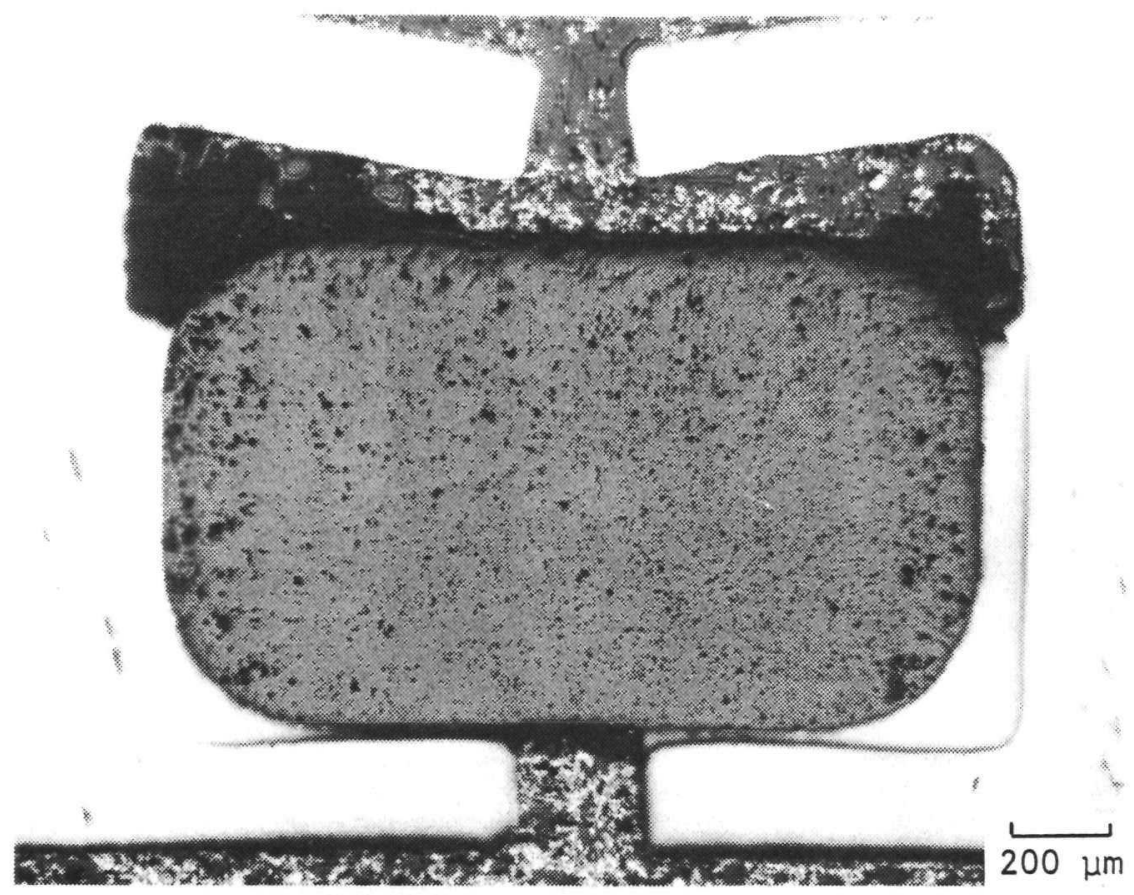

(a)

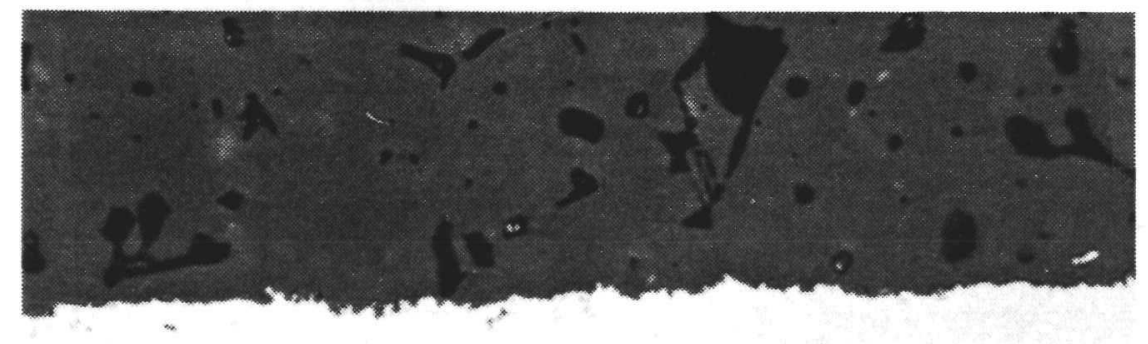

3.

A17773

(b)

Fig. 3-6. Vanadium-niobium-brazed polycrystalline $\mathrm{Al}_{2} \mathrm{O}_{3}$ to niobium seal joint: (a) $50 \mathrm{x}$, (b) $500 \mathrm{x}$ 


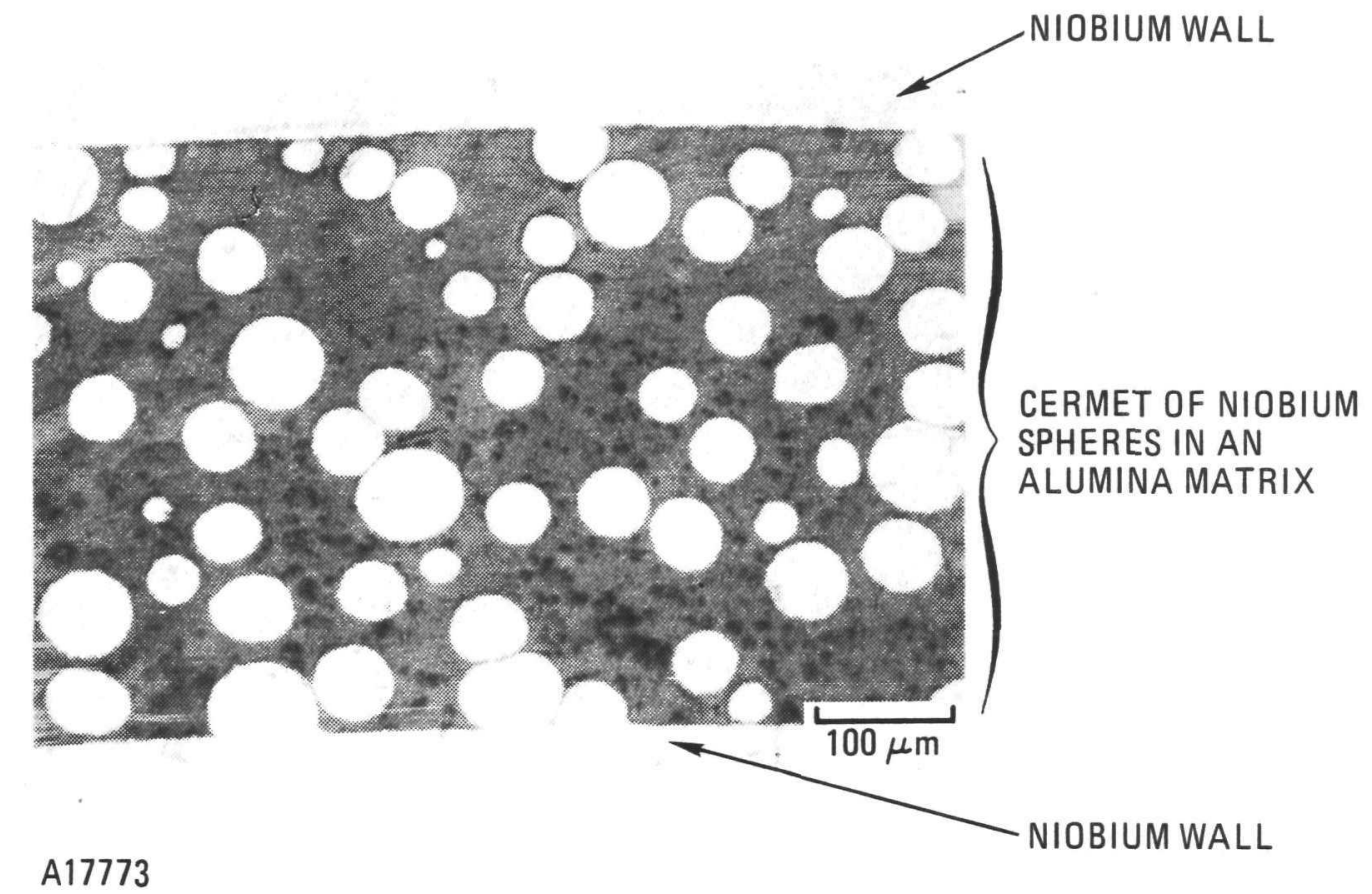

Fig. 3-7. Photomicrograph of alumina-niobium cermet 
allows the cermet to yield somewhat to reduce internal stresses. The spheres also appear to function as crack stoppers to inhibit the fracture-propagation characteristics of ceramics. In addition, the cermet has a higher thermal conductivity than a given thickness of ceramic.

Based on a literature survey and evaluation of candidate ceramics (Ref, 3-3) with respect to radiation resistance, electrolytic degradation, thermal expansion match, and cesium compatibility, yttria and YAG have been selected as matrix materials for cermets with longer life potential than alumina. However, alumina is being used to reestablish the cermet technology.

An essential step in cermet fabrication is autoclaving of green cermet sandwiched between niobium walls at high temperature and high pressure. The Autoclave Engineers autoclave at TE operates up to $1550^{\circ} \mathrm{C}$ and $68.9 \mathrm{MPa}(10,000 \mathrm{psi})$. Figure $3-8$ is a photograph of the console of this unit. The autoclave has been refurbished by (1) installing a new heater, (2) replacing the molybdenum hearth plate, (3) replacing the molybdenum extension tube, and (4) replacing the molybdenum restraint member. This equipment has been checked out at operational conditions and found to be in good working order.

Although the initial development tests have a supply of niobium spheres, a commercial vendor of these spheres no longer exists. In order to rectify this situation, a TAFA plasma torch system for spheroidizing niobium powder has been ordered. This unit is expected to be delivered during November 1984.

\subsection{METAL-CERAMIC SEAL TESTING}

A seal insulator test plan has been circulated and approved. This plan calls for testing cesium compatibility of ceramic materials, thermal cycling, and measuring the electrical resistance of these materials at temperature. Figure 3-9 presents the test logic. 


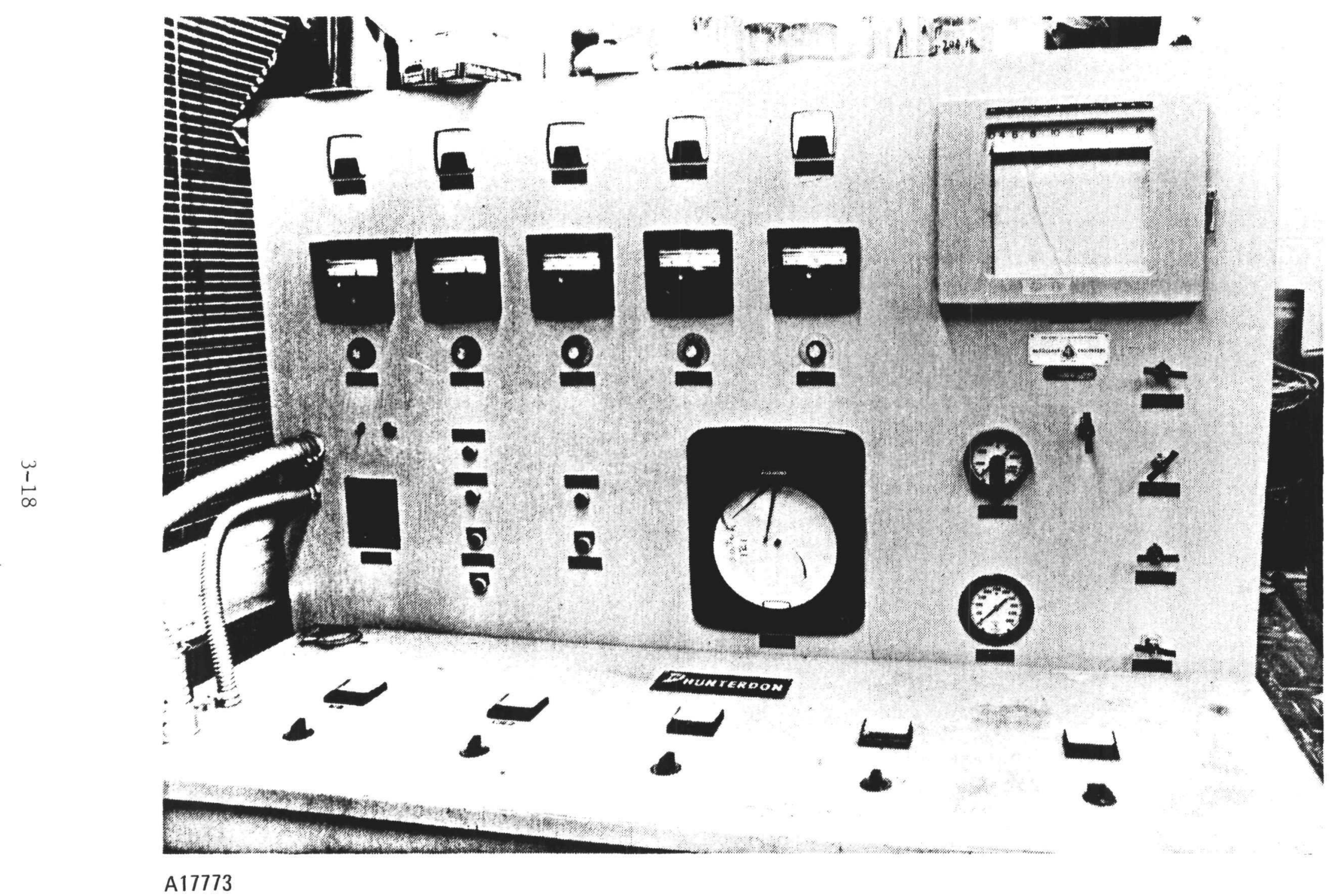

Fig. 3-8. High-temperature, high-pressure autoclave 


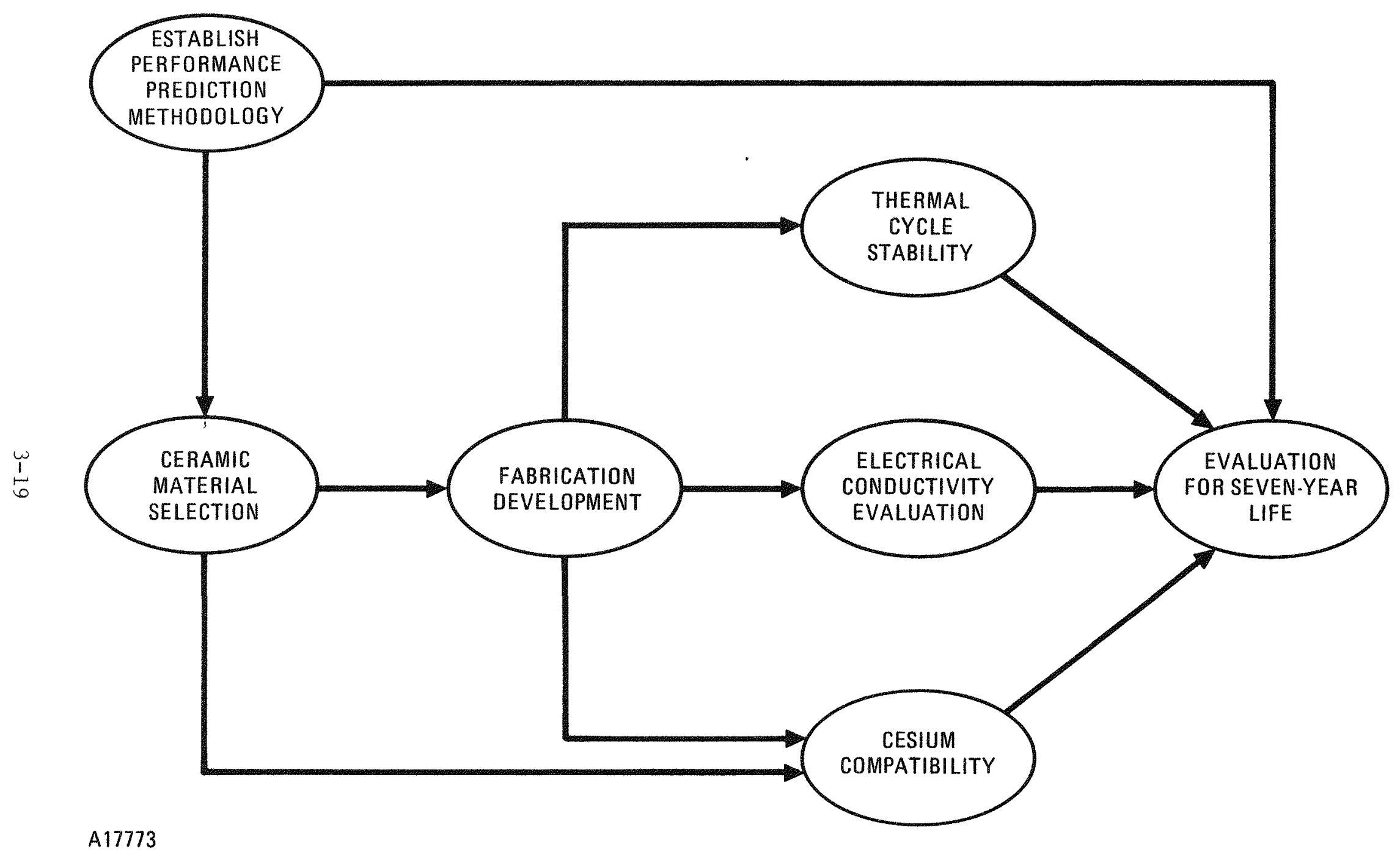

Fig. 3-9. Seal insulator test plan logic 
Cesium compatibility studies have begun. The remaining studies are not planned until the next reporting period. In order to rapidly obtain information concerning the effects of cesium on the various ceramics, accelerated tests were conducted. Instead of testing the ceramics at $12,000 \mathrm{~h}$ at temperature in 1 torr of cesium vapor, the accelerated study used higher cesium pressures to obtain 1200 torr-h in fewer test hours. Thus, test materials could be examined in a relatively short time.

A cesium compatibility test stand has been fabricated. Figure 3-10 shows a schematic of the test setup. The test stand has been operated with preliminary samples, and early problems with a steel bell jar collapse and a leaky valve have been corrected. Both valves $A$ and $B$ have been eliminated and replaced with an all-welded assembly (see Fig. 3-2).

Test samples, weighing approximately $1 \mathrm{~g}$ each, of alumina, singlecrystal alumina (sapphire), and YAG were placed in three test chambers, each operating at a different temperature. The three chambers were operated at 1100,1250 , and $1400 \mathrm{~K}$, respectively, for $200 \mathrm{~h}$, with an initial cesium pressure of 60 torr, which degraded during the test.

The preliminary test results suggest that no weight gain or change in thickness occurred at any of the three temperatures or for the three ceramics. However, the YAG samples darkened after $300 \mathrm{~h}$ at temperature, possibly because of cesium exposure. The degree of darkening increased with temperature. Electrical resistance did not change during this period.

\subsection{REFERENCES}

3-1. "Quarterly Report on the Space $R$ and D Program for the Period Ending July 31, 1972," Los Alamos National Laboratory Report LA-5021-PR, August 1972.

3-2. Dunlay, S., S. Matsuda, and V. Poirier, "Cylindrical Diode Characteristic with Sublimed Electrode Surfaces," Thermionic Conversion Specialists Conference, San Diego, California, October 1971. 


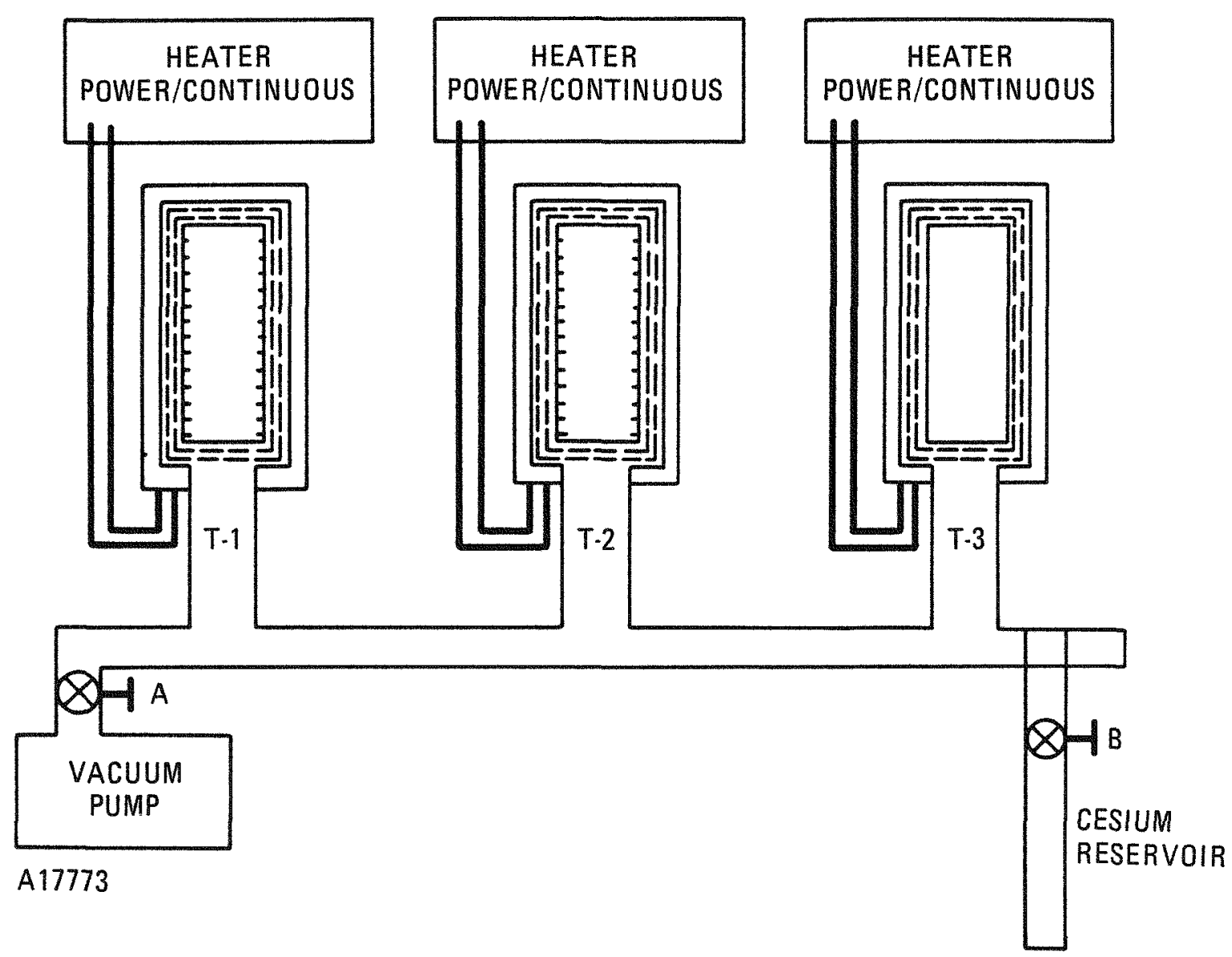

Fig. 3-10. Conceptual drawing of cesium compatibility test stand 
3-3. Gulden, T. D., E. J. Britt, and J. Dunlay, "Thermionic Insulator Material Database," Paper R-6-69 presented at SP-100 Program: Proceedings of the First Program Integration Meeting, Danvers, Maine, June 13-15, 1984. 


\section{METAL-CERAMIC SHEATH INSULATOR}

\subsection{TASK OBJECTIVES/APPROACH/REQUIREMENTS}

\subsubsection{Sheath Insulator Functional Requirements}

The sheath insulator is intended to electrically isolate each collector of the thermionic converters, while allowing reject heat from the collector to be conducted to the heat rejection system. Depending on the electrical configuration of the thermionic elements, the voltage across a sheath ranges from $0.6 \mathrm{~V}$ (i.e., output voltage of a single thermionic element) to the output voltage of the power system.

Two types of sheath insulator designs have been developed: (1) the graded trilayer type produced by plasma spraying and (2) a cermet design composed of ceramic interspersed with niobium spheres (shown in Fig. 4-1).

\subsubsection{Sheath Insulator Operating Requirements}

The seven-year lifetime requirements for the $S P-100$ program results in a peak fast neutron fluence of $1.7 \times 10^{22} \mathrm{n} / \mathrm{cm}^{2}(\mathrm{E}>0.18 \mathrm{MeV})$, which can produce substantial damage in many conventional materials. In the current system design, which produces power at $100 \mathrm{~V}( \pm 50 \mathrm{~V}$ from ground potential), the sheath insulator experiences a maximum voltage drop of $50 \mathrm{~V}$, which corresponds to an electric field of approximately $2000 \mathrm{~V} / \mathrm{cm}$. This moderately high electric field and the operating temperatures of $-1100 \mathrm{~K}$ raise concerns over possible electrolysis effects which could degrade insulator performance. Classical dielectric breakdown is not likely for most good insulators at this relatively modest field strength. However, this possibility should not be ignored in the sheath insulator 


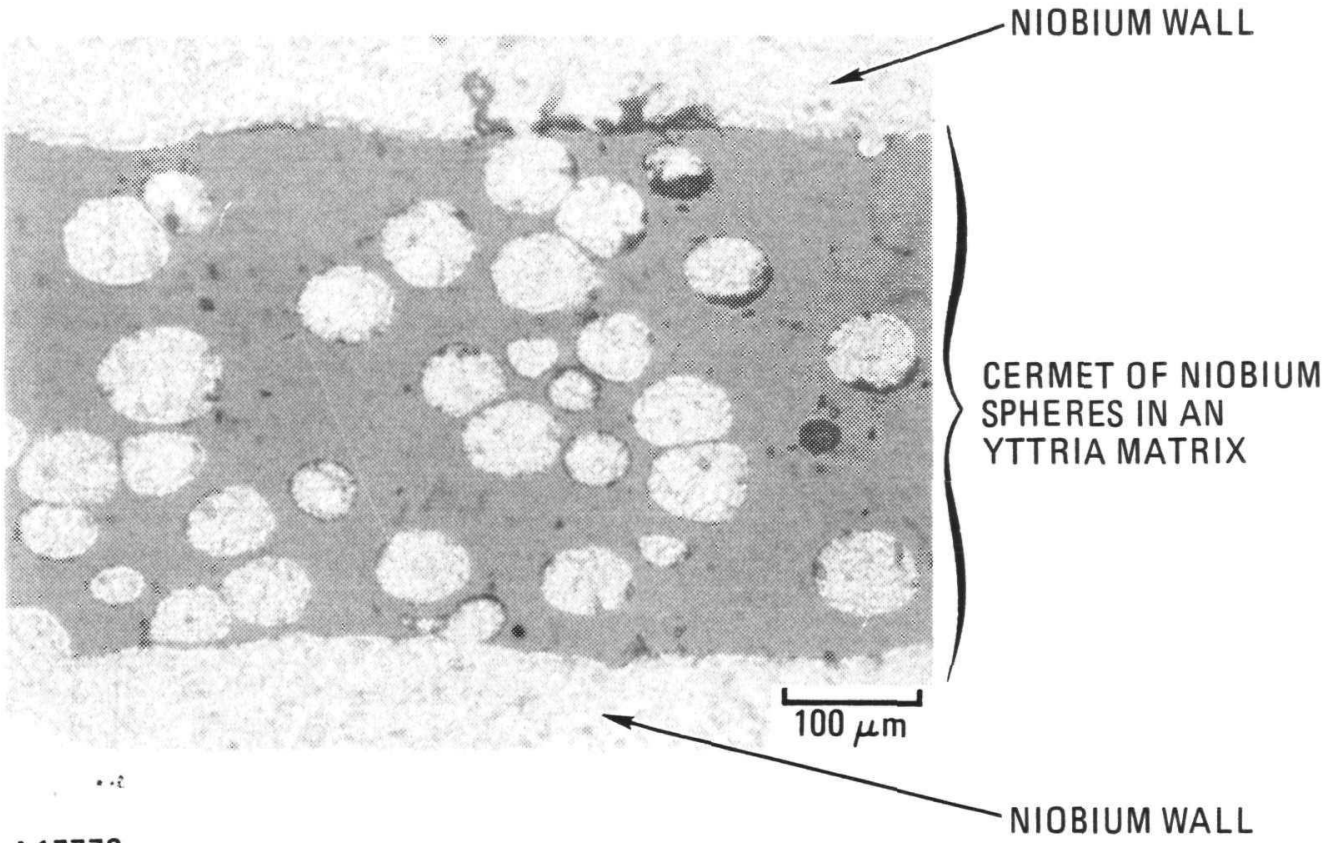

A17773

Fig. 4-1. Photomicrograph of yttria-niobium cermet 
development and testing effort. Table 4-1 summarizes the insulator operating requirements.

\subsubsection{Candidate Materials for Sheath Insulator}

A wide variety of high-temperature ceramic insulator materials and sheath insulators in the TFE is available. Each has its own characteristic strengths and weaknesses relative to the TFE insulator design and performance requirements. Table 4-2 ranks several candidate insulator materials relative to their ability to meet key design and performance requirements.

Alumina has been demonstrated to be fully adequate to meet the requirements of the early generation of TFEs with lifetimes of up to $20,000 \mathrm{~h}$. However, the seven-year lifetime for the SP-100 program requires materials with improved radiation resistance, while meeting the other performance requirements.

Table 4-2 shows that $\mathrm{Y}_{2} \mathrm{O}_{3}$ and $\mathrm{Y}_{3} \mathrm{Al}_{5} \mathrm{O}_{12}$ are prime candidates for sheath insulators. For the sheath insulator where cesium compatibility is not a significant concern, the covalently bonded materials $\mathrm{Si}_{3} \mathrm{~N}_{4}$ and $\mathrm{Si}_{2} \mathrm{ON}_{2}$ could be considered as backups if fabrication processes and insulator designs could be developed to avoid thermal expansion mismatch.

\subsubsection{Objectives and Test Plan for Sheath Insulators}

This task is intended to specify a sheath insulator design to meet these requirements. This task uses a combined analytical and experimental approach. The existing data base will first be used to identify important life-limiting degradation mechanisms and those ceramic materials that best withstand such degradation. The feasibility of fabricating sheath insulators with the selected ceramics will be established. Tests will examine the integrity of the interface bond between the metal and ceramic and determine its thermal conductance. Accelerated tests at temperatures and/or voltages higher than the design conditions will 
TABLE 4-1

SP-100 THERMIONIC REACTOR SHEATH-INSULATOR

OPERATING REQUIREMENTS

\begin{tabular}{ll}
\hline & \multicolumn{1}{c}{ Range } \\
\hline Metal-ceramic seal & \\
Neutron fluence, $\mathrm{n} / \mathrm{cm}^{2}(>0.1 \mathrm{MeV})$ & Maximum $1.7 \times 10^{22}$ \\
& Average $1.0 \times 10^{22}$ \\
Potential, $\mathrm{V}$ & Maximum 50 \\
& Average 25 \\
Temperature, $\mathrm{K}$ & Maximum 1130 \\
& Average 1080 \\
Cesium environment, torr & Normal $<1$ \\
\hline
\end{tabular}


TABLE 4-2

RANKING OF INSULATOR MATERIALS RELATIVE TO DESIGN AND PERFORMANCE REQUIREMENTS

\begin{tabular}{|c|c|c|c|c|c|c|c|}
\hline & \multirow[b]{2}{*}{ Requirements (a) } & \multicolumn{6}{|c|}{ Material } \\
\hline & & $\mathrm{Al}_{2} \mathrm{O}_{3}$ & $\mathrm{Y}_{2} \mathrm{O}_{3}$ & $\mathrm{MgAl}_{2} \mathrm{O}_{4}$ & $\mathrm{Y}_{3} \mathrm{Al}_{5} \mathrm{O}_{12}$ & $\mathrm{Si}_{3} \mathrm{~N}_{4}$ & $\mathrm{Si}_{2} \mathrm{ON}_{2}$ \\
\hline 1. & Radiation resistance & 3 & 2 & 1 & 1 & 2 & 1 \\
\hline 2. & $\begin{array}{l}\text { Resistance to elec- } \\
\text { trolytic } \\
\text { degradation }\end{array}$ & 1 & 2 & 3 & 1 & 1 & 1 \\
\hline 3. & $\begin{array}{l}\text { Thermal expansion } \\
\text { compatibility }\end{array}$ & 1 & 1 & 2 & 1 & 3 & 3 \\
\hline 4. & Cesium compatibility & 1 & 1 & 1 & 1 & 2 & 3 \\
\hline
\end{tabular}

(a) Rankings 1 through 3 are in order of ability to meet requirements. 
explore electrolytic degradation processes in selected sheath insulator designs.

Figure 4-2 shows the sheath test plan logic. Prototypic sheath components will be fabricated using techniques and ceramic materials judged compatible with SP-100 (Table 4-1) and preapplication requirements. The preapplication requirements consist of the ability to withstand the thermal cycling and thermal shock that could result from equipment startup and shutdown during in-core and out-of-core testing. Some of the insulator sheaths which qualify will be put on life test to evaluate the stability of the thermal and electrical conductivity.

Analytical work will support the testing and aid in evaluating the likelihood of a seven-year lifetime for the sheath design candidates. This work will model the time-dependence of electrical-conductivity degradation mechanisms. The electrical performance characteristics of the sheath insulators will be modeled analytically, then verified using experimental data. To project lifetime, a simple correlation model will be developed using results from accelerated electrolysis tests made on candidate ceramic materials. A physical model of ionic transport will also be developed for high-temperature, electrically stressed ceramics. Input data for the two models will be gleaned from the 1iterature, experiments, and program electrical-conductivity stability tests. The ability of each sheath design to meet the design requirements will then be projected from analytical calculation.

\subsection{FABRICATION DEVELOPMENT}

\subsubsection{Cermet Sheath Insulator}

The cermet fabrication technique can be adapted to trilayer, pentalayer, and insulator seal structures. Figure 4-3 shows a photomicrograph of a pentalayer sheath in excellent condition after $14,000 \mathrm{~h}$ of operation in a G-series converter heated by electron bombardment. No cracks or interaction are evident between the niobium and the alumina. 

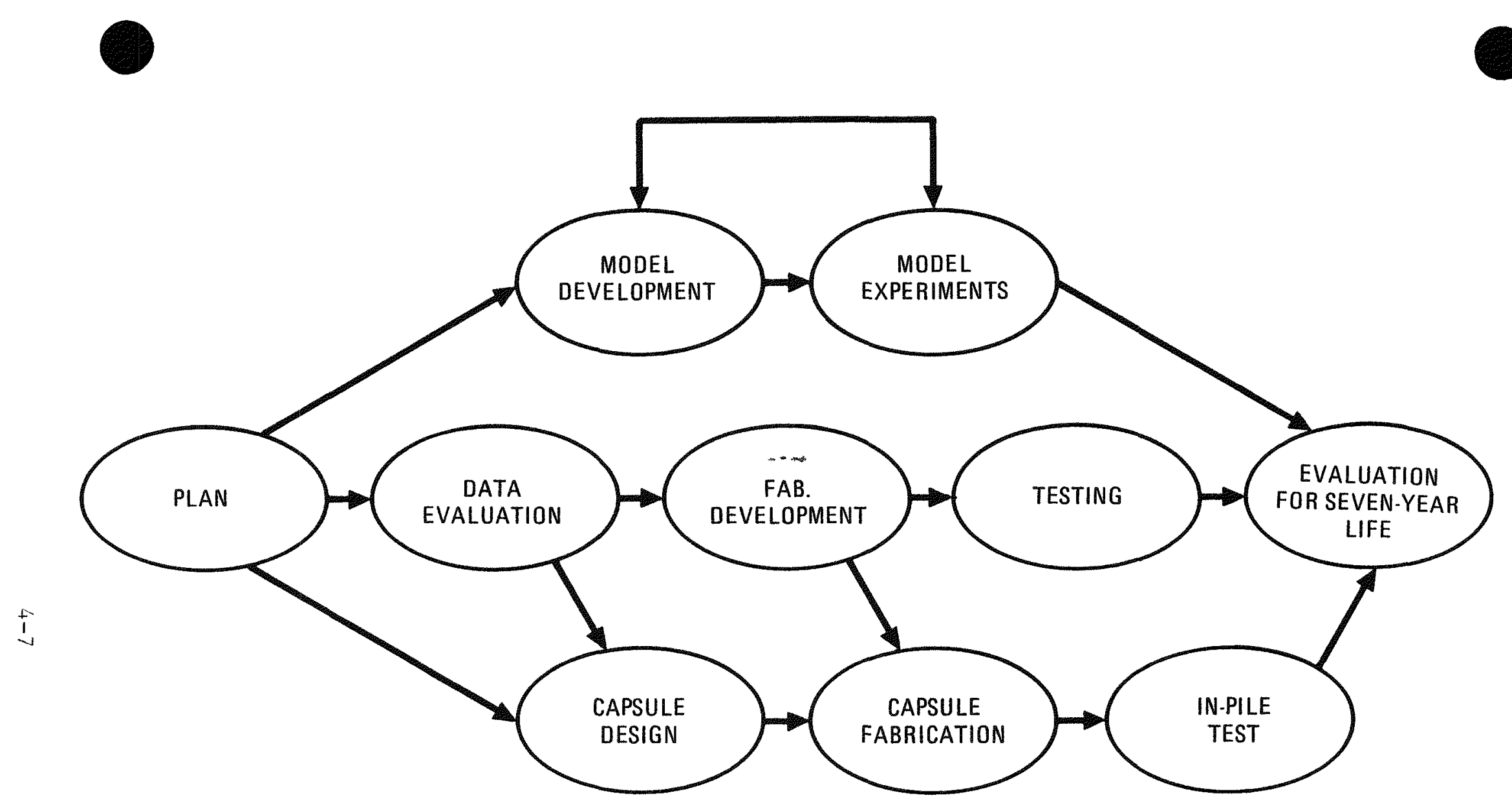

A17773

Fig. 4-2. Sheath insulator test plan logic 


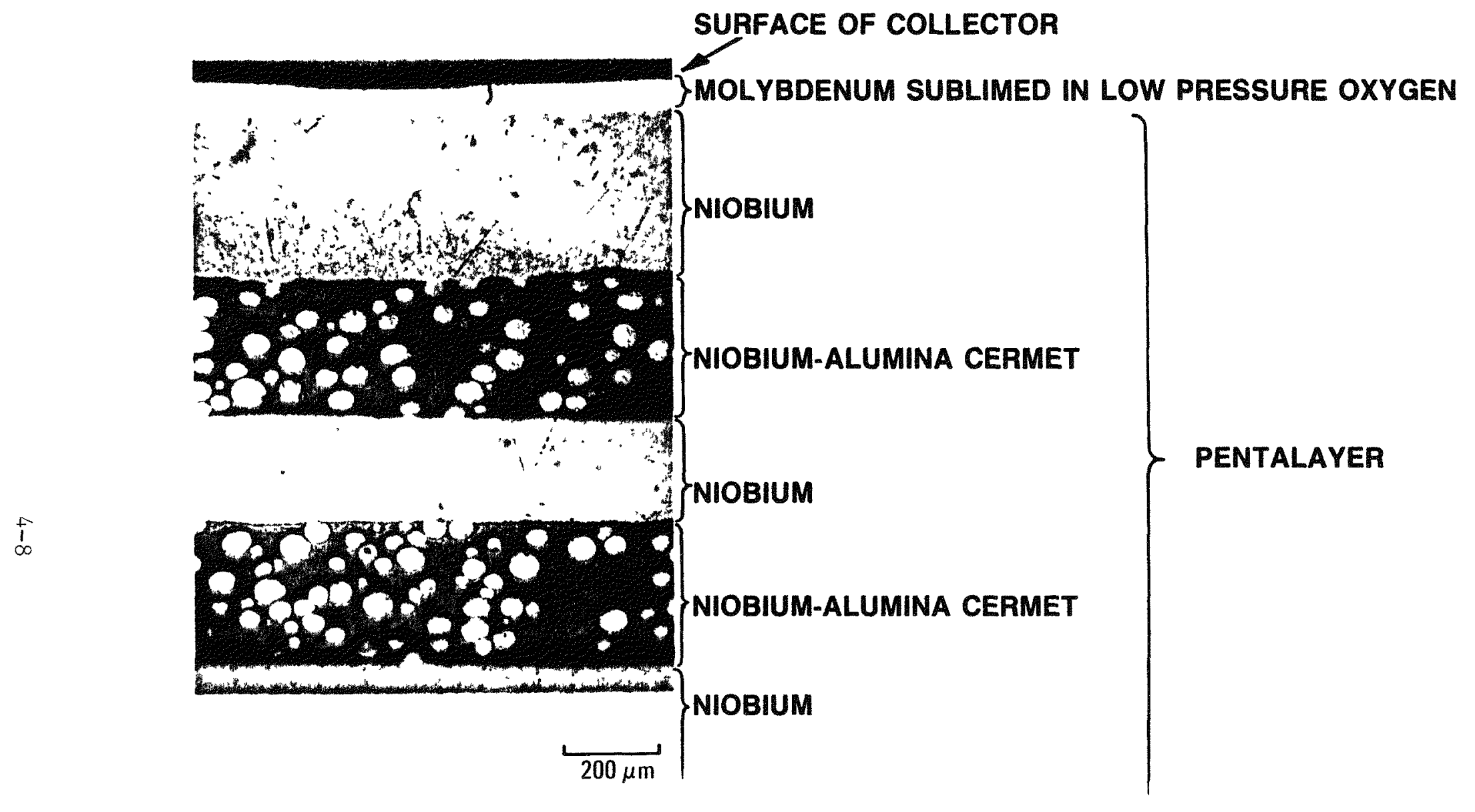

A17773

Fig. 4-3. Photomicrograph of pentalayer-collector from 14,000-h G-series converter 
The pentalayer sheath combines the functions of both the insulator seal and trilayer sheath in the F-series converter so that the emitter sleeve (Mo-Re in the G-series) can be quite short and the intercell volume minimized. Consequently, the fuel fraction and/or TFE voltage can be increased. An additional advantage is that the pentalayer maximizes the area of the emitter-to-collector seal.

The primary steps in fabricating a cermet component are as follows:

1. Coat the niobium spheres with wax.

2. Coat the spheres with ceramic powder.

3. Cold press [276 to $413 \mathrm{MPa}(40,000$ to $60,000 \mathrm{psi})]$.

4. Low-temperature sinter $\left(1250^{\circ} \mathrm{C}, 30 \mathrm{~min}\right)$.

5. Machine green cermet to approximate dimensions.

6. Fit green cermet into niobium.

7. Autoclave $\left[1550^{\circ} \mathrm{C}, 68.9 \mathrm{MPa}(10,000 \mathrm{psi}), 3 \mathrm{~h}\right]$.

8. Machine cermet component to final dimension.

A set of 24 cermet structures [approixmately $1.27 \mathrm{~cm}$ long $\times 1.27 \mathrm{~cm}$ diameter $(0.5 \mathrm{in}$. $x 0.5 \mathrm{in.})]$, with a cermet layer approximately $0.038 \mathrm{~cm}$ ( $0.015 \mathrm{in}$.) thick, was fabricated with niobium volume fractions of $30 \%$, $35 \%, 40 \%$, and $45 \%$ in combination with alumina, yttria, YAG and aluminayttria (YAG composition) powders. Figure 4-1 shows a photomicrograph of a yttria cermet. Al1 24 compacts were electrically insulating at the end of step 5. However, after autoclaving (step 6), only the yttria components with a volume fraction of $35 \%$ remained unshorted. Microscopic inspection showed agglomeration of the niobium spheres. Review of the fabrication procedure indicated that the mixing technique used for yttria was significantly different from that used with the other ceramics. A sample of each of the ceramic compositions has been supplied to RA for cesium compatibility testing.

A source of high-purity $\mathrm{YAG}$ [i.e., $\mathrm{Y}_{3} \mathrm{Al}_{2}\left(\mathrm{AlO}_{4}\right)_{3}$ ] has been a problem. For example, the YAG material used to make the initial cermet structure was obtained from Laser Crystals, Inc. and had a neodymium impurity of 
around $0.8 \%$. TE has investigated the formation of YAG by the following steps:

1. Blend alumina and yttria powders corresponding to the YAG composition.

2. Cold press [207 MPa (30,000 psi)].

3. Sinter at zero pressure for 3 to $19 \mathrm{~h}$ at $1400^{\circ}, 1550^{\circ}$, and $1700^{\circ} \mathrm{C}$.

The compacts were analyzed by $X$-ray diffraction to measure the reaction between the alumina and yttria (see Fig. 4-4). The compact sintered at $1400^{\circ} \mathrm{C}$ did not form YAG. Most of the alumina and yttria remained unreacted, but the presence of the complex oxides $\left(\mathrm{AlYO}_{3}, \mathrm{Y}_{4} \mathrm{Al}{ }_{2} \mathrm{O} 9\right.$, and $\mathrm{Y}_{3} \mathrm{Al}_{5} \mathrm{O}_{12}$ ) could be detected.

The compact sintered at $1550^{\circ} \mathrm{C}$ showed a large amount of $\mathrm{YAG}$, along with small amounts of $\mathrm{AlYO}_{3}, \mathrm{Y}_{4} \mathrm{Al}_{2} \mathrm{O} 9$, alumina, and yttria. The compact sintered at $1700^{\circ} \mathrm{C}$ gave almost $100 \%$ conversion to $\mathrm{YAG}$, with trace amounts of $\mathrm{Y}_{3} \mathrm{Al}_{5} \mathrm{O}_{12}$ and $\mathrm{YAlO}_{3}$ evident due to a small excess of $\mathrm{Y}_{2} \mathrm{O}_{3}$ in the mixture. Therefore, the chance appears reasonable that YAG can be made at the autoclave conditions of $1550^{\circ} \mathrm{C}$ at $68.9 \mathrm{MPa}(10,000 \mathrm{psi})$.

\subsubsection{Graded Sheath Insulator}

The facility used to fabricate graded metal-ceramic trilayers, shown in Fig. 4-5, was reestablished with GA funding. This equipment includes a computer-controlled plasma gun head movement and a special powder feed hopper for uniform fine powder transport to the gun head. Three graded $\mathrm{Nb}-\mathrm{Y}_{2} \mathrm{O}_{3}-\mathrm{Nb}$ trilayer assemblies were electron-beam-welded together and shipped to BMI for autoclave, hot isostatic pressing (HIP). One assembly was pressed at $68.9 \mathrm{MPa}(10,000 \mathrm{psi})$ and $1730^{\circ} \mathrm{C}$. A sheath insulator, 


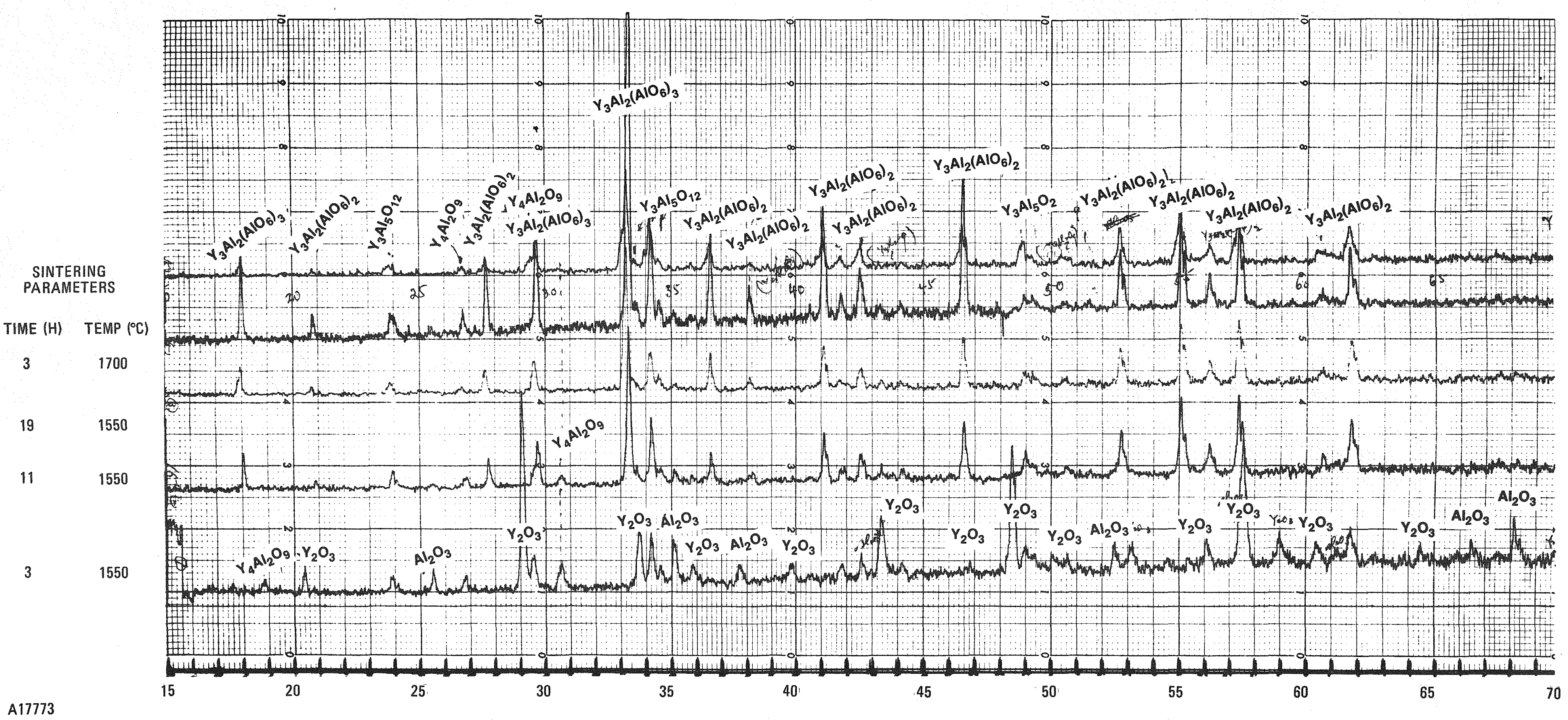

Fig. 4-4. X-ray diffraction patterns of yttria-alumina compacts corresponding to YAG composition [al1 compacts cold pressed at $206.8 \mathrm{MPa}$ $(30,000 \mathrm{psi})$ and presintered at $1250^{\circ} \mathrm{C}$ for $0.5 \mathrm{~h}$ ] 
BLANK 

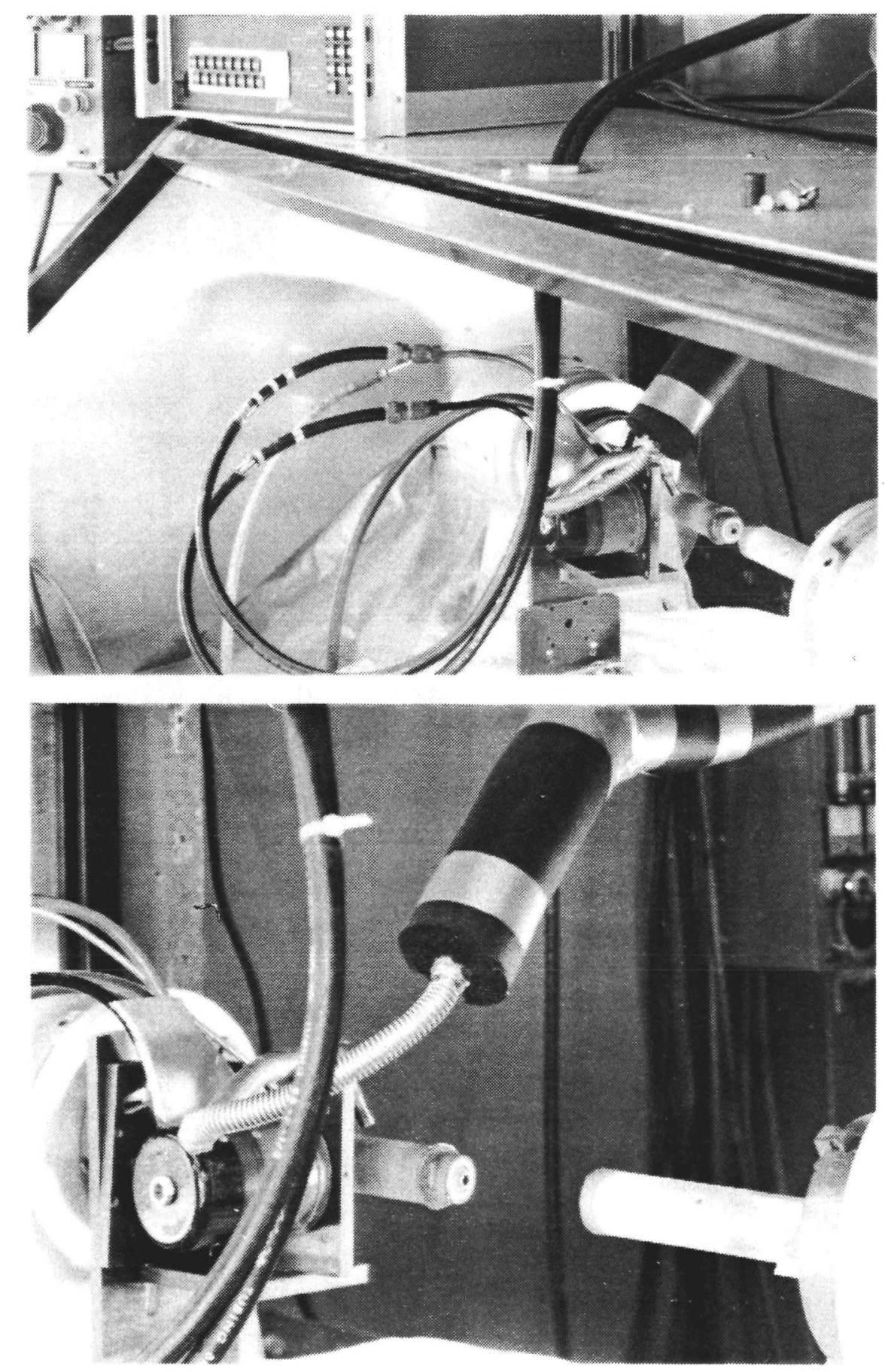

A17773

Fig. 4-5. Equipment for fabrication of plasma-sprayed graded trilayer (showing the plasma spray chambers, glass lathe, computer control, and sheath insulator holder) 
with the configuration shown in Fig. 4-6, was machined from this assembly. Some of the niobium of this sample was embrittled in the HIP process. Oxygen is suspected to be the cause of this embrittlement and the ceramic cracking which resulted from it. An improved getter is planned for the next graded trilayer.

\subsection{TESTING OF SHEATH INSULATOR ASSEMBLIES}

An out-of-core sheath insulator test plan detailing materials selection, test design, and analyses was circulated and approved. Table 4-3 summarizes the tests planned. The categories of tests are described below.

\subsubsection{Thermal Conductance}

Each sheath insulator will be inspected for metallic-ceramic interface bonding uniformity by qualitatively determining the radial thermal conductance. The sheath insulator will be uniformly heated on its interior surface by a filament in a vacuum environment. The surface temperature will be $1350 \mathrm{~K}$ with a radial heat flux near $5 \mathrm{~W} / \mathrm{cm}^{2}$. The outer surface will be visually scanned for uniformity of brightness. Highcontrast photographs will document the surface brightness. Figure 4-7 shows a schematic of the test apparatus.

\subsubsection{Electrical Conductivity}

All sheath samples will first be briefly subjected to voltage standoff and electrical conductivity measurements to ascertain their ability to withstand the base-design electrical requirements at the indicated conditions prior to stability tests (Fig. 4-8). Electrical stability of at least two designs will be determined out-of-core in vacuum at the indicated conditions. Frequent measurements of conductivity will enable an accurate time history. Occasionally, I-V sweeps will be made to detect changes from a purely resistive load which could reflect polarization or physical damage to the trilayer. After 2000, 5000, and $8000 \mathrm{~h}$, 


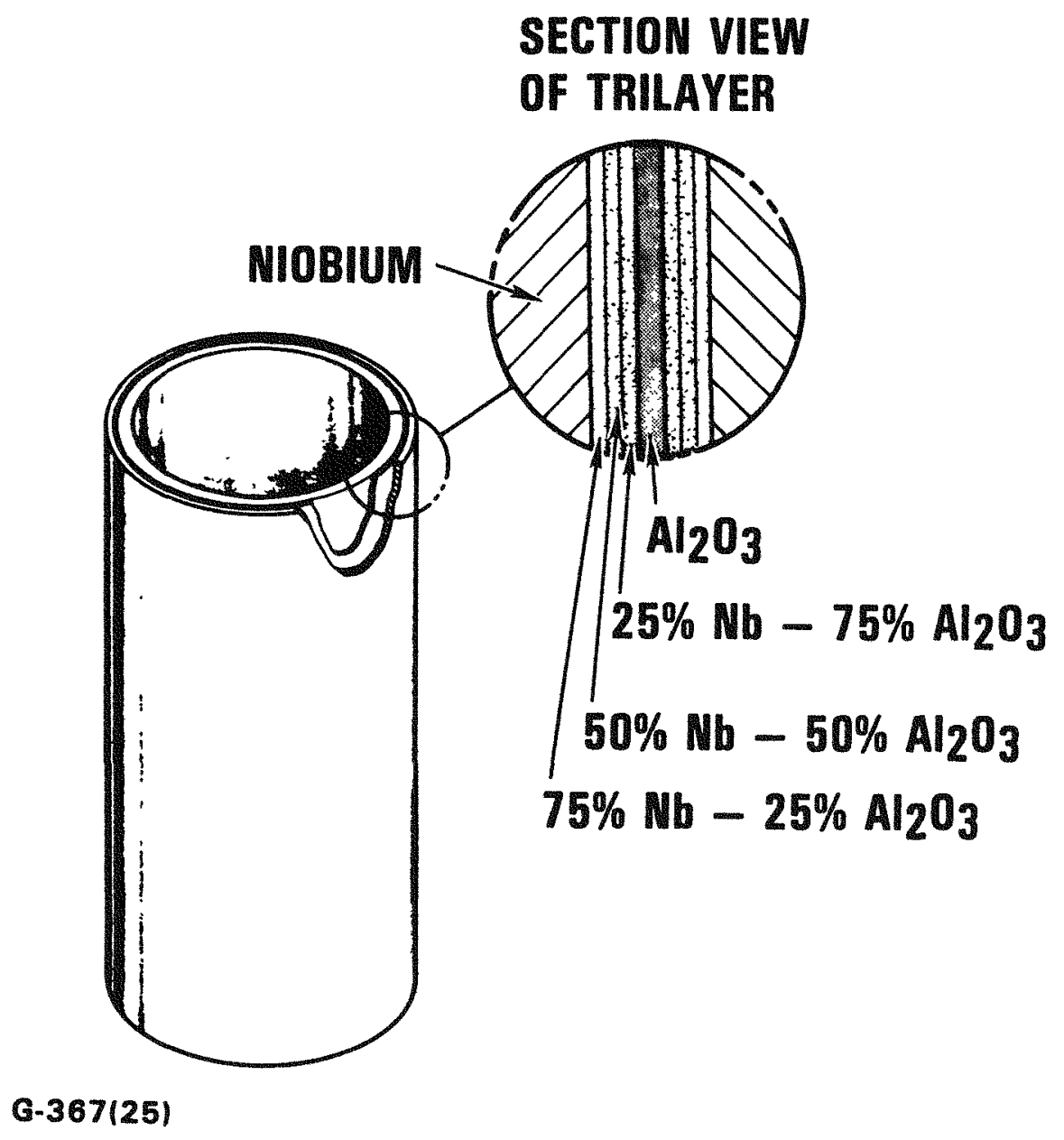

Fig. 4-6. Schematic diagram of graded trilayer sheath insulator 
TABLE 4-3

SHEATH INSULATOR TESTS

\begin{tabular}{|c|c|c|c|}
\hline Requirements & Type of Test & Number of Tests & Description \\
\hline Thermal conductivity & Bonding integrity & $\begin{array}{l}\text { A11 specimens before/after } \\
\text { electrical conductivity } \\
\text { and thermal tests }\end{array}$ & $\begin{array}{l}\text { Visual and infrared photo- } \\
\text { graph at } 1350 \mathrm{~K}, 5 \mathrm{~W} / \mathrm{cm}^{2} \text {, } \\
\mathrm{dT} / \mathrm{dt}<20 \mathrm{~K} / \mathrm{min}\end{array}$ \\
\hline \multirow[t]{3}{*}{ Electrical conductivity } & Voltage standoff & Al1 insulator sheaths & $150 \mathrm{~V}, 1200 \mathrm{~K},<1 \mathrm{~min}, \mathrm{TBD}$ \\
\hline & Electrical conductivity & Al1 insulator sheaths & $\begin{array}{l}50 \mathrm{~V}, 300,700,900,1200 \mathrm{~K}, \\
<1 \mathrm{~h}, \mathrm{TBD}\end{array}$ \\
\hline & $\begin{array}{l}\text { Electrical stability } \\
\text { (out-of-core, in-core, } \\
\text { TBD)(a) }\end{array}$ & Two designs & $\begin{array}{l}10,25,50,100 \mathrm{~V} ; 1100 \\
1250,1400 \mathrm{~K}, \text { up to } 8000 \mathrm{~h}\end{array}$ \\
\hline $\begin{array}{l}\text { Resistance to debonding } \\
\text { in preapplication } \\
\text { period }\end{array}$ & $\begin{array}{l}\text { Thermal shock and } \\
\text { cycling }\end{array}$ & $\begin{array}{l}\text { As required to assist in } \\
\text { sheath design }\end{array}$ & $\begin{array}{l}\text { Bond integrity after cycling } \\
500 \text { to } 1200 \mathrm{~K} \text {; dT/dt } \\
\sim 20 \mathrm{~K} / \mathrm{min}\end{array}$ \\
\hline $\begin{array}{l}\text { Electrical properties } \\
\text { and conductivity data } \\
\text { to support analytical } \\
\text { work }\end{array}$ & $\begin{array}{l}\text { Accelerated electrical } \\
\text { conductivity degrada- } \\
\text { tion test and TBD }\end{array}$ & $\begin{array}{l}\text { TBD by analytical work } \\
\text { requirements }\end{array}$ & $\begin{array}{l}400 \text { to } 2000 \mathrm{~V} / \mathrm{cm} ;(\mathrm{b}) 1000 \text { to } \\
1400 \mathrm{~K} ; 10 \text { to } 1000 \mathrm{~h}\end{array}$ \\
\hline
\end{tabular}

\footnotetext{
(a) $\mathrm{TBD}=$ to be determined.

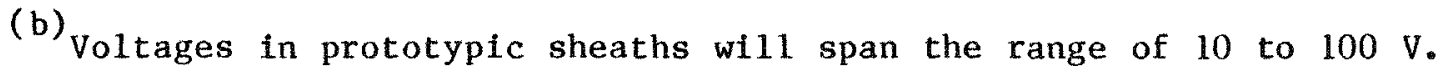




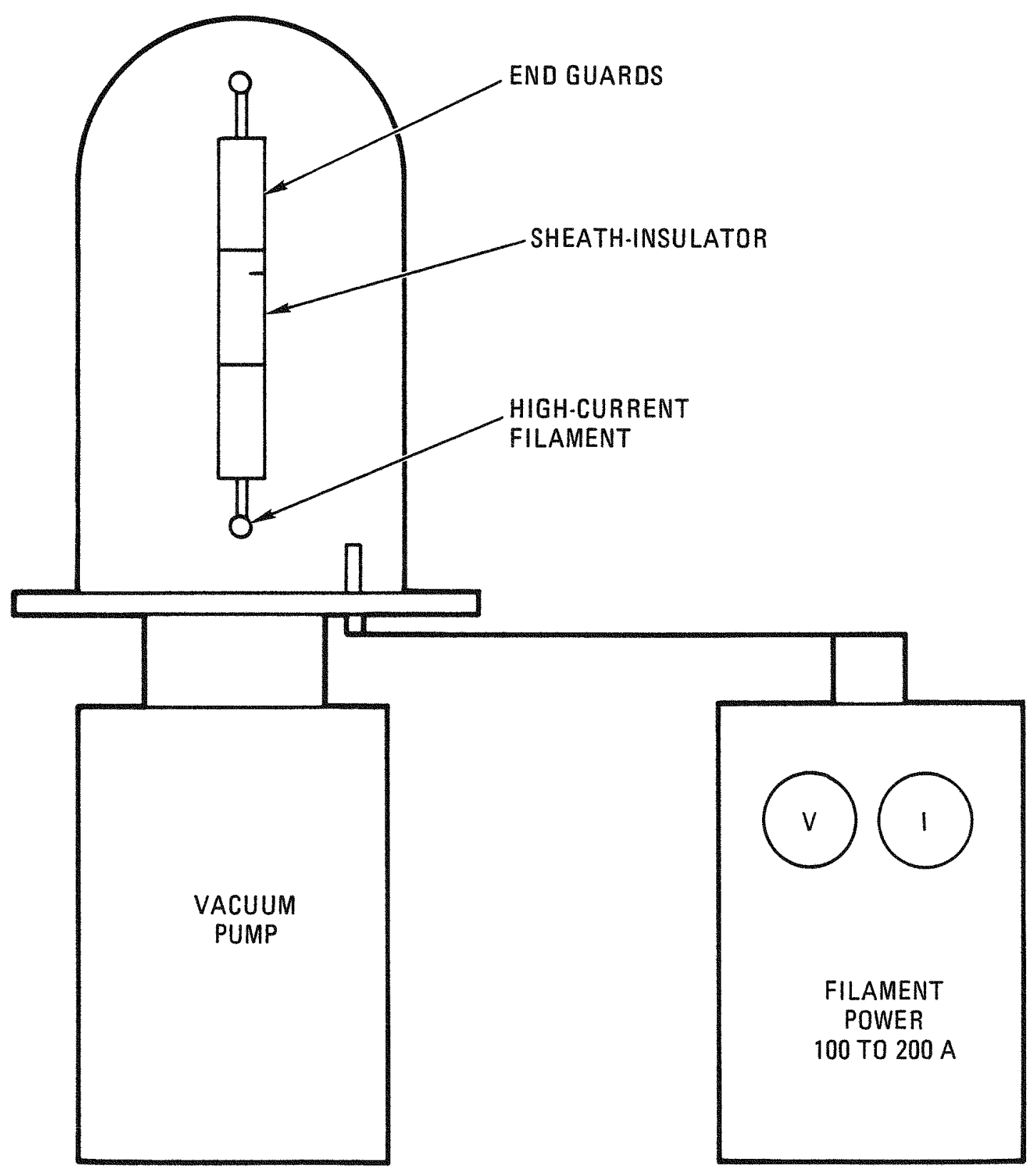

A17773

Fig. 4-7. Test stand for inspecting trilayer bonding 


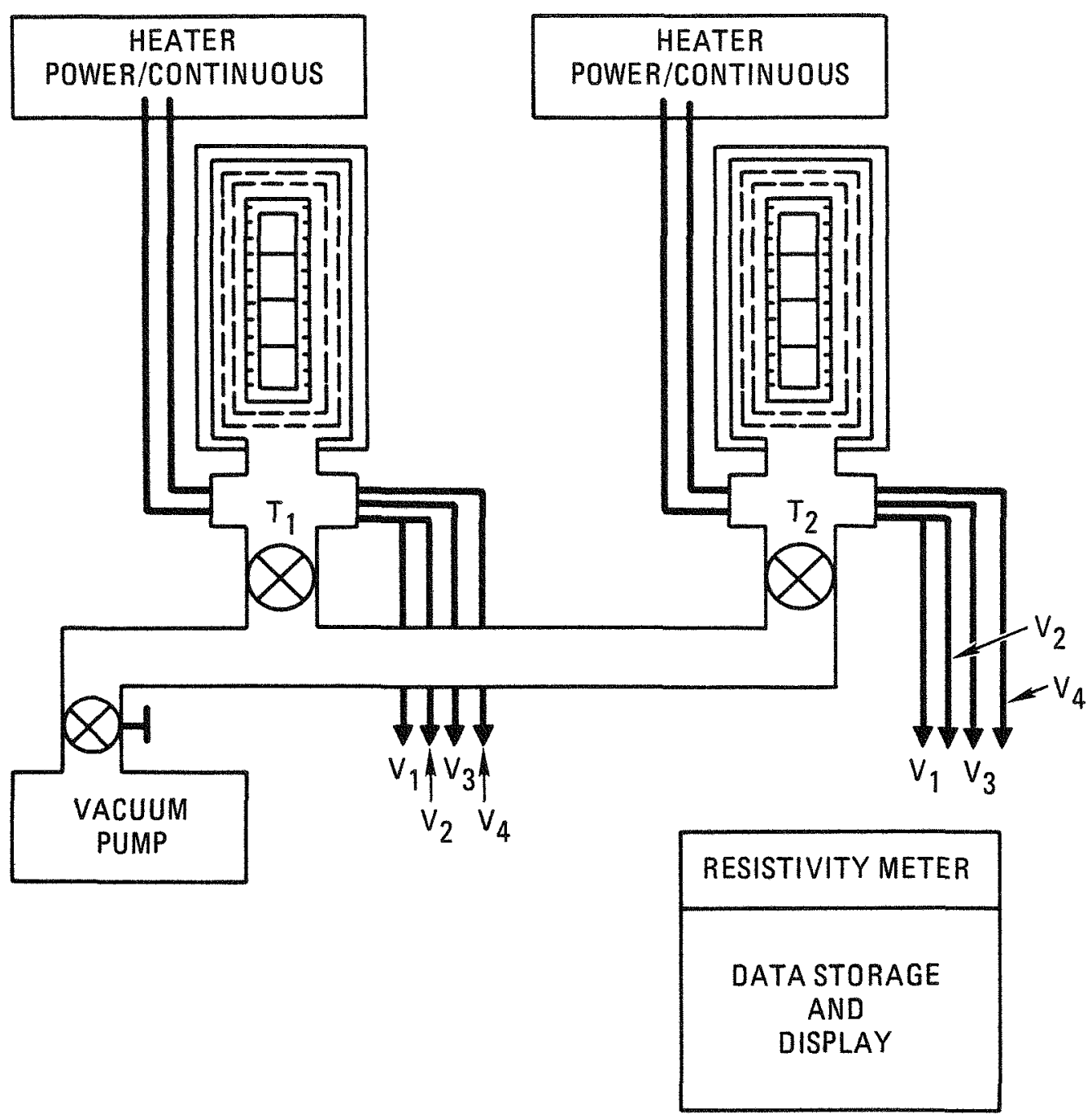

A17773

Fig. 4-8. Electrical conductivity of sheath insulator test stand 
samples will be removed from test stand and inspected for changes in trilayer bonding or structure using metallurgical tests. Figure $4-9$ shows sheath samples under test conditions.

\subsubsection{Electrical Properties and Conductivity Data to Support Analytical Work}

Measurements will be made, as suggested by required analytical modeling work. In particular, test samples will be electrically stressed in vacuum at 1000 to $1400 \mathrm{~K}$ and 400 to $2000 \mathrm{~V} / \mathrm{cm}$. Electrical conductivity will be frequently measured to enable an accurate time history. occasionally, I-V sweeps will be made to detect changes from a purely resistive load. Tests will be modified and samples replaced as required to best research the electrical conductivity degradation behavior of the ceramics tested. Some accelerated tests for electrolytic changes will be performed by operating sheath insulator samples at temperatures and/or electric fields higher than design conditions.

The vacuum system and DAS for the thermal conductance tests are complete and awaiting test specimens. Systems for electrical behavior tests have been completed. Ovens similar to those used for the cesium compatibility tests are being fabricated (see Figs. 4-7 through 4-9). They are larger and modified to use all refractory materials to avoid metal spray on electrical insulators. To break in the equipment, testing will begin on preliminary test samples as soon as they are delivered.

\subsubsection{Resistance to Debonding in Preapplication Period}

As required to support the fabrication phase and to establish the stability of the sheaths during temperature cycling, sheath insulators will be temperature cycled 10 times from 500 to $1200 \mathrm{~K}$ in vacuum. Each cycle will last about $1 \mathrm{~h}$. After the test, the sheath will be inspected again for debonding. As required, metallographic tests will inspect the trilayer bonding. 


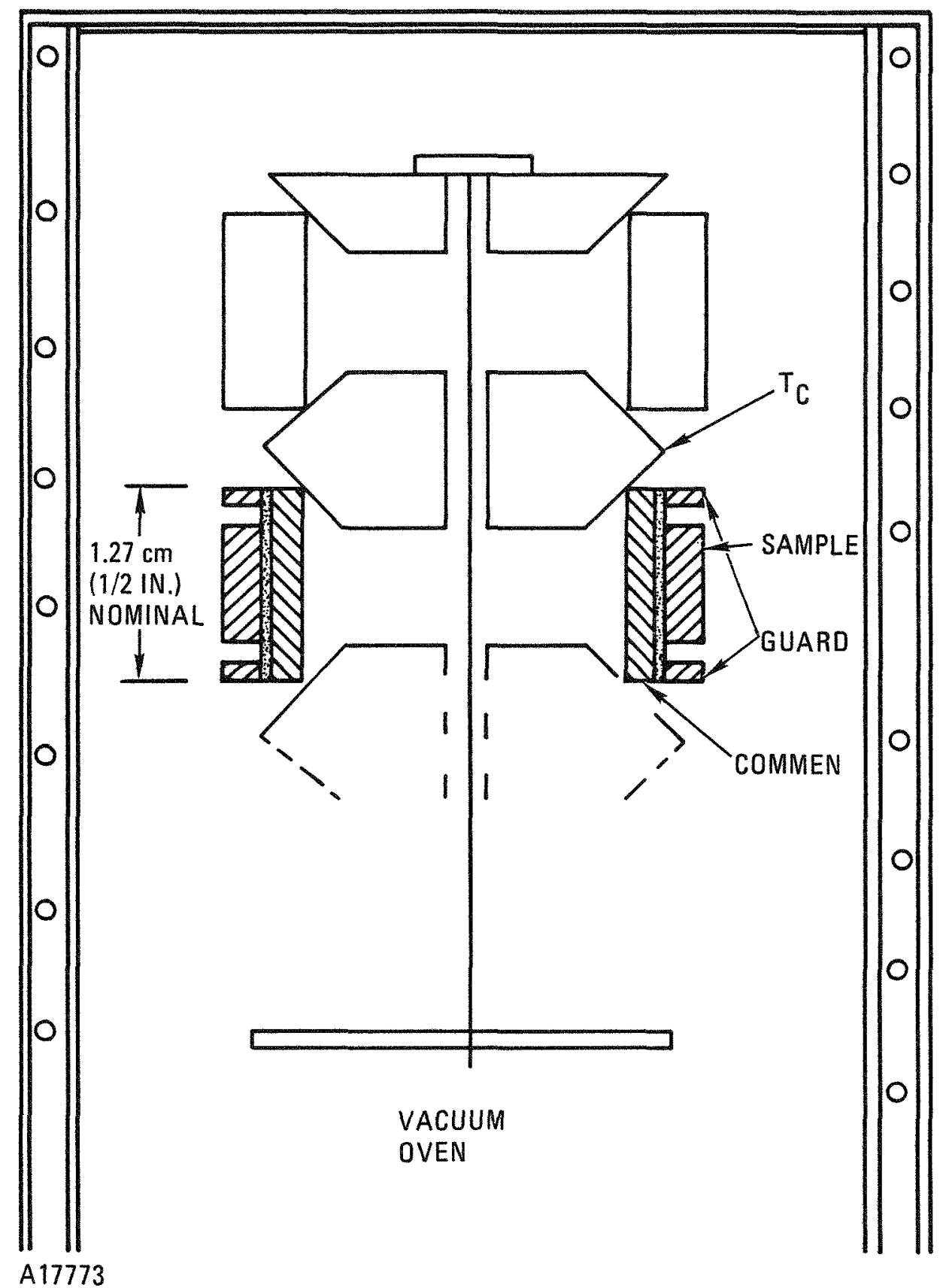

Fig. 4-9. Sheath sample in test oven 
4.4. SHEATH INSULATOR ANALYSES

4.4.1. Electrolytic Degradation in Ceramic Insulators

The application of an electric field across an ionic conductor can cause separation and transport of lonic species, much like in a conventional electrochemical cell. This ionic transport can result in breakdown of the insulator structure and severe degradation of its insulating properties. All ionic conductors are subject to electrolytic effects to varying degrees, depending on temperature, electric field, electrical resistivity, and ionic transference number. In the case of oxide materials, the ionic transference number and the electrical conductivity are generally strong functions of oxygen pressure, which controls their defect structure. Figure 4-10 illustrates the oxygen pressure dependence of the ionic transference number, $t_{i o n}$, and the electrical conductivity in yttria.

For a high tion and a high electrical conductivity, the electrolytic degradation can be severe in the absence of an oxygen source external to the ceramic insulator. In the case of $\mathrm{Y}_{2} \mathrm{O}_{3}$ sandwiched between two layers of niobium, since the low $\mathrm{PO}_{2}$ controlled by the $\mathrm{Nb} / \mathrm{Nb}_{2} \mathrm{O}_{5}$ reaction results in an ionic transference number much less than unity, electrolytic effects are not likely to be a major problem. However, because of the relatively low resistivity of $\mathrm{Y}_{2} \mathrm{O}_{3}$, this should be confirmed experimentally.

Current carried by electrons is expected to strongly dominate ionic currents in typical materials that would be suitable choices for sheath insulators. However, ionic currents cause permanent electrolytic changes in the insulator properties. These changes should be detectable in accelerated electrolysis tests by operating samples at temperatures and electric fields higher than the design conditions. The changes in properties could include departure from ohmic conduction (the sheath insulator assembly becomes a rectifying junction), changes in the electrical 


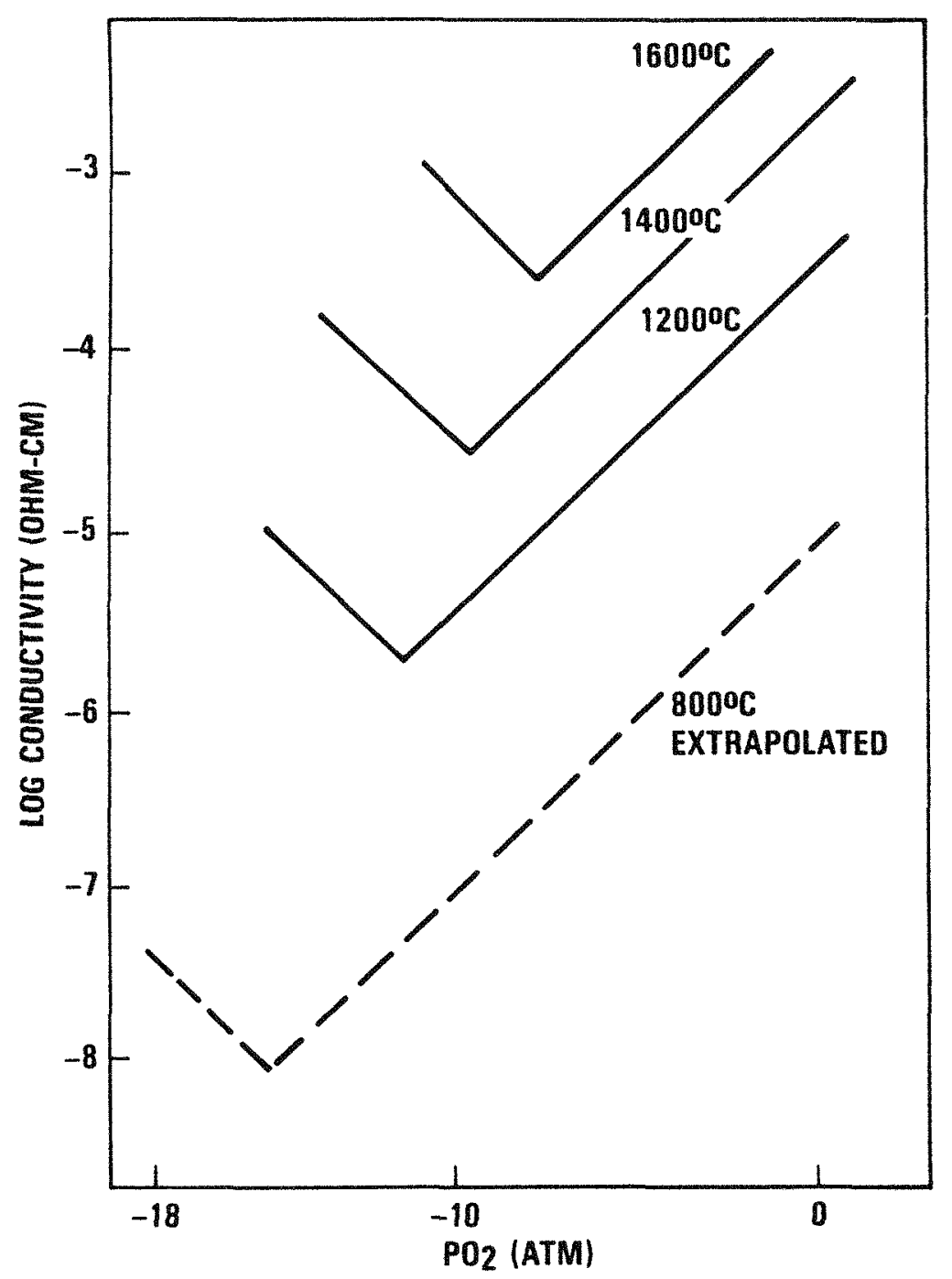

FROM TALLAN AND VEST

A17773

Fig. 4-10. Electrical conductivity and transference number for $\mathrm{Y}_{2} \mathrm{O}_{3}$ (sheet 1 of 2) 


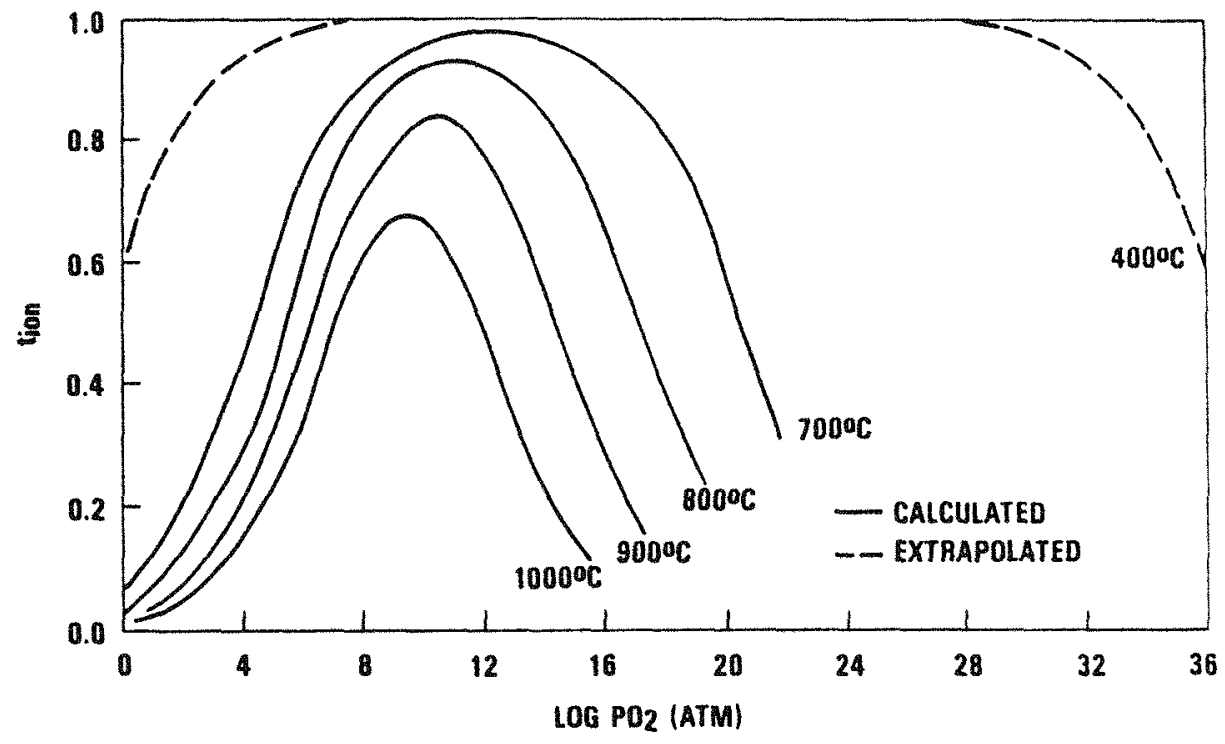

IONIC TRANSFERENCE NUMBEA OF UNDOPED $\mathrm{Y}_{2} \mathrm{O}_{3}$ AS A FUNCTION OF OXYGEN PARTIAL PRESSURE DETERMINED FROM am! MEASUREMENTS

A17773

Fig. 4-10. Electrical conductivity and transference number for $\mathrm{Y}_{2} \mathrm{O}_{3}$
(sheet 2 of 2 ) 
and thermal conductivities, and redistribution of the elemental composition in insulator materials.

\subsubsection{Analytical Modeling}

An analytical model has been developed to predict the timedependence of the electrical conductivity and material transport in the sheath insulator. Two levels of approximation are being used. In the first-order model, the ionic conductivity for the electrically stressed ceramic is expressed as a function of temperature, the activation energy for transport of an ion, and the electric field.

The first-order analytical model is based on the assumption that the ionic conductivity in an electrically stressed ceramic can be approximately expressed as a function of temperature, the Gibbs energy which binds an ion, and the electric field, as shown in Fig. 4-11. For the temperature and electric field regime in the present applications, the ionic current is expected to be approximately linear with electric field and to have an Arrhenius temperature dependence.

Data obtained in the testing program are designed to establish the validity of this first-order approximation. Accelerated tests will be done by operating a sheath insulator sample at high temperature and/or electric field until the properties have changed beyond some preselected 1imits. The time for these changes to occur is assumed to be proportional to $\mathrm{J}_{i o n}$, and thus, the reciprocal of the degradation time for samples at various temperatures should show an Arrhenius form. Figure 4-12 shows an example of the type of data that these accelerated tests may produce. Such a plot can then be extrapolated to predict relative rates of ion transport at typical values of operating temperatures and electric fields.

The analytical model is being extended to a second order of approximation by treating the sheath insulator as a multilayer structure, with a central ceramic layer bounded by layers of metal. The transport of both 


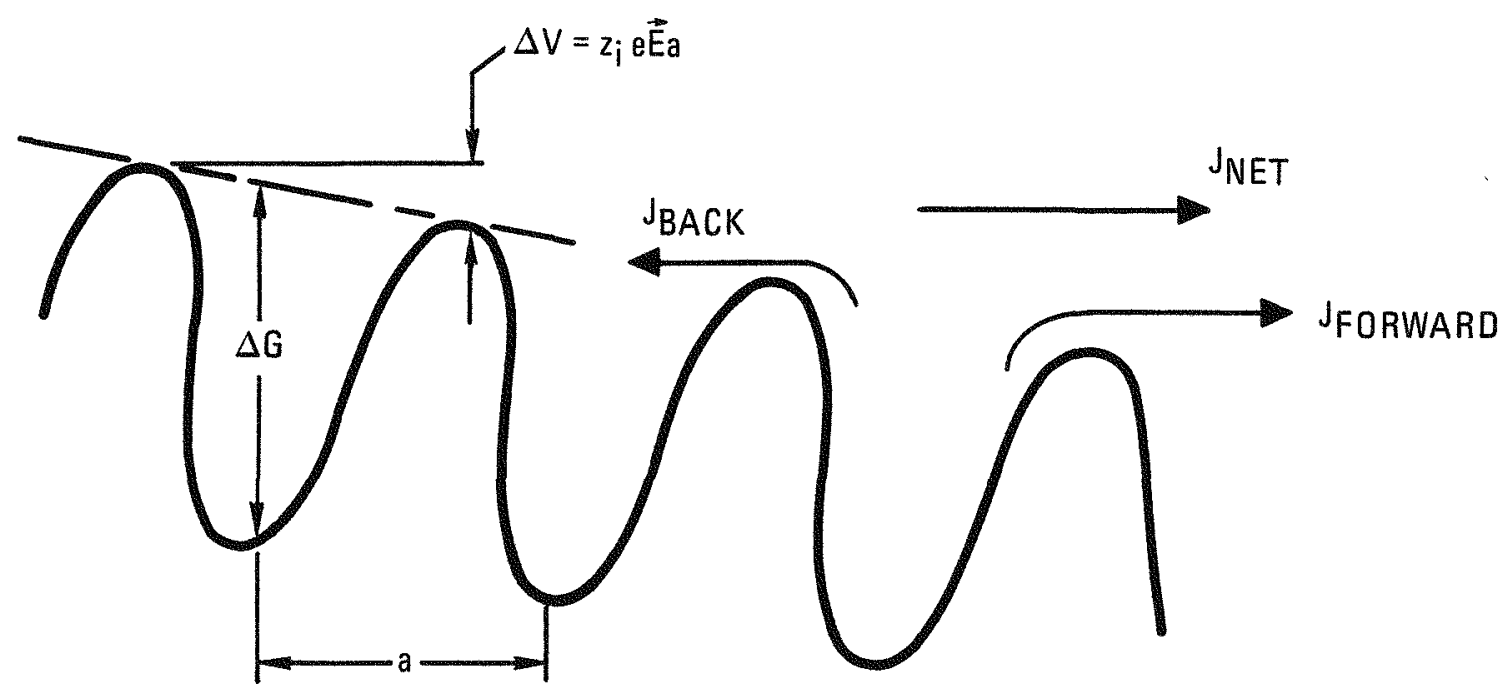

POTENTIAL BARRIERS FOR ION TRANSPORT WITH APPLIED ELECTRIC FIELO

FORWARD ION CURRENT

$$
J_{F O R W A R D}=K \exp \left[\frac{-\Delta G+(\Delta V / 2)}{k T}\right]
$$

REVERSE ION CURRENT

$$
J_{B A C K}=K \exp \left[\frac{-\Delta G-(\Delta V / 2)}{k T}\right]
$$

NET ION CURRENT

$$
\begin{gathered}
J_{N E T}=K \exp \left(\frac{-\Delta G}{k T}\right) \operatorname{sinH}\left(\frac{\Delta V}{k T}\right) \\
J_{N E T}=K\left(\frac{z_{i} \operatorname{eaE}}{2 k T}\right) \exp \left(\frac{-\Delta G}{k T}\right) \\
\text { FOR } \Delta V=z_{i} \text { eE } \ll<2 k T
\end{gathered}
$$

A17773

Fig. 4-11. Correlation model of ion transport 


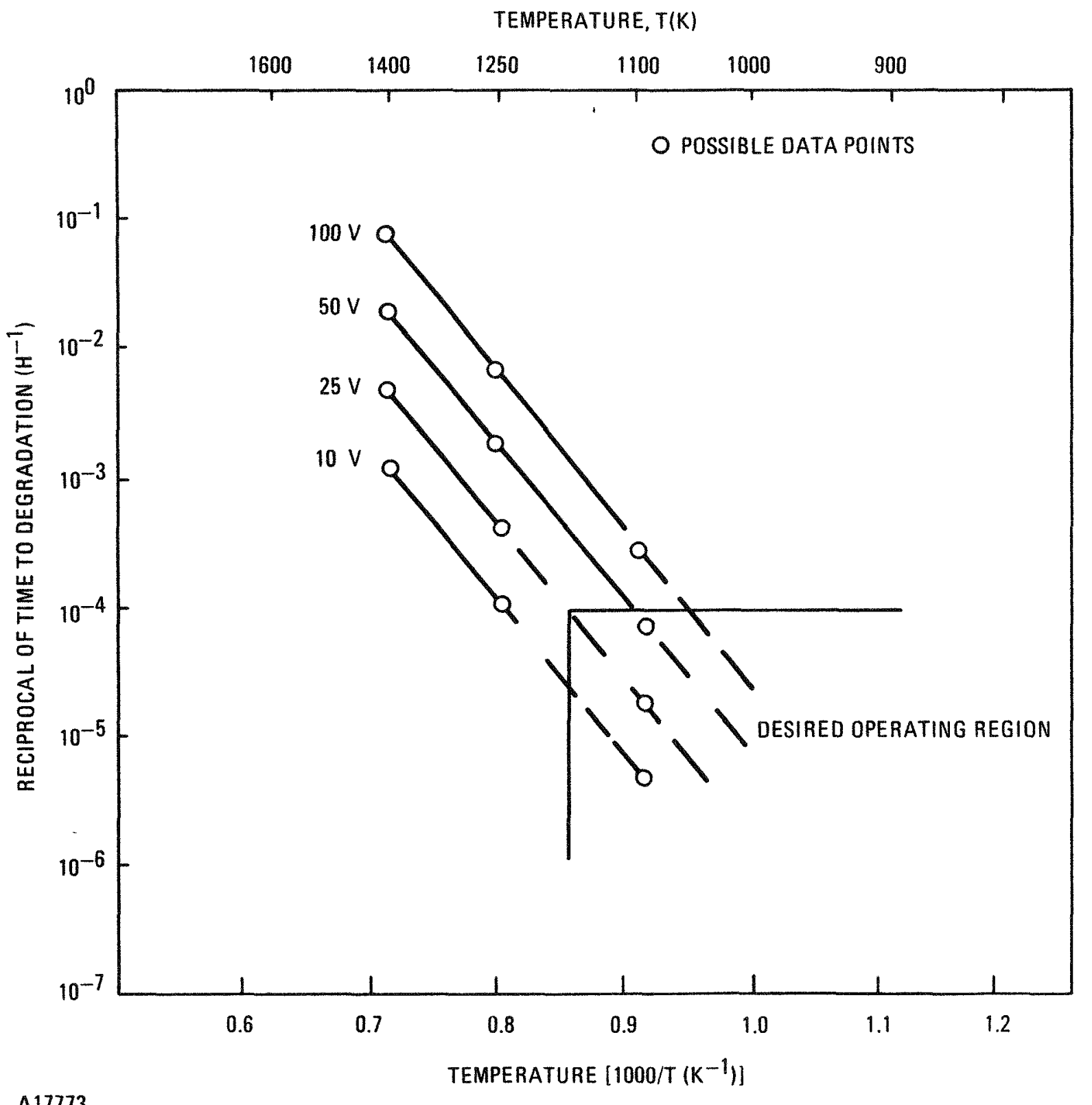

A17773

Fig. 4-12. Example of possible data to be obtained from accelerated electrolysis tests 
ions and electrons through the structure is modeled with a numerical solution of transport-continuity equations in each region and by matching boundary conditions at the interfaces and edges. The transport of electrons is treated with the band theory of insulators. Transport coefficients for the most mobile ions in the lattice will be obtained from calculations based on chemical equilibria involving the materials, the temperature, and the oxygen pressure.

Additional processes can be imagined to occur at the electrodes when an electric field is applied. Figure 4-13 depicts such a process schematica11y. At the anode interface, $\mathrm{O}^{-}$ions tend to be attracted to the anode when field $\mathrm{E}$ is applied. Some of them are captured in the niobium anode, leaving behind a charged oxygen vacancy, represented as $\mathrm{V}_{\mathrm{o}}{ }^{+}$, which will start moving toward the cathode. The anode acts like a source of oxygen vacancies. Likewise, at the cathode interface, the electric field, which tends to drive the oxygen vacancies into the cathode, should increase the recombination rate.

A computer program which solves finite difference forms of the continuity equations for vacancy transport has been prepared and is being used for initial parametric study. A steady-state solution is obtained for some boundary conditions. This steady state can also be solved in analytically closed form. The analytical steady state of the vacancy profile and the computed profile have been compared to check out the computer program. The two profiles agree (see Fig. 4-14).

4.4.3. Degradation Modes

Possible degradation mechanisms which have been identified theoretically (i.e., oxygen anion loss from the cathode or an increase in lattice defects, leading to increased conductivity) will be compared to 


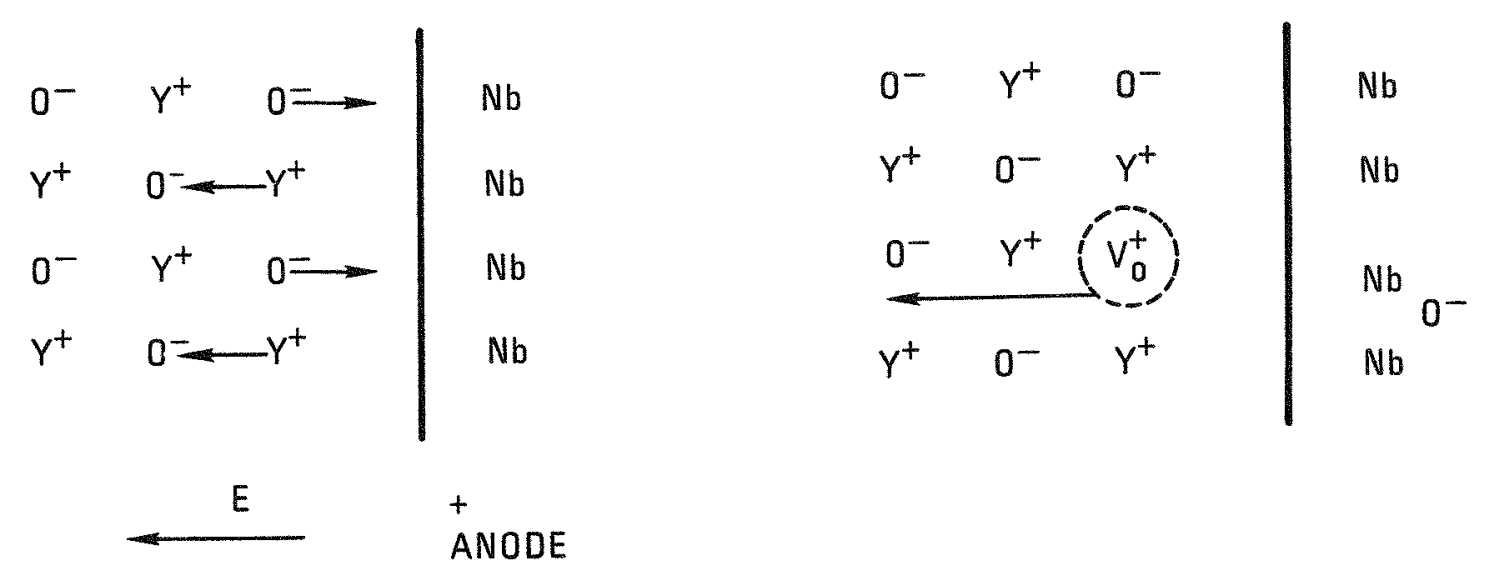

A17773

Fig. 4-13. Generation of oxygen vacancies at the anode of $\mathrm{Nb}-\mathrm{Y}_{2} \mathrm{O}_{3}-\mathrm{Nb}$ cell. (Thermal agitation + electric field favor capture of $\mathrm{O}^{-}$in $\mathrm{Nb}$ anode.) 

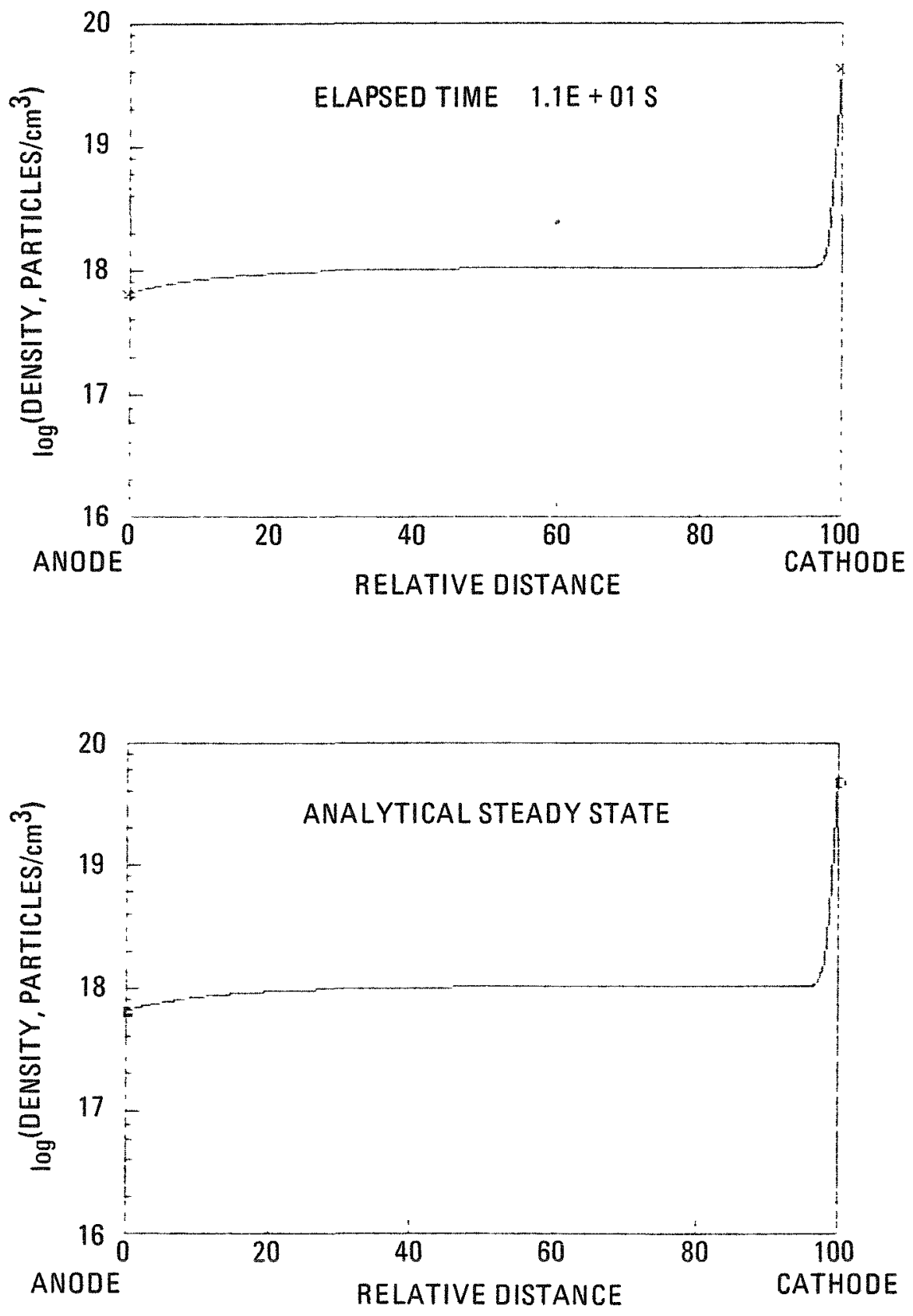

A17773

Fig. 4-14. Comparison of the analytic solution and computed result for steady vacancy profile in $\mathrm{Y}_{2} \mathrm{O}_{3}$ 
the experimental data to verify the model. Two simple modes of electrical degradation are conceivable:

1. An increase in lattice defects with time leads to an increase in conductivity with time.

2. The disappearance of oxygen anions at the cathode interface, as they migrate toward the anode, leads to the growth of a yttrium layer between the niobium cathode and $\mathrm{Y}_{2} \mathrm{O}_{3}$. Even without the mechanical consequences associated with the eventual accumulation of neutral vacancies at the cathode interface, this process results in a decrease in $\mathrm{Y}_{2} \mathrm{O}_{3}$ thickness and an increase in the electric field in time.

A maximum acceptable level of oxygen loss is anticipated to be on the order of $1 \%$ in seven years:

$$
\frac{\mathrm{dN}_{\mathrm{OX}}}{\mathrm{dt}} \text { B } 4.5 \times 10 \frac{11}{\mathrm{a} t o m s} \times \mathrm{cm}^{-3} \times \mathrm{s}^{-1}
$$

For a sheath insulator thickness of $0.5 \mathrm{~mm}$ and a temperature of $1100 \mathrm{~K}$, an activation energy for oxygen to move across the anode interface from $\mathrm{Y}_{2} \mathrm{O}_{3}$ into the niobium must be as follows:

$$
\mathrm{E}^{-} \geqq 3.85 \mathrm{eV}
$$

This is a very sensitive parameter, since the same level of degradation is obtained in only one year if $\mathrm{E}_{r}=3.66 \mathrm{eV}$. Values of that order do not appear unrealistic. Obviously, a way of evaluating or measuring this parameter is needed to assess the insulator lifetime.

Post-test analyses of sheath trilayer samples should help in choosing a realistic model. These analyses will then be used to project the Iffe characteristics of the sheath insulator and its acceptable operating environment. 


\section{CONVERTER PERFORMANCE}

\subsection{TASK OBJECTIVES/APPROACH/REQUIREMENTS}

\subsubsection{Objectives}

This task has three objectives:

1. Produce a reliable correlation between the emitter temperature and the electrical behavior of a test device similar to the fueled emitter capsule.

2. Select a suitable method for obtaining oxygenated performance, based on previous data and planar converter tests.

3. Measure thermal and electrical performance of an oxygenated converter cell that is approximately prototypic of the reactor designs and monitor their stability with time.

In addition, the G-series diode, which operated $14,000 \mathrm{~h}$ with electrical heating, will be analyzed with a variety of diagnostic techniques.

\subsubsection{Performance Requirements}

The specific performance requirements are as follows:

1. Electric power density of $2.5 \mathrm{~W} / \mathrm{cm}^{2}$.

2. Current density of $5.9 \mathrm{~A} / \mathrm{cm}^{2}$.

3. Output potential of $0.42 \mathrm{~V}$.

These performance goals will be achieved at an emitter temperature of $1700 \mathrm{~K}$, a collector temperature of $1085 \mathrm{~K}$, and an interelectrode spacing 
of $0.5 \mathrm{~mm}$ (20 mils). These performance goals are subject to change depending on $\mathrm{SP}-100$ system requirements and design analyses.

\subsubsection{Approach}

Figure 5-1 gives the logic diagram for the converter performance task. After a review of the converter performance data base, the two most promising technical approaches for achieving the performance requirements were chosen: (1) use of molybdenum coatings sublimed onto a niobium collector in a low-pressure oxygen atmosphere and (2) use of a cesium-cesium oxide vapor in the interelectrode space. Encouraging results have been found using both technical approaches.

These options will be explored using variable-spacing planar converters within the time and resource constraints of the program. The best performing electrode pairs and reservoirs will be selected for the interelectrode spacing and temperatures of the GA baseline system design. Two planar converters have been tested: (1) an oxygenated collector and (2) an external cesium oxide reservoir. Sections 5.2 and 5.3 describe the results.

Cylindrical converters will be built with the selected electrode pairs. The design of these cylindrical converters will be as prototypic of the baseline TFE as possible. Two cylindrical converters are being supplied by TE for testing at RA. The first test device, TD-1, will test emitter temperature correlation. It is an analog to the in-core fueled emitter test capsule. This part of the cylindrical converter effort supports the fueled emitter deformation task. RA will parametrically characterize the thermal and thermionic emission characteristics of this ana$\log$ in order to recommend in-core emitter temperature correlations. Data may include cesiated emitter work function, effective emitter emissivity, electron cooling parameters, and ignition current characteristics.

A test facility, including a vacuum system, a driving supply, and heater-coolers, has been prepared for $\mathrm{TD}-1$. The techniques used in the 

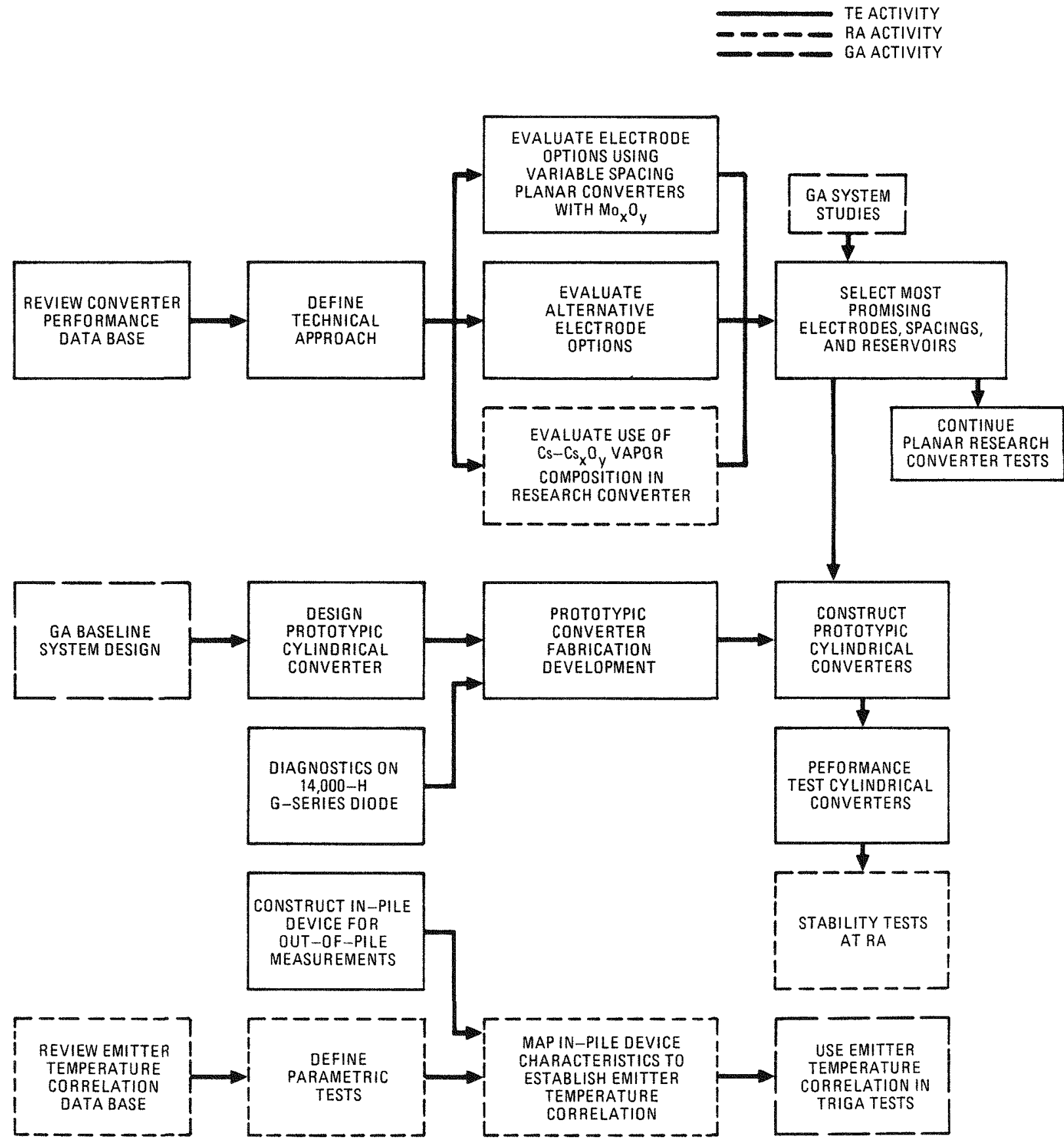

A 17773

Fig. 5-1. Idealized task logic 
previous program to measure in-pile emitter temperature, based on electrical and thermal characteristics, have been reviewed, and the data required for the TD-1 test have been identified (see Section 5.4).

Accuracy requirements for the salient test parameters are as follows :

$\begin{array}{ll}\text { Emitter temperature } & \leq-20 \mathrm{~K} \\ \text { Collector temperature } & \leq \pm 15 \mathrm{~K} \\ \text { Reservoir temperature } & \leq 44 \mathrm{~K} \\ \text { Interelectrode spacing } & \leq .2 \mathrm{mils} \\ \text {.Efficiency of cylindrical } & \leq 1 \%\end{array}$
converters

The anticipated parameters ranges are as follows:

$\begin{array}{lc}\text { Emitter temperatues } & 1600 \text { to } 1900 \mathrm{~K} \\ \text { Collector temperatures } & 850 \text { to } 1100 \mathrm{~K} \\ \text { Interelectrode spacings of } & 10 \text { to } 40 \mathrm{mils} \\ \text { planar converters } & \\ \text { Cesium pressures } & 0.1 \text { to } 3.0 \text { torr }\end{array}$

The most critical measurement is emitter temperature. It will be determined by thermocouples and optical pyrometer determinations for planar converters and by thermocouples for cylindrical converters. All other temperature measurements will use thermocouples.

The second cylindrical converter will be fabricated by TE and performance tested at RA. Figure 5-2 shows the design of the prototypic cylindrical converter. The emitter diameter, emitter length, and interelectrode spacing correspond to the SP-100 thermionic reactor design. In this design, the electrodes are much thicker than the prototype in order 


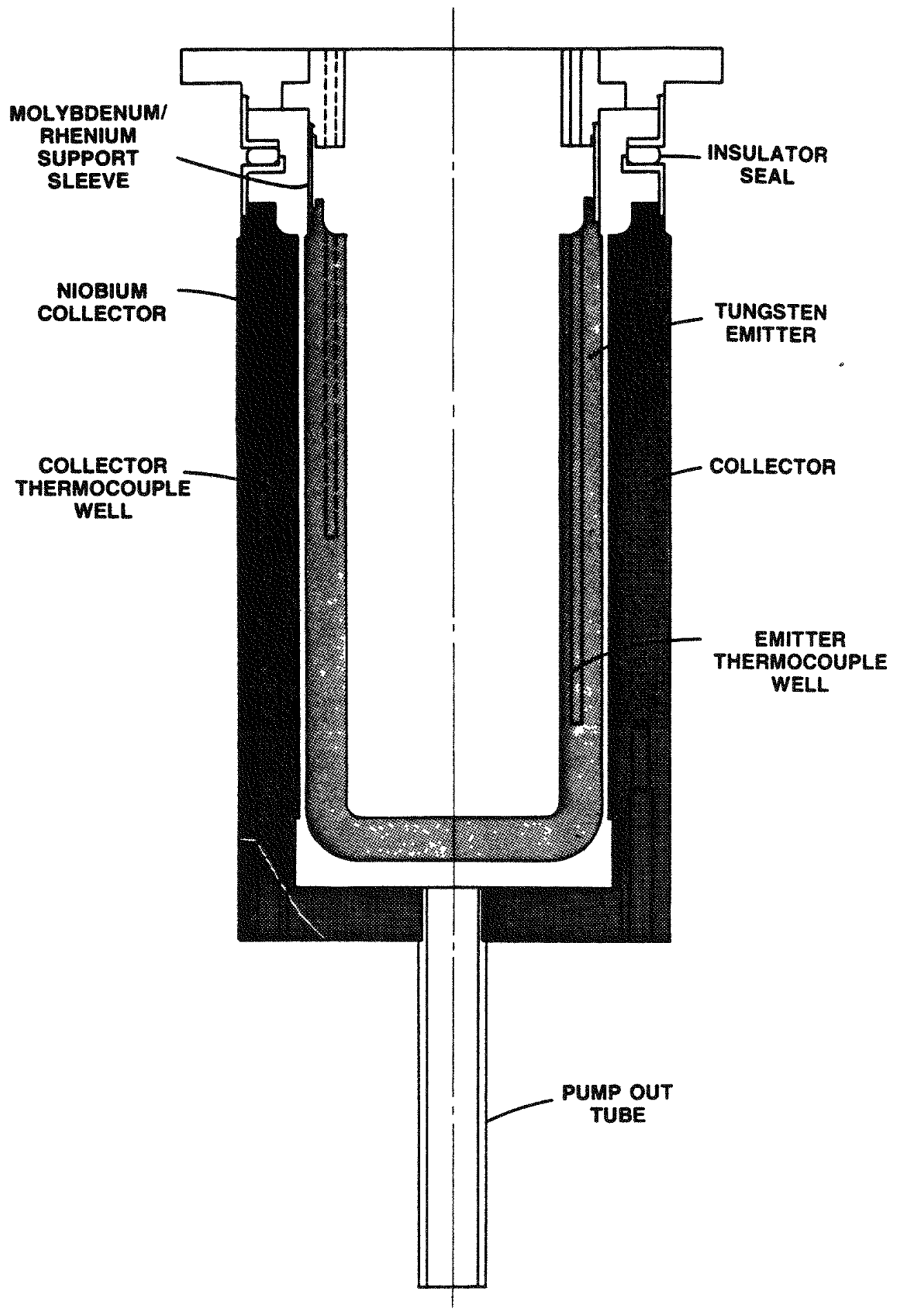

A17773

Fig. 5-2. Prototypic cylindrical converter 
to measure the emitter and collector temperatures accurately by inserting thermocouples. Because of the extra thick emitter and collector, the potential losses along these electrodes will be lower than in a TFE. In order to minimize this discrepancy, several design options are being evaluated for reducing electrode thickness.

The converter will be tested to measure electrical and thermal performance. The performance stability will also be monitored. A modified test arrangement will be used for the cylindrical converters to allow static testing with a de load. It will provide for calorimetric measurement of the heat rejected from the collector so that an efficiency determination can be made. The same test stand equipment, as built for TD-1, will be used for testing the second converter.

The thermionic diode for establishing the correlation between electrical output and emitter temperature is quite similar to the in-pile unit shown in Fig. 2-4. The primary differences are that it will be heated out-of-pile by electron bombardment and that the emitter is thicker to accommodate thermocouple wells. As with the in-pile devices, the spacing is $1.0 \mathrm{~mm}$ and the collector is polycrystalline niobium. RA will map the output characteristics of this diode to establish correlation to the emitter temperature.

\subsection{CONVERTER PERFORMANCE OF AN OXIDE-COLLECTOR CONVERTER}

Tests at TE have demonstrated that thermionic converters built with a sublimed molybdenum coating on niobium collectors can provide signficantly higher power output at interelectrode spacings of $0.5 \mathrm{~mm}$ than diodes with bare collectors. In such a converter, oxygen transport to the emitter increases its current density at a given temperature and cesium presssure. Consequent1y, converters with oxide collectors can operate at lower cesium pressure (relative to those with bare collectors) and reduced potential losses in the plasma at high interelectrode spacings. Additional output can result from the lower collector work function of the oxide. 
In order to provide thermionic performance data relevant to the SP-100 system studies, TE mapped the current-voltage characteristics of converter 282 at collector temperatures between 850 and $1100 \mathrm{~K}$ for emitter temperatures of $1600,1700,1800$, and $1900 \mathrm{~K}$ at interelectrode spacings of 10,20 , and 40 mils. The emitter of this converter was electropolished powder metallurgy tungsten and the collector was molybdenum sublimed in a low-pressure oxygen atmosphere onto niobium. A piece of identically coated niobium was analyzed as having an oxygen concentration of $9140 \mathrm{ppm}$ by weight. Figure 5-3 shows the configuration of this research converter with planar electrodes. A bellows permits the interelectrode spacing to be varied.

These measurements were primarily intended to investigate, for a given emitter temperature, the sensitivity of output power density as a function of electrode spacing at collector temperatures as high as $1100 \mathrm{~K}$. Previous studies of oxide collector converters had demonstrated the insensitivity of their power density to electrode spacing near the optimum collector temperature (typically around $850 \mathrm{~K}$ ). Figure $5-4$ shows the power density of converter 282 as a function of electrode spacing, parametric in current density, for an emitter temperature of $1700 \mathrm{~K}$ and a collector temperature of $1000 \mathrm{~K}$. The cesium reservoir was optimized as the electrode spacing was varied. These data demonstrate that the electrical output of this converter is remarkably insensitive to electrode spacing under these conditions. This insensitivity was typical for this converter over the entire test ranges of emitter and collector temperatures.

Figure 5-5 gives the current-density - voltage characteristics of converter 282 for six collector temperatures between 850 and $1100 \mathrm{~K}$ and an emitter temperature of $1700 \mathrm{~K}$. These characteristics represent optimized cesium envelopes for an electrode spacing of $0.5 \mathrm{~mm}$. Figure 5-6 presents the corresponding output power density as a function of collector temperature for current densities between 2 and $12 \mathrm{~A} / \mathrm{cm}^{2}$. 


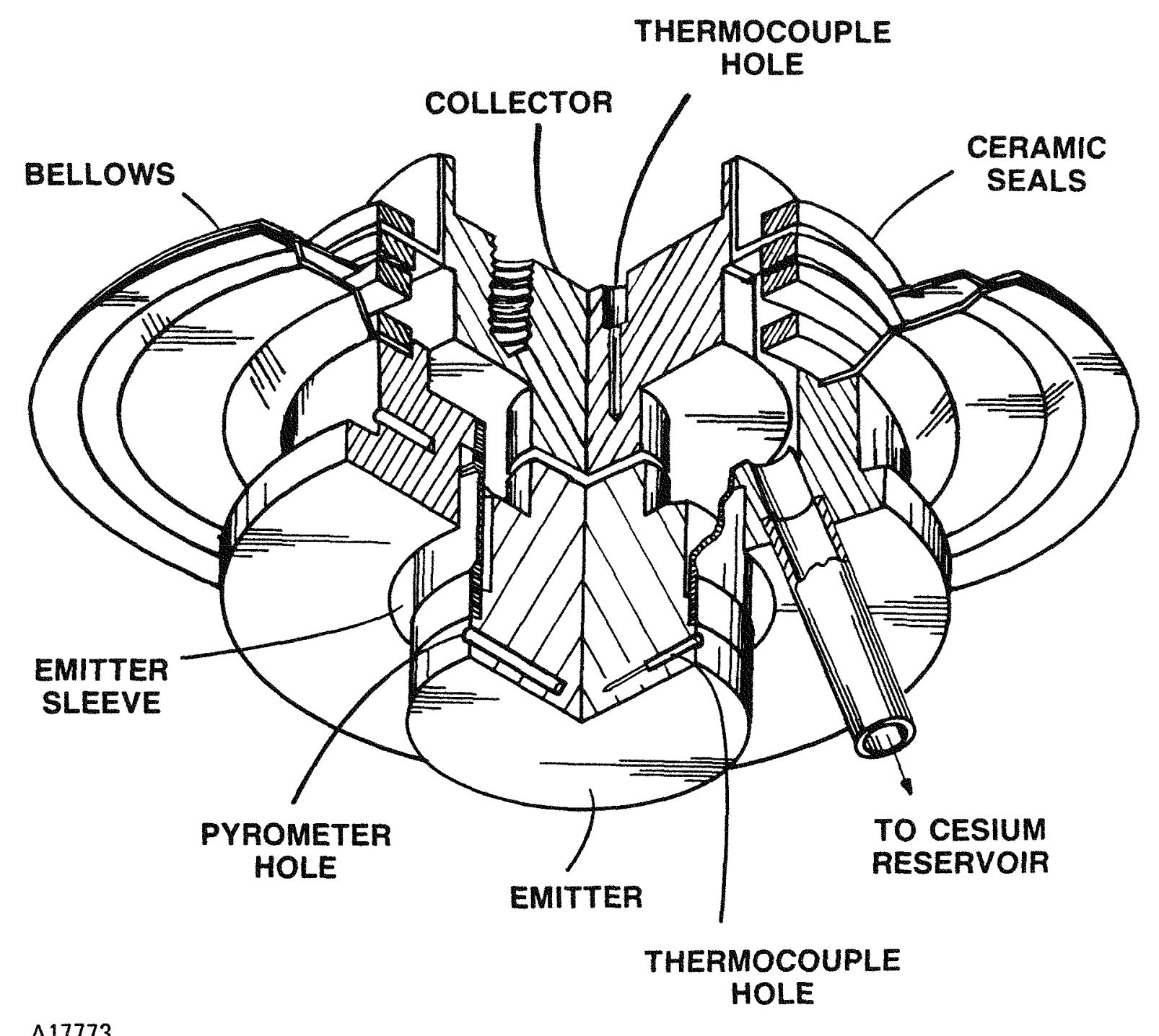

Fig. 5-3. Variable spacing research converter 


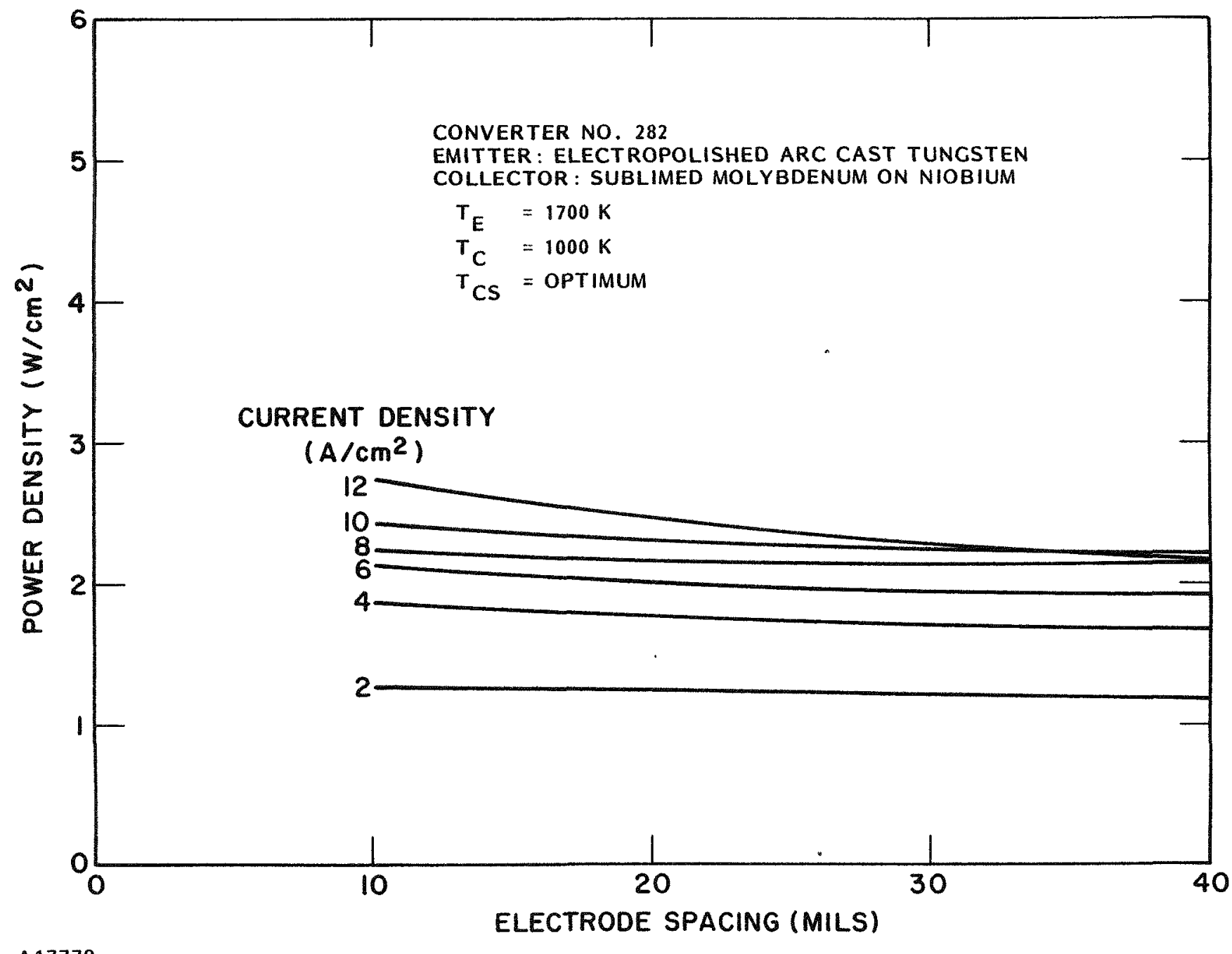

A17773

Fig. 5-4. Electrical power density as a function of electrode spacing, parametric in current density 


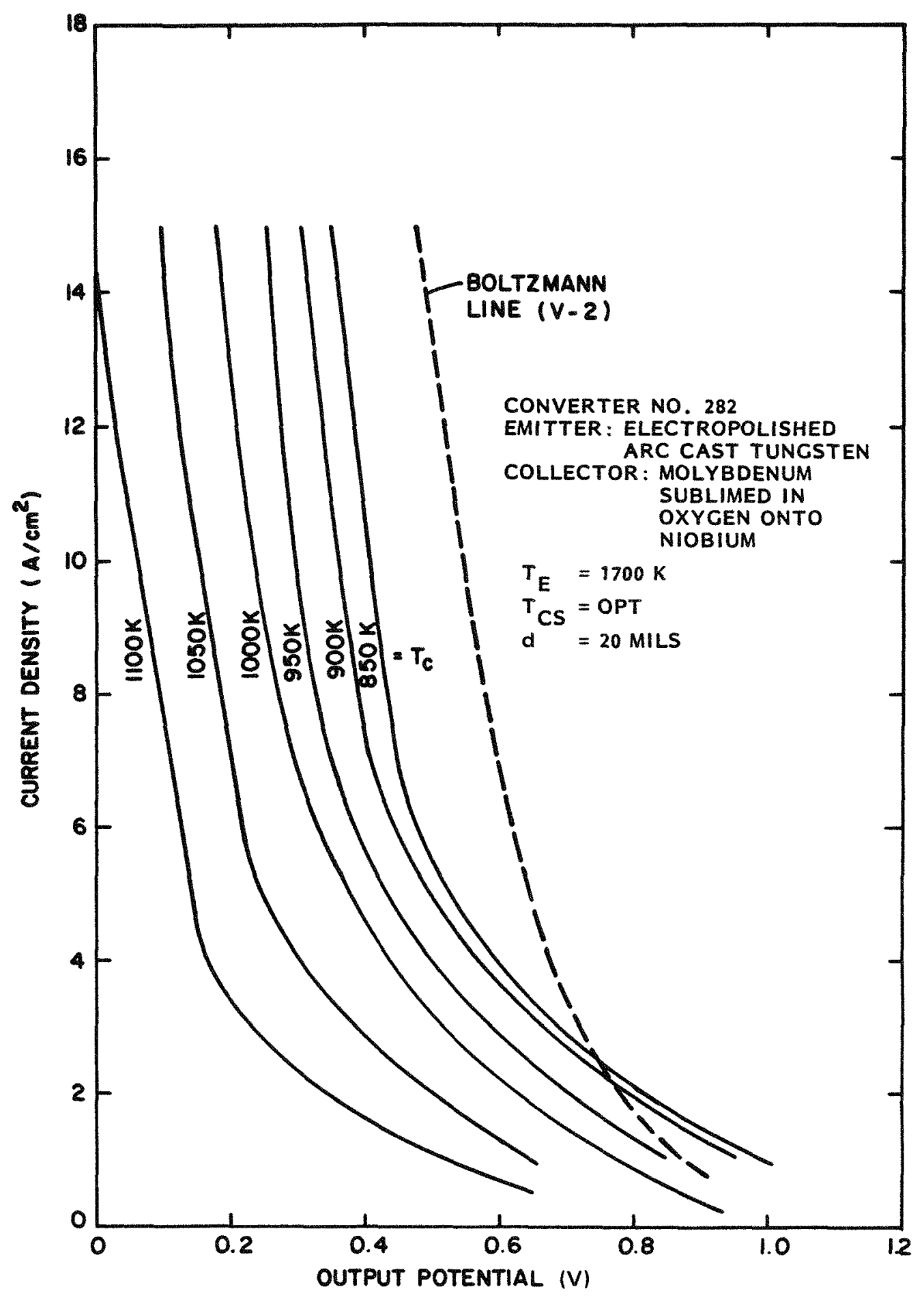

A17773

Fig. 5-5. Optimized current density voltage characteristics for emitter temperature of $1700 \mathrm{~K}$ 


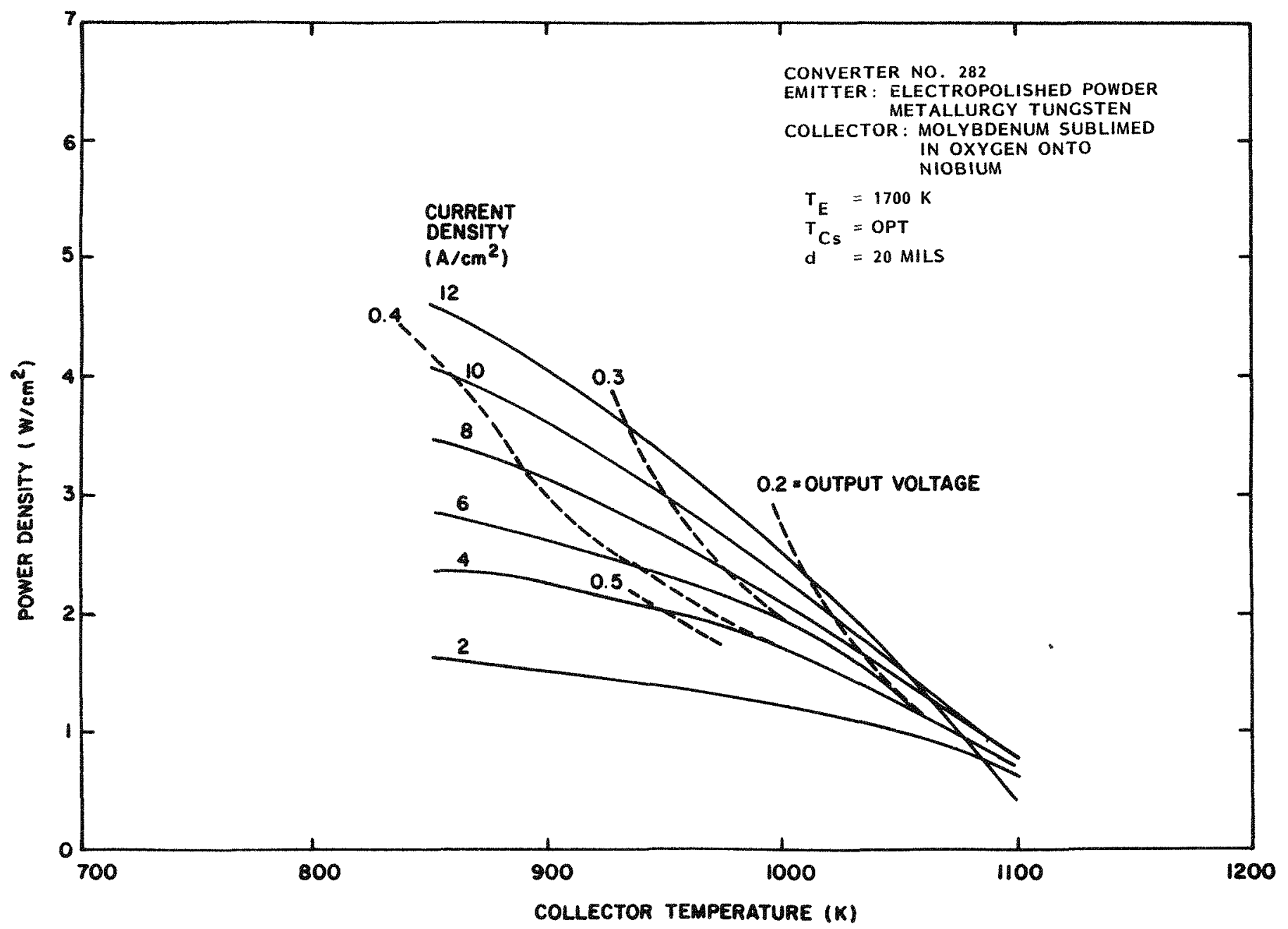

A17773

Fig. 5-6. Electrical power density as a function of collector temperature, parametric in current density 
The foregoing data were taken after converter 282 had been tested for about $800 \mathrm{~h}$ at conditions significantly different from those of the SP-100 program (see Fig. 5-7). Although the data in Figs. 5-5 and 5-6 were taken at equilibrated temperatures, the electrodes did not have time to equilibrate. This fact is evident from the subsequent stability test that began at around $900 \mathrm{~h}$. Over less than $100 \mathrm{~h}$, the output power density increased to $3 \mathrm{~W} / \mathrm{cm}^{2}$ at a spacing of $0.5 \mathrm{~mm}$ and emitter and collector temperatures of 1750 and $1075 \mathrm{~K}$, respectively. Thus, the assumed power output was achieved at test conditions closely approximating those of the GA thermionic reactor baseline system design. Figure 5-8 shows the orderly change in converter 292 output characteristics during this electrode equilibration period.

\subsection{CESIUM-CESIUM OXIDE CONVERTER}

\subsubsection{Dual Reservoir Alternative to Oxygenated Collectors}

Oxygen dispensed to the emitter electrode is desirable in a thermionic converter in order to obtain good performance at wider interelectrode spacings. Previous work developed oxygenated collectors which release oxygen to supply the needs of the emitter surface. An alternative approach, with the potential for longer life, is a converter having dual reservoirs of cesium and cesium oxide, both connected to the interelectrode volume. A converter of this type was recently tested, and oxygenated performance was observed to benefit from the dual reservoirs.

\subsubsection{Converter Design}

The test vehicle is a variable-spacing planar converter. Figure 5-9 shows a cross section of the converter. The converter was modified to accommodate an additional cesium oxide reservoir. Commercial $\mathrm{Cs}_{2} \mathrm{O}$ is introduced in the reservoir in an argon atmosphere and valved off before being connected to the converter. The converter also features a pumpout valve to be connected to an existing outgassing and cesiation vacuum line (see Fig. 5-10). The cesium is transferred to its final reservoir after 


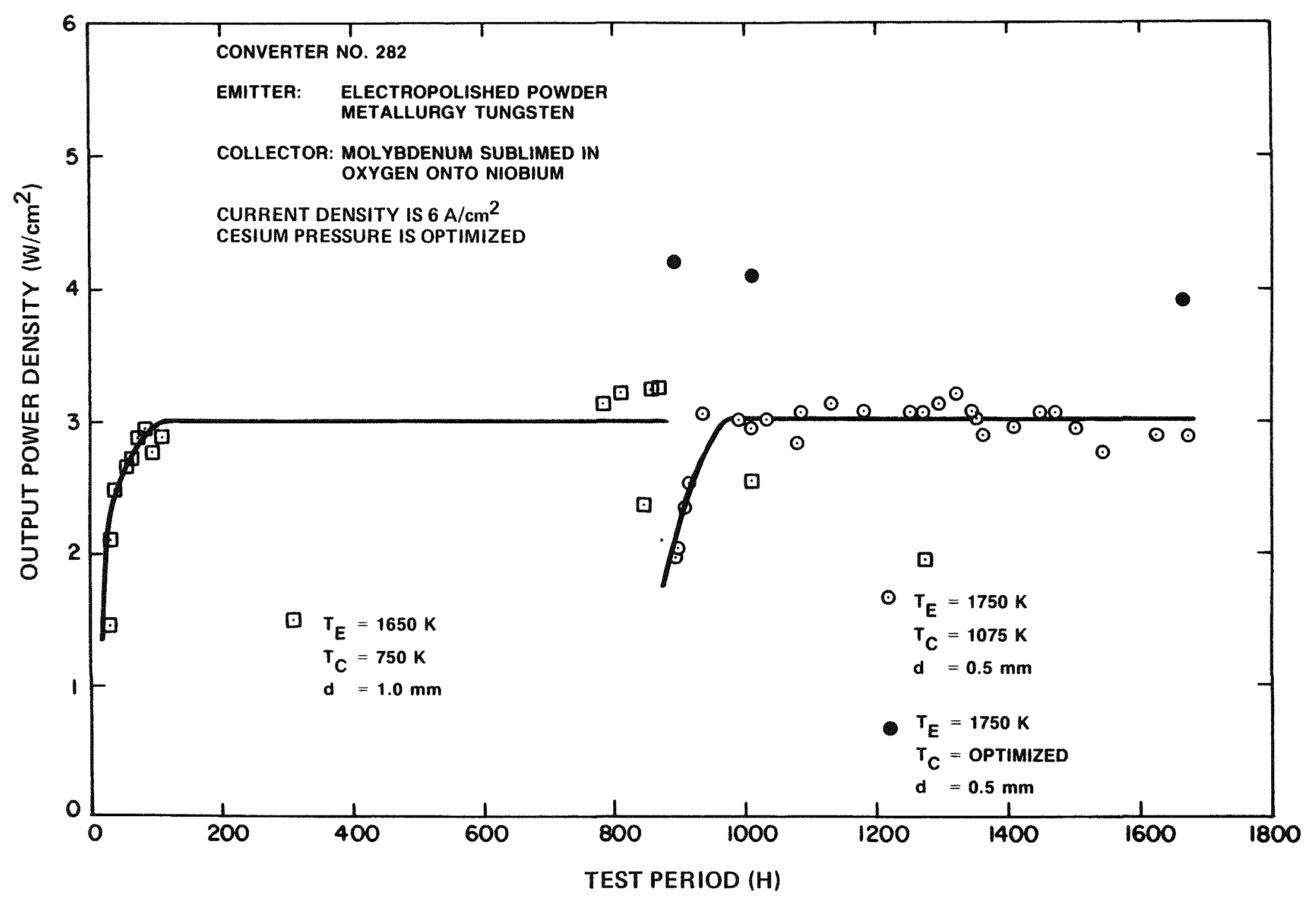

A17773

Fig. 5-7. Output power density of converter 282 as a function of test period 


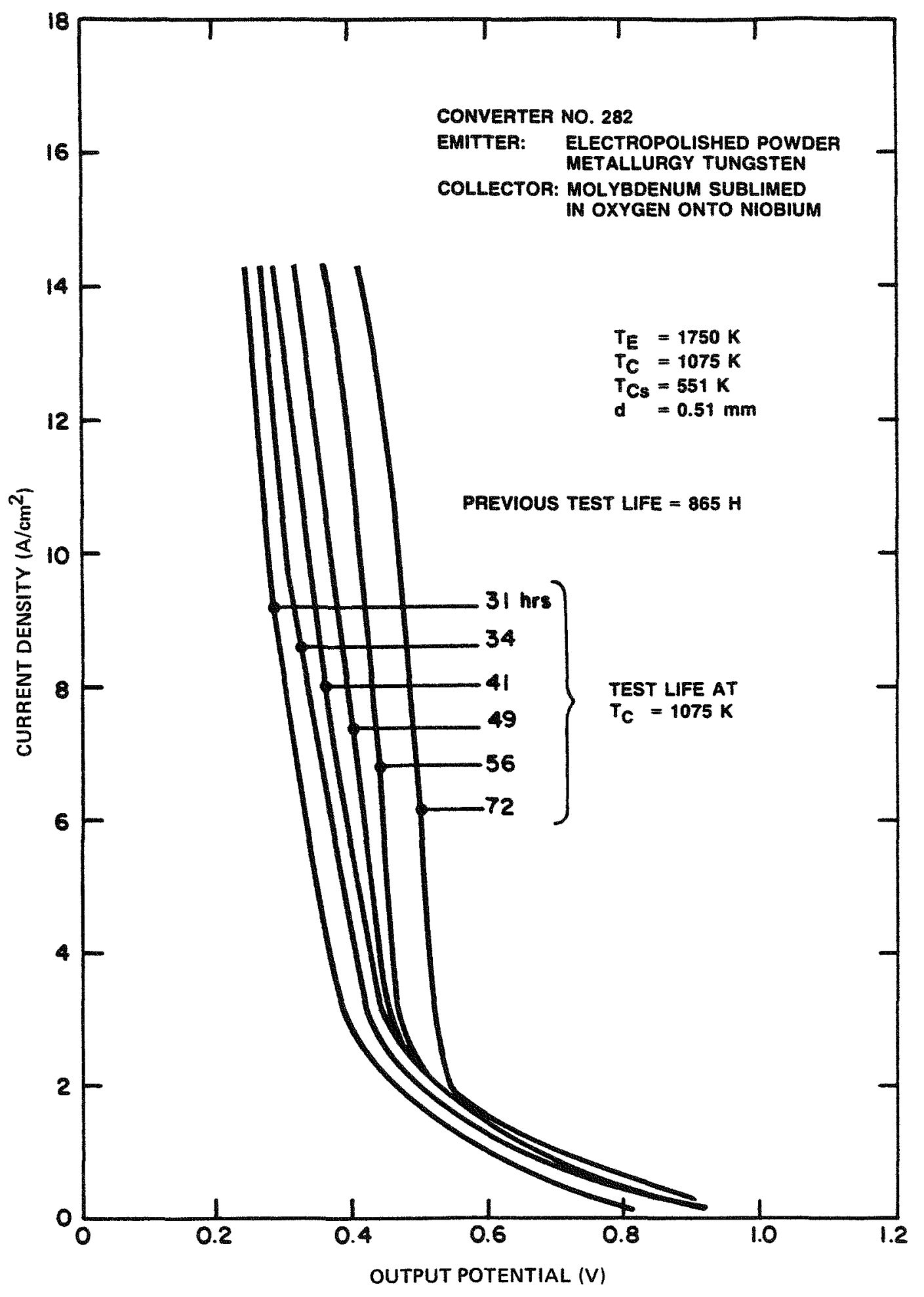

A17773

Fig. 5-8, Current density versus voltage characteristics, parametric in test period at a collector temperature of $1075 \mathrm{~K}$ 


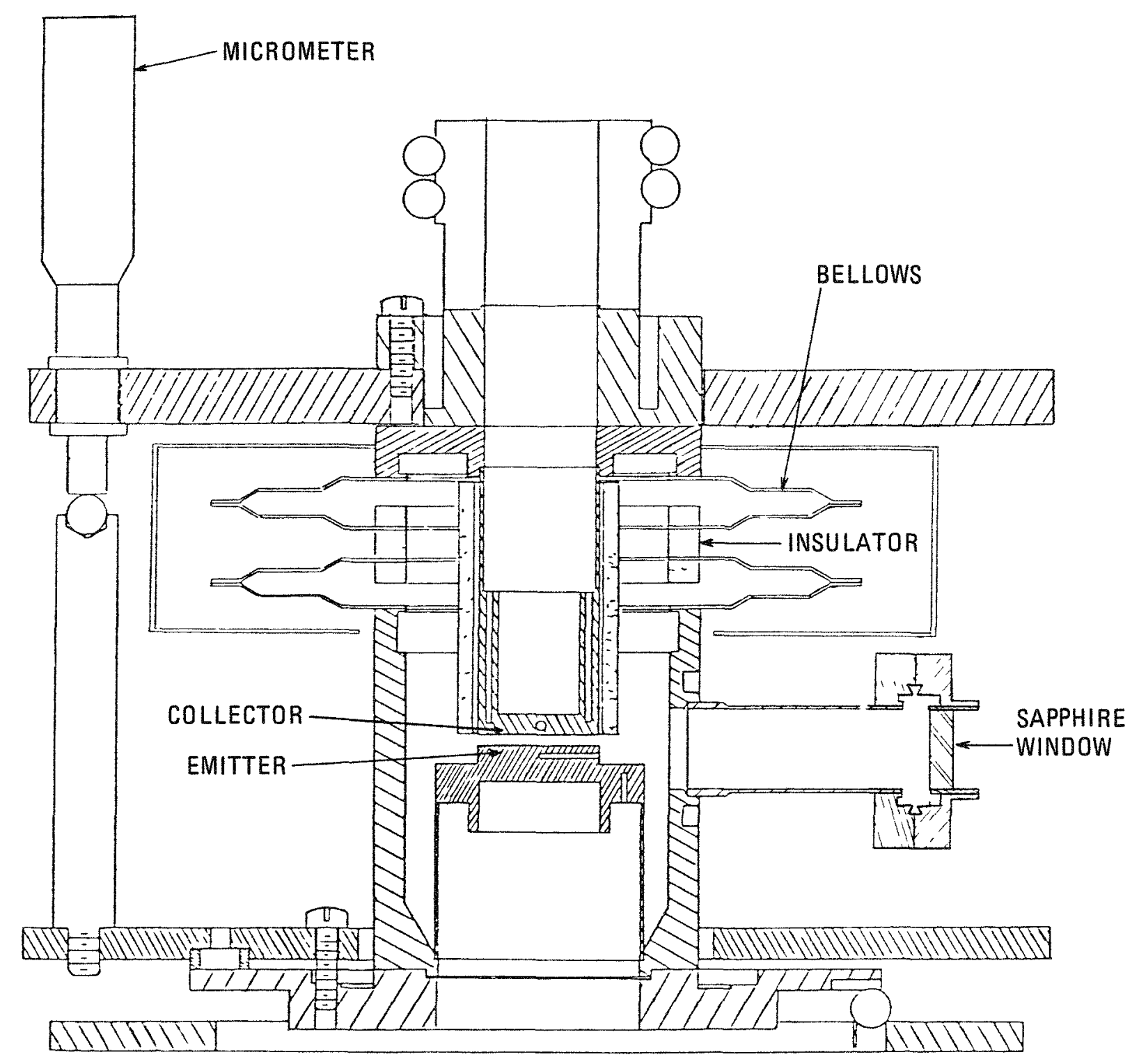

A17773

Fig. 5-9. Variable spacing cesium-cesium oxide converter 


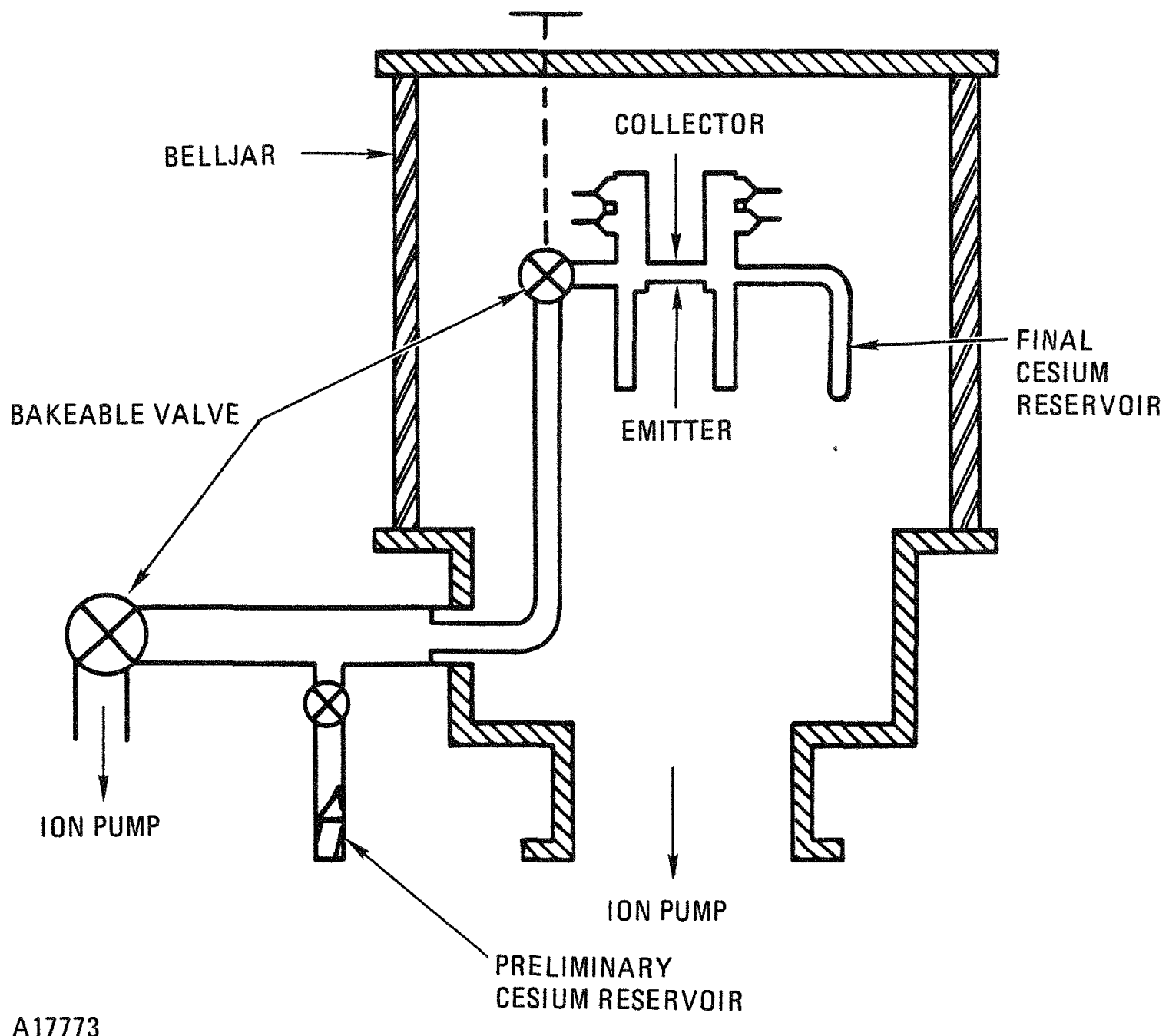

Fig. 5-10. Schematic of apparatus for cesium-cesium oxide converter tests 
recovering the argon in the cesium oxide reservoir. The sapphire window allows visual inspection of the discharge and emitter temperature calibration. The emitter is an electropolished tungsten layer which is chemically vapor-deposited from $\mathrm{WF}_{6}$ on a molybdenum substrate. This layer does not exhibit a strong preferential (100) orientation. The collector is polycrystalline niobium.

The emitter is measured by a tungsten-rhenium ( $W-5 \% \operatorname{Re} / \mathrm{W}-26 \% \operatorname{Re})$ thermocouple, which is calibrated with a micropyrometer. The collector, cesium reservoir, and cesium-oxide reservoir temperatures are determined by chromel-alumel thermocouples. Several more thermocouples also monitor the temperatures of various spots in the whole converter assembly, including window, flanges, bellows, and valves.

\subsubsection{Test Procedures}

During these experiments, the cesium-oxide reservoir was kept at a temperature higher than the cesium reservoir, thereby providing a cesiumoxide pressure 500 to 1000 times lower than the cesium pressure. After finishing the performance mapping with the separate reservoirs, a common reservoir was established by transferring the cesium into the cesiumoxide reservoir. The effect of a common reservoir was then observed.

Throughout the testing, the results will be compared with data obtained at TE on non-oxygenated, close-spaced converters and converters in which a molybdenum-oxide layer deposited on the collector acts as an oxygen dispenser.

\subsubsection{Results}

This cesium-cesium oxide converter test showed that the performance obtained with the dual reservoirs was comparable to an oxygenated collector converter. Good control of both vapors was maintained throughout the test. However, operation at high $\mathrm{T}_{\mathrm{CsOx}}$ could not be maintained for long because of cesium-oxide transfers into the cooler cesium reservoir. 
Figure 5-11 shows a family of $J-V$ curves for the converter which are parametric in both cesium and cesium-oxide pressure.

The performance at $\mathrm{T}_{\mathrm{E}}=1600$ to $1700 \mathrm{~K}$ with $20 \mathrm{mil}$ spacing is similar to a converter with an oxygenated sublimed molybdenum collector. The optimum collector temperature was fairly 1ow $\left(\mathrm{T}_{\mathrm{C}} \cong 800 \mathrm{~K}\right)$. Collector work function determined from ignited back emission appears to be very low (i.e., 1.15 to $1.35 \mathrm{eV}$ ). However, the performance at optimum collector temperature is typical of a converter with a barrier index of $\mathrm{V}_{\mathrm{B}}=2$ to $2.05 \mathrm{~V}$. The performance was observed to degrade at higher collector temperatures. Figure 5-12 shows the variation of performance with $\mathrm{T}_{\mathrm{C}}$ and compares it with a $\mathrm{TE}$ molybdenum oxide collector converter.

Near the end of the test period, the two reservoirs were mixed together, and the converter was operated with only one mixed vapor. The pressure of the cesium-cesium oxide mixture could still be changed with this arrangement, although the relative composition was not controllable. The performance with the mixed reservoir was similar to the earlier data. Very high backcurrents from the collector continued. The collector backcurrent was also observed to vary with the temperature of the emitter as well as with that of the collector. This may indicate positive ion production at the emitter, which is unlike the Saha-Langmuir equation.

The test results indicate that cesium-cesium oxide converters may be a viable alternative to oxygenated collectors if the performance at the design collector temperatures is adequate. 


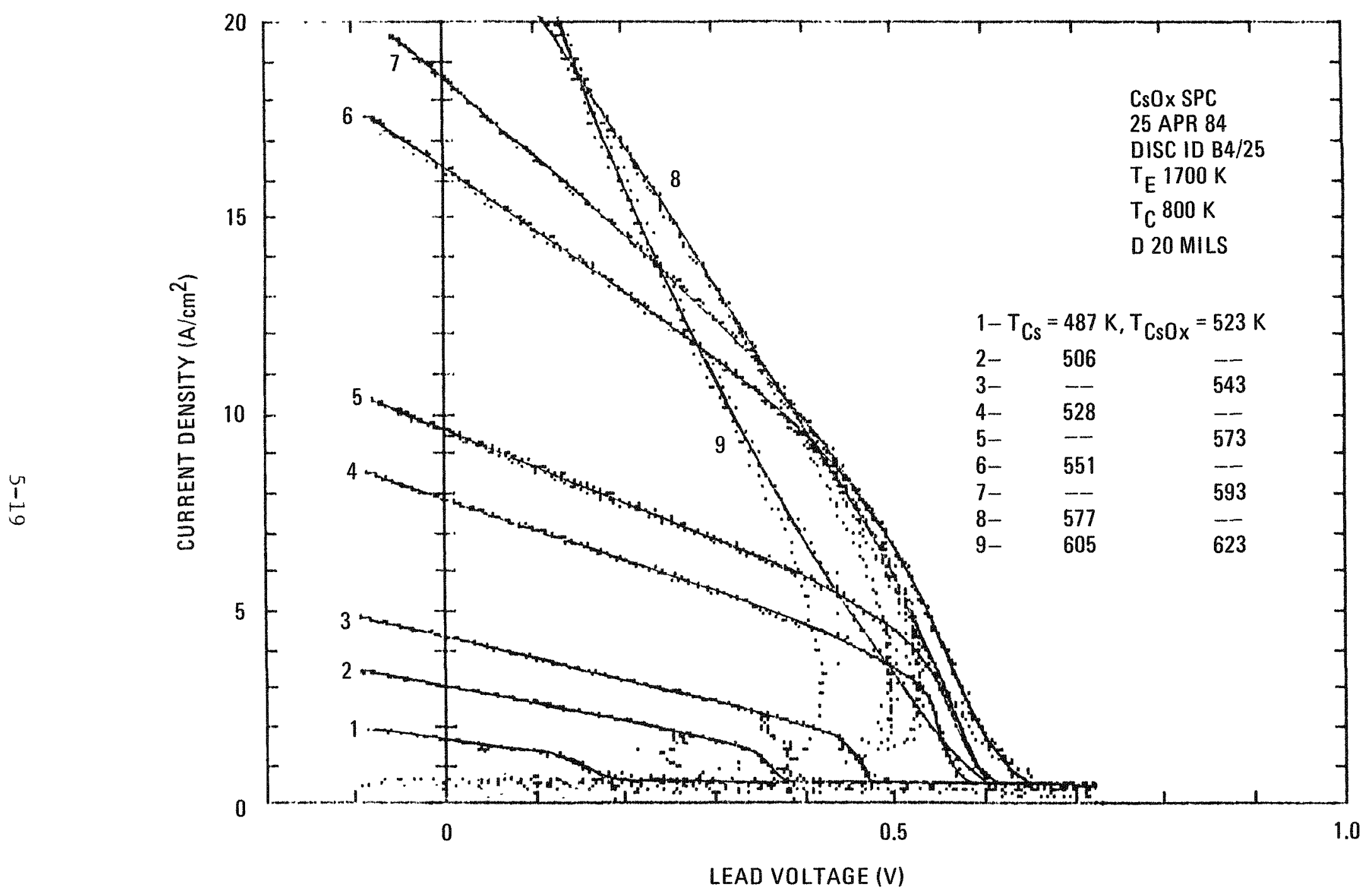

A17773

Fig. 5-11. Cesium and cesium oxide pressure family of $\mathrm{J}-\mathrm{V}$ curves 


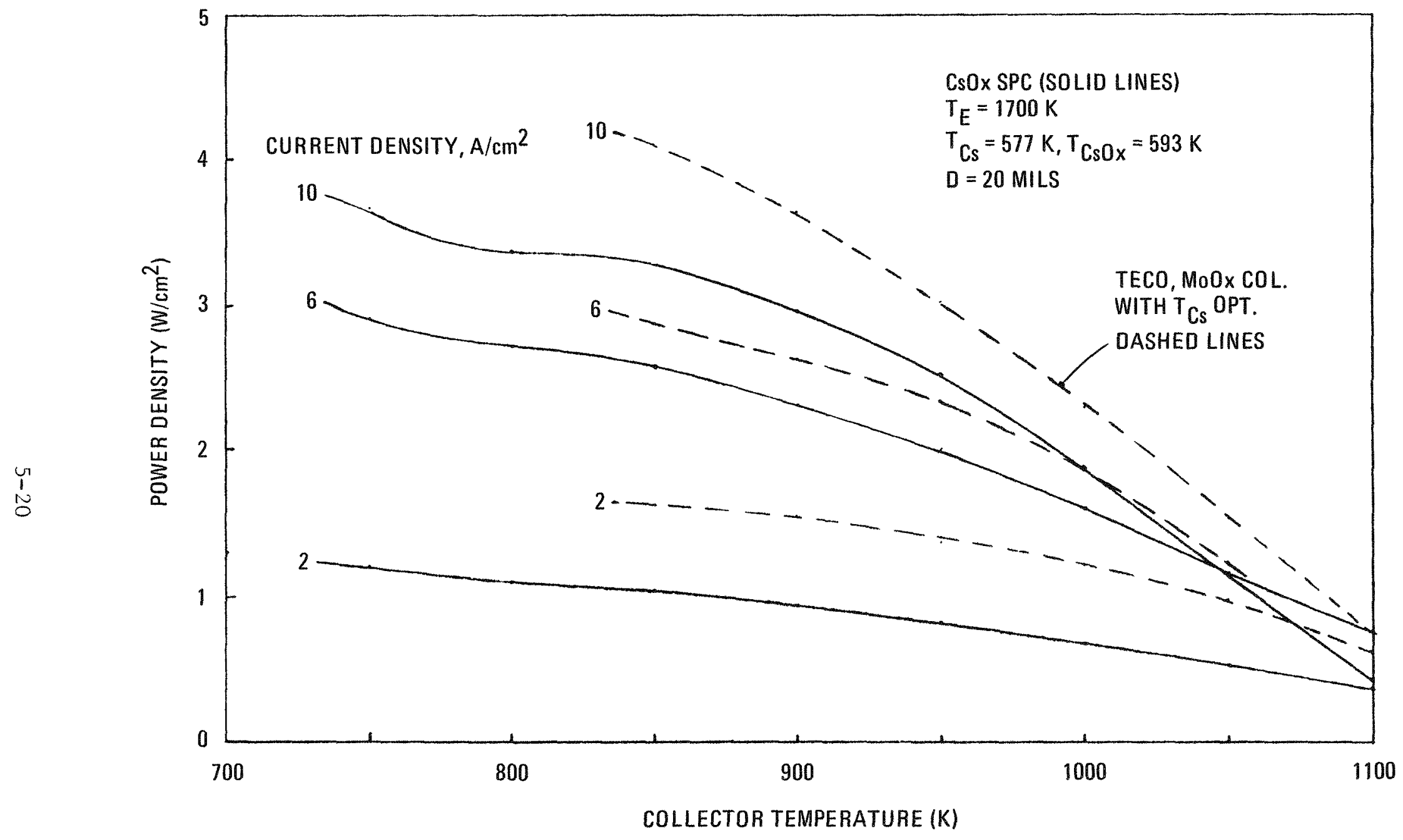

A 17773

Fig. 5-12. Variation of performance of cesium-cesium oxide converter with collector temperature 
5.4. FUELED EMITTER TEMPERATURE CORRELATION

\subsubsection{Test Device Design}

Electron cooling was selected as the method for controlling emitter temperatures for a variety of reasons:

1. Emitter temperature control with gas gap cooling is difficult (even with the gas) at the emitter temperatures (1650 to $1850 \mathrm{~K}$ ) and heat fluxes $\left(20\right.$ to $40 \mathrm{~W} / \mathrm{cm}^{2}$ ) of interest.

2. Local cooling of the emitter is less affected by emitter distortion with electron cooling than with gas gap cooling.

3. Electron cooling is more prototypic.

4. Electron cooling allows the electronic characteristics of the emitter to determine its temperature. This is a more reliable technique than the use of thermocouples. To use electron cooling, the fueled emitter is installed in a collector and exposed to cestum vapor as in a typical thermionic converter. However, the resulting test devices are not thermionic converters. The gap between emitter and collector is $40 \mathrm{mils}$, which is four times the normal gap size. This results in a substantial voltage drop across the gap and allows for significant emitter distortion during the test. No special surface treatment of the emitter or collector is being used to enhance performance. As a result, the test devices are anticipated to operate with a negative output voltage, particularly at the lower emitter temperatures. Thus, the fueled emitter capsules in these tests will be power consumers rather than power producers.

The operating condition of a fueled emitter test device with thermionic cooling will be evaluated for lead current, lead voltage, collector 
temperature, reactor power, device location in the core, and fuel enrichment. The data are used to estimate average emitter temperature and input power.

\subsubsection{Input Power}

The input power to the fueled emitter can be estimated using three independent techniques: (1) fuel enrichment, (2) emitter location in the core, and (3) overall reactor power. Inaccuracies are due mainly to neutron flux variation throughout the core. These are well mapped, as shown in Figs. 5-13 and 5-14. The temperature drop across the gas gaps, which cools the collector, serves as a first-order estimator of collector heat flux and, thus, emitter input power. Figure 5-15, taken from the six ce11s in TFE-6F3, shows the changes in collector heat flux that can be detected using this technique. However, absolute values tend to disagree with other estimators by about $\pm 10 \%$. Input power can also be calculated by combining the estimated emitter temperature and the device operating current, as shown in Fig. 5-16. Errors of $\pm 50 \mathrm{~K}$ in emitter temperature correspond to input power errors of $\pm 10 \%$ in the test regime of interest.

\subsubsection{Emitter Temperature}

The simplest way to calculate emitter temperature is to combine reactor-power estimators of device input power and measured operating current (Fig. 5-16). However, much more information is available from the electronic characteristics of the device, as illustrated in the current-voltage illustration in Fig. 5-17.

Several techniques can be used to estimate emitter temperature:

1. Ability of the emitter surface to emit electrons which is uniquely determined by the emitter temperature and cesium pressure. The current density at point 2 in Fig. 5-17 (i.e., the inflection point in the ignited mode curve which occurs at about half the saturation current), combined with the cesium 


\section{THERMIONIC TEST REACTOR}

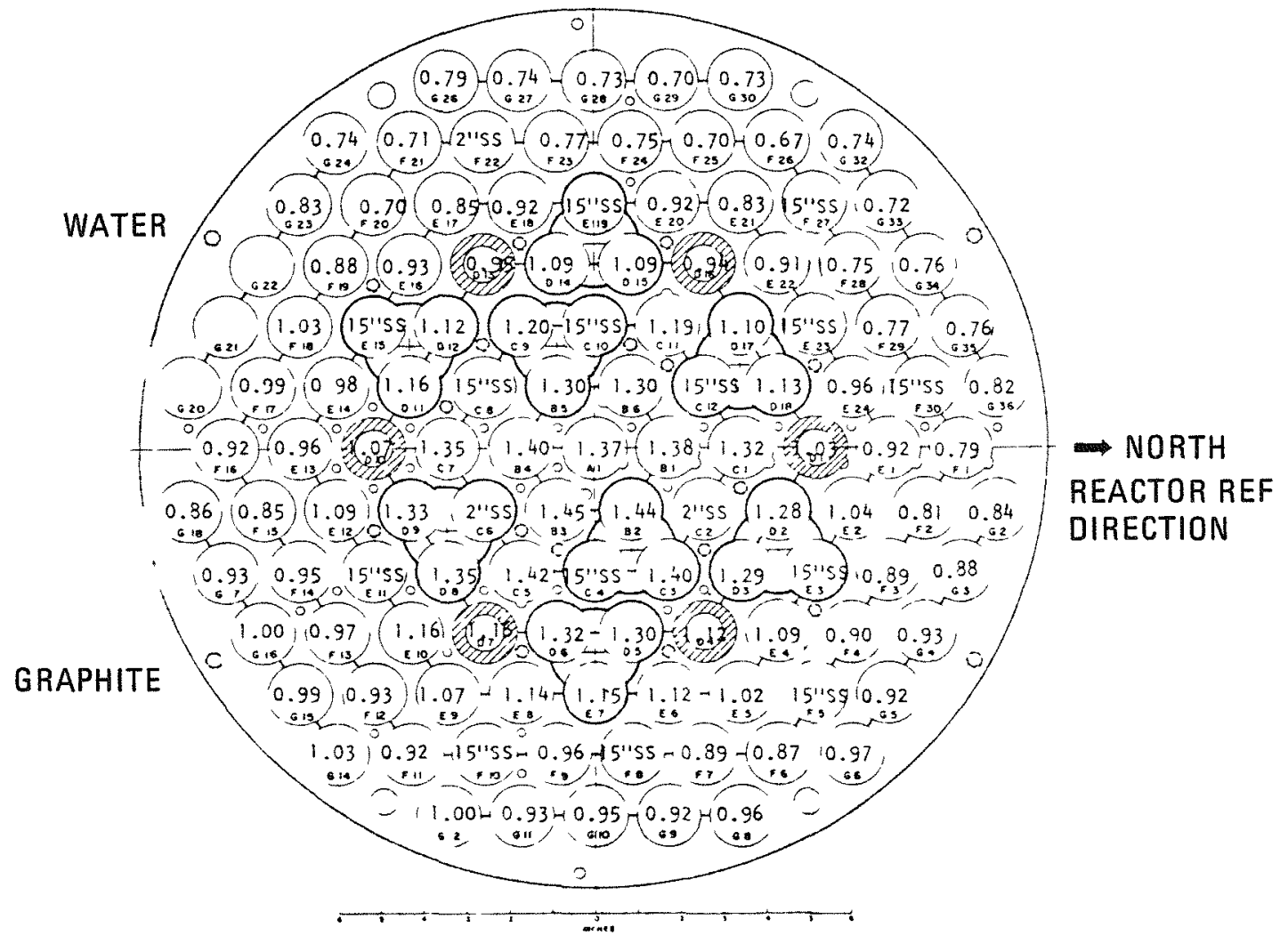

TRIGA FLIP CORE TOP GRID PLATE

A17773

Fig. 5-13. Relative power distribution (local power/core average power) 


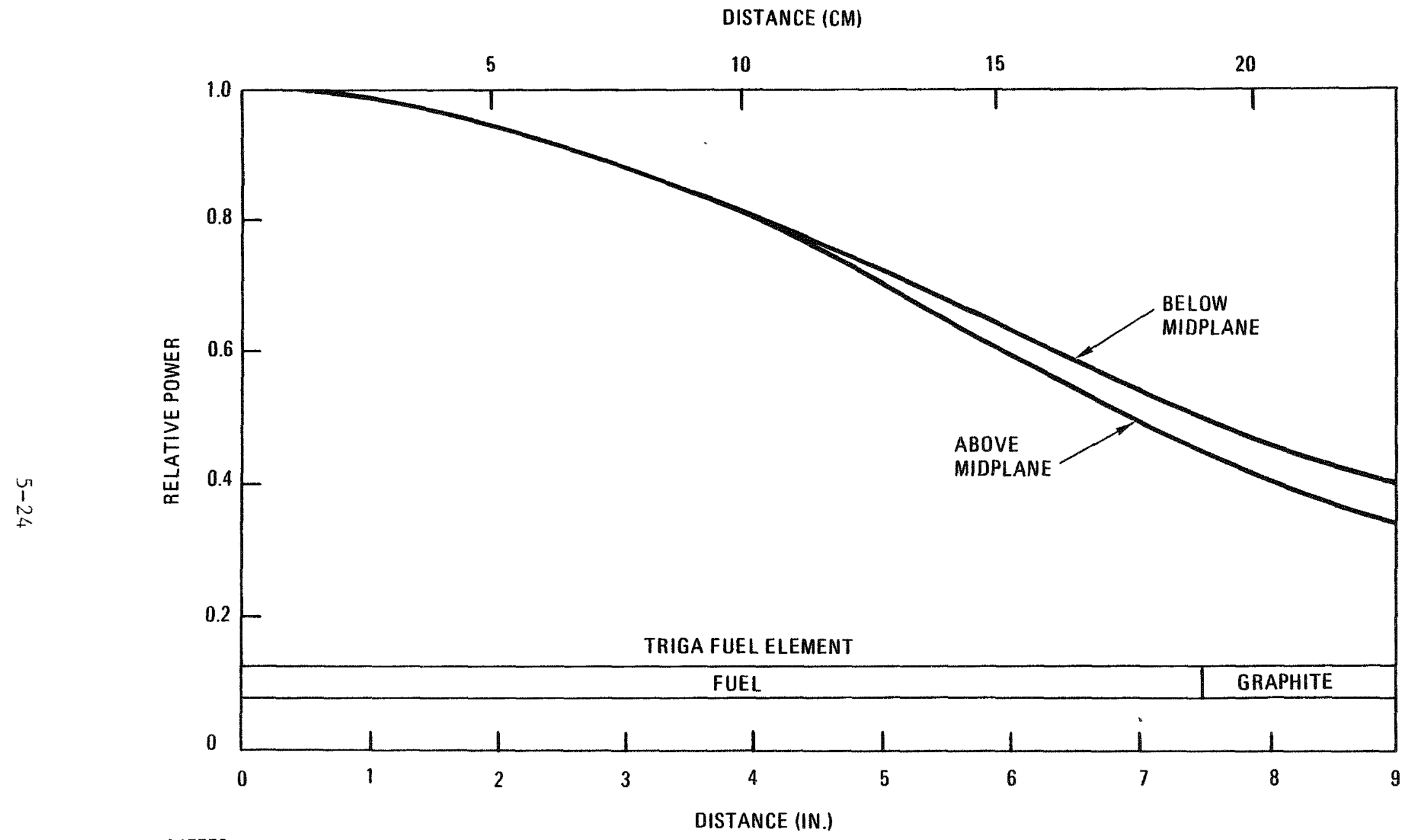

A17773

Fig. 5-14. Composite axial TFE power profile 


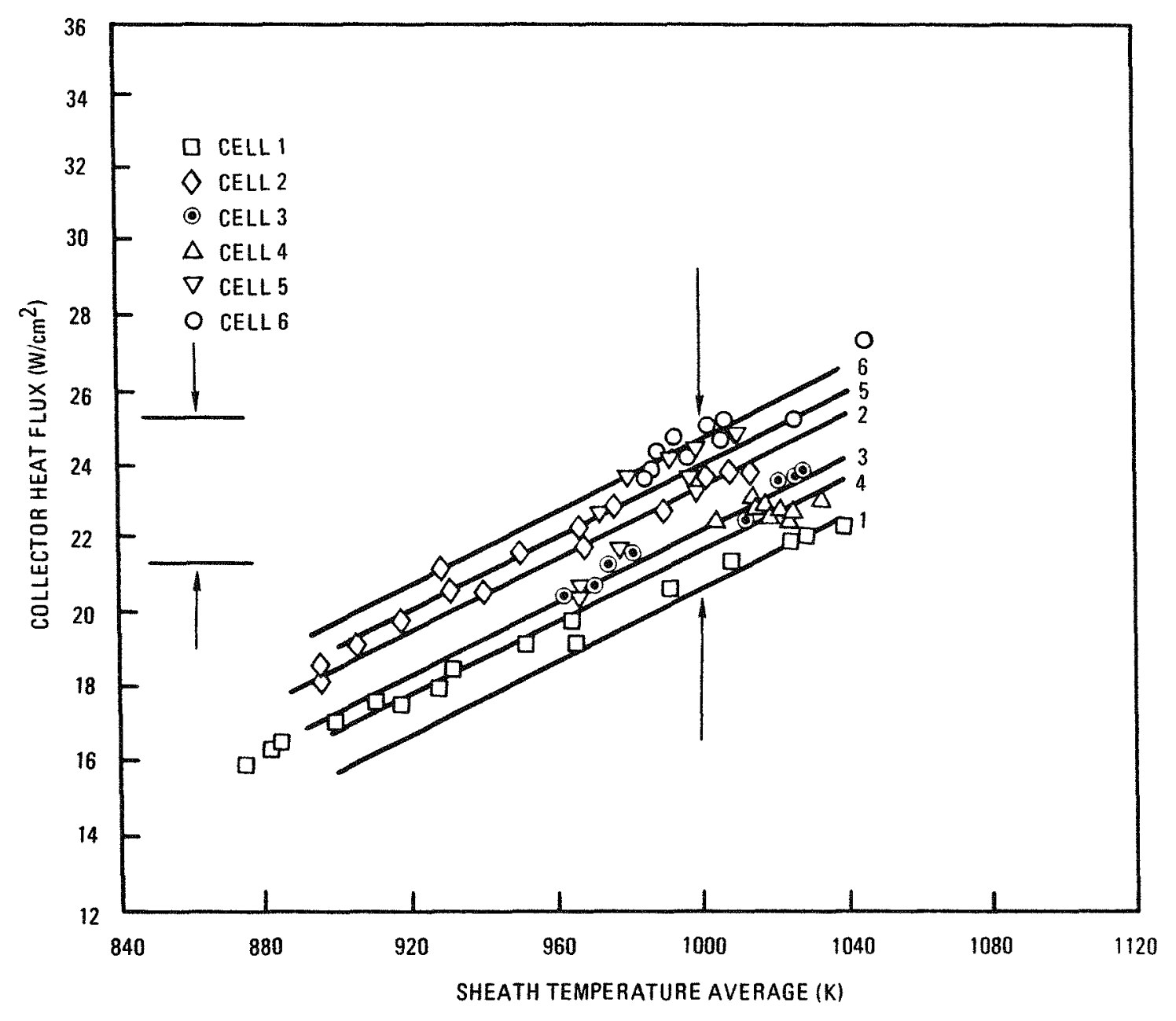

A 17773

Fig. 5-15. Collector heat flux correlation with sheath (collector) temperature 


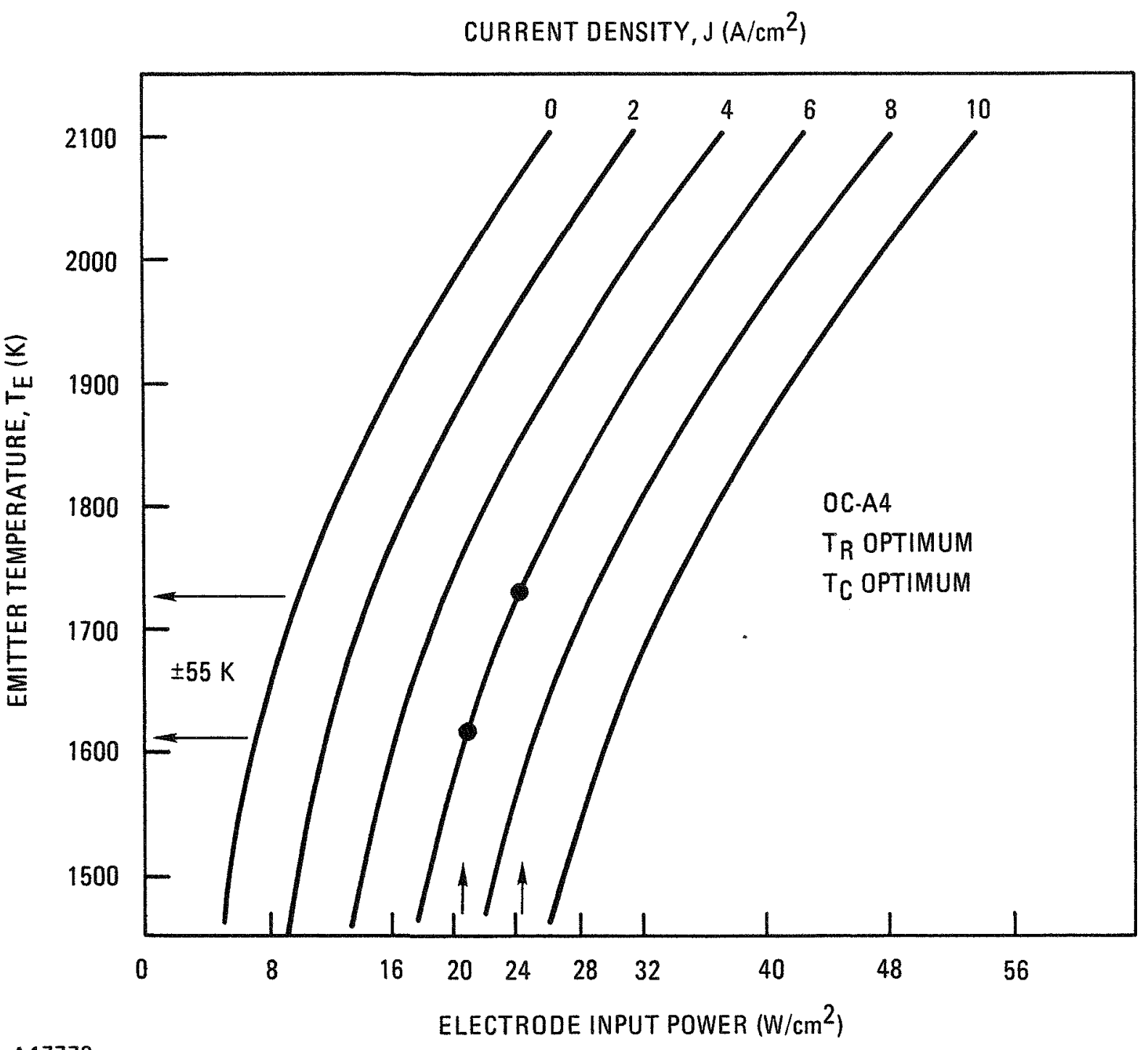

A17773

Fig. 5-16. Correlation between input power, emitter temperature, and current density 


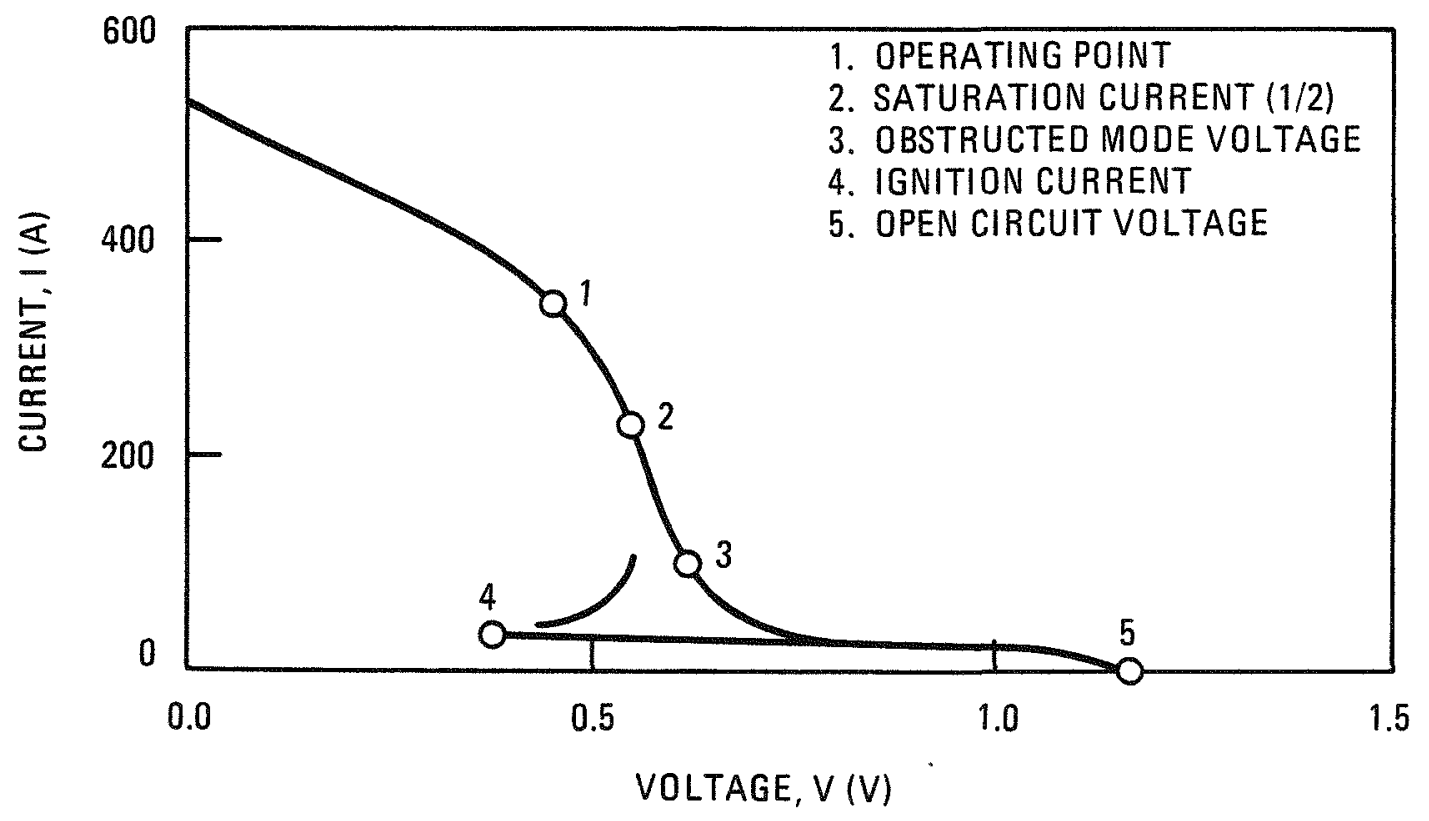

A17773

Fig. 5-17. Current-voltage characteristic of a test device provides estimators of operating condition 
pressure (determined by the cesium reservoir temperature), provide sufficient information to calculate emitter temperature. An error of approximately $\pm 80 \mathrm{~K}$ is anticipated using this technique.

2. Operating-point voltage at the current near the knee of the current-voltage curve. Previous data have shown that the reproducibility of this measure of performance, even between converters of different types, allows an emitter temperature estimate of $\pm 50 \mathrm{~K}$ for cylindrical, out-of-pile converters, as shown in Fig. 5-18.

3. Output voltage at low-current densities in the obstructed mode of operation. This is exemplified by point 3 in Fig. 5-17. This correlates well with emitter temperature of cesium optimized converters. Figure 5-19 shows the errors incurred using this method in both cylindrical and planar converters. An error of $\pm 50 \mathrm{~K}$ is anticipated.

4. Current density in the unignited mode. The ignition current is shown as point 4 in Fig. 5-17. Several correlations have been developed previously and, as shown in Fig. 5-20, a correlation can be obtained which estimates emitter temperature with a scatter below $\pm 50 \mathrm{~K}$. A more detailed analysis of the unignited mode is being used to refine this technique.

The technique is based on the fact that the unignited mode has an apparent saturation current which is dependent only on cesium reservoir temperature, interelectrode spacing, and emitter temperature, and not on the emitter material or the work function of the emitter. This is true as long as the electron space charge is not fully compensated by surface ionization (electron-rich conditions). Electron-rich conditions prevail throughout the expected operating range of the capsules for fueled emitter deformation tests. However, equating apparent 


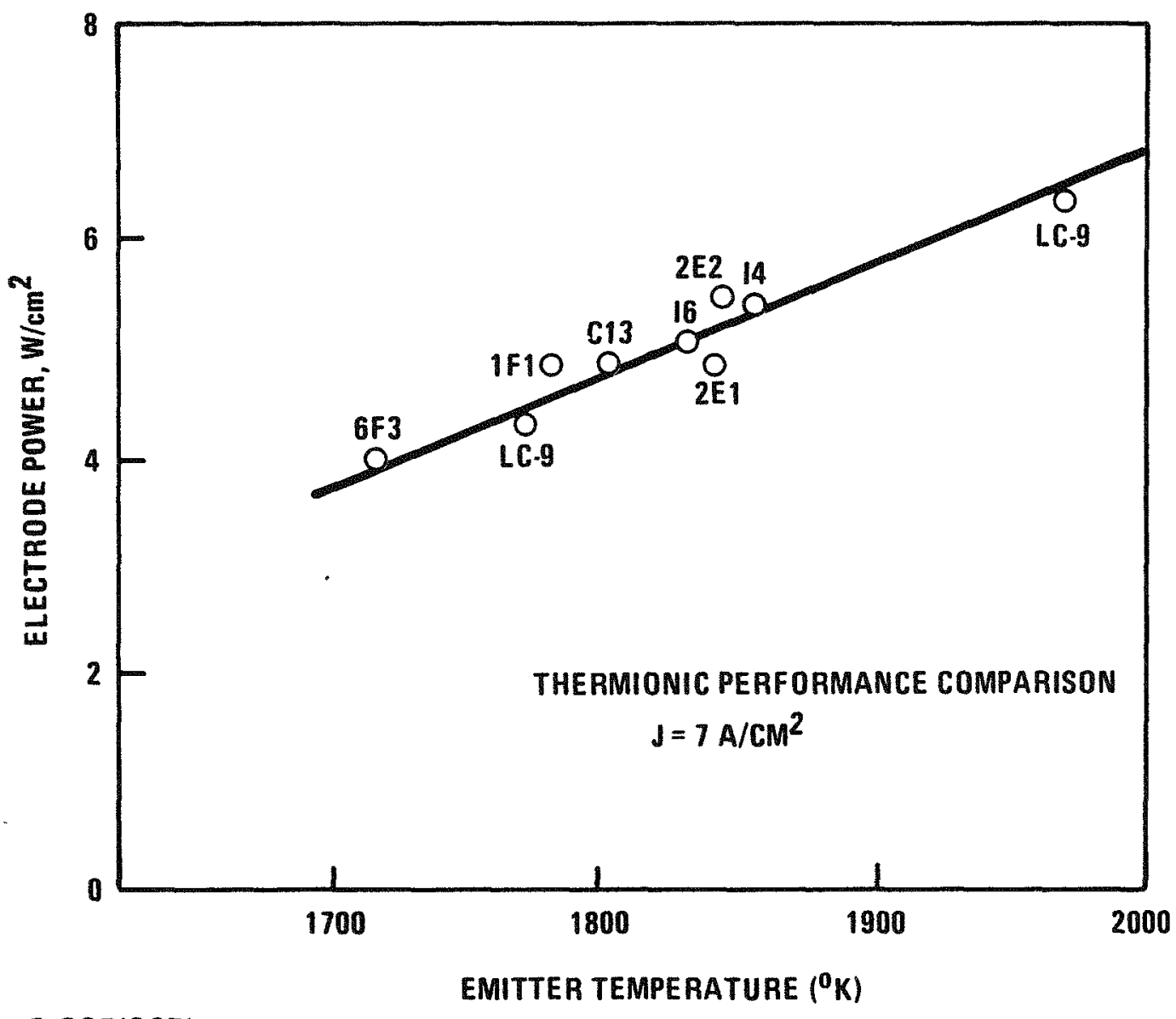

G-335(36R)

Fig. 5-18. Thermionic performance comparison at a typical operating point 


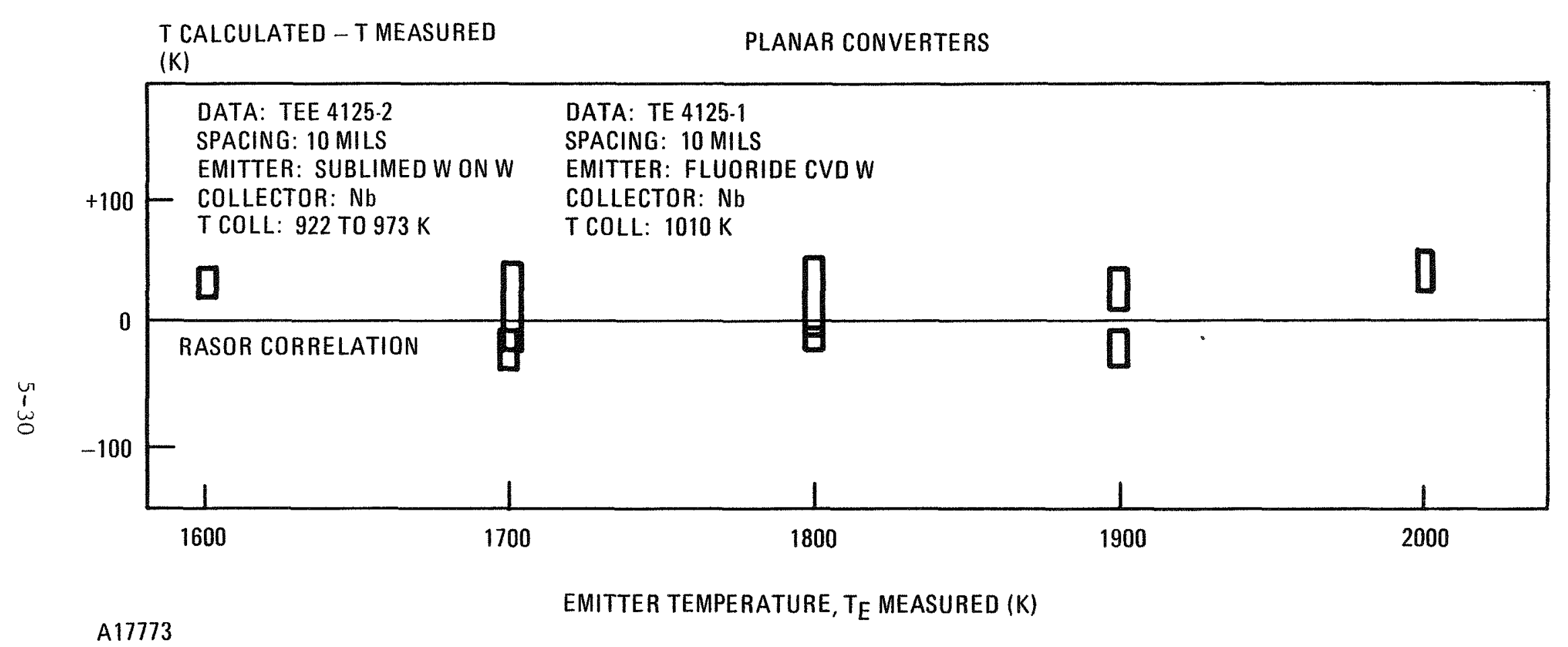

Fig. 5-19. Emitter temperature estimate errors observed using the obstructed mode 


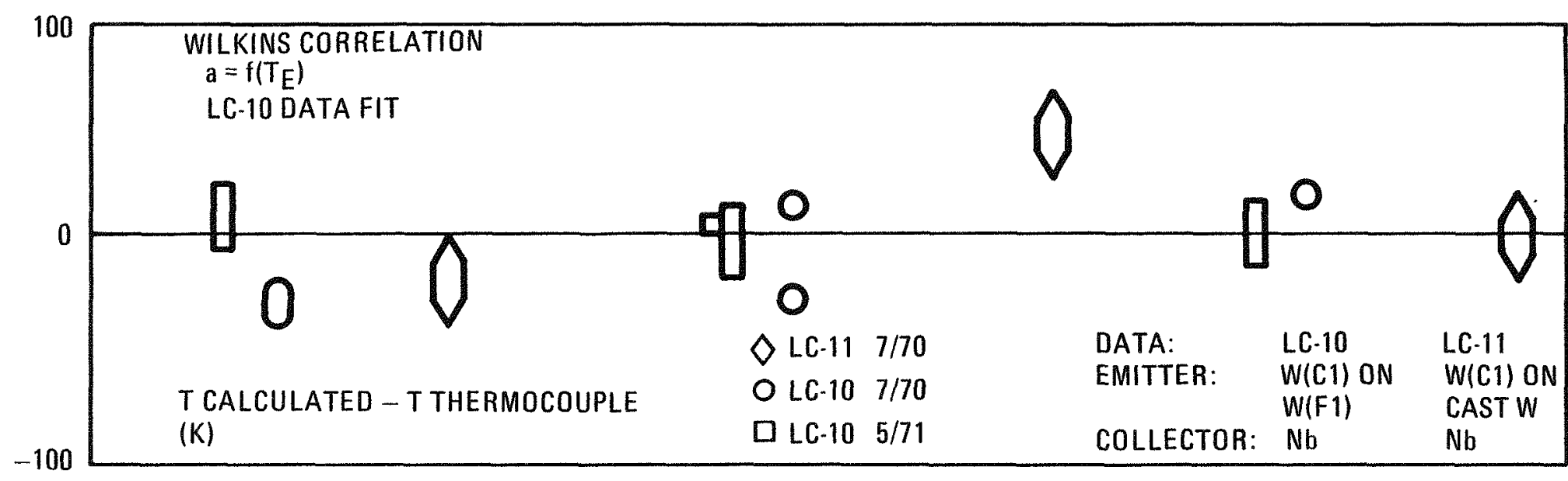

A17773

Fig. 5-20. $\mathrm{T}_{\mathrm{E}}$ (ignition current): single parameter fit required 
saturation current with ignition current is difficult. At low emitter temperatures, the unignited mode $I-V$ characteristic saturates, then has a turnup in current just before the ignition point, so that the ignition current is slightly higher than the saturation current. This is not a serious problem, since the true saturation current is still quite apparent from the $I-V$ curve. Since ignition occurs before the unignited mode saturates at high emitter temperatures, the ignition current is less than the saturation current, and the true saturation current is not apparent. However, these can be reasonably calculated by sophisticated computer programs. Calculated curves can be fit to experimental curves with good accuracy using emitter temperature as a parameter even if the saturation portion of the experimental curve cannot be measured.

5. Open circuit voltage. This is shown as point 5 in Fig. 5-17, which indicates the difference in temperature between emitter and collector. This estimate is relatively poor and subject to errors (e.g., caused by leakage currents).

As shown schematically in Fig. 5-21, all of these techniques will be used in conjunction to estimate average emitter temperature. Resulting temperatures are expected to be accurate to within $\pm 50 \mathrm{~K}$ with high confidence.

\subsection{G-SERIES CONVERTER}

In the previous TFE program, a G-series thermionic converter was built and tested for approximately 14,000 h. This advanced converter was built with a (110) tungsten emitter and a collector of sublimed molybdenum on a niobium substrate. The interelectrode spacing was $0.5 \mathrm{~mm}$, and the emitter sleeve was molybdenum-rhenium, which is ductile at room temperature. This converter also incorporated a pentalayer sheath insulator (which combined the functions of the seal and trilayer sheath insulators in the F-series converters). Consequently, with this design concept, the 


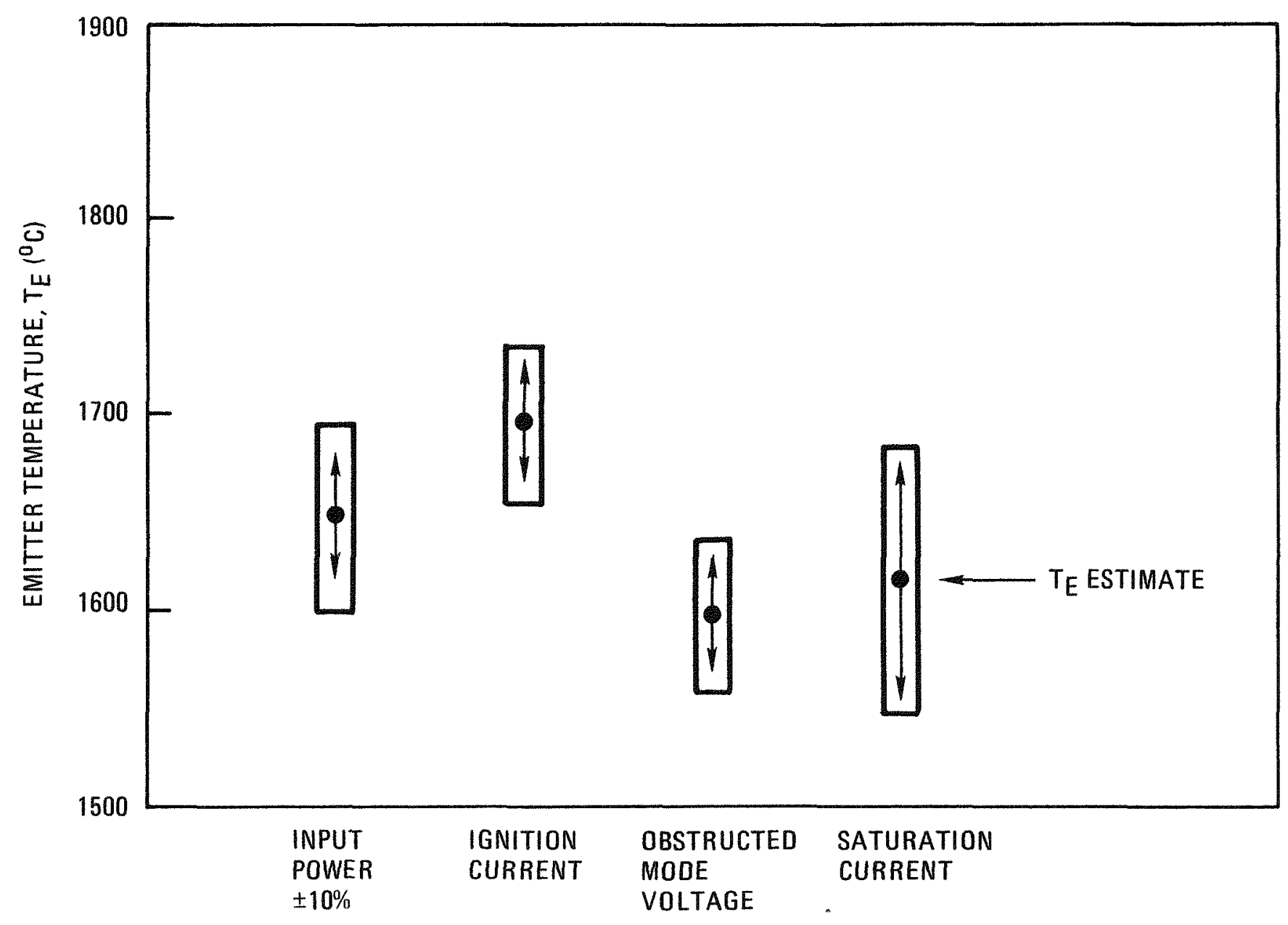

A17773

Fig. 5-21. Emitter temperature estimate will be synthesized using several diagnostic tools 
volume of the intercell region is reduced, and a higher fuel fraction is possible in the core. The G-series converter also had a cup-shaped collector to increase the conversion area per diode. This converter operated stably at an output power density of $4.8 \mathrm{~W} / \mathrm{cm}^{2}$ for more than $14,000 \mathrm{~h}$ at an emitter temperature of $1800 \mathrm{~K}$ and a collector temperature of $875 \mathrm{~K}$. Since this converter incorporated several advanced features under consideration for the SP-100 thermionic reactor system (i.e., sublimed molybdenum collector and molybdenum-rhenium sleeve), diagnostic studies were performed to provide valuable information on its integrity. Table 5-1 summarizes these studies. One of the most important results is that the electron beam weld between the molybdenum-rhenium sleeve and the tungsten emitter showed good bonding and no Kirkendall voids (see Fig. 5-22). Another encouraging result is the excellent condition of the pentalayer.

After a review of the converter performance data base, the two most promising technical approaches for achieving the task objectives were (1) use of molybdenum coatings sublimed onto a niobium collector in a low-pressure oxygen atmosphere and (2) use of a cesium-cesium oxide vapor in the interelectrode space. 
TABLE 5-1

CONVERTER DIAGNOSTICS ON G-SERIES CONVERTER

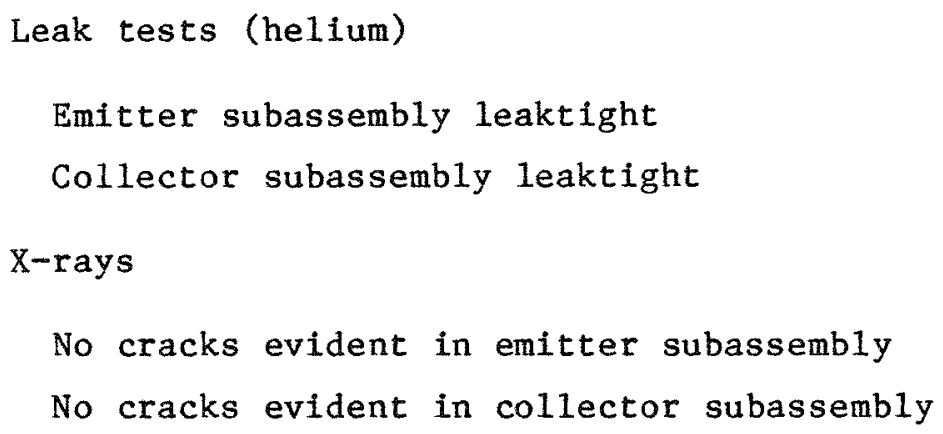

Micrographs

EB weld between Mo-Re sleeve and tungsten emitter showed good bonding and no Kirkendall voids

EB weld between Mo-Re sleeve and Mo- $\mathrm{Nb}$ intercell showed good bonding CVD fluoride tungsten emitter

No evidence of grain growth

Sublimed tungsten coating well defined

Pentalayers of $\mathrm{Nb} / \mathrm{Nb}-\mathrm{Al}_{2} \mathrm{O}_{3}$ layers

No cracks apparent

No indication of interaction between niobium and $\mathrm{Al}_{2} \mathrm{O}_{3}$

Electron diffraction scan (EDS) of EB weld between Mo-Re sleeve and tungsten emitter

Molybdenum concentration drops from $50 \%$ (at end of sleeve) to $<4 \%$ over a distance of approximately $0.127 \mathrm{~cm}(0.050 \mathrm{in.)}$, as expected

Rhenium concentration masked by overlapping tungsten line 


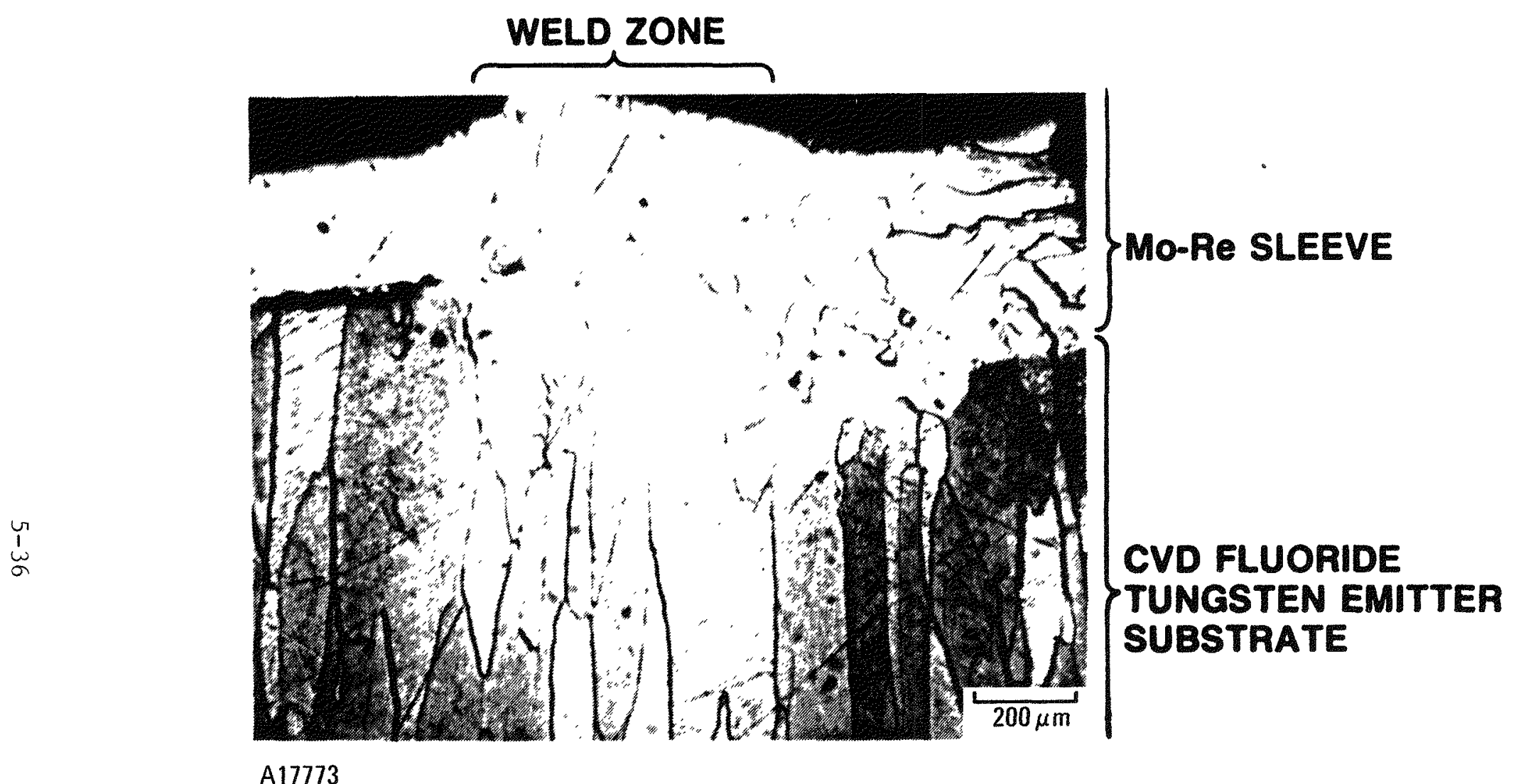

Fig. 5-22. Photomicrograph of electron beam weld between Mo-Re sleeve and tungsten emitter of 14,000-h G-series converter 